\title{
Report of the
}

\section{5th NATIONAL CONFERENCE ON}

\section{WEIGHTS AND MEASURES 1960}

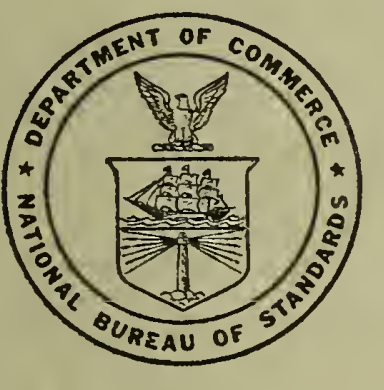

U.S. DEPARTMENT OF COMMERCE

NATIONAL BUREAU OF STANDARDS

MISCELLANEOUS PUBLICATION 235 


\section{SELECTED WEIGHTS AND MEASURES PUBLICATIONS OF THE NATIONAL BUREAU OF STANDARDS}

NBS Handвоок 44-2d Edition-1955 Specifications, Tolerances, and Regulations for Commercial Weighing and Measuring Devices:

Loose Leaf (does not include binder) $\$ 1.00$

NBS HANDBоок 67 Checking Prepackaged Commodities..... NBS Circular 501 Federal and State Weights and Measures Laws. .35

NBS Circular 540 Weights and Measures Case Reference Book.

NBS Circular 547 Precision Laboratory Standards of Mass

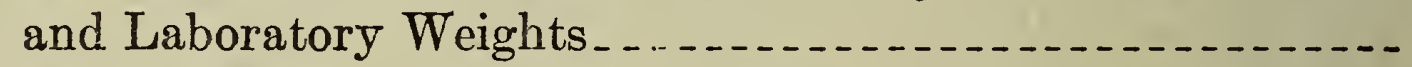

NBS Circular 593 The Federal Basis for Weights and Measures.

NBS Monograph 15 Calibration of Line Standards of Length and Measuring Tapes at the National Bureau of Standards..-

AVAILABLE REPORTS OF THE

NATIONAL CONFERENCE ON WEIGHTS AND MEASURES

1947 Miscellaneous Publication 189 _. _. $40 \varnothing$

1953 Miscellaneous Publication 209.... $40 \phi$

1954 Miscellaneous Publication $212 \ldots \ldots$. _. $50 \phi$

1955 Miscellaneous Publication $216 \ldots$.... 706

1956 Miscellaneous Publication 219 _... $70 \notin$

1957 Miscellaneous Publication 222 _. _ $55 \notin$

1958 Miscellaneous Publication 225 ... 656

1959 Miscellaneous Publication 228_... $65 \notin$

Index to the Reports of the National Con-

ference on Weights and Measures from the

First to the Thirty-sixth, 1905 to 1951 , Mis-

cellaneous Publication 203.............. 20\&

ORDER ALL PUBLICATIONS, WITH REMITTANCE, FROM THE SUPERINTENDENT OF DOCUMENTS, GOVERNMENT PRINTING OFFICE, WASHINGTON 25, D.C. 



\section{Report of the}

\section{5th National Conference on \\ Weights and Measures 1960}

Sponsored by the National Bureail of Standards

Attended by Officials From the Various

States, Counties, and Cities, and

Representatives From U.S. Government,

Industry, and Consumer Organizations.

Washington, D.C., June 6, 7, 8, 9, 10, 1960.

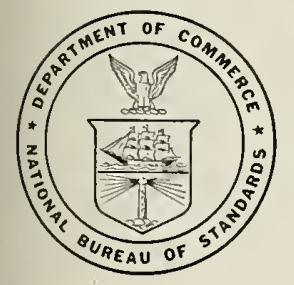

United States Department of Commerce

Frederick H. Mueller, Secretary

National Bureau of Standards

A. V. Astin, Director

National Bureau of Standards Miscellaneous Publication 235

Issued December 16, 1960 


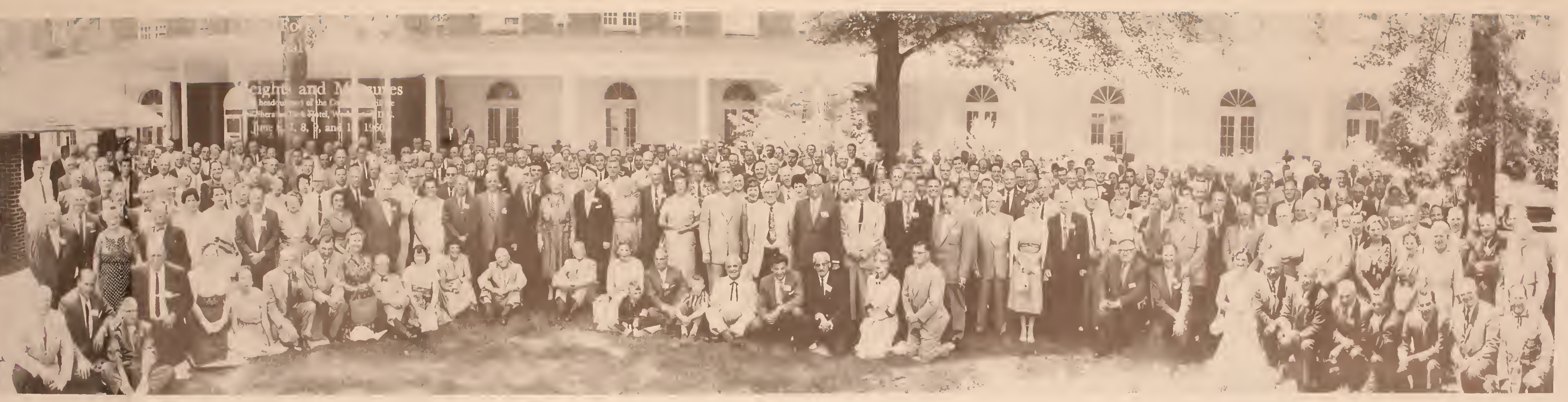



Officers and Committees

Committee Meetings

FIRST SESSION-MORNING OF TUESDAY, JUNE 7,1960

Address, by Hon. Frederick H. Mueller, Secretary of Commerce.........

Presentation of Honor Awards . . Address of Conference Chairman, by H. E. Crawford, Inspector of

Weights and Measures, Jacksonville, Florida _...................

Address of Conference President and Appointments to Standing Committees, by A. V. Astin, Director, National Bureau of Standards.

Moving Ahead in Accurate Commercial Measurement in the United States, by D. N. MeDowell, Director, Wisconsin State Department of Agriculture, State of Wisconsin

SECOND SESSION-AFTERNOON OF TUESDAY, JUNE 7, 1960

Report of Committee on Education, Presented by J. F. True, Chairman, State Sealer, Division of Weights and Measures, State Board of Agriculture, State of Kansas.

Report of Subcommittee on Public Education and National Weights and Measures Week, by J. E. Bowen, Chairman, City Sealer of Weights and Measures, Newton, Massachusetts.

The Banana Market, by R. B. Tewksbury, Assistant Traffic Manager, Fruit Dispatch Company, Weehawken, New Jersey.

Report of the Weights and Measures Advisory Committee, by A. T. IIcPherson, Chairman, Associate Director for Engineering, National

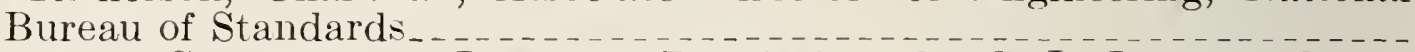

Report of Committee on Laws and Regulations, by G. L. Johnson, Chairman, Director, Division of Weights and Measures, Department of

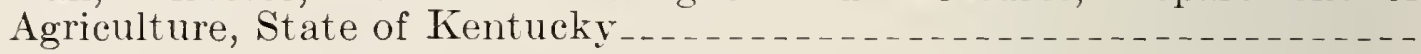

THIRD SESSION-MORNING OF WEDNESDAY, JUNE 8, 1960

Report of Executive Committee, by H. E. Crawford, Chairman, Inspector of Weights and Measures, Jacksonville, Florida _............

Pharmaceutical Graduates, by J. J. Moran, Technical Director, Scientific Sales Division, Kimble Glass Company, Vineland, New Jersey - . -

State Mass Standards, by H. S. Peiser, Chief, Mass and Scale Section, Metrology Division, National Bureau of Standards

Weights and Measures Standards Used by the Air Force, by Colonel Richard Stolle, Deputy Chief, Quality Control Office, Headquarters, Air Materiel Command, Wright Patterson Air Force Base, Ohio .......

Temperature Compensated Meters in LP-Gas Service, by E. F. Wehmann, Assistant Chief Engineer, Neptune Meter Company, Long Island City, New York

FOURTF SESSION-MORNING OF THURSDAY, JUNE 9, 1960

Current Position of the U.S. Department of Agriculture Regarding the Labeling of Poultry and Foultry Products, by F. E. Blood, Deputy Director, Poultry Division, Agricultural Marketing Service, U.S. Department of Agriculture _......................................

Weights and Measures in Aerosol Commodities, by H. E. Peterson, President, Peterson Filling and Packaging Company, Danville, Illinois (representing Chemical Specialties Manufacturers Association) .......-

Philosophy of Law Enforcement, by Major P. II. Crews, Executive Officer, Department of State Police, State of Virginia _...............

Report of Committee on Nominations and Election of Officers, by Robert Williams, Chairman, County Sealer of Weights and Measures, Nassau

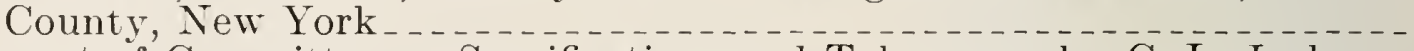

Report of Committee on Specifications and Tolerances, by C. L. Jackson, Chairman, Chief, Division of Economic Practices, Department of

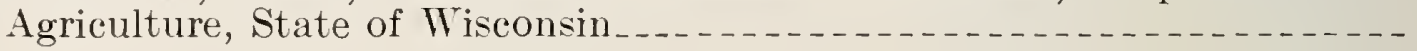


Report from the Food and Drug Administration, by C. T. Hubble, Director of Division of Administrative Review, Bureau of Enforcement, Food and Drug Administration, U.S. Department of Health, Education, and Welfare

Twentieth Century Problems in Equity in Quantity, by Mrs. Mildred E. Brady, Editorial Director, Consumers Union, Nount Vermon, New York

The Federal Trade Commission and Consumers, by J. R. Heim, Director, Bureau of Consultation, Federal Trade Commission ...............

Labor's Stake in Consumer Protection, by S. H. Ruttemberg, Director of Research, American Federation of Labor and Congress of Industrial Organizations, Washington, D.C

Weights and Measures in Californa-A Consumer View, by Helen E. Nelson, Consumer Counsel, Governor's Office, State of California_.....

BREAKFAST MEETING OF THE INCOMING EXECUTIVE COMMITTEE OF THE CONFERENCE, FRIDAY, JUNE 10, 1960

\section{SIXTH SESSION-MORNING OF FRIDAY, JUNE 10,1960}

Report of the Committee on Resolutions, by H. R. Kennell, Chairman, Commissioner, Department of Labor, State of West Virginia_......... Open Forum-Weights and Measures Administration:

New Developments in Testing Equipment, by Office of Weights and Measures, National Bureau of Standards _..................... Uniform Reporting and Records, by L. J. Gordon, Director, Weights and Measures Research Center, Denison University, Granville, Ohio

Establishing a Bureau of Standards in Oklahoma, by V. C. Kennedy, Jr., Executive Director, University of Oklahoma Research Institute, Norman, Oklahoma_....................................... National Type Approval, by C. H. Stender, Assistant to Commissioner of Agriculture, State of South Carolina

Report of Auditing Committee, by J. H. Lewis, Chairman, Chief, Weights and Measures Section, State Department of Agriculture, State of Washington

Report of the Treasurer, by C. C. Morgan, Treasurer, City Sealer of Weights and Measures, Gary, Indiana Introduction of and Statement by Congressman Byron L. Johnson of

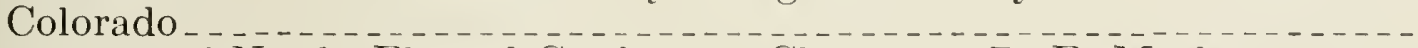
Statement of Newly Elected Conference Chairman, R. E. Meek.......

Persons Attending the Conference Specifications, Tolerances, and Regulations for Commercial Weighing and Measuring Devices as Published in National Bureau of Standards Handbook 44-2d Edition. ................................ 


\section{OFFICERS AND COMMITTEES}

\section{OFFICERS}

(As elected by the Forty-fourth National Conference to serve during the Forty-fifth National Conference)

President: A. V. Astix, Director, National Bureau of Standards. Secretary: W. S. Busser, Chief, Office of Weights and Measures, $\}$ Ex officio
National Bureau of Standards.

Chairman: H. E. CraWford, Inspector of Weights and Measures, Jacksonville, Florida.

rice Chairmen:

R. MI. BodexweIser, County Superintendent of Weights and Measures, Mercer County, New Jersey.

H. N. Duff, Supervisor, Weights and Measures Section, Department of Agriculture, State of Colorado.

J. I. Moore, Field Super risor, Weights and Measures Dirision, Department of Agricuiture, State of North Carolina.

Wr. E. SHEEHY, County Sealer of Weights and Mieasures, Fairfield County, Connecticut.*

Treasurer: C. C. Morgax, City Sealer of Weights and Measures, Garr, Indiana.

Chaplain: RaLPH MAgoffis, Director, Bureau of Inspection, Department of Agriculture, State of South Carolina.

(As elected by the Forty-fifth National Conference to serve during the Fortysixth National Conference)

President: A. V. Astix, Director, National Bureau of Standards.

Secretary: W. S. Busser, Chief, Office of Weights and Neasures, $\} E x$ officio
National Bureau of Standards.

Chairman: R. E. MEek, Director, Dirision of Weights and Measures, State Board of Health. State of Indiana.

Vice Chairmen :

J. W. D. Harrex, State Oil Chemist, State Oil Laboratory, Department of Rerenue, State of Georgia.

H. D. Robrrsox, Deputy State Sealer, Department of Agriculture, State of Maine.

A. D. Rose, County Sealer of Weights and Measures, Kern County, California.

J. D. Waltox, Superrisor, Weights, Measures and Markets, Dallas, Texas. Treasurer: C. C. Morgax, City Sealer of Weights and Measures, Gars. Indiana. Chaplain: R. W. SeArles, Deputr County Sealer of Weights and Measures, Medina County, Ohio.

\section{EXECUTIVE COMMITTEE}

(As elected by the Forty-fifth National Conference)
A. T. Astix
II. S. BUSSEY
I. E. MEEK
J. IT. D. HARYEY
H. D. Robinson $\}$ Ex officio
A. D. Rose
J. D. WALTON
C. C. MIORga
R. T. SEARLES
E. W. Bucklix, of Montgomery County, Maryland.
H. H. Houstox, of Colorado.
Natmax Kalecman, of Hartford, Comnecticut.
H. R. Kexaell, of West Tirginia.
J. H. LEWIS, of Washington.
J. F. MCCARThY, of Boston, Massachusetts.
William Miller, of Passaic Countr, New Jersey.
J. J. Powers, of Philadelphia County, Pennsylrania.
JoHx Seres, of Lackawanna. New York.
Delbert Walrath, of Montana.

* Retired. 


\section{STANDING COMMITTEES}

(As constituted at the conclusion of the Forty-fifth National Conference. the personnel and organization of each of the standing committees of the Conference ale as listed. As reported, the membership of each committee reflects the appointments made hr the President of the Conference to fill racancies that have occurred from expiration of term. and the elections br the serelal committees of chairmen for the ensuing rear. The remaining term of office for each committee member, in rears, is shown by the figme in parentheses following each entry.)

\section{COMMITTEE ON EDUCATION*}

J. F. True, of Kansas, Chairman (3).

H. E. Crawford, of Jacksonville, Florida (1).

IV. A. KerLix, of Alameda Countr, California (2).

J. E. Bowes, of Newton, Massachusetts (4).

C. H. Stexder, of South Carolina (j).

\section{COMMITTEE ON LAWS AND REGULATIONS*}

Robert Irruliams, of Nassau County, New York, Chairman (2).

G. L. JoIn Nson, of Kentucky (1).

J. G. Gustafson, of Minneapolis, Mimnesota (3).

H. M. 'Turrell, of Penmsyl rania (4).

J. H. LEwIS, of Washington (5).

\section{COMMITTEE ON SPECIFICATIONS AND TOLERANCES*}

C. L. JACKsox, of Tisconsin, Chaimman (2).

D. M. Turneuld, of Seattle, Washingtoli (1).

R. W. Searles, of Medina County, Ohio (3).

A. H. Dittrich, of New Hampshire (4).

T. C. Harris, Jr., of Virginia (5).

\section{COMMITTEES ACTING ONLY DURING THE FORTY-FIFTH NATIONAL CONFERENCE}

Committee on. Nominations: Rorert Wildians, of Nassau Counts. New Iork, Chailman; Nalls Berkymax, of Florida; S. H. Christe, JR., of New Jelsey; F. M. Greene, of Connecticut: C. H. Stender. of South Carolina: H. M. TurRELl, of Pennsylvania ; L. E. Wrtт, of Milwankee, Wisconsin.

Committee on Resolutions: H. R. Kexsel, of West Virginia, Chairman: Wr. C. Boyd, of Indiana; IT. II. CrAmer, of New Jelsey ; P. I. Morris, JR., of Georgia; J. F. McCARTHY, of Boston, Massachusetts; RAYMoNd REBUfFo, of Nevada; A. D. Rose, of Íeru Countr, California.

Committee on Auditing: J. H. Lewrs, of Washington, Chairman: N. I'. TInLEmax, of Green Bay, Wisconsin; J. D. WAltox, of Dallas, Texas.

\section{IN CHARGE OF LADIES' PROGRAM}

Mrs. W. S. Bussey, Mrs. M. W. Jensex, Mrs. H. F. Wollix.

\section{IN CHARGE OF REGISTRATIONS}

Mrs. F. C. Bell, Mrs. E. L. Brueckyer, Mrs. M. M. Brodmerket, Mrs. E. M. mamahon, Miss Eleaxor A nderson.

\section{PRESS REPRESENTATIVES}

P. F. WAish, J. F. Reilly, R. T. Cook.

*W. S. Busser, Secretary of the Conference, is ex officio nomroting secretary to each committee. 


\section{COMMITTEE MEETINGS, MONDAY, JUNE 6, 1960}

Monday was set aside for meetings, both open and executive, of the Conference committees. Announcements of the meetings on Monday were carried in all invitations, all pre-Conference publicity, and in the tentative and printed programs.

A large number of delegates took advantage of the committee meetings, and, as a result, attendance and participation were exceptionally good.

The Conference committees that met on Monday were the Executive Committee, the Committee on Laws and Regulations, the Committee on Specifications and Tolerances, and the Committee on Education. 


\title{
REPORT OF THE FORTY-FIFTH NATIONAL CONFERENCE ON WEIGHTS AND MEASURES
}

\section{FIRST SESSION-MORNING OF TUESDAY, JUNE 7,1960}

\author{
(H. E. Crawforn, Chairuax, Presiding)
}

'The invocation was delivered and the memorial service for departed nembers was conducted by the Conference Chaplain, Mr. R. E. Magoffin, Chief Chemist, Department of Igriculture, State of South Carolina.

\section{ADDRESS BY HON. FREDERICK H. MUELLER, SECRETARY OF COMMERCE}

It is a great pleasure for me to be with you today at this 45 th National Conference on Weights and Measures, and to extend to you the greetings of the Department of Commerce. Tre in the Commerce family have as our particular duty the promotion and development of the nation's business, trade and industry. Our Department also plays a vital role in science and technology.

You share many of oul interests. In your capacity as weights and measures officials in cities, counties, and states throughout the country, you provide the basis for equity in commercial transactions.

Your work may seen to lie behind the scenes, and you may sometimes feel that it is mappreciated, but let me point out that the very foundation of business, trade, and commerce is trust and confidence on the part of buyer and seller. You make possible this atmosphere of confidence.

A housewife buys a pound of butter, a prairie farmer sells his grain (rop, a manufacturer of steel delivers toms of sheet metal. In each case, there is an implied faith that, as goods are exchanged for money, there is the same just balance for buyer and seller.

The National Conference on Weights and Measures, an institution almost as old as its sponsor, the National Bureau of Standards, seens to me to represent an ideal relationship between Federal and local governments. The nltimate goal of this cooperation is to encourage commerce and to protect the consumer.

'The traditional pattern of responsibilities in the Conference strengthens our free enterprise system which we all value so highly and which is giving Anericans the highest standard of living on earth.

There is no orerriding Federal control-the regulation of commercial transactions involving quantity rests with local officials. The Federal government, through the National Burean of Standards, provides technical assistance, and calibration of the state standards of measurement. 'This partnership-with the Federal government doing what it can best do, and local authorities doing what they should do-is something we should prize and strive to initiate in other areas where the interests of the people involve Federal-State relations.

1 With the exception of formal papers and committee reports, the record of the 45 th National Conference on Weiglits and Measures has been learranged, consolidated, condensed, and, in some cases, comments have been eliminated wherever necessary to reduce the printed report to essentials for future reference. 
The National Bureau of Standards values its long and pleasant relationship with the Conference, for it is by this means that the national standards of measurement, maintained by the Bureau, are translated into everyday use.

Weights and measures must deal with a host of problems involving legislation, administration, and cooperation among officials, and representatives of commerce and industry. Aside from these essentially human relation problems, there are many problems which can be solved only by scientific research.

It is in this category that the measurement programs of the National Bureau of Standards can make significant contributions to the important job you are doing in your States. We in the Department of Commerce are well aware of the importance of a strong program at the National Bureau of Standards. This is based not only on a recognition of the excellent work of the Bureau's scientific staff, but also on an acknowledgement of the pressing demands for the Bureau's services by science, industry, and such groups as the National Conference on TVeights and Measures.

The scientific research programs of the National Bureau of Standards provide the broad base for its technological competence. This competence enables the Bureau to serve as advisor's to you in the specialized problems of weights and measures administration. The strengthening of the Bureau's basic program which has taken place in the last few year's will undoubtedly result in practical benefits to you who are engaged in the day-to-day business of weights and measures.

In the future, your activities will no doubt become more complex and refined. This is surely the direction of things, and the Bureau will be in a position to assist you in this transition.

To mention just one area, it does not require great foresight to see the time coming when electronic equipment will play a greater part in your work. This is a trend which is to be accepted and welcomed for the greater services which you can offer to the public. It is also, however, a step which requires much preparation and planning. I am certain that this challenging development will come about in the same spirit as in your past relationships.

For yours is an ancient and yet a dynamic profession. We find references to weights and measures in the Bible. They are mentioned in our Constitution. 'The subject occupied the attention of the great men of our early history.

I am sure you recall the oft-quoted phrase of John Quincy Adams, who said, "Veights and measures may be ranked among the necessaries of life to every individual of human society."

Children soon learn the meaning of questions like "how much?" and "how many?" It is perhaps not too much to state that measurement is a fundamental part of all knowledge. It is given to you to play a vital role in this activity which is so essential to the conduct of the Nation's business and commerce. We look to you for assurance that equity will prevail.

Tomorrow, we initiate another member into the Nation's measurement family-the new State of Hawaii. We will do this by presenting our sister State from across the sea with a set of State standards of physical measurement.

I am looking forward to participating in this occasion. I note 
that you have scheduled the ceremony as one of your formal sessions, and I would like to take this opportunity to invite all of you here today to join with me in the ceremony of presentation.

And now, I would like to touch upon a subject of great mutual interest, the outlook for the future of our economy.

I repeat, your public service is a continnous contribution to the strength and progress of our economy.

For the first time in history, the Gross National Product - the total value of goods and services-has reached the $\$ 500$ billion alt itude-the highest prosperity peak ever reached by any nation on earth. Your efforts helped in this spectacular adrance.

Public confidence is high. Business activity is good. Employment is better-with a noticeable pickup in construction.

Personal income for the first 4 months of 1960 was at the annual rate of $\$ 394.5$ billion, an increase of $\$ 21$ billion or 5.5 percent above that of the same period last year. This buying power flowed into department stores, automobile sales rooms, and other markets and was reflected in industrial production.

Business spending for new plant and equipment is adding vigor to the economy. Companies are moving forward with programs which should be 14 percent above last year's capital outlays.

Other business indicators also are grounds for confidence.

As for the months ahead, I do not expect either boom or doldrums. Instead, I look forward to a high level of business activity and employment all through the year. I anticipate that, when 1960 ends, the Gross National Product for the entire 12 months will reach an all-time record peak.

In the coming decade, of course, we should expect pauses from time to time for breath-catching. But, through growth in population, education, savings, research, invention and production, we have unprecedented resources for sustainable growth.

Let's not drop the ball. Let's take adrantage of our free enterprise heritage. Let's build a better America.

If government, business, and labor have the brains and the backbone to use our free enterprise economy right and hold inflation at arm's length, the next 10 years could be the best years of our lives.

\section{PRESENTATION OF HONOR AWARDS}

Dr. Astin presented "Honor" A wards" to 16 member's of the Conference who, by attending the 44th Conference in 1959, reached one of the four attendance categories for which recognition is madethat is, attendance at 10, 15, 20, and 25 meetings.

\section{HONOR AWARD RECIPIENTS}

20-Year Certificates

J. W. Saybolt, Robert Williams.

V. D. Campbell.

15-Year Certifieates

10-Year Certificates

H. L. Badger, IT. H. Hem, G. I. Johnson, Ir. .T. Kehoe, H. A. Lason, H. D. Leisenring, I. M. Levy, B. D. Miller, TT. M. Milligan, Mack Rapp, G. C. Reiley, Wr. A. Schemer, E. C. Westwood. 


\section{ADDRESS OF CONFERENCE CHAIRMAN}

\section{By H. E. Crawrond, Conference Chairman, Inspector of Weights}

and Measures. Jacksonville, Florida

While I have not had the privilege of serving in the field of weights and measures as many years as the two distinguished gentlemen who preceded me as your chairman, I have greatly enjoyed my associations with this group ever since I attended the 24 th $\mathrm{N}$ ational Conference on Weights and Measure-my first one-in 1931.

Like every new official, I came thirsting for knowledge in our field. I am happy to say that my desires were fully met. That we learn here rubs off on the other fellow. Much of value has rubbed off on me through association.

It has been interesting to read during the past year the reports from many State and local jurisdictions, telling of the standards and equipment they have acquired since our last Conference. Included in these items are heavy-duty test trucks equipped with 1,000-pound weights, medium heary-duty test truck units carrying 500 -pound weights, and I.P gas testing units. Many jurisdictions have acquired office and field standards, and officials all over the Nation have purchased equalarm scales to be used for the purpose of checkweighing prepackaged commodities.

It is also an indication of progress to note that many departments have increased their efficiency by employing new inspectors in order to provide the added services needed. Tre all recognize that the backbone of any department is its personnel. Without men of adequate education, good mechanical aptitude, administrative ability, interest, and initiatire, a weights and measures agency camnot provide the services the law contemplates and camnot give proper prestige to the department it represents.

The States of Missouri and Washington are to be congratulated. They enacted complete new laws during the past year based on the Model Law, bringing the Nation that much nearer to uniformity in weights and measures enforcement. Several other States have also contributed toward uniformity by promulgating Handbook 44 codes and other weights and measures regulations.

Training schools held in many State jurisdictions have become invaluable. They have been conducted by personnel of the National Bureau of Standards Office of Weights and Measures and cover principally a review of Handbook 44 and testing procedures for weighing and measuring devices. Inspectors who attend these classes become better informed in the several phases of their duties, resulting in the upgrading of this highly specialized service.

IVeights and measures nationally has undoubtedly completed the most successful year in its history. Never during previous years has it received as much attention of the public, commercial interests, and educational institutions. All this recognition has been due to the combined efforts of interested agencies-the National Bureau of Standards and its Office of Weights and Measures, the National Conference on Treights and Measures, and rarious trade associationsall wholeheartedly dedicated to this cause.

On March 1-7, 1960, Weights and Measures Week was observed nationwide for the third time. This observance, a project of the standing Committee on Education, was assigned to a subcommittee 
headed by J. Ellis Bowen. This subcommittee was entrusted with the responsibility of making plans and arrangements for the event.

A report on the "Treek's" observance will be made at another session, so I will comment on it but briefly. 'The success of this project is a direct result of the organized efforts of the Committee on Education and its subcommittee. Every official in America was contacted and made acquainted with the promotional material arailable. I would like to say here that, without the use of frequent communications, this "Veek's" observance would have been a failure. This is an example of what can be accomplished by a coordinated nation wide effort. Our Committee on Education and its subcommittee should be sincerely congratulated on this outstanding job well done.

This National Conference organization could use this coordinated nationwide effort in many other areas. For example, in package control, the adoption and enforcement of Conference recommendations, specifications, and tolerances, and in other fields.

Some of the State and local southern jurisdictions are attempting to use this system now. On weekends, each official reports shortweight findings of nationally distributed standard-packed commodities. The official who receives these reports mimeographs and distributes the information to all contributing officials. Many discrepancies in package weights have been discovered, and this exchange of information has resulted in a concerted effort in the participating jurisdictions. A similar national program should be far more effective than this regional effort.

Success in other phases of weights and measures can be attained through communications among officials, followed by their immediate attention to the subjects at hand. Communication is the lifeline of any successful project.

Your chairman was privileged to address the National Association of State Departments of Igriculture in Nashville, Tennessee, last October 22 on invitation of its president, the Honorable Parke ('. Brinkley, Virginia Commissioner of Agriculture. He stated that their association would like to know the principal problems we in weights and measures were running into currently and how their association could best aid our organization in meeting its responsibilities.

Mr. WV. S. Bussey, Chief, NBS Office of Weights and Measures, was also present at this meeting as a consultant. 'Together' we attended the several hearings of the new Committee on Treights and Measures, which were presided over by Chairman Ben .J. Butler, former Kentucky Commissioner of Agriculture. These were busy sessions. Several pertinent resolutions received farorable association action, while other's were referred to the organization's Executive Committee for further study.

In 36 States, the enforcement of weights and measures is assigned to the Department of Agriculture. 'There is no other division serving as many people as does this agency. It is my firm belief that we may look forward to closer relations with the heads of these departments and to having their cooperation in securing better up-to-date uniform laws and regulations, arlequate equipment, and adequate personnel properly trained. Our two organizations have mutual objectives and can benefit through continued effort toward their realization.

Adverse publicity appeared in onr newspapers nationally when 
certain officials were indicted on serious charges. It is apropos to urge more competent and more efficient weights and measures services. Officials should have all work done well and throughly. Full and complete tests should be made on all derices, to hold the respect and support of all citizens. That we have accepted as good practice in the past decade cannot always be considered as proper procedure today.

The accomplishments of the National Conference on Wreights and Measures from its inception have been constructive and continuously progressive. These meetings have resulted in closer cooperation and collaboration among weights and measures officials and allied commercial interests.

TTe are fortunate to have the sponsorship of the National Bureau of Standards and the services of its Office of Weights and Measures, the personnel of which have provided our sereral handbooks, familiar to all officials. These handbooks are perfect references on subjects of our daily concern.

The most recent NBS publication is Handbook 67, Checking Prepackaged Commodities, by M. IT. Jensen. We recommend that all officials follow this outlined procedure in the checkweighing of commodities.

In the future, many new weighing and measuring devices will be used by industrial and commercial interests. Some are in use now. We have already witnessed the successful operation of electronic scales employing load cells instead of levers. Hydraulic scales will be entering the commercial field also. Automatic devices are even now weighing and measuring millions of packages daily. Some officials have already seen a previer of a gasoline-dispensing derice being designed to register the flow of gasoline by a turbine meter. TTe are entering a new era of weights and measures and must keep in stride with this rapid transition.

Now let us talk about a new project-the Library of the Office of Weights and Measures at the National Bureau of Standards. The Library expects to acquire and preserve every known volume on this subject that can be secured. If you will search your county, city, or State records and files, you may be able to make significant contributions. If any document is found that you think might be of value to the Library, write a brief description of what you have and send this to the Office of Weights and Measures. 'They will in turn advise if it will be of value to them. A few have already done this, and the cooperation of all other officials in adding to this collection will be appreciated.

TTe of the National Conference on Weights and Measures can be proud of our past record, but can never rest on our laurels if we are to progress. The past is only a prologue. 'There will be many unavoidable problems encountered in the years ahead, so we must cooperate and communicate and be constantly alert to meet the challenge of the future. 


\section{By A. V. Astin, Director, National Bureau of Standards}

Since my position as President of the Conference stems from my position as Director of the National Bureau of Standards, it is my design to give a brief report on developments at the National Bureau of Standards. 'There have been, since the last Conference, a number of significant activities: Fiscal operations, program achievements, organizational changes, and a critical evaluation of the Bureau's programs. Let us consider these areas.

First, in the fiscal area, the National Bureau of Stanclards is enjoying this year the largest increase in its operating appropriation in its history. We have this year for operating expenses $\$ 17.5$ million, representing an increase of nearly $\$ 5$ million, or about 40 percent over the amount available to us last fiscal year. "With this increase, we have been able to bring about a number of needed improvements in our program. These have covered essentially three types of activities. First, we have achieved some program expansion. Second, we have refinanced some of our activities, taking over funding with our own money activities which had been supported by tranfers from other government agencies. Third, we have purchased equipment in order to make available to our scientists more up to date technical laboratory tools. With the increase in program, we have been able to initiate activities which will put us in a much better position to render the measurement services which are needed by the nation's technology.

For the next fiscal year, the appropriation has already been passed, and we know that there will be a more modest increase in our program-approximately 8 percent. 'This essentially is just about enough to consolidate the gains which were possible this year. However, along with this modest increase for operating expenses, we were given by the Congress a very substantial amount to initiate the construction of new laboratory facilities. $\$ 23.5$ million was made arailable to start laboratory construction at our new site in Gaithersburg, Maryland.

For your inspection, there is available a model of our proposed laboratory facilities at Gaithersburg. You may see the long-range plan for the Bureau's facilities in this model. Three of the units shown in that model will be started during the coming fiscal year. The first is a new nuclear radiation facility, one of the most significant items of which is a porrerful new linear electron accelerator. This will provide accelerated electrons to 40 million volts of energy, but of terrific intensity, and with a beam output of some 40 kilowatts. This represents approximately a 100,000-fold increase over the beam intensities which have been available to our scientists. 'This and related facilities will provide rery important new tools to meet measurement requirements in the nuclear radiation area. Next, the $\$ 23.5$ million will permit the construction of a fine mechanical engineering facility. Included will be a 10-million-pound testing machine and a 1-million-pound dead weight machine. 'These will permit us to provide calibration services for the measurement of large thrusts, an area which is of increasing importance to the development of rockets 
for missiles and satellites. In addition, the appropriation available will permit the construction of the power plant for the total site, and some of the general site development which is necessary for the complete relocation which will come about within the next $\check{y}$ years.

In the area of program achievements, the most important developments have been in extending the accuracy and range of our measurement standards so that we can provide more effective calibration services. In frequency standards we have achieved, using atomic beam derices, the most stable and accurate frequency standards yet developed. Tre have developed a cesium beam device which gives a frequency stability of a few parts in $10^{10}$, or expressed in another way, this represents the stability of a second in several thousand year's. With this new frequency standard, we are monitoring the various standard broadcast frequencies, including our own WWV. We made an addition to our standard frequency broadcasts during the past year in the rery-low-frequency area, establishing services at 20 and 60 kilocycles.

We have made significant progress in developing wavelength standards. There is an international eflort underway to replace the meter bar with a wavelength standard. We expect that this will be formalized this coming October by international agreement. Getting ready for this change has entailed a great deal of laboratory work and equipment development, and this has been progressing very favorably.

In the area of high-temperature measurements, we can report quite satisfying progress. 'Two or three years ago, I called attention to the inadequacy of our facilities in this area. We have recently improved significantly our ability to calibrate high temperature measuring devices. We have been able to get together devices not only to produce high temperatures but also to analyze and characterize them.

A number of years ago I also called your attention to a critical need of industry for improved length-calibration services. Specifically, there was a request for the development of gage blocks which could be used to calibrate to a ten-millionth of an inch. TVe have now had gage blocks under examination for approximately a year which appear to be capable of such stability.

During the past year, we completed a number of important and very precise determinations of fundamental physical constants, one of the most significant being a redetermination of the Faraday, the basic unit for measuring electrical charge, and along with this the most accurate determination of the atomic weight of silver which has yet been made.

There were many more significant program achievements during the year, but I think this will serve to indicate that we are making progress in returning to the public some reward for the increasing investment in our programs.

During the past year, there were a number of very important organizational changes at the National Bureau of Standards. The one, I think, of greatest interest to this Conference was the re-establishment of a metrology division, organized mainly around our former Optics and Metrology Division. We have brought back into this Metrology Division work on mass standards and capacity standards which had been previously in another organizational unit.

The head of this new division is Mr. Alvin G. MreNish, who has had a long interest in the basic physical standards which will be the center of the activities in this division. 
We also established an instrumentation division, under the leadership of Mr. Montgomery, and we brought in much of the work on electronic instrumentation, electronic engineering, as well as our Office of Basic Instrumentation.

We also made some reorganizations in our Electricity Division, focusing attention on the basic electrical standards, and named a new chief of this division, Dr. Chester II. Page.

We split our Atomic and Radiation Physies Division into two divisions, one dealing with radiation physies and the other with atomic physics, and set up as head of the newly established Atomic Physics Division, Dr. Lewis Branscomb.

We have given some attention to weights and measures and calibration and standards activities and have assigned $\mathrm{Mr}$. W. A. Wildhack as a special assistant to the Director, with duties of working with Dr. McPherson on the measurement standards and weights and measures activities.

One further change: In our Central Radio Propagation Laboratory we found it necessary, due to the rapidly increasing size of the program of the laboratory, to create a fourth division, and this is an additional organizational change which is coming about during the current year.

Most of these changes, particularly those that I emphasized earlier, are aimed at providing more effective service to the weights and measures areal.

I mentioned earlier that evaluation of the Bureau's activities represented a significant development during the past year. Perhaps the most important of these evaluations was the issuance of a report by a special committee established by the National Academy of Sciences at the request of the Secretary of Conmerce. The purpose of this committee was to evaluate the total program of the Department of Commerce in relation to national needs, and this included several of the bureaus in the Department other than the National Bureau of Standards. The report of the committee emphasized that science and technology are playing an increasingly larger role in the industrial and business activities of the Nation. And concurrent with this, the role of the Department of Commerce in the progress of the Nation's science and technology was specifically emphasized.

Among the recommendations of the committee was one to establish in the Department of Commerce an Office of Assistant Secretary for Science and Technology to be filled by an official with professional and management experience in science and technology. The objective behind this recommendation is, of course, one of emphasizing the role of science and technology in the Nation's commerce and industry and at the same time providing a means within the Department for developing a stronger overall scientific program.

Panels on the committee dealt with the individual bureaus in the Department, and the one which looked at the National Bureau of Standards made a number of specific recommendations, some of which I will call to your attention. One of their observations was as follows:

The development of accurate methods of measurement and of standards is of vital importance to the commerce needs of our country. Their needs for standards should be fully met. This the Burealu is not now doing only because of inadequate funds for its operation and for buildings and ficilities within its area... 
This I am rery pleased to report to rou. but along with it the committee recommended a number of wars by which the Bureau could be improred. It suggested first of all an increase in technical effort of perhaps fifteen percent a rear. It endorsed the plan for our new facilities at Gaithersburg. The report made some rather detailed recommendations for eraluating some of our specific programs about which there might be some question, and it recommended that we seek ways of improring the utilization of our adrisory committees. Included in this, of course, is the adrisory committee which represents the interests of this Conference.

Another evaluation of the Bureau's activities was conducted by the Aero-Space Industries Association. That Association reriered the needs of defense industry primarily in terms of measurements services provided by the Bureau and pointed to a number of gaps in our program in terms of what industry wants or expects from the Bureau. The have established an active program, under Dr. McPherson's leadership, in an effort to derelop programs to fill some of the urgent needs which the Aero-Space Industries Association pointed out.

It may never be possible or practicable for the Bureau to provide all of the measurements services which are needed by the industries of this country. There is a sugestion which I pass on to rou for consideration. This is that the weights and measures jurisdictions in the States might provide some real assistance to industrial firms by calibrating some of the derices needed by industry.

A number of jurisdictions have receired requests in the past, but in general there are now legal means by which weights and measures jurisdictions can perform measurement services for private sources. I am not sure it is a desirable change to seek to provide such serrice. Certainly some mechanism must be dereloped to provide on a reasonable, local or regional basis increased measurement service to American industry. You will hear a little more about this in a talk by Colonel Stolle. I rould like to hear, either directly from members of the Conference, or through the Conference Secretary, Mr. Busser, of reactions of weights and measures officials as to whether there is an opportunity for weights and measures jurisdictions to contribute to the solution of this problem. Perhaps, if it appears to be a reasonable approach, I might establish a special study committee, consisting of some representative Conference members to explore this rery important problem.

You have been adrised in the past of our concern about the adequacy of present State standards. The have been conducting a rather intensire derelopment program at the National Bureau of Standards, pointing to providing, at some time in the future, new sets of modern standards to the States.

Some of the work on the derelopment of improred new standards will be presented to you by the chief of our Mass Section, Mr. Peiser, at a scheduled talk. Some of the prototypes which have been dereloped as proposed new standards for the States will be presented to the State of Hawaii, and you will have a chance to see what these proposed new standards look like. Is rou know, before we can initiate a program of presenting new standards to the States, Congressional approral is required, and we hope that our activities in 
this area will be far enough advanced so that we can present such a proposal to the coming session of the Congress.

You have been advised at prior occasions of the "moisture in wheat and grain" problem. I am happy to report that we were able to recruit one of our former staff member's to work on this problem. He has completed an extensive survey of measurement methods for measuring moisture, and on the basis of this survey we have planned to initiate a development program in our own laboratories and have assigned one of our staff member's to this responsibility.

I am very pleased to report siguificant progress in our training program. Our staff participated in 22 State training programs during the past year, and we have completed our own plans to initiate a program here in Washington for the training of instructors. By concentrating on training instructors, we feel that we can extend this activity more rapidly than if we attempted to do all of the training ourselves.

In the publication field, your chairman has already made reference to the appearance of Handbook 67 , on checking of prepackaged commodities. There is now in press the kitchen reference card on weights and measures items, which many of you have requested. This is being prepared so that local jurisdictions can overprint their own name on the card and use it for whatever value this will bring about in the States and other local jurisdictions. Our office will advise you when the card is available.

Your chairman has also mentioned the important work which we have been doing in collecting references of an archival nature on weights and measures. In addition, Dr. Judson has made substantial progress in collecting a variety of important data on activities of interest to weights and measures officials. It is hoped that this will be available for distribution before too long.

Work on handbook 26, which many of you are anxiously a waiting, is still in progress. We have had some difficulty, which I think appears near resolution, of deciding just what it was going to say, but I feel reasonably conficlent that this handbook, in a form all of you will like, will be in your hands before the next Conference.

I now have a happy responsibility, as President of the Conference, to make some appointments.

First, our appointments to the Weights and Measures Adrisory Committee to the National Bureau of Standards: 'This committee currently consists of Dr. McPherson of our staff as Chairman, Mr. Westwood of Salt Lake City, Mr. Moss of the American Petroleum Institute, Commissioner Brinkley of the State of Virginia, and Mr. Gustafson of the Creamery Package Company. 'The terms that are expiring are those of Professor Gordon of Dennison University, and of Mr. Rollin Meek of the State of Indiana. Your Conference Chairman has recommended that the two individuals whose terms are expiring be reappointed to new terms, and it is my great pleasure to reappoint them to new :3-year terms. In general, I feel that rotation on these committees is desirable, but I think these two individuals possess such unique qualifications that I would be most happy to see then each continue to selve another:3 year's.

Now, on the standing committees of the Conference, there are some racancies, which should be filled. 'There are three appointments for: 
full terms, each of 5 years, and then there is one appointment to serve an unexpired term, this being for 1 year.

On the Committee on Education, and to succeed Mr. Irvine M. Lerr of Chicago, Illinois, whose term is expiring, I appoint Mr. Carl Ḧ. Stender of South Carolina for a full term of ỹears.

To fill the racancy caused by the resignation of $\mathrm{Mr}$. Thomas $\mathrm{C}$. Harlis from the Committee on Education, I appoint Mr. Howard E. Crawford of Jacksonville, Florida, to fill this unexpired term of 1 vear.

On the Committee on Lars and Regulations to succeed Mr. J. 'T. Kennedy of the District of Columbia, whose term is expiring, I appoint Mr. John H. Lerris of Thashington for a full term of 5 years.

To the Committee on Specifications and Tolerances to succeed Mr. Clyde O. Cottom of Michigan, whose term is expiring, I appoint Mr. Thomas C. Harris, Jr., of Tirginia for a full term of 5 years.

All three of the members retiring from these standing committees this rear have rendered outstanding service to the National Conference on Treights and Measures and to weights and measures administration nationally.

I am sure that the Conference will wish to express its appreciation to these outgoing members by giving them a standing rote of thanks at this time.

With this happy duty completed, I conclude my report to the Conference with my personal thanks to each of you for all you are doing to promote accurate, uniform, and reliable measurement throughout the United States.

\section{MOVING AHEAD IN ACCURATE COMMERCIAL MEASUREMENT IN THE} UNITED STATES

\section{By D. N. McDoweln. Director. Wiscomsim state Department of Agrimlture. sitate of Trisconsin}

I am pleased to hare the opportunity to appear on the program of the 45th Sational Conference on Treights and Measures. In making: this presentation, I am pririleged to represent not only the State of Trisconsin, but the National Association of State Departments of Agriculture. I am personally thrilled by this opportunity because I believe that the function of improving accuracy of commercial measurement in America is a task of the highest order. Treights and measures officials have a most rital but extremely complex responsibility-one which we may describe as bridging a gap between modern applied measurement technology and the human element, with billions of dollars in the balance.

Bridging this gap between the man and the machine is not an exact science-it is an art. It is not purely science, not solely human relations, not entirely opinions, not completely legalistic. Effective weights and measures administration calls for a combination of these. The art is in achiering a proper balance. Our basic challenge, it seems to me, is to bring into sharper focus our best technology, our best know-how in dereloping laws and regulations and enforcement programs, our best refinements in human understanding and human relations, and the highest order of communications at all lerels. All of these forces must and do have a part in the total. If we are having 
some difficulties in getting the kind of job done that needs to be accomplished, it is not because we do not have the tools a vailable to work with. It is because the administrative framework is not organized so that as a team we are putting our best foot forward in the right way, in the right place, and at the right time.

Talk alone will not do the job. For that reason we are glad to be on your Conference program this year to give you a positive progress report of actions recently taken by the National Association of State Departments of Agriculture and by our own State of Wisconsin-not just to give you a little talk. Te trust that some of the recent eflorts by our National Association, emanating from the States themselves, in cooperation with the National Conference on Weights and Measures, will help amplify and strengthen some of your fine efforts and bring them into sharper focus on the job before us.

Commissioner Brinkley of Virginia and Commissioner Butler of Kentucky at two preceding. Conferences have done a splendid job of giving you some of the thinking, problems, and objectives of a State director or commissioner of agriculture in weights and measures administration. Some of the thinking and interest expressed by these two gentlemen have now borne fruit. We are happy to report that, at the last meeting of the National Association of State Departments of Agriculture, held at Nashrille, 'Tennessee, October 19 to 23, 1959, 10 resolutions were offered and 5 were passed on weights and measures. One of the most significant called for a study of the administrative machinery each State now has, including funds, salaries, equipment, laws, and regulations. 'This will give all of us a better' picture of how we are equipped to do the job. Inother calls for a program to insure uniform specifications and tolerances, tests, and accurate instruments in moisture determination for grain-a "must" to insure fair and equitable payments to farmers for grain. Another resolution suggested that the U.S. Department of Agriculture, through its Packer's and Stockyards Branch, cooperate with and utilize livestock scale testing facilities of the States. New adequate physical laboratory standards were requested for the States in another' resolution.

A change from the traditional bushel to a weight basis in grain trading was the suggestion of another resolution. Originating from this Conference, this was a continuation of our association activity in this area which had been started at our Madison, Wisconsin, meeting one year before, at which time a conmittee was set up and I was named the chairman. Our first step was to call together a national group representing farm and trade organizations and other interested groups in Chicago last spring. George Johnson, Kientucky, represented your Conference on this committee. Our own weights and measures people pitched right in in cooperation with George Johnson. U.S. Department of Agriculture oflicials were conferred with, and contacts were made with national farm organizations and grain trade groups. A 1-page brochure was printed for farmer and public dissemination and is being given nationwide distribution. I State action committee was set up to review, in our own State, the roadblocks which have successfully delayed this necessary marketing eftieiency move which was studied and recommended by your National Conference as long as 25 years ago. I request was then forwarcled to all commissioners and directors of agriculture and other agencies heading up weights and measures administration that similar action 
committees be set up at the State level across the country. The have had replies from 18 States to date and, with only two exceptions, sentiment has been in favor of the change, and in many cases action has started at the State level.

Some of the comments received from the various States include the following:

I am instructing that a committee such as yours be set up.

Reports from leaders in our State are substantially in favor of this change.

In our State we have for a considerable number of years been trading on the basis of pounds or tons.

Generally speaking, farmers and grain people would recommend a changeover to the weight basis by the U.S.D.A., both in grain purchases and in their crop reports.

We have considerable trouble with many farm products under the bushel system, and it would please us to see net weight come in this and many other marketing programs.

We are ready, law-wise, to transfer to the weight system.

I am requesting a study of the legislative changes that may be required to effectuate this objective.

We will set up a committee and try to get consent of our people to go all out for this program.

\section{Some were noncommittal. For example:}

I plan on retiring in the not-too-distant future so I think I will call this to the attention of my successor.

It is an extremely controversial subject.

We are still a bushel State. It will take some time for the oldsters to see weight instead of measure.

This is a clearcut example, in my opinion, of a situation which neerls no further study or talk. It needs united action by those people who understand the problem.

There is another area in the field of marketing and reights and measures which we have been concerned about. It is in the field of weighing livestock. In Wisconsin we market approximately $11 / 2 \mathrm{mil}$ lion veal calves per year. The estimate that the weighing of these calves involves at least 1 million individual drafts. Most of these calves are weighed over livestock scales which have 5 -pound graduations. If people who are purchasing livestock over scales were not tempted by the dollars and cents involved of 2 or 3 pounds per calf and would weigh so as to average out exactly in the middle of 5 pounds, I assume that we could say there was nothing to be concerned about. While we do not have figures to show what portion of the 5 pounds is going to the seller and what portion is going to the buyer on the 1 million drafts per year, we do not believe it would be out of line to suggest that in actual practice it is entirely possible that on the average as much as $21 / 2$ pounds per draft may be involved. With the average price of veal calves last year at 25.7 cents per pound, this would amount to $\$ 642,500$ in our State over a year's time. If this be the case, I am not saying that livestock buyers are pocketing any or all of this $\$ 642,500$; I am saying that this amount of money can be used to inflate the price to mislead the farmer and make it very tough sledding for competitor to stay in business in the face of this type of competition. From our study of this matter to date, it appears that these calves should be weighed on scales with 1-pound graduations. This would remove, to a substantial degree, the temptation to err on one side of the balance and to help assure more precise 
and fair weighing of a very valuable cash crop in our State. Tre plan to get information out to farmers pointing out the monetary value of more accurate and precise weighing of veal calves. Tre may find that a regulation to that effect may be necessary. 'This does not seem to be out of line in view of the fact that our milk intake scales, which weigh up to 1,000 pounds, have a 1-pound graduation and portable platform scales also have 1-pound graduations. Many commodities weighed over these scales are not as expensive as veal calves.

Over the past 5 or 6 year's, we in Trisconsin have given considerable study to our responsibility of assuring accuracy of commercial measurement. Times have changed. Tre no longer" barter "over" a scale, but we are squarely in the middle of an era of consumer packaging. Time, place, and distance are no longer a factor, nor is who weighs or: when. In line with this, we recently suggested that our Division of Economic Practices study a change in the approach in enforcement, with the objective of getting more return for the money spent. Claire Jackson, who is chief of this division, gave a progress report on this study at the Southern Conference on Treights and Measures, held at Richmond, Virginia, November 9 to 12 , in a paper entitled "Changing Times in Teights and Measures."

The major thing we would try to accomplish in this change would be to place the responsibility of doing the necessary testing and maintenance to insure its accuracy upon the user of the derice and place inspectional emphasis wherever possible on the end result--the commodity itself. I quote from Mr. Jackson's paper the changes which we are in the process of considering:

1. Scales, meters, gasoline pumps, and other commercial weighing and measuring derices will not be approved or sealed. They will be tested on a planned and systematic spot check or survey basis. The more spot checking we can do, the better. We are doing that now on packaged commodities. In my opinion, the statewide survey of food package weights that we conducted last year did more to assure accuracy of packaged commodities than all the sealing of derices completed in the past 10 years.

2 . The must increase our efforts in informing the public and buyer's and seller's of the true economic significance of elrors in weight and measure, and clearly let the users of weighing and measuring devices know that it is their problem and their full and real responsibility not only to maintain accurate devices, but to use them accurately.

3. We will have to take more definite and sometimes more drastic legal action under the law when we find illegal devices in use. As part of the educational process, more publicity may be given to such prosecutions.

4. As a result, the selvice agencies will be required by users to do more testing and to provide more extensive and better quality service. Csers will begin to understand not only the economic significance of errols in weighing and measuring. but will comprelsend the serious legal consequences of faulty equipment and procedures.

5. It will require that our laws and regulations be gradually changed to remove the seal or approval concept. Our laws and regulations will be more strongly tested. We may be forced to remove some of the resirable but not necessarily enforceable provisions which, with the best of intentions, we have lermitted to creep into some of onr laws and legulations. Onr laws and regulations will contain only those provisions which have a real and important bearing on weighing and measmling accuracy.

6. Commodity checkweighing will be a major vear-lound part of on overall inspection progran.

7. In summarizing this change, we believe our llograms will have to be harder litting. This will take sounder and stronger laws and regulations, more technical competence in testing and working with weighing and neasuring devices, more specialization, more knowledge of general industry and trade practices, and better public information prograns. This will give us a much sounder basis to obtain funds to carry on the work. 
'These changes will not be made orernight; they will require realinement of personnel and funds, changes in our law and regulationsa gradual change over several years. May I challenge you as indiriduals and as a group rorking together as a fine public servant team to make these eraluations and adjustments as quickly as feasible.

Are we using our best technical know-how in weights and measures administration? I mentioned the need to do so earlier in my presentation. The words I often hear bandied about in our department "bull sessions" are "technological obsolescence". "To meet this need, we have just completed a consolidation of all our laboratory services in our. department in an attempt to keep up to date in the fields of chemistry, bacteriology, and allied sciences. As I made preparations for this talk, I became more aware of the need for precision and uniformity in this fast moving field of commercial measurement-a field so fundamentally basic to all economic activity.

I ras greatly impressed by Ralph Magoffin's paper at the Southern Conference on what he called "type approval". I share his feeling that such a program, whether it be state or national, be clearcut and competently administered. I am not familiar enough with all the "pros and cons" to make a recommendation to you today. But from a. brief study of the present program, it appears that united study and action of some type along this line is long overdue. Either the States will have to be better equipped or they will have to get together at the national level on a minimum design and manufacturer specification program for weighing and measuring devices. This is an opportunity for us as administrators to bring our best scientific know-how into focus on a common but important problem. I might humbly suggest that you change the name of this program. You may well leave the word "approval" out and call it something more understandable for better communication with your corrorkers and superiors at home.

Thank you again for giving me this opportunity to "compare notes" with you. The National Association of State Departments of Agriculture is on the move in this basic and vital field of our American economy. Keep up the good rork. Keep us informed. If you do, we are going to move ahead together.

\title{
SECOND SESSION-AFTERNOON OF TUESDAY, JUNE 7,1960
}

\author{
(R. MI. Bodentmeiser, Vice Champian, Presiding)
}

\section{REPORT OF COMMITTEE ON EDUCATION}

Presented by J. F. True, Chairman, State Sealer, Division of Weights and Measures, State Board of Agriculture, State of Kansas

The Committee on Education submits the following itemized report on its activities since the last Conference and its recommendations to this Conference.

1. National Weights and Measures Weel:-At the request of the 44th National Conference, a Subcommittee of the Committee on Education was established to consider and coordinate all matters pertaining to the affairs of National Weights and Measures Week. Mr. J. Ellis Bowen was appointed chairman of this subcommittee, and, through his able and devoted leadership, the Week was an outstanding 
success. Mr. Bowen will give his report on the activities of the Treek following this presentation.

The committee expresses its appreciation to Mr. Bowen and to all others who have contributed their ellorts to this worthy project.

A new subcommittee for the 1961 Wreek will be appointed by the committee chairman prior to the adjournment of the Conference. The committee recommends that an allocation in the amount of $\$ 8300$ be made to the new subcommittee chairman to cover the expenses involved in the promotion of the 1961 Week. It is further recommended that approval be given for the use of certain of these funds to purchase for resale minor items involved in this promotion. 'The subcommitte chairman will be accountable for the return of surh funds to the Conference treasurer as are not required in the activity of his subcommittee.

2. Weights and ILeasures Publications.-The committee wishes to call attention to and endorse the recommendations of the Executive and Advisory Committees found in the published report of the 19.5!) Conference, as follows:

\section{Exeouthe: Con M I'TEe}

Publication Policy of the Sutional Bureau of Stundards Regarding Wreights and Measures Publications.-The committee is of the unanimous opinion that the splendid progress made towald achieving the desired miformity in sitate laws, administration, and inspection methods duning the last half century has been largely due to the cooperative proglan developed by the National Buleam of standards. The Bureau's employees have been and alre recognized anthorities in the many phases of weights and neasures supervision and administration. 'Their' publications, which have always had the ungualified recommendation of the Bureau and the endorsement of this Conference, serve as vital guides to State and local weights and measules officials. Handbook 11, Weights and Measures Administration, for example, was first issued in 1927, reissued as Handbook 26 in 1941, and a new edition is now being prepared.

The methods of administration as recommended in this handbook are basic and right. They have never been questioned. They have withstood the test of time.

The committee unanimonsly recommends that the publications policy of the Office of Weights and Measmes continue on the samb basis that has proved so very effective in the past and that the revision of Handbook zo be prepared and published as soon as plateticalble.

\section{AwVISORY COMAITIEE}

Publication Policy of the office of IIrights and Wrasures.- The committen Was asked to consider the possible need for nodificalion of the publication policy of the National Bureau of Standalds Office of Weights and Measures to provide for the review and endorsement of some of its publications by the National Conference prior to their issuance by the Bulean. Fxtensive discussion of the feasibility of such an alrangement and of its possible allantages and disadvantages led to a manimoms lecommendation that the office of Woights and? Measures publication continne as in the past.

'The Committee on Education wishes 10 go on reroled as also recommending that the National Burean of Standands publish the revised edition of Handbook 26 at the earliest possible time and that all of her National Bureau of Standards handbooks and publications be revised and republished as they go out of print ol as necessity demands. It is also recommended that no change be made by the National Burean of Standards from past publication policies regarding weights and measures publications. 
3. Weights and Measures Periodical.-Your committee explored the possibility of obtaining a publisher for a national weights and measures periodical. Efforts were unsuccessful in obtaining the services of anyone who would be willing to undertake the responsibility of publishing such a periodical. It is felt that a national weights and measures publication would be helpful and desirable, and it is suggested that the committee continue to explore further possibilities of such a publication.

4. Technical Training.-At the request of individual States, the National Bureau of Standards, through its Office of Weights and Measures, has continued its program of technical training of weights and measures officials. The committee recommends that all States and local jurisdictions a vail themselves of this technical training. It also recommends that, as training schools are offered by the Office of Weights and Measures at its training laboratory in Washington, D.C., each State should arrange to send at least one representative to such a training school so that he may carry on a continuous training program within his respective State.

5. Endorsement of Publications.-The committee has received a request to endorse a second booklet prepared by the Scale Manufacturers Association entitled "When You Install Right, You Save All Ways". 'This second booklet gives suggestions for the selection, installation, and maintenance of livestock scales and is a followup of a booklet prepared last year by this association for other types of scales.

Since the first booklet was endorsed by the Conference last year, the committee is of the opinion that this second booklet may rightfully be endorsed by the Conference and so recommends. The committee feels, however, that, as a matter of policy in the future, the Conference should refrain from endorsing any publications not of an official nature-that is, any publication not prepared by the National Bureau of Standards or the National Conference on TVeights and Measures.

The committee wishes to thank all members and organizations who have contributed to its efforts during the past year and solicits suggestions for its consideration during the coming year which would be of interest to the members of the Conference and to the general subject of weights and measures education.

\author{
J. F. True, Chairman \\ J. E. BoweN \\ T. C. Harris, JR. \\ W. A. KerLIN \\ I. M. Levy \\ W. S. Bussey, Secretary
}

(On motion of the committee chairman, seconded from the floor, the report of the Conference Committee on Education was adopted by voice vote.)

Mr. Arbanese: I am A. J. Albanese; I am president of the Connecticut Sealers Association. At the Conference last year, two resolutions were offered by my association, both concerning consumer protection. The National Conference at that time referred these resolutions to the Committee on Education to be reported on this year. I believe the committee should have reported on this matter. 
Mr. True: The Committee on Education regrets that this matter was not attended to. It was not brought up during the open meeting lield by the committee on Monday and simply was orerlooked.

(On motion by Mr. R. E. Meek, seconder from the floor, the Comnecticut resolutions again were referred by the Conference to the committee on Education.)

\section{REPORT OF SUBCOMMITTEE ON PUBLIC EDUCATION AND NATIONAL WEIGHTS AND MEASURES WEEK}

\section{Presented by J. Eluis Bowex, Chairman, City Sealer of Weights and Measures, Newton. Massachusetts}

In my comments this afternoon I will not dwell at length upon the history of, and reasons for, our promotion of National Weights and Measures TVeek.

Summarizing very briefly, such promotion is dedicated to the improvement of the public service for "which we have, by virtue of our positions, all accepted responsibility.

A paramount slogan of weights and measures administration and that of National Weights and Measures Week is "That Equity May Prevail." Equity, in this instance, is dependent on the actions of the producer, manufacturer, and purreyor or other commercial interest on one hand, actions of consumers on the other hand, and actions of weights and measures officialdom. All are rital in this state of equity we envision, and all must be aware of their responsibilities. It is clearly our duty to practice our responsibilities, and as mentors, guide the other parties, and herein enters public relations for three realsons.

1. It is our duty to cooperate with and advise commercial interests in the proper use of weighing and measuring mechanisms and devices for numerous specific purposes, and to enforce statutes, rules, and regulations regarding their use and practices relating thereto. In intelligent understanding of this, our function, by commercial interests is essential to harmonious cooperation between us.

2. It is our duty to assist consumers to receive full value for money paid. Self evident it is that when consumers are educated to what to look for-zero balance on scales with no load, our seals of approval prominently displayed, proper labeling practices, etc.-they themselves are enabled to avoid financially expensive pitfalls.

Your subcommittee has received one letter from which I would like to quote an excerpt: "Too few appreciate fully the great impact for good their Weights and Mealsures Divisions have on the econony of the people in their jurisdictions, and on the Nation. For instance, in a great many weights and measures jurisdictions throughout the nation, the weights and measures official is relegalted to a position inferior to that of the dogcatcher. One lone weights and measures official camnot hope to change this situation."

In answer to that is our third reason: Among consumers, are members of various appropriating bodies on whom we are dependent for funds with which to purchase the needed modern tools, and qualified manpower to provide the best of public service to which we are committed. Incidents of good public edncation promotion will, and do, convey to them an appreciation of the chanacter of weights and measures administration, its attitudes, integrity, and its problems 
in delirering its potentialities to the fullest extent as an asset to the community.

It has been convincingly demonstrated in too many communities to leare any doubt that a cultivated public support of weights and measures can, and does, provide for its extension to meet its full responsibilities. There this is done, every department benefits personally, and the community benefits as a whole.

In 1958 and 1959 National Weights and Measures Treek was solely a grassroots operation, with a sort of paternal blessing by the National Conference but without any substantial organized coordination. Even so, the movement accomplished much and gathered momentum.

Iour Subcommittee on Public Education and National Weights and Measures Teek was activated at the 44 th National Conference on Weights and Measures in 1959, on recommendation of our parent committee, the Committee, on Education. 'This subcommittee, whose members were appointed for a 1 -year term, is chaired by a member of the Education Committee, your speaker; in addition thereto, J. Fred True, chairman of the parent committee, appointed three member's from reights and measures officialdom-John L. O'Neil, a State Inspector of Kansas, A. D. Rose, County Sealer from Bakersfield, California, and John H. Lewis, Chief of Treights and Measures for the State of Trashington-and three members from industry-Arthur Sander's, Executive Secretary of the Scale Manufacturer's' Association, G. Theon Tright, Executive Director of the Gasoline Pump Manufacturer's' Association, and George B. Travis, Vice President of the National Association of Food Chains. IT. S. Bussey, Secretary of the National Conference became Secretary of the Subcommittee. On January 1, 1960, to the regret of the subcommittee, Mr. Travis resigned. Mr. W. M. Flint, a Vice President of the National Association of Food Chains, was appointed to fill the racancy.

Due to the great geographical separation of the subcommittee members, all suggestions, interchange of ideas, and approral of recommendations were of necessity accomplished by mail, with the exception of one personal conference between the chairman and the secretary, held in Boston, Massachusetts, on the occasion of the secretary's visit to such city subsequent to the last National Conference.

The subcommittee wrote to the chief weights and measures official in every state requesting the designation of a State coordinator to represent such jurisdiction in dealing with the subcommittee. A second letter of request was sent to jurisdictions not heard from, and was responsible for the final appointment of 38 State coordinators. The subcommittee found itself dealing with some individuals in States where no coordinator had been appointed, and endeavored to give equal service to them.

Secretary Bussey submitted to the subcommittee all clippings of publicity, copies of proclamations, and radio, TV, and personal addresses, etc., that had been collected resultant of the 1959 TVEKK. Such material was carefully read and evaluated, and that deemed the best thereof ras incorporated in the 1960 promotional recommendations, together with many suggestions from all orer the country.

A 38-page Guide Booklet, of which over 100 copies were distributed, was published, all material therein having been first submitted for approval to each individual member of the Subcommittee. Our Booklets were mailed to all State coordinators, News Letters and Scale 
Journal in December of 1959. Included were instructions for submission of material to publishers, 2 sample proclamations, 2 news stories, 8 special feature articles, 3 editorials, 2 radio or 'TV script introductions, 10 spot announcements, 2 radio or 'T' dialogues, 1 public address, sample material for 4 pamphlets, recommendations regarding displays, several suggestions for adaption of material for year round opportunities, and it catalogue of aids in promoting public relations.

It is realized, of course, that no one window sticker, rubber stamp, or postage meter plate impression is, by itself, likely to produce a marked public relations impact. Howerer, such appearing often enough are like the $\log$ and phonograph trademark with the caption "His Master"s Voice" of the Victor" Phonograph Company, and do register with persons exposed thereto. The cumulative effect of these and other aids, displays, proclamations, 'TY and radio promotions, newspaper stories, special feature articles, pictures, and editorials have produced a tremendous impact, that has made the effort of all who have taken advantage thereof more than worth while.

Millions of people who had little or no comprehension of weights and measures administration activities, and undoubtedly millions more who needed reminding, including appropriating authorities to whom I have previonsly alluded, have had the vahue of our protective services forcefully brought to their attention. Complete statistics have not been received firom all participating jurisdictions; hence we know that actual accomplishments are in excess of the figures we are able to report to you at this time. I short report of some of the accomplishments reported for Tational Weights and Measures Treek 1960 follows.

Orer 6.500 mats of the shield cmblem were ristributed for use by newslualers and other publications, the total cireulation of which (*onstitutes many millioms. 5,000 of these mats were purchased and distributed by I)etecto Srale Company and were used, in the main, by chain and othel stores and various commercial rnterprises who conperated wholeheartedly in thousands of adrertisementis. The total number of mats distributer is more than a 50 percent increase or last year.

Proclamations by govelnors, commissioners, county boards and mayols totaled 148, comluared with 92 so issued last year, an increase of more than jo percent. such proclamations provided foumdation and anthority for over 1,200 published news stories, editorials, and special feature articles, three times as many as last rear. 509 different press photographs appeared throughout the countr.y. I'rorlamations also opened the door and lent authority to a reported 9T4 "TV and radio demonstrations by picture. spot ammonncenents. and plugs of varions sorts that reached the eyes or eal's. ol both, of adritional millioms of pelsoms all across the land. In addition, $12+$ personal appearances were made by weights and measures officials via T' and loadio. Compared with 90 last ycar, $24101^{\circ}$ (Ner $21 / 2$ times as many platfolm appearances were made by weights and measures officials before live andiences.

In addition to rubber stamps of the emblem in the hands of many from last rear, 38 additional new rubber stanps of the week amblem were ordered and used this real. It is impossible to exaretly (a)loulate how many of these imporessions of the emblem resulter. Our best alproximation, based on surell information as we do have, could be said very conservativels, to be more than a quater of a million. New York State alone reports : $: 2.800$ througl the use of !) stallus: in my own city, with a last rear's old rubler stamp. 17,270 were imprinted this yeal.

Numbers of weights and measures neckties, tie clips, antomobile indentification plates, etc., were ordered and nsed to adrantage.

Briefs describing the purposes and methods of ponntion were distributer by Scale Manufacturers Association to the number of 400 , and in adrition thereto 50 copies of "The Weights and Measules stol"y" fol use as sallule press releases or for pamphlet use. 
One thousand four hundred food chain executives received an executive bulletin from the National Association of Food Chains briefing them on National Weights and Measures Week and recommending support of local programs celebrating such.

Toledo Scale Company posters bearing a large size shield emblem appeared on public display.

Hobart Manufacturing Company distributed 10,000 pamphlets entitled "What are Weights and Measures?" to various jurisdictions in 14 States. Hobart reports, "This was our first effort on anything of this nature, and we did get a late start. We could have used more. Letters from weights and measures officials have been quite complimentary."

Detecto Scales, in addition to distributing 5,000 mats previously mentioned, enclosed letters therewith to 1,300 department stores and 3,500 supermarkets suggesting that they tie in with National Weights and Measures Week and use such mats in their advertising. Detecto also sent letters totaling 1,400 to advertising agencies and publicity and creative service organizations re a National Weights and Measures Week tie-in, offering the free loan of weighing equipment. Mr. Mack Rapp of Detecto, who is a member of Toastmasters International, wrote to 2,200 branches of this group urging them to invite local weights and measures officials, or one of their own members, to speak on the services and importance of weights and measures activities.

The Ford Motor Company has informed us that there is no way to assess the actual increase in demand, due to the subcommittee's recommendation, of their History of Measurement posters. However, they have informed us that 8,000 such posters were distributed between January 1 and March 21, 1960. Certainly such widespread use of this item has contributed much to the promotion of weights and measures public education during this period, and undoubtedly many will remain in constant use, particularly in schools.

We have had reports of 20 still slide or motion picture showings, exhibits, or window displays to the number of 48 , and the distribution of handbills, flyers, and literature in phamphlet form totaling 111,020.

Over 50,000 bumper and window stickers appeared before the public eyes. If visualized as evenly distributed geographically in 50 States, the average would be about 1,000 per State. However, such was not the case as, except for an odd hundred or two here and there, quantities of from 1 to 4 thousand were utilized in 16 States, resulting in a concentrated impact in such jurisdictions. In my own city it is estimated that 90 percent of the retail stores carried window stickers on their front doors.

Pitney-Bowes Incorporated has reported delivering 17 metered mail plates featuring the WEEK. This is another instance where there is no way of exactly calculating the total pieces of mail that were impressed, because such figures have not been reported. From my own City Hall 13,604 pieces of outgoing mail were so impressed in a 3 -week period. If this be an average number for each plate, approximately a quarter of a million envelopes carried the WEEK's message this year.

These are some of the highlights of the 1960 WEEK. Each and every one of these fine things that have proven effective in one locality can, and should, be used in all other jurisdictions.

We have really "gotten up a lot of steam" compared with previous years. Any official who does not get on this bandwagon of acquainting his public with the value of his services is "missing the boat."

We have been aware that our purpose is not limited to National Weights and Measures Week only, but is related to weights and measures public education at all times throughout the year. In this connection I would say, in passing, that every official in this room has a golden opportunity in his hands, right this minute, to go home and publish a good weights and measures story in his local newspaper, based on his attendance at this Conference. If three or four hundred of us do this, I do not need to spell out that hundreds of thousands of readers will be impressed with the value of our services. Those who may here be elected or appointed to any office or committee have in their hands an even stronger platform on which to build a good weights and measures story. If you, as an individual, feel that you 
are not adept in writing such material, you may help yourselves to samples of such, that you may vary to suit your local circumstances, that I will leave here, and that you may pick up at the end of this session.

Experience has conclusively demonstrated that it is the individual enthusiasm and ingenuity of local officials, in adapting news releases to their local circumstances, through inclusion of local statistics, local accomplishments, or other local flavor, that is the chief ingredient of success.

Many weights and measures officials are timid about this matter of public education or communication directed to educating the citizenry for its own protection, but they need not be. Just glance at some of the material displayed at this Conference, and the record of much that is not here, produced and publicized during the past year by those sitting right beside you at this moment.

Weights and measures service is one of dignity, purpose, and integrity in matters of public concer'n, and is not one for which any apology is necessary. Te are members of one of the most important factors contributing to our nation's economy. As a group, we have a definite and important responsibility in the fair and equitable distribution of consumer goods. We are protectors of the investment of a myriad of merchandise totaling billions of dollars. The good job that we do for our citizens, whether buyers or seller's, is fundamental to the health and to the pocketbooks of all individuals and to our national economy based on free enterprise by honest men and their mutual interests, to the exclusion of cheats and frauds.

In our service to people, reights and measures administration is committed to a single standard of quality: the most effective, and hence the best.

We have a wonderful opportunity for coustructive accomplishment, but we must seize it and promote it constantly-otherwise we deserve to lose it, and fail to measure up to our obligation to do our best. It does require work, but, after all, there is no satisfactory substitute for work. No activity can be successful or prosperous for any length of time unless devotion and time and effort is expended to assure such success.

We think of ourselves as an instrument dedicated to the achievement of an objective. Onl objective, in this instance of which I speak, is promoting weights and measures public education, and thus service, for the sake and benefit of all people.

Mr. Sanders: 'That was an excellent report; Mr. Bowen has gone far beyond normal responsibility in this work. I suggest the Conference render him a standing rote of thanks.

(Thereupon the delegates rose and applanded.)

\section{THE BANANA MARKET}

By R. B. Tewrsutri, Lssistant Traffe Manager, Finit Dispatch Company, Weehawien, Tew .Jersey

Bananas became a staple foodstuff in the Lnited States about ofo years ago when fast steamships and railroad refrigerator cal's came into general use. For thousands of years before that, bananas had been a foodstuff for tropical people, but it took moder'n transportation 
to expand the lowly banana into a commercial product of almost worldwide distribution. The banana appears to be one of the very first food products to be cultivated by man.

Most of the bananas now entering the United States and Canadi are grown on the mainland of Central America and in Ecuador, South America. Ecuadorian shipments have increased markedly during the past few years. Bananas must be grown where the soil is fertile, well drained, and where the temperature never falls below $50^{\circ}$.

Total importations into the United States and Canada now rum about こั0 million stems per year. The per capita consumption in recent years has leveled at about $17-18$ pounds annually.

'There are several large domestic importers of bananas at present and a considerable number of small importers. The domestic market has been plentifully supplied with bananas so far this year, and the consuming public has thus had the benefit of attractively low prices as compared with many other fruits and regetables on the market.

In past years, the banana supply has fluctuated considerably because of windstorms in the tropics, political upheavals in the producing countries, strikes, wars, adverse weather conditions, and similar emergencies. Bananas cannot be held for more than a reek or two after arrival in this country because of their highly perishable nature. They must be transported swiftly, gently, and with great care taken at ail stages of their journey. 'They must be kept within a relatively high and narrow temperature range as compared with other fruits and regetables. The Cnited Fruit Company utilizes, therefore, the most modern refrigerated ships and the most modern refrigerator. cars and trailer trucks obtainable in transporting its product.

The company employs a large staff of trained perishable freight inspectors at all ports and at many interior railroad junction points to carefully inspect the carloads of bananas and to decide on and supervise the protective services required in rail transit-namely, heating, icing, and rentilation. Bananas are unique in requiring this specialized protective care by the shipper, although some thought has been given to extending a similar shipper's protective service to other products of tropical origin such as tomatoes and avocados.

The increased volume of long distance trucking of bananas in the past 2 or 3 years has resulted in quicker deliveries to interior destinations from the ports, thus reducing somerhat the protective care required in transit. However, during seasons when bananas are in surplus supply, very few trucks arrive at the ports, and the fruit therefore must be loaded on the railroad. The cars are then held, sold, and diverted during the next 2 or 3 days after ship discharge. During this holding period they are under the constant care of our specially trained perishable freight inspectors. In the first 4 months of this year, 56 percent of our importations still moved by railroad and only 44 percent by truck.

Bananas are always harrested green. 'They are transported out of the farms to the nearest loading station by muleback, tramway, tractor cart, aerial tramway, or small boat or canoe. At the loading station, the banana stem is strung, washed, and bagged in a clear perforted polyethylene tube. This protective film remains on the bunch clear through to the jobber's ripening plant in the States. The bananas are brought down to the tropical seaports in open, slatted, or ventilated banana cars on tropical railways. The hours of harvest- 
ing must be well correlated with the arrivals of the ships, so that there is no delay. Is soon as the trains arrive at the loading ports, the fruit is rapidly passed into the precooled holds of the waiting ship by means of conveyor belts and gantries.

A modern banana ship can carry from 50,000 to 80,000 stems of bananas and may l'm as large as 7,000 gross tons, with an overall length of 450 feet, speed of 18 to 20 knots, and a total refrigeration capacity of 200 tons. 'These ships may be insulated with as much as 9 inches of fiberglass. The largest ships carry 250 freight carloads of bananas or the equivalent of three long freight trains. The bananas may be loaded at a pulp, temperature of $70^{\circ}$ to $80^{\circ}$, which is quickly reduced in 12 10.24 hours to the desired carrying temperature of $54-55^{\circ}$ for the gros michel variety, which is the principal variety of commerce at the present time. Other varieties which are now being tried in the domestic market, such as carendish and lacatan, may require higher ship temperatures up to $58-60^{\circ}$.

An average voyage to T.S. ports takes from 3 to 9 days. At present, most bananas are coming through the following U.S. ports: New York, Baltimore, Charleston, Miami, Tampa, Nobile, New Orleans, I sos Angeles, Siln Francisco, and Seattle.

At the domestic ports, banamas are transferred to the waiting cars or trucks by means of modern gantries and "curveyor" belts, which are designed to minimize brakage and bruising. It the colder ports, this special dischamoging equipment is corered and heated in the winter so that the hanana may not chill on its way from the ship to the heated and insulated sheds. In the wintertime, the temperature in the ship's holds is laised several degrees for 12 hours before arrival in order to warm up the cal'go to oflset any danger of chilling during discharge. In this way, banana callgoes can now be dischanged safely in zero and subzero weather.

Refrigerator cars for banana loading are carefully selected by the railroads and must be clean, tioht, and dry. 'The interior of every truck and trailer is also carefully inspected to insure cleanliness and safe carriage for this delicate foodstuft.

Because of the extra care given by large shippers to bananas throughout their journey, this commodity has remained at the rery bottom of the anmul cham list published by the Association of American Railroads. Tear after year, banama claims average only 2 to 3 dollars per car shipped, as compared with claims from $T$ dollars to 100 dollars or more per car shipped for of her fruits and regetables.

Tnited Fruit has many fine banana terminals at the valious polts, designed specifically for the exacting handling requinements of this highly perishable food pooduct. I will select the terminal at Baltimore for further discussion, as this is the latest and most modern of all. It has been recently visited by Mr. Bussey and other Government officials, and it is practically at Washingtons doorstep. The Baltimore and Ohio Railroad cooperated with the United Fruit Company in the design and construction of this fruit terminal, which was first placed in service in the fall of 1958. It is a flexible terminal designed for loading many cars and trucks in any combination with a minimum of lelay.

As the stems come off the gantries, they are gently transferred to sidewise moving curveyol belts. There are forr gantries, one for each hatch, and four curveyor belts to match. 'The bananas on each 
of these endless belts move past both the car and truck loading platforms as required. There is a minimum of transfer points and a maximum of smooth handling.

The stems are classified by trained banana selectors into 9's, 8's, and $r$ 's, and into first-class greens, specials, ripes, turnings, or broken bunches. A colored paper sticker is used to designate the classification as called by the selector. The color paper system serves to guide the men who later remove the stem from the belt and stow it in the appropriate car or truck. These vehicles are loaded with the bottom tier bananas standing on their butts, and then one or two flat layers are placed on top of the standing tier. When the loadings are finished, the doors are promptly closed and the car or truck is on its way.

Every time a truck or car is loaded, it is tare weighed and gross weighed by our trained salaried weighmasters. These men subtract the tare from the gross, arriving at the net weight of the bananas. This net weight is billed to the consignee. We never rely on stencil, "standard," or estimated weights. In the case of refrigerator cars, the stenciled tare weights have frequently been found inaccurate by as much as 1,000 to 2,000 pounds. The originating railroads invariably utilize our weights nowadays for computing their freight bills to consignees on banana cars, as they have found our weights to be more accurate than the stencil reights or the weights obtained by railroad labor.

We take many precautions to insure that the jobber is always billed a correct and accurate weight, whether he purchases by car or truck. In the case of trucks, we purchase and install at our docks our own 10- by 60-foot truck scales in accordance with our own engineer's specifications. 'These scales must be four-section, heavy-duty, mounted in stabilized pits, with substantial piling support underneath. The concrete walls and floors of the pits must be waterproof and kept dry at all times by means of sump pumps. Our weighers inspect the pits daily to make sure no foreign matter is present and that the lever systems are working freely and unimpeded. The scale is balanced at the start of each weighing period and at frequent intervals during the day.

At docks where we have two truck scales, such as at Baltimore and at Weehawken, a "test truck" is weighed on both scales every morning. If more than a 10 - to 20 -pound error is found, an inspection is promptly made and repairs made as necessary. For example, of 81 typical consecutive daily test weighings at Weehawken, only 8 weighings showed any difference at all between the 2 scales. The eight differences were only from 10 to 20 pounds, which can be attributed to normal differences in the average weigher's interpretation of a balanced beam on scales of this size. I think that you will all agree that these figures are an indication of the accuracy of our scales and the skill of our weighmasters. I doubt whether we could have obtained any such trouble-free record with the use of dials, automatic printers, or electronics.

We have always favored the simple type-registering beam for our company use and have always made certain that only thoroughly trained salaried weighmasters are utilized.

TTe have always kept in close touch with the National Bureau of Standards and with other scale authorities, and have been ready and 
willing to adopt any new improvements in weighing equipment which promised to give us greater accuracy than we have enjoyed through the years. We have felt that the fewer working parts and gadgets used and the simpler the entire operation can be kept, the better for us on our busy docks. At some of our ports we have used devices to facilitate the reading of the swing of the beam, such as the Spinks over-and-under indicator, but we have not found it desirable to go to automatic printer or dial attachments or electronic load cell and remote reading devices. We feel that all these extra complications are costly to install and to maintain, and that we simply could not afford to run the risk of holding up ship discharge in case of sudden failure of any of the numerous and delicate parts of these intricate devices.

In the case of railroad cars, our trained weighmasters perform the tare and gross weighing on lailroad-owned track scales, which are located by the railioads just outside our loading docks. The cars are sealed by the railroad sealer's before they leave the docks after loading, and are promptly moved by switch engines over the track scales, one car at a time. Our weigher's insist that the couplers be completely separated at each end of the car, and that the car be at rest when they bring the beam to balance. In some cases, the railroad has a representative present in the scale house, but our weighmaster balances the beam himself or makes sure that the beam is properly balanced by the railroad weigher. Two sets of beam tickets are punched, one set for our company billing office and the other set for the railroad billing office.

We have a working agreement with all originating railroads that they will constantly maintain their seaboard scales in first-class condition for banana weighing. These scales are tested and serviced at least quarterly. Copies of these quarterly reports are sent to us by the railroads for our records. Between quarterly tests our weigher's inspect the pits and make sure that the scales are in proper condition at the beginning of each weighing day. Any irregularities found by us are promptly called to the attention of our railroad scale departments. With ordinary freight car weighing, railhoad working rules permit errors of up to plus or minus 300 pounds and, in some cases, 500 pounds. We consider banana freight in a special class, and errors of this magnitude would not be tolerated.

Because of constant vigilance through the years, we have built up a reputation in the eyes of our wholesale customers for consistent weighing accuracy, attested by the fact that our Claim Department very rarely has a complaint or claim for short weight. We are naturally proud of this record in view of the fact that during the year 1959 we made more than 200,000 weighings of more than 100,000 vehicles. (54,616 cars and 48,086 carlot equivalents in trucks figured at 21,500 pounds as an arerage carlot.) ITe are known among heavyduty scale manufacturers as "fussy" customers, both on first-purchase specifications and on strict, continual, and careful maintenance of om scales. We would like to keep this reputation. State and Federal authorities have complimented us on our carlot and trucklot weighing systems, and this makes us very happy.

After leaving the seaboards, the cars and trucks proceed as rapidly as possible to the 1,800 bamana wholesalers or jobbers scattered throughout the United States and Canada, where the vehicles are

$560160-60-3$ 
promptly unloaded and the bananas hung in specially designed banana-ripening rooms. After an average of 3 to 5 days ripening under thermostatically controlled temperature and humidity conditions, the banana stems are removed to the packing area, where the hands are cut off the stalk and placed on padded tables and the stalk thrown away. The hands or part hands, known as clusters, are then trimmed of any bruised or damaged fingers, weighed, and placed in a weighing tray on a platform scale until the net weight exceeds the 40-pound minimum. A pound or two more normally is added by the jobber to take care of evaporation and shrinkage on the way to the store. The clusters in the tray are then carefully packed into banana boxes with various padding and packing materials, depending on the season of the year. The standard banana box holds 40 pounds net weight, but some boxes as low as 25 pounds net are occasionally used. The boxes may be of rood, aluminum, or nonreturnable paperboard. After packing, the boxes are transported by delivery trucks from the jobber to the retail store.

Most jobbers use a dial packing scale of the Chatillon platform-type, 50 -pound capacity with a 13-inch dial graduated to quarter pounds. The weighing trays may or may not be fixed to the platform.

Many stores presently do not weigh bananas in front of the customer at the time of actual sale, any more than they weigh meats at the time of purchase in a modern supermarket. The weighing, banding, and prepricing of banana clusters is done by some chains at the rarehouse or jobber level, by other chains at the store level. Small computing scales are used. When chain stores adrertise the price of the bananas by the pound, they eliminate complaints for short reight by making sure that each taped cluster contains a little more weight than the price calls for. 'This allows for eraporation and shrinkage between the time of pricing and the time of sale. The longer the expected period between taping and sale, the larger the excess weight allowed.

Then bananas are not advertised on a weight basis, the store manager has no problem and may price his taped clusters on some basis other than weight, such as color and appearance. Complaints of short weight of bananas have been rather rare, and chain stores today make every effort to satisfy the customer and avoid any embarrassment.

Many years ago ripe yellow banana stems were hung up in grocery store windows and individual bananas were cut off the stem by the grocer and sold for so many fingers for a nickel or a dime. Most bananas today are sold on a prepacked, prepriced, prebanded weight basis. There is considerable variation in the color, the scarring, and the general appearance of these retail size clusters on the produce stands. The arerage housewife today is impressed more by the bright color and attractive appearance of the fruit than she is by concern over the exact reight. When bananas are in oversupply, it is common for large chains to feature bananas in mass displays at a low price, such as ? or 10 cents a pound. Then bananas are scarce, the price may be as high as 17 or 19 cents a pound. Adrertised low price is definitely a factor in attracting the housewife to the store and to the banana counter, but when she gets there the quality, color and fresh appearance of the fruit undoubtedly become the dominant factor in her decision to purchase.

Bananas are nutritious, well balanced, wholesome, and flavorful, and a truly satisfying food. They are well recognized as such by dieti- 
tians, medical men, school teachers, and parents. Our company's Home Economics Department has prepared an attractive recipe booklet, copies of which I have here, along with copies of our Story of the Banana booklet, for any of you who niay be interested.

We feel that, in this era of convenience foods, faddist foods, glamorized foods, vitamins, food additives and supplements, dietary, and processed foods of all kinds, there will always be a definite demand in the market for the lowly banana, eaten chiefly in the raw state. Children love them; lunch boxes require them. IThen properly handled and ripened, they have a mnique flavor and textme which no other fruit or vegetable and no synthetic or processed product can resemble even remotely.

We have recently greatly increased our research budget in an attempt to produce a more plentiful supply of first-quality bananas at all seasons of the year and to develop even faster and better means of transportation from tree to consumer. We are investigating tropical prepackaging, hydrocooling, cartonization, containerization, piggyback, and even jet air cargo to speed this unique food to your table in the most attractive and healthful condition. Surely a far cry from the Philadelphia Centennial Fxhibition of 1871, where individual banana fingers were sold as a curiosity, wrapped in tinfoil, at the luxury price of 25 cents apiece.

\section{REPORT OF THE WEIGHTS AND MEASURES ADVISORY COMMITTEE}

\section{By A. T. McPrmersox, Associate Director for Engineering, $N$ ational Bureau of Standards}

The Weights and Measures Advisory Committee conducted considerable business by correspondence and met at the National Bureau of Standards in Washington, D.C., on April 1, 1960. The committee now includes the following individuals: The Honorable P. C. Brinkley of Virginia; Dr. L. J. Gordon of Denison University; L. T. Gustafson, Creamery Package Manufacturing Company; R. E. Meek of Indiana; J. E. Moss of the American Petroleum Institute; and E. C. Westwood of Salt Take City. Five members were present for the meeting. Dr. A. 'T'. McPher:son, Associate Director for Engineering of the National Bureau of Standards, served as chairman. 'The work of the committee may be summarized as follows:

\section{Publication of Revision of Handboots 26 on Weights and Measures Administration}

The principal concern of the committee during the rear has been with the relationship of the National Conference to the Bureauparticularly in the matter of publications, as exemplified by the manuscript of a revision of Handbook 26. 'The point at issue, as indicated by the report at the last National Conference, was whether this Handbook should be published as a regular Bureau document or whether it should be printed and distributed by the Bureau as a recommendation of the National Conference. During the past year, members of the committee completed a study of the 500 -page manuscript and unanimously reaffirmed their earlier recommendation that this document be published by the Burean without reference to the National Conference. During its meeting in April, the committee 
discussed this subject in considerable detail with the Director of the Bureau, and a plan was developed for making such changes in the language as to indicate that the recommendations are those of a consensus of qualified experts in the field of weights and measures administration rather than the specific recommendations of the Bureau alone.

(NOTE: Following the meeting of the committee a draft of such a revision was prepared and is now in the hands of the Director.)

\section{Catibration and Measurement Services for Federal Agencies and Industry}

The committee gave preliminary consideration to the increasing volume of services that State and local weights and measures officials are being called on to provide for Federal agencies, their contractors, and industry generally. These services consist principally in the calibration of large weights and tank trucks and other large containers and in the inspection and certification of scales, flow meters, and other measuring devices which are used in research, development, and manufacturing. Since these devices are not used in commerce and trade, they normally are not legally within the jurisdiction of weights and measures officials.

In view of the fact that this subject had been scheduled on the program of the National Conference, the committee made no recommendation.

\section{Moisture Content of Agricultural Commodities}

The committee heard a report from Mr. E. R. Weaver who was in the process of making a survey of the very extensive literature on moisture determination and analyzing possible methods of approach to the determination of moisture in grain.

The committee recommended that the Bureau place emphasis on, and expedite this work which is to be done in cooperation with the U.S. Department of Agriculture.

\section{State Standards}

A progress report was presented to the committee on the development of prototypes of new State standards. It was reported that the Bureau's goal was to complete the procurement and study of these prototypes in time to include a plan in the 1962 Federal legislative program for providing the new standards to the States.

\section{Training Activities}

The committee was informed that the Office of Weights and Measures this year has been able to comply with all requests to assist with technical training schools conducted at the State level. This has included about 22 programs conducted in the field and one in the District of Columbia. During the past year the Office of Weights and Measures has acquired considerably expanded and improved facilities for training at the Bureau. It is planned that the new training laboratory will be used for concentrated courses intended to prepare State and local officials at the supervisory level to conduct training 
schools in their own jurisdictions. Details of the courses are being developed and it is hoped that experimental training can begin shortly.

Members of the committee praised the training assistance which has been provided by the Office of Weights and Measures and expressed approval of the expanded facilities. 'These have been made available for training at the Bureau in accordance with a recommendation of the committee made in 1958. Attention was called to the difficulty which some jurisclictions may encounter in financing travel to Washington, and the hope was expressed that the Bureau will find it possible to continue its participation in field training programs as needed.

\section{Motion Picture Program}

The committee was advised that the Office of IVeights and Measures had developed plans for a new public-information film of the sort suggested by the committee at its last meeting. The script prepared for this film proved unacceptable to the Bureau, primarily because the approach which had been used might be interpreted as an effort to influence legislation.

Discussion of this topic indicated that the film "AssignmentWeights and Measures", which was intended for public information, has been very widely used and has proved rery helpful to weights and measures officials. In view of the lack of understanding among consumers concerning the functions of weights and measures departments, the committee urged that the script for the informational film be reworked with regard to its introduction and reconsidered with a view to proceding with its production as quickly as possible.

\section{National Periodical on Weights and Measures}

The lack of suitable national publication in the weights and measures field was discussed by the committee. Various methods whereby the Bureau might assist in the publication of a news letter or national journal were mentioned. The committee requested the Office of Weights and Measures to survey these possibilities and explore with the Director the feasibility of making recommendations for such a publication to the Committee on Education of the National Conference.

\section{IIousehold Weights and Measures}

The committee was pleased to learn that the "Kitchen Card", which it had urged the Burean to reissue, had been revised and cleared for publication with interested agencies in the Department of Agriculture, and Health, Education and Welfare. Ifter discussion of possible ways to distribute the card, the committee recommended that the Bureau make master copies available to State and other weights and measures offices, colleges, and interested consumer groups for duplication and distribution.

\section{Items for Future Consideration}

Items that were brought before the committee and reserved for future consideration included: (1) the possible need for study of 
methods of reighing frozen products: and (2) the need for trpe approral of weights and measures equipment on a nationwide basis.

\section{REPORT OF COMMITTEE ON LAWS AND REGULATIONS}

Presented br G. L. Jomxsox. Chaiman. Director. Division of Weights and Measures, Department of Agriculture. Siate of Kentucky

The Committee on Laws and. Regulations of the 45 th National Conference on Treights and Measures submits its report-a tentatire report as amended by this final report. 'The committee is grateful for the many constructive suggestions receired by mail and during its open meeting on Monda 5. June 6.

1. Aerosol Bomb-Type Containers.-Although this subject has been under study by the National Bureau of Standards, the Weights and Measures Department of the City of Miami, Florida, and others, the committee has no recommendation to make at this time relative to the proper labeling of products packed in aerosol-type containers. The Conference is fortunate in that Mr. H. E. Peterson. President, Peterson Filling and Packaging Compans, Danville, Illinois, will deliver an address on this subject. It is hoped that satisfactory solutions to the many problems in this area will be forthcoming in the early future.

Con motion of the committee chairman, seconded from the floor, item 1 was adopted bs the Conference bs roice rote.)

2. Bed sheets-Measurements.-The matter of proper labeling of bed sheet sizes was referred to the committee for study. It was pointed out in the letter of referral that the sheet sizes set forth in labeling and in adrertising are the sizes "before hemming" and that accordingl $l_{Y}$ it is difficult, if not completel $\bar{Y}$ impracticable, for a consumer or a reights and measures official to check the accuracy of the measurement declarations. The committee has not conducted a special study in this area, nor has it contacted sheet manufacturers, because the answer under good weights and measures practice is obvious. The committee recommends that bed sheets be labeled, adrertised, and sold br finished sizes.

(Item 2 was adopted br roice rote.)

3. Writing Paper and Enielopes in Package Form.-It has been called to the attention of the committee that much writing paper and enrelopes, notebook paper, and other stationery items in package form are not being labeled as required by the IIodel Law and the Iodel Package Marking Regulation. The committee rishes to point out that such items should be so marked as to show sheet size and count, and all jurisdictions are urged to give attention to this matter.

It is the opinion of the committee that writing paper put up in tablet form can properly be sold by the tablet count; thus sheet size and count should not be required on tablets.

(Item 3 was adopted by roice rote.)

t. Temperature Compersated Meters.--The use of temperature compensated meters, especially in the liquefied petroleum gas field has 
been increasing rather rapidly. The committee has been asked to consider the legal aspects of the use of such meter's.

The committee has found no record of official recommendation in this regard by either the American Petroleum Institute or the Liquefied Petroleum Gas Association and is of the opinion that definite Conference action at this time would be premature. It must be pointed out, however, that the Mordel Law and most State statutes are so worded as to establish the gallon as a 231 -cubic-inch unit of volumetric measurement, without regald to temperature. This would be interpreted by the committee as requiring a 231-cubic-inch gallon at the time and temperature of delivery.

(Item 4 was adopted by roice vote.)

5. National Type Approval.-During the year, and as a result of a referral of the topic by the Southern IVeights and Measures Association, the committee has considered the general matter of national type approval of commercial weighing and measuring derices. The committee's conclusion has been that it would be inappropriate to bring in any definite recommendation at this time. The committee proposes, however, to retain this topic on its agenda for continued study and intends to direct such study along two lines:

1. The development of suitable Federal legislation to establish a national system of type approval applicable throughout the country.

2 . The extension of the plan of state trpe approval to all states not presently laving adequate legislation for this purpose. (Such State action could be effectively encouraged through the drafting of a suituble additional paragraph for the Model state Law on Wreights and Measures.)

\section{DISCUSSION OY THE FOREGOING ITEM}

Mr. Wrignt: I represent the Gasoline Pump Manufacturers Association. I have consulted with representatives of other manufacturers affected, and I believe that these comments will be in line with their thinking. I should like to request that the committee consider a third point, and consider it first. "That is the question, "Is type approval itself a good thing?" This is a very serious matter.

If the manufacturers of devices are making devices that conform to the requirements of Handbook 44, why should we have type approval? We have had some serious experiences with State typeapproval problems. The have encountered delays of 3,6 , sometimes up to 24 months in receiving decisions.

We would like to be per'mitted to appear before the committee and testify on this matter.

Mr. Jornson: I am sure the committee will angee with Mr. Wright that this subject must be approached very carefully.

Mr. Sanders: 'The scale manufacturers think type approval is a very expensive operation-expensive to the manuficturers of devices and expensive to the government. It is our feelng that any mannfacturer who puts out a derice that does not meet Handlbook 44 requirements is rery foolish, and that such a device should be condemned. Condemnation is the simplest way to eliminate from service devices that do not conform.

(Item 5 was adopted by roice rote.)

6. Trading in Grains by Weight.-Director Donald MrcDowell of the Wisconsin Department of Igriculture has reported to the Con- 
ference on this matter. The committee urges that the Conference and all reights and measures officials individually actirely pursue this progressive more.

(Item 6 was adopted by roice rote.)

7. Model Regulation for Package Marking Requirements.-The committee, in item 3 of its final report to the 44 th National Conference, recommended that the Office of Weights and Measures of the National Bureau of Standards, study and prepare a revision of the Model Regulation for Package Marking Requirements and submit it to the 45 th National Conference, through this committee. The committee also recommended that the Office of Weights and Measures negotiate with the Federal Food and Drug Administration toward the modernization of the quantity regulations issued under the Federal Food and Drug Act. Both of these requests have been complied with by the Office of Treights and Measures. No progress report has been received from the Federal Food and Drug Administration. The proposed rerision of the Model Regulation for Package Marking Requirements is appended to and is made a part of this report.

It has been the endearor in the preparation of this revision, to simplify the regulation, and make it more readily understandable. A positive approach has been taken, and although it may appear to be considerably different from the current regulation and the Federal Food and Drug Administration, the intended meaning is practically the same. The committee feels that this new regulation represents a decided improrement.

[The completely revised rersion of the Model Regulation for Package Marking Requirements, under the new title "Model State Regulation Pertaining to Packages: Exemptions, Marking Requirements, Variations," was presented br the committee. After an amendment from the floor relating to the strle of quantits declaration on a package - analog rersus digital-the recommendation of the committee prerailed. The principal participants in the discussion on this point were Mr. Kendall, Mrr. R. Y. Miller, Mrr. Sanders, MIr. Christie, MIr. Harris, Mr. R. E. Meek, and the committee chairman. ]

[Copies of the new Model Package Regulation are arailable without cost from the Office of Weights and Measures, National Bureau of Standards, Tashington 25, D.C.]

\section{MODEL STATE REGULATION PERTAINING TO PACKAGES: EXEMPTIONS, MARKING REQUIREMENTS, VARIATIONS}

\footnotetext{
Pursuant to the authority rested in me as set forth in sections of chapter of - [cite sections authorizing promulgation of general regulations and special package marking regulations], I,

State Director of Treights and IIeasures, herebs adopt and promulgate the following regulation:
}

\section{REGULATION NO. -}

1. APPLICATIOX.-This regulation shall apply to ans commodity in package form-that is, any commodits put up or packaged in ans manner in adrance of sale (except an auxiliars container, not intended to be sold to the consumer intact, enclosing packages that are indiriduall marked in conformance with the requirements of this regulation) and to ans item on which there is marked a selling price based on an established price per unit of weight or measure: Provided, That a package shall be exempt from the requirement for declaration of quantity if, in terms applicable to the commodity, it contains (a) in the case of a commodity not a drug or cosmetic, less than $1 / 2$ ounce avoirdupois, less than 1/2 fluid ounce, or less than 6 units, (b) in the case of a drug, less 
than 6 units, or (c) in the case of a cosmetic, less than $1 / 4$ ounce avoirdupois, less than $1 / 8$ fluid ounce, or less than 6 units. (Exemptions involving declarations in telms of count shall be permitted only if the units of commodity can easily be counted without opening the package.)

2. DECLARATION OF IDENTITY. - The declaration of identity shall positively identify the conmodity in the package by description, generic term, or the like, unless the commodity may easily be identified through the wrapper or container.

3. DECLARATION OF QUANTITY.

3.1. NET QUANTITY. The declaration of quantity shall disclose the net quantity of the commodity-that is, the quantity of commodity in the package exclusive of wrapper's and any other material packed with such commodity.

3.2. TERMS-WEIGHT, MEASURE, OR COUNT.-The declaration of the quantity of a particular commodity shall be expressed in such terms of weight, measure, or count, or a combination of count and weight, measure, or size, as have been firmly established in general consumer usage and trade custom and as give accurate information as to the quantity of the commodity. But if thele exists no firmly established general consumel usage and trade custom with respect to the terms used in expressing such declaration of quantity, the declaration shall be in terms of liquid measure if the commodity is liquid, or in telms of weight if the commodity is solid, semisolid, viscous, or a mxture of solid and liquid: Provided, That, if the commodity is a textile material, the declaration shall be in terms of linear measure unless the material is one in which there exists a firmly established general consumer usage and trade custom to declare the quantity in terms of weight, in which case the declaration may be in terms of weight.

3.3. UNITS-WEIGIT T, MEASURE.-A declaration of quantity (a) in units of weight shall be in ter'ms of the avoirdupois pound or ounce; (b) in units of liquid measure shall be in terms of the United States gallon of 231 cubic inches or liquid-quart, liquid-pint, and fluid-ounce subdivisions of the gallon, and shall express the volume at $68^{\circ} \mathrm{F} .\left(20^{\circ} \mathrm{C}\right.$. $)$ except in the case of a commodity that is normally sold while frozen or refrigerated, when the declaration shall express the volume at the temperature normally prevailing when such commodity is sold; (c) in units of linear measure shall be in terms of the yard, foot, or inch; and (d) in units of dry measure shall be in terms of either the United States bushel of 2,150.42 cubic inches or peck, dry-quart, and dry-pint subdivisions of the bushel, or the United States standard barrel of 7,056 cubic inches or of three-quarters, one-half, and one-third barrel subdivisions: Provided, That, in the case of drugs, in lieu of any requilement to the contrary, the declaration of quantity may be in terms of a unit of the apothecaries or metric system of weight or measure : $A n d$ provided further, That, in the case of a commodity packed for export shipment, the declaration of quantity may be in terms of a system of weight or measure in common use in the country to which such shipment is to be exported.

3.4. UNITS WITH TWO OR MORE MEANINGS.-When any unit of weight or measure having two or more distinct meanings is employed in a declaration of quantity, the declaration shall identify the particular meaning of the term as it is employed in the declaration. For example, distinction shall be made between "avoirdupois" and "fluid" ounces, and between "liquid" and "dry" quarts and pints. However, such distinction may be omitted when, by association of terms (as in "1 pound 4 ounces" or "1 pint 8 fluid ounces"), the proper meaning is obvious.

3.5. PRESCRIBED UNITS.-A declaration of quantity shall be expressed in terms of the largest whole unit of weight or measure (for example, 1 quart liquid shall be expressed as "1 quart liquid" and not as "2 pints liquid" or "32 fluid ounces"). However, when this results in a whole number and a fraction, the fraction may be expressed in its equivalent in the next smaller whole unit (for example, 13/4 quarts liquid may be expressed as "1 quart 11/2 pints liquid" or "1 quart 1 pint 8 fluid ounces," but not as " 1 quart 24 fluid ounces" ; 11/. pounds may be expressed as "1 pound 4 ounces") : Provided, That, if there exists, with respect to a particular commodity, a firmly established general consumer usage and trade custom to express the declaration of quantity as a fraction of a unit of weight or measure larger than the total quantity being declared or as a number of units smaller than the largest whole unit of weight or measure involved, the declaration, if informative to consumers, may be made in accordance with such usage and custom.

3.6. REDUCTION OF FRACTIONS.-Declarations of quantity may employ only binary-submultiple common fractions or decimal fractions. A common fraction shall be reduced to its lowest terms, and, except in the case of drugs, a 
decimal fraction shall not be carried out to more than two places: Provided, That, if there exists, with respect to a particular commodity, a firmly established general consumer usage and trade custom contrary to the requirement for reduction of a common fraction to its lowest terms, the declaration may be made in accordance with such usage and custom.

3.7. SUPPLEMENTARY DECLARATIONS.

3.7.1. METRIC SYSTEM.-A declaration of weight or measure in U.S. customary units may be supplemented by a declaration in uaits of the metric ssstem.

3.7.2. COUNT TO BE SUPPLEMENTED.-A declaration of quantity in terms of count shall be supplemented by a declaration of the weight, measure, or size of the indiridual units of the commodity, or of the total weight or measure of the commodity, unless a declaration of count alone is fully informatire to the consumer.

3.7.3. WEIGHT OR MEASURE TO BE SUPPLEIENTED.-A declaration of quantity in terms of weight or measure shall be supplemented by a declaration of the count or size of the individual units of the commodity, unless a declaration of weight or measure alone is fully informative to the consumer.

3.8. CHARACTER OF DECLARATION.-A declaration of quantity shall express arerage net quantity: Provided, That a declaration mas express minimum quantity when such declaration is definitels so identified br the addition of some such words as "minimum quantity" or "not less than".

3.9. QUALIFICATION OF DECLARATION PROHIBITED.-In no case shall a declaration of quantity be qualified by the addition of the words "when packed" or any words of similar import, nor shall any unit of weight, measure, or count be qualified by any term (such as "jumbo", "giant", "full", or the like) that tends to exaggerate the amount of commodity.

4. DECLARATION OF RESPONSIBILITY.-Any package kept, offered, or exposed for sale, or sold, at any place other than on the premises where packed, shall bear on the outside of the package the name and address of the manufacturer, packer, or distributor.

5. LANGUAGE.-All information required to appear on a package shall appear thereon in the English language.

6. PROMINENCE AND PLACEIIENT.-All information required to appear on a package shall be prominent, definite, and plain, and shall be conspicuous as to size and style of letters and numbers and as to color of letters and numbers in contrast to color of background. Such information shall appear on each part or panel of the package that is likely to be displayed when the package is exposed or offered for sale, or sold, under customary marketing conditions. Any required information that is either in hand lettering or hand script shall be entirely clear and equal to printing in legibilty.

7. INFORUATION REQUTRED ON OUTSIDE CONTAINER.-All information required to appear on a package shall also appear on any outside container or wrapper that is used, unless such container or wrapper is transparent and the information on the package is easily legible through such outside container or wrapper.

8. VARIATIONS TO BE ALLOWED.

8.1. PACKAGING VARIATIONS.

8.1.1. VARIATIONS FROII DECLARED NET QUANTITY.-Variations from the declared net weight, measure, or count shall be permitted when caused by unaroidabe deriations in rreigning, measuring, or counting the contents of individual packages that occur in good packaging practice, but such variations shall not be permitted to such extent that the average of the quantities in the packages of a particular commodity comprising either a shipment or other delirers of the commodity or a lot of the commodity that is kept, offered, or exposed for sale, or sold, is below the quantity stated, and no unreasonable shortage in ans package shall be permitted, eren though orerages in other packages in the same shipment, delivers, or lot compensate for such shortage. Variations above the declared quantity shall not be unreasonably large.

8.1.2 VARIATIONS FROM DECLARED MINIIIUM QUANTITY.-Where the minimum quantity is declared, no packaging rariations below the declared minimum shall be permitted, and rariations above the declared minimum shall not be unreasonably large.

8.2. VARIATIONS RESULTING FROM EXPOSURE-Variations from the declared weight or measure shall be permitted when caused by ordinary and customary exposure to conditions that normalls occur in good distribution practice and that unavoidably result in change of weight or measure, but only 
after the commodity is introduced into intrastate commerce: Provided, That the phrase "introduced into intrastate commerce" as used in this paragraph shall be construed to define the time and the place at which the first sale and delivery of a package is made within the State, the delivery being made either (a) directly to the purchaser or to his agent, or (b) to a common carrier for shipment to the purchaser, and this paragraph shall be construed as requiring: that, so long as a shipment, delivery, or lot of packages of a particular commodity remains in the possession or under the control of the packager or the person who introduces the package into intrastate commerce, exposure variations shall not be permitted.

8.3. MAGNITUDE OF PERMITTED VARIATIONS.-The magnitude of variations permitted under paragraphs 8.1., 8.1.1., 8.1.2., and 8.2. of this regulation shall, in the case of any shipment, delivery, or lot, be determined by the facts in the individual case.

9. REVOCATION OF CONFLICTING REGULATIONS.-All provisions of all orders and regulations heretofore issued on this same subject that are contrary to or inconsistent with the provisions of this reglation, and specifically

are hereby revoked.

\section{EFFECTIVE DATE}

This regulation shall become effective on

Given under my hand and the seal of my office in the City of

A.D. 19

on this

day of

Signed

(Item 7 as amended was adopted by voice vote.)

8. Model State Law on Weights and Measures.-The Model State Law on Weights and Measures was completely revised by the 44th National Conference. Developments during the year, however, have indicated several additional changes that might be considered at this time. Some of these proposed changes have originated with the committee, some with other Conference committees, and some have been received from other sources. They will be presented individually and in the order of their position in the Model Law.

8.1. Meaning of Terms.-Definitions of terms as used in the Model Law are listed in Section 1. It has been suggested that subsection (7) of Section 1 should be expanded to include an explanation of the meaning of the phrase "introduced into intrastate commerce." The committee agrees with this suggestion, and it is recommended that Section $1(7)$ be amended to read as follows:

SEC. 1 (7). The term "intrastate commelce" shall be construed to mean any and all commerce or trade that is begun, carried on, and completed wholly within the limits of the State of into intrastate commerce" shall be construed to define the time and place at which the first sale and delivery of a commodity is made within the State, the delivery being made either directly to the purchaser or to a common car riel for shipment to the purchaser.

8.2. Specific Powers and Duties of Director: Regulations.-In order to clarify, simplify, and eliminate unnecessary wording, it is recommended that Section 9 be amended to read as follows:

SEC. 9. SPECIFIC POWERS AND DUTIES OF DIRECTOR: REGULATIONS.-The director shall issue from time to time reasonable regulations for the enforcement of this Act, which regulations shall have the force and effect of law. These regulations may include (1) standards of net weight, measure, or count, and reasonable standards of fill, for any commodity in package form, (2) rules governing the technical and reporting procedures to be followed, and the report and record forms and maxks of approval and rejection to be used, 
by inspectors of reights and measures in the discharge of their official duties, and (3) exemptions from the sealing or marking requirements of section 15 of this Act with respect to weights and measures of such character or size that such sealing or marking would be inappropriate, impracticable, or damaging to the apparatus in question. These regulations shall include specifications, tolerances, and regulations for weights and measures of the character of those specified in section 11 of this Act, designed to eliminate from use, without prejudice to apparatus that conforms as closely as practicable to the official standards, those (1) that are not accurate, (2) that are of such construction that they are faultythat is, that are not reasonably permanent in their adjustment or will not repeat their indications correctl $s$ - or (3) that facilitate the perpetration of fraud. The specifications, tolerances, and regulations for commercial reighing and measuring derices, together with amendments thereto, as recommended by the National Bureau of Standards and published in National Bureau of Standards Handbook 44 and supplements thereto, or in any publication revising or superseding Handbook 44 , shall be the specifications, tolerances, and regulations for commercial

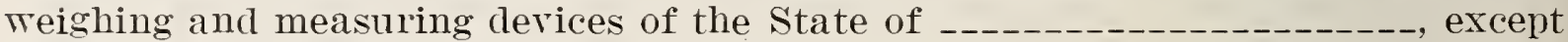
insofar as specifically modified, amended, or rejected by a regulation issued by the director. For the purposes of this Act, apparatus shall be deemed to be "correct" when it conforms to all applicable requirements promulgated as specified in this section ; other apparatus shall be deemed to be "incorrect."

8.3. General Testing.-Although the Model Law has, for many years, required the annual testing of all commercial weighing and measuring devices, it has been recognized that very few, if any, State departments are in position to fulfill this mandate. In many instances device owners are forced to operate devices illegally, simply because the State (or local) weights and measures department cannot discharge its obligations. It has also been suggested that many weighing and measuring devices are much more durable today than they were a few years ago.

Another factor of importance to this consideration is that modern trends in merchandising continue to make necessary increased emphasis in the "supervisory" aspects of weights and measures administration, as contrasted with the "mechanical" aspects. Many years ago the National Bureau of Standards recommended in Handibook 26 that the efforts of a weights and measures department be divided equally between the supervisory and mechanical aspects of the work. 'This balance is still the unachiered aim of most State and local agencies. Last year the annual testing proviso was modified somewhat. It is now suggested that a slight further modification be made and that it be spelled out rather clearly that the director is given the authority to set the frequency of tests at his discretion. It is recommended, therefore, that Section 11 be amended to read as follows:

SEC. 11. SAME: GENERAL TESTING.- When not otherwise provided br law, the director shall have the power to inspect and test, to ascertain if ther are correct, all weights and measures kept, offered, or exposed for sale. It shail be the duty of the director, within a 12-month period, or less frequently if in accordance with a schedule issued by him, and as much oftener as he may deem necessary, to inspect and test, to ascertain if they are correct, all weights and measures commercially used (1) in determining the weight, measurement, or count of commodities or things sold, or offered or exposed for sale, on the basis of weight, measure, or of count, or (2) in computing the basic charge or payment for services rendered on the basis of reight, measure, or of count: Provided, That with respect to single-service devices - that is, devices designed to be used commercially only once and to be then discarded-and with respect to derices uniformly mass-produced, as by means of a mold or die, and not susceptible of individual adjustment, tests may be made on representative samples of such devices; and the lots of which such samples are representative shall be held to be correct or incorrect upon the basis of the results of the inspections and tests on such samples. 
8.4. Packages: Declarations of Quantity and Origin; Variations; Exemptions. - In order to provide that the identity of the commodity be shown on the outside of a package, and to eliminate the use of the word "tolelances" in Section 26, it is recommended that this section be amended to read as follows:

SEC. 26. SAME: PACKAGES: DECLARATIONS OF QUANTITY AND ORIGIN; VARIATIONS; EXEMPTIONS.-Except as otherwise provided in this Act, any commodity in package form introduced or delivered for introduction into or received in intrastate commerce, kept for the purpose of sale, or offered or exposed for sale in intrastate commerce shall bear on the outside of the package a definite, plain, and conspicuous declaration of (1) the identity of the commodity in the package unless the same can easily be identified through the wrapper or container, (2) the net quantity of the contents in terms of weight, measure, or count, and (3) in the case of any package kept, offered, or exposed for sale, or sold any place other than on the premises where packed, the name and place of business of the manufacturer, packer, or distributor: Provided, 'That in connection with the declaration required under clause (2), neither the qualifying term "when packed" or any words of similar import, nor any term qualifying a unit of weight, measure, or count (for example, "jumbo", "giant", "full", and the like) that tends to exaggerate the amount of commodity in a package, shall be used: And provided further, That under clause (2) the director shall, by regulation, establish (a) reasonable variations to be allowed, which may include variations below the declared weight or measure caused by ordinary and customary exposure, only after the commodity is introduced into intrastate commerce, to conditions that normally occur in good distribution practice and that una voidably result in decreased weight or measure, (b) exemptions as to small packages, and (c) exemptions as to commodities put up in variable weights or sizes for sale intact and either customarily not sold as individual units or customarily weighed or measured at time of sale to the consumer.

8.5. Advertising Packages for Sale._-The feeling has been expressed by numerous people that there should be a section in the Model Law dealing with packages being adrertised at a stipulated price with no indication of the quantity contained in the packages. It has been suggested that when the price is quoted the advertisement should also state the quantity. To cover this situation the committee recommends a new section to be numbered. Section 29, to read as follows:

SEC. 29. SAME: ADTERTISING PACKAGES FOR SALE.-Thenever a commodity in package form is advirtised in any manner and the retail price of such commodity is mentioned, there shall be declared conspicuously in such advertisement the actual weight, measure, or count of the contents of the package as is declared on the package.

8.6. Renumber Remaining Sections.- Tith the adoption of new Section 29 , it will be necessary to renumber all subsequent sections of the Model Law by adding 1 to the present number.

8.7. Liquid Fuel.-The 44th National Conference authorized and directed the Conference Secretary to prepare a new Model Law section that would include, among other requirements, a requirement that a delivery ticket be left with each delivery of liquid fuel for domestic users. The committee and other weights and measures officials have been giving this matter much thought during the year. The oil-heat industry has likewise given it serious study. The committee recommends a new section on this subject to be numbered Section 38, to read as follows:

SEC. 38. IEATING AND COOKING OIL.-All heating and cooking oil shall be sold by liquid measure or by net weight in accordance with the provisions of section 25 of this Act. In the case of each deliver'y of liquid fuel not in package 
form, and in an amount greater than 10 gallons in the case of sale by liquid measure or 100 pounds in the case of sale by weight, there shall be rendered to the purchaser either (a) at the time of delivery or (b) within a period mutually agreed upon in writing or otherwise between the vendor and the purchaser, a delivery ticket or a written statement on which, in ink or other indelible substance, there shall be clearly and legibly stated (1) the name and address of the vendor, (2) the name and address of the purchaser, (3) the identity of the type of fuel comprising the delivery, (4) the unit price (that is, the price per gallon or per pound, as the case may be), of the fuel delivered, (5) in the case of sale by liquid measure, the liquid volume of the delivery, together with any meter readings from which such liquid volume has been computed, expressed in terms of the gallon and its binary or decimal subdivisions, and $(6)$ in the case of sale by weight, the net weight of the delivery, together with any weighing scale readings from which such net weight has been computed, expressed in terms of tons or pounds avoirdupois.

8.8. Offenses and Penalties.-To clarify the meaning of subsection (2) of Section 43, and to make it completely compatible with the foregoing suggested changes, it is recommended that Section $43(2)$ be amended to read as follows:

SEC. 44(2). Use, or have in possession for the purpose of current use for any commercial purpose specified in Section 11, a weight or measure that does not bear a seal or mark such as is specified in Section 15, unless such weight or measure has been exempted from testing by the provisions of Section 11 or by a regulation of the director issued under the authority of Section 9 of this Act.

(Item 8 was adopted by voice vote.)

9. Statement of Policy of the Board of Directors of the Oil Heat Institute of America.-The following statement of policy has been received from the Managing Director of the Oil Heat Institute of America. The committee appreciates the interest that has prompted this statement of policy and sincerely hopes that all retail distributors will diligently support and effectuate the policy as outlined.

The Board of Directors, Oil Heat Institute of America, on April 5, 1960, approved the following statement of policy:

The Oil Heat Institute of America, Inc., urges the use of printer type meters for the retail delivery of liquid household fuel. However, the Institute is aware that there are many retail fuel oil distributors who for financial, economic, or other valid reasons do not have this equipment. For these reasons we do not believe such equipment should be required by law or regulation. From time to time truck equipment must be replaced, rebuilt, or repaired. We urge the installation of printer type meters at that time.

\section{(Item 9 was adopted by voice vote.)}

10. Conference Aim: Uniformity.-From time to time it comes to the committee's attention that State and local weights and measures officials have recommended statutory amendments or administrative promulgations without full regard to the models adopted by the Tational Conference or attention to other Conference actions. This seems particularly inadvisable, since the principal aim of the Conference, indeed the main justification for its existence, is uniformity among the States. The committee strongly urges that all officials who contemplate legislative or administrative revisions work with the Conference secretary to the end that each State and municipality may have the benefit of the work of the Conference and, at the same time, the Conference may gain through an awareness of the thinking 
of each jurisdiction. Suggestions for the improrement of the Model Law and Model Regulations are always solicited.

(Item 10 was adopted by voice vote.)

\author{
G. L. Johnson, Chairman \\ J. G. Gustafson \\ H. M. TURRELL \\ ROBert WILliaMs \\ W. S. Busser, Secretary
}

(On motion of $\mathrm{Mr}$. Johnson. seconded from the floor, the report of the Committee on Laws and Regulations, as amended, was adopted by voice vote.)

\title{
THIRD SESSION-MORNING OF WEDNESDAY JUNE 8, 1960
}

(H. N. Duff, Vice Champinan, Presiding)

\section{REPORT OF THE EXECUTIVE COMMITTEE}

Presented by H. E. Crawrord, Chairman, Inspector of Weights and Measures, Jacksonville, Florida

The Executive Committee of the 45th National Conference met, according to custom, at a breakfast meeting on the last day of the 44th Conference. During that session certain expenditures were approved and plans were made for this 45th Conference.

The committee met again on Monday, June 6, in open session and availed itself for comments and suggestions from the delegates.

It is pleasing to report that the delegates who made their opinions known were satisfied with the plan and arrangements of the meeting.

The chairman of each standing committee was heard with respect to the activities of his committee.

The hope was expressed by several delegates that the National Bureau of Standards would continue and expand its services to the States in weights and measures enforcement.

Uniformity of enforcement procedures was discussed and NBS Handbook 67 was commended to the States as the procedure for package checking.

The Executive Committee is grateful for the opportunity to serve the Conference and weights and measures and expresses its appreciation to those who appeared before it during the open meeting.

(On motion of the chairman, seconded from the floor, the report of the Executive Committee was adopted by roice rote.)

\section{PHARMACEUTICAL GRADUATES}

By J. J. Morun, Technical Director, Scientific Sales Division, Kimble Glass Company, Vineland, New Jersey

Requirements for pharmaceutical graduates were adopted at the 11th National Conference on Weights and Measures, held in 1916. These requirements were published in Handbook No. 1 of the 
National Bureau of Standards in 1918, and were continued virtually unchanged in the succeeding Handbook M-85 of 1929 and the first edition of Handbook 44 published in 1949.

Prior to publication of the second edition of Handbook 44 in 1955 , a thorough study of graduates was made by the Office of Weights and Measures of the Bureau and the Conference Committee on Specifications and Tolerances. Manufacturers of graduates were given an opportunity to offer suggestions at the beginning of the study, and after the initial draft was prepared. We were privileged to assist in this work.

Handbook 44-2d edition was published in 1955, and the specifications and tolerances in it have been adopted by most of the States. However, with respect to pharmaceutical graduates, we find that requests for graduates made according to the older requirements still greatly outnumber the orders for the new graduates in some sizes. This indicates that most pharmacists are unfamiliar with the changes in requirements.

Theoretically, of course, manufacturers could help this situation by discontinuing the older ware. Practically, this is not possible. Graduates are used for many purposes other than the compounding of prescriptions, and the older ware is satisfactory for such work.

We are very much interested, nevertheless, in seeing that the best and most accurate measures are used for prescription work. Hence, we were very happy to accept an invitation from Mr. Bussey to talk to you today on the significant changes made in the specifications and the reasons for these changes.

The principal changes made in the specifications for pharmaceutical graduates concern :

1. The sizes of graduates permitted.

2. The permissible shape of small sizes.

3. The values of the subdivisions for each size, and the numbering of certain subdivisions.

4. The elimination of graduations in the lower portion of graduates.

\section{Sizes of Graduates}

Prior to 1955 , there was no restriction on the number of sizes of pharmaceutical graduates. However, the needs of the pharmacist in compounding prescriptions had gradually caused certain sizes of U.S. customary unit graduates to become popular, even before the first requirements were adopted in 1916 by the National Conference. In fact, the Bureau published a drawing in 1918 showing the same sizes used today.

Originally, all prescriptions were written in U.S. customary units, so that graduates in these units were the first available. With the increase in interest in the metric system, some medical schools began to teach medical students to use this system, and graduates had to be provided for this work.

'To simplify manufacture, the same glass blanks were used for both systems and the capacities in the metric system were made as closely as practical the same as in the U.S. system. As a result, the metric graduates had odd volumes in some cases, as shown in the table below: 


\begin{tabular}{c|c}
\hline U.S. customary system & Metric system \\
\hline Size & Size \\
60 minim & $5 \mathrm{ml}$ \\
120 minim & 10 \\
4 fluid dram & 15 \\
8 fluid dram & 30 \\
2 fluid ounces & 60 \\
4 fluid ounces & 125 \\
8 fluid ounces & 250 \\
16 fluid ounces & 500 \\
32 fluid ounces & 1,000 \\
\hline
\end{tabular}

In preparing the 1955 revision, the question of sizes was considered. Since the above sizes were being used exclusively, it seemed desirable to require them. As will be seen later, this step was also necessary in order to set up other new requirements for subdivisions.

The sizes in U.S. units were accepted without change, since they increase logically in size. This was not true of the metric sizes, so it was decided to adopt sizes like those used for measuring cylinders in general laboratory practice, namely, 5, 10, 25 (instead of 30 ), 50 (instead of 60 ), 100 (instead of 125 ), 250, 500, 1,000. 'This resulted in complete elimination of the old equivalent to the 4-dram size, namely, $15 \mathrm{ml}$. 'The new metric series does satisfy prescription writers.

\section{Shape of Graduates}

Traditionally, pharmaceutical graduates have had an essentially conical shape. It is probable that this shape was adopted at a time when cylinders were difficult to produce. The shape does have the advantage of being comparatively much shorter for the volume contained than the usual cylinder ; hence, easier to handle.

However, the cone is not a satisfactory shape when volumes must be measured accurately. The accuracy of a measurement depends on the diameter of the measure at the level to be read. Near the top of the conical measures, these diameters can be quite large. This is not usually important for volumes of the order of 8 fluid drams or more, since these volumes generally represent a diluting liquid, such as water, to be added to a concentrated drug.

On the other hand, the concentrated drug must be measured accurately to assure the proper dosage. Account of this fact was taken in 1955 , and it was decided to prohibit the conical shape for volumes of less than 8 fluid drams and insist on cylindrical graduates for the small instruments.

To increase further the probability that small measurements would be made accurately, a requirement in force for precision cylindrical graduates used in chemical laboratories ras adopted for the new cylinders; namely, that the inside diameter must not exceed one-fifth the total length of the graduated portion. For conical graduates, the diameter at the top graduation can be as large as one-half the total graduated length, and, at the one-fourth capacity level, diameter and length to this point can be equal.

While the restriction on diameter causes the new cylinders to be 
taller than the older cone-shaped small graduates, the much greater accuracy possible in an area requiring accuracy must be the gorerning factor. A study of the two shapes will make this increase in accuracy erident.

The table below compares certain diameters of typical new and old small measures and the errors in measurement when the liquid levels are set within $1 \mathrm{~mm}$ of the graduation line.

\begin{tabular}{|c|c|c|c|c|c|}
\hline \multirow{2}{*}{$\begin{array}{l}\text { Size of } \\
\text { graduate }\end{array}$} & \multirow{2}{*}{$\begin{array}{c}\text { Graduation } \\
\text { line at }\end{array}$} & \multicolumn{2}{|c|}{ Conical graduate } & \multicolumn{2}{|c|}{ Cylindrical graduate } \\
\hline & & Diameter & Error & Diameter & Error \\
\hline $\begin{array}{r}5 \mathrm{ml} \\
10 \mathrm{ml}\end{array}$ & $\begin{array}{r}1 \mathrm{ml} \\
5 \mathrm{ml} \\
2 \mathrm{ml} \\
10 \mathrm{ml}\end{array}$ & $\begin{array}{l}15 \mathrm{~mm} \\
18 \mathrm{~mm} \\
18 \mathrm{~mm} \\
22 \mathrm{~mm}\end{array}$ & $\begin{array}{r}16.0 \% \\
5.0 \% \\
12.5 \% \\
1.0 \%\end{array}$ & $\begin{array}{r}9.5 \mathrm{~mm} \\
9.5 \mathrm{~mm} \\
13.0 \mathrm{~mm} \\
13.0 \mathrm{~mm}\end{array}$ & $\begin{array}{l}7.0 \% \\
1.4 \% \\
6.5 \% \\
1.3 \%\end{array}$ \\
\hline
\end{tabular}

The adoption of the cylindrical shape for small sizes made another new requirement necessary concerning double-scale graduates. Double-scale graduates hare both U.S. customary and metric gradations. They are used in pharmacies where prescriptions in both systems are compounded to cut down on the number of graduates required. Since the diameters of the new cylinders are smaller than those of the replaced cones, two scales are impractical. Hence, double-scale instruments are prohibited for these new small crlinders.

This new regulation regarding small double-scale cylinders will aid also in the prevention of errors in compounding resulting from use of the wrong scale in an area where accuracy can be rery important.

\section{Subdivisions}

The conical graduates in use prior to 1955 had an important defect in the subdivisions placed on many sizes. It was customary to hare two or more different degrees of subdivision on a single size, depending on the diameter. This could contribute to errors in reading.

For example, the 120 minim size was graduated in 5 minims to 40 minims and in 10 minims above 40 minims: the 4 fluid dram size in $1 / 4$ drams to 1 dram and in $1 / 2$ drams above 1 dram; the 8 fluid ounce in $1 / 4$ ounce to 2 ounces and in $1 / 2$ ounce above 2 ounces. The $250 \mathrm{ml}$

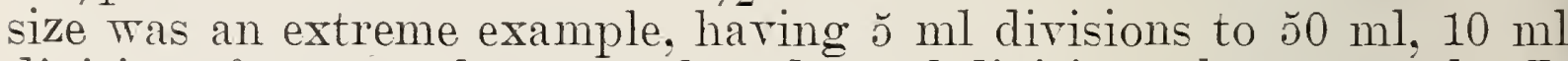
dirisions from $50 \mathrm{ml}$ to $100 \mathrm{ml}$, and $25 \mathrm{ml}$ divisions abore $100 \mathrm{ml}$. It is apparent that errors could occur easily.

To eliminate the possibility of error in reading the divisions on an instrument, it was decided that each size of graduate should hare only one degree of subdirision. For example, the 120 minim size rould have dirisions of 10 minims: the 4 fluid dram dirisions of $1 / 2$ dram; the 8 fluid ounce divisions of $1 / 2$ ounce; and the $250 \mathrm{ml}$ dirisions of $25 \mathrm{ml}$.

\section{Numbering}

Another defect of the older specifications was lack of a requirement for numbering of specific lines. Each manufacturer could select the lines to be numbered according to his own particular ideas. 
During the 1955 study it became evident that this situation should be corrected. Accordingly, requirements were established that numbers should be required for at least every second line, and that these lines should be longer than the unnumbered lines between them. Errors in reading are thus made even more improbable.

\section{Elimination of Lower Graduations}

Probably the most important innovation made in 1955 was the prohibition of graduations in the lower one-fourth to one-fifth of the graduates.

Many prescriptions require the dilution of small quantities of concentrated drugs. It has been the custom in some prescription departments to use a graduate of the size corresponding to the diluted product, measure the small quantity of concentrate in the lower portion of the graduate, and then fill to the top mark with the diluting liquid. It is obvious that the concentrate will not be measured as accurately in the large graduate as if it were transferred to this instrument from a piece of smaller diameter.

For example, suppose a prescription calls for $10 \mathrm{ml}$ of concentrate to be diluted to $250 \mathrm{ml}$. If the $10 \mathrm{ml}$ were measured in the old $250 \mathrm{ml}$ graduate, an error of 10 percent could easily occur. If the measurement is made in the new $10-\mathrm{ml}$ cylinder, the error would be only 1.3 percent, less than one-seventh as great.

As a second example, assume 4 fluid drams is to be diluted to 8 fluid ounces. Measured in the old style 8 ounce graduate, the error in the 4 dram could be 6.7 percent. Measured in the new 4-dram cylinder the error would be less than 1.4 percent, or one-fifth as much.

\section{Conclusion}

The aim of the Committee on Specifications and Tolerances in making the 1955 revision was to provide the pharmacist with a better set of tools for measurement of volume. Reviewing the results, we find:

1. Elimination of graduations near the bottom prevents measurements that can easily be in error by large pelcentages.

2. Cylindrical small graduates increase the accuracy of measuring small volumes.

3. Uniform subdivisions minimize the possibilities of wrongly estimating the value of a graduation.

It would seem that the work of revision was done well.

\section{STATE MASS STANDARDS}

By H. S. Peiser, Chief, Mass and Scate Section, Metrology Division, National Bureau of Standards

Mr. Chairman, permit me to begin with an acknowledgment. I have the great honor to speak on this occasion and on this subject for the team at the National Bureau of Standards working on mass standards. This team includes men who have a greater scientific competence in this field than I have-such are Mr. Russell and Mr. Macurdy-and men of far greater experience with the problems of 
State offices of weights and measures-such are Mr. Bussey and $\mathrm{Mr}$. Jensen of the Office of Weights and Measures. If I do not acknowledge their individual contributions and opinions, as I here expound them, it is only because we do work as a team. In it, our individual identities and contributions are apt to be lost in the common endeavor of the Bureau as a whole.

Throughout the history of the United States, Congress has been keenly aware of the desirability of supplying to the States uniform and constant standards of mass. Although at times you hear criticism of the tardiness with which the Congress has translated farsighted advice by George Wrashington, Thomas Jefferson, and other famous presidents into weights and measures legislation, it can be claimed that through congressional actions the States of the Union have on the whole been more generously supplied with more constant and uniform standards that the subdivisions of any other nation. This was a basic need for the unprecedented and rast developments in commerce and technology which constitute an important part of the proud history of the United States.

As, on the one hand, we move into the era of atomic energy and space exploration, with their needs for more accurate measurement, and as, on the other hand, through modern metallurgy, physics, and engineering, one can supply today technically better standards of mass, the National Bureali of Standards feels obliged to anticipate the likely demand for technical recommendations for the best kind of mass standards with which the States can play their part in the even more enterprising developments of the future.

Shortcomings of some primary mass standards employed by some States include:

1. Bare brass is not so corrosion resistant that its surface will not pick up gases and vapors from the atmosphere which will cause significant increase in mass with time.

2. Bare brass is not so abrasion resistant that regular use will not cause loss in mass.

3. Gold plate is even more subject to abrasion, as well as to imperfections through which water vapor is adsorbed, often causing chemical or electrolytic attack on the substrate metal. Gold is also rery subject to attack by mercury.

4. Tariable adjusting material and contamination enclosed in an adjusting carity cause variability of standards having such features.

5. Internal metallurgical unsoundness with small communicating channels to the outside leads to fluctuations in mass due to exchange of matter with the surrounding atmosphere, which in turn leads to chemical corrosion on a greatly increased interface area between the metal and the atmosphere.

In addition, I could mention individual malpractices and maltreatments in the history of some standards of individual States. We must furnish standards which, as far as possible, are immune to a limited amount of unprofessional handling.

It is time to turn to the positive question: What are our specifications for the optimum primary mass standards? In Appendix 1, the Office of Weights and Measures specifications are reproduced. Consider them as an experimental proposal open for criticism and comments. The set of standards being donated to the State of Hawaii this afternoon are built to these specifications.

The following are summaries and explanatory comments on these specifications:

1. The standards shall be a set of one-piece weights of standardized engineering construction. with (ases and lifter's such that they need never be touched by hand or unduly exposed. 
2. The metallic material of the weights shall have the following properties:

(a) It shall be abrasion resistant so that the mass of the weights is not significantly changed by regular, even though careful, use. In this was the need for State office stanclards may disappear.

(b) It shali be capable of being polished to a bright mirror finish so that a careful operator will discern scratches and other imperfections, as well as foreign material.

(c) It shall be nonmagnetic.

(d) It shall be capable of being electrolytically or chemically etched by a process which will permit a measured downward adjustment of mass without deteriorating the finish.

(e) It shall be capable of being plated by a well-adhering hard metal of similar color, with little or no chance of plating defects, or, alternatively, of being microwelded without the introduction of defects, so that the occasional larger weight reduced below tolerance can be rehabilitated. This type of readjustment would be recorded as part of the history of the weight.

(f) It shall have a density close to the agreed density of definition for the apparent mass-in-air basis. This is a stringent restriction of great technical import, but I am bound to follow the advice of wise counsels in not discussing the details within this talk. I cannot, however, help making one personal recommendation to this Conference. If commercial mass measurement were to be extended to materials of low density (less than $0.5 \mathrm{~g} / \mathrm{ml}$ ) or if it were to be required to weigh materials with greater accuracy than hitherto found necessary, this basic question of buoyance correction-for that is what I am referring to-must be understood. Who, if not this Conference, is to lay down the basic definitions and conventions? Who, if not this Conference, is to recommend what shall be the definition of the mass of goods in trade? Sliall it be true mass? Shall it be apparent mass? These, as yet, are not practically significant questions at State level, but it is worrying to me and limiting to progress to higher weighing precisions that these fundamental questions - so eminently worthy of study by your technical committees-are not discussed, let alone resolved.

3. The mass standards shall furthermore comply with the following desiderata :

(a) They shall comprise a set of weights capable of being mutually intercompared by weighing each weight (except the smallest) with one, two, or three weights of lower denomination, and conversely each weight (except the largest), together with one or two other weights of the set, with a weight of the next higher denomination. In this way the State office cau exercise some check on the mass constancy of the weights and detect mishandling of individual weights without reference to external standards or authorities.

(b) They shall be in pounds (decimal fractions and multiples of a pound, down to one-millionth of a pound). A thousandth of a pound may be called millipound, and a millionth of a pound, micropound. Such nomenclature would be convenient and in conformity with metrological practice.

Although decimal fractions of a pound are in current use, for instance on supermarket scales, this suggestion by the National Bureau of Standards would appear to amount to a major departure from past practice. Such it is not really intended to be. All we are concerned with is to avoid the use of overlapping series of primary mass standards. We do not wish in any way to limit or to discourage by our proposal the use of ounces, grains, and other mass units. The only point we aim to make unequivocally is that only one of the series in a given range should be the primary-standard-series, the others being derived. The balances which I will describe later and which we are proposing for State use make easy the intercomparison of the primary weights with weights having nominal values in different mass units.

It is an incidental advantage to State laboratories that, when asker to weigh an odd quantity of material, they will no longer have to give the value in pounds plus ounces plus binary subdivisions of an ounce plus grains plus decimal fractions of a grain.

(c) The smallest weight of the set shall be no larger than the lighest absolute weighing precision commonly needed-that is, the smallest significant mass difference.

(d) No two reights in the set (except the smallest) shall have the same 
nominal value. The purpose here is to reduce possible ambiguities in assembling any nominal load. ${ }^{1}$

(e) The series shall be so designed that, with a minimum total number of weights, all possible nominal loads can be assembled.

(f) The theorist will now wish to add the further condition, to simplify and speed up the handling, that on statistical average the least number of weights are required to assemble a random selection of loads. This would lead uniquely to a $6-3-2-1$ ratio of the nominal masses of weights within a decade. This 6-3-2-1 series of weights would be unfamiliar, unpopular, and illogical because it ignores the more common occurrence of the figures 5 compared with 6 . So with an increase of less than 10 percent in the number of weights that have to be added to the pan, we have provisionally standardized on the 5-3-2-1 series.

4. The adjustment tolerances of State standards shall not be inferior to corresponding laboratory standard weights-that is, present-day NBS Class S-1 tolerances.

So much, then, for the weights themselves. From the beginning, however, congressional directives have coupled the subject of standards for the States with instruments for their intercomparison. In the mass field, that means balances. The National Bureau of Standards cannot and should not divorce its recommendations on weights from parallel recommendations for sets of new balances. Again, Appendix 2 gives the technical portions of the specifications of prototype State balances as sent out by our Office of Weights and Measures.

I want to emphasize that, in addition to quite stringent conventional performance specifications, we have insisted on a quite specific and as yet rather unusual construction: the one-pan two-knife-edge type of balance.

Such an important decision the National Bureau of Standards did not take lightly, but only after careful thought and experiments indicated important gains in simplicity of construction at the high precisions at which we are aiming and further gains in operational speed and simplicity. Our confidence in the correctness of our decision is considerable by now, but of course we cannot be certain yet. We discussed our views with most balance manufacturers of high repute; and after some opposition from some quarters, we have won, if not all their support, their admission that they can see no serious flaw in our arguments. Similarly, we have discussed our ideas with some of the best known national standards laboratories abroad, as well as the International Bureau of Weights and Measures in France. After some cautious skepticism, we have again found overwhelming support and encouragement. Several of our colleagues and opposite numbers abroad were just arriving at the selfsame conclusions. Now we submit the plan to you, asking for your approval or your reasoned rejection.

In a sense, you represent the most important outside opinion. Only if you are convinced that weighing at the State level will become simpler, more precise, more free of errors, and faster, can the change be justified.

Let me emphasize the one-pan two-knife balance is by no means new. Indeed, it was not new even when after the last war a Swiss manufacturer introduced balances of this type into the metric laboratory balance field. Much credit is due to that firm, and I gratefully acknowledge the loan of a current model of their $1 \mathrm{~kg}$ balance for your inspection and handling.

${ }^{1}$ Note that for the 5-3-2-1 series a simple rule can eliminate all ambiguities (except those involving the two smallest weights). The lule might be that any load must be assembled with the minimum number of weights. 
What is or may be novel in the thinking at the National Bureau of Standards is:

1. The idea of using balances of this type at or near the highest attainable precision.

2. The idea of using them for weight calibrations of high precision.

We are here concerned only with the second aspect. Let me assure you also that the difference between the conventional three-knife balance and the two-knife type is not so very drastic. You still have a beam balancing on a plane and a load-bearing pan suspended by means of a knife edge from the beam.

The principal difference is that the counterpoise pan with its suspension is replaced by a counterpoise weight rigidly fixed to the beam. The total load on the pan side must balance the fixed counterpoise (within the equilibrium range of the balance). In addition to the load to be weighed, there must be built-in weights than can be added to or removed from the pan-suspension assembly such that any load to be weighed can be enhanced to the maximum capacity of the balance. Put in another way, a load to be weighed, instead of being compared with a similar standard load added to the opposite side of the balance (as in the conventional two-pan type), is compared with built-in weights taken ofl the pan in the one-pan two-knife balance.

Before enumerating the principal advantages of the one-pan twoknife balance, I wish to answer these questions: Why, with this principle well know, was it not applied to weight calibration before? What are its disadvantages or supposed disadvantages? To what extent are they less serious than they have been considered?

1. Transposition weighings cannot be performed on a one-pan balance. Any balance has twice the sensitivity for transposition that it has for direct or substitutional weighings. The sensitivity, however, depends on the instrumental read-out of the balance. The indication of damped balances may, for example, be read to a hundredth of a division by appropriate verniers, thus providing an increase of a factor of about 10 in sensitivity over free-swinging balances that have in the past been considered the most sensitive type. With modern instrumentation, my colleagues have shown (Reference 1) that the sensitivity of a free-swinging balance can also be increased at least tenfold without undue difficulty. The loss of the factor of 2 can therefore be readily recovered. Nevertheless, at the highest attainable precision, this could again become a real disadvantage of this type of balance.

2. The sensitivity of a balance is in general a function of load. Most balances are designed to have a lower sensitivity - that is, a lower precisionat higher loads. As one-pan two-knife-edge balances always weigh at very near to their maximum load, this has to many appeared to be a disadrantage.

However, this argument loses practically all its force when it is realized that on modern balances the last two or three figures should be obtainable by direct reading, which demands constant sensitivity independent of load eren for three-knife balances. In any event, this argument could only be serious if it were difficult to achieve adequate precision at the lowest load to be weighed within the range of a balance, or if the useful range of a one-pan two-knife balance were smaller than that for conventional balances. Neither of these points appears to apply.

3. Some have held that knife-edge friction is a serious limitation to balance precision and that this increases with load. We have shown that good knife edges have friction smaller than we have been able to detect. Due to departure from straightness of knife edges, effective friction may actually decrease with increasing load, but I and others should be cautious in making any predictions.

4. Knife-edge wear has been thought possible to be a function of load. As one-pan two-knife balances always carry the maximum load, this was believed 
to be an argument against this trpe of balance. It is, howerer, such a simple matter to elongate the load-carrring edge that this can hardly be a serious argument. Moreorer, despite a most diligent search in published and for unpublished information. Te hare failed to find anr lesearch results which support ans serious limitation on this. A good steel or sapphire knife edge can, it seems, be loaded and unloaded at maximum load of the order of $10^{\top}$ times without serious damage. So this factor should not worry a State which on ans one balance calibrates onls 100 weights per dar, 300 dars per rear, for 100 rears! Please do not misquote me on this point. Other sources of knife-elge wear or damage mar be rerr serious.

5. The most serious limitation of one-pan two-knife balances lies in temperature changes affecting the balance equilibrium and sensitirity. This is a complex subject which is besond the scope of this paper simpls because it has been shown that the effect with careful design is too small to be significant for the precision of State balances, and that it is apt to be orershadorred bs the effect of tilt in the balance table. This latter influence affects both trpes of balances in proportion to their angular sensitiritr.

So much for the disadrantages, real and apparent. I can now briefly sum up the arguments in faror of one-pan two-knife balances. The believe them to be of orerwhelmingly greater importance.

1. The principal source of rariabilits of sensitivits, namels, that due to total load change, is eliminated. The balances can thus be simpls constructed to gire a direct read-out of beam inclination with respect to the horizontal expressed in the desired mass units.

2. Eren the simplest reighing against built-in weights taken off the pan is independent of arm ratio and the mass of the pan suspension. Direct reighings on conrentional balances depend on zero mass difference betreen the two pans and a unit arm ratio. These hare to remain constant throughout the life of the balance, and present a maintenance problem.

3. A design requirement is for the two-knife edges to be parallel to rers high precision, which is a far simpler instrumental condition than that appertaining to three-knife balances for which these three knires must all be parallel, to similarls high precision, and coplanar (or the center knife displaced from the plane of the other two knife edges br a definite but rers small distance).

4. The arrestment error is an important source of uncertaintr in weighing. It can be reduced under laborators conditions if the knires need not be taken out of contact with their matching planes during a weighing series. This is instrumentalls far harder to achiere for three-knife balances. The few tro-pan balances which hare this feature still proride for the terminal knife edges to be remored from contact with their planes.

5. Another source of uncertaints in weighing is due to air currents in a balance case, mostl $r$ caused br thermal conrection effects. One balance manufacturer has rers thoughtfulls studied how, bs means of baffles, to minimize these effects on a two-pan balance. It is too earls to sar how successful will be his proposed solution. At the National Bureau of Standards we hare made a studs along different lines and hare shown that a rertical temperature gradient inside a balance case will greatle reduce this source of error. This appears to be simpler for one-pan balances, presumabls in part because on one pan the "sail" effect br the conrection currents is less than on two pans.

6. Fet another source of weighing uncertaints is balance pan swing and oscillations in the suspension. Other things being equal, this effect will be lessened br haring just one instead of two pans. The pan arrestment mechanism. one of those functions is to suppress swing, is equalls simplified.

7. The weight-loading mechanism for large-capacits balances is simplified, too, by haring just one pan to load and bs not requiring a transfer mechanism. Access to smaller-capacits balances is made more conrenient and less disturbing by haring to load only one side of the balance.

8. The arm length can be shorter than the pan radius. Short arm length reduces the balance period and beam distortion under load. Both can lead to greater precision.

9. Substitution weighing against built-in weights is faster than substitution reighings on a two-pan balance. Speed is an operational adrantage, obriouslr. Additionalls, hoterer, since changes in ambient conditions cause uncertaints in weighings and since, other things being equal, the range of ambient conditions is lessened bs speed, faster weighing schemes are in general preferable to slower ones. 
10. Substitution-weighing schemes against external mass standards on onepan balances are faster than transposition weighings on two-pan balances, so that the loss of sensitivity of substitution weighings is partly compensated.

11. The correction of mass standards can be applied as an instrumental correction in the weighing scheme. If the balance is damped, all paper work and calculation (other than the noting down of the final mass value of the unknown weight) is eliminated, even for work of the highest precision used at the State level.

In conclusion, I wish to show a brief demonstration film of the use of a one-pan two-knife balance for a high precision weight calibration. The great simplicity of the procedure and the ease of teaching it to a newcomer into the subject will, I hope, convince you more than anything else that the imnovation proposed by the National Bureau of Standards will help you to do faster', simpler, speedier, and more precise calibrations.

Reference 1.-H. A. Bowman and L. B. Macurdy. A photoelectric followul and recording system, and its application to remote observations of the beam in high precision balances. J. Research NBS 63C, 91 (1959).

\section{APPENDIX 1. PRECISION STANDARDS OF MASS}

1. This specification covers three groups of avoirdupois weights that will comprise one set of mass standards.

\section{Classification.}

2.1. Class.-The weights shall be of one class to be known as Class $\mathrm{X}-1$. 2.2. Designation and form.-The set shall consist of 32 weights arranged in 3 groups as follows:

Group A.-Group A shall consist of one weight of each of the following nominal values, avoirdupois: $30,20,10,5,3,2,1,0.5,0.3,0.2$, and 0.1 pounds. Each weight shall be cylindrical in shape with a hole through the weight for lifting. (See specification paragraph 3.2.1.1. and figure 1.)

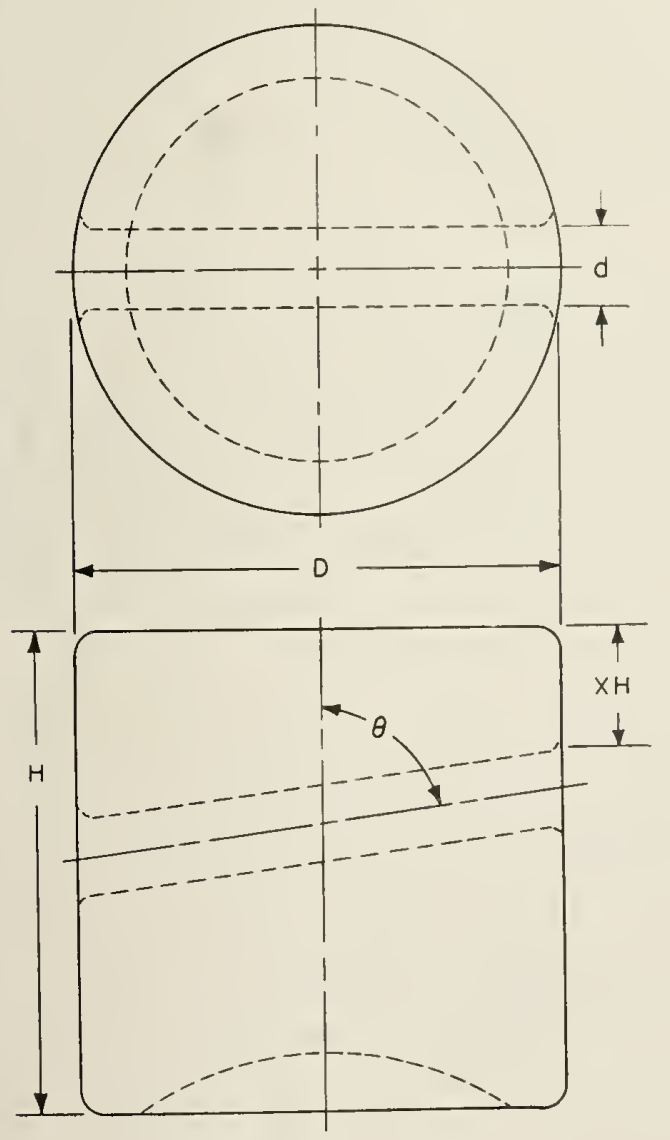

FIGURE 1. GROUP "A" WEIGHTS 
Group B.-Group B shall consist of one weight of each of the following nominal ralues, aroirdupois: $0.05,0.03,0.02$, and 0.01 pound. Each weight shall be a simple crlinder (no hole for lifting). (See specification paragraph 3.2.1.2. and figure 2.)

Group C.-Group C shall consist of one weight of each of the following nominal ralues, aroirdupois: $0.005,0.003,0.002,0.001,0.0005,0.0003,0.0002$, $0.0001,0.00005,0.00003,0.00002,0.00001,0.000005,0.000003,0.000002,0.000001$, and 0.000001 pound. The weights shall be made of sheet metal. (See specification paragraph 3.2.1.3. and figure 2.)

3. Requirements.

3.1. Material.

3.1.1. The weights shall be made of the nickel-chromium allos "Nichrome T" ( 80 percent nickel and 20 percent chromium) or from a material that shall hare been approred by the National Bureau of Standards as being equiralent to Nichrome $\mathrm{T}$ in hardness, densitr, magnetic properties, resistance to corrosion, susceptibility to oxidation, expansion coefficient, and porosits. The sheet metal weights (Group C) shall be as hard (quenched or cold rorked) as feasible.

3.1.1.1. The allor shall be essentially nonmagnetic and shall hare a density between 8.3 and 8.5 at $15^{\circ}$ to $25^{\circ} \mathrm{C}$.

3.2. Construction.-Each weight shall be a single piece and homogeneous.

3.2.1. Design.

3.2.1.1. Group A.-Group A weights shall be crlindrical in shape. The diameter (D) and height $(\mathrm{H})$ of each weight shall be essentially equal (the diameter shall not differ from the height bs more than 10 percent of the height). Each weight shall hare a circular lifting hole passing obliquely through it, forming an angle $(\theta)$ of 80 to 85 degrees with the

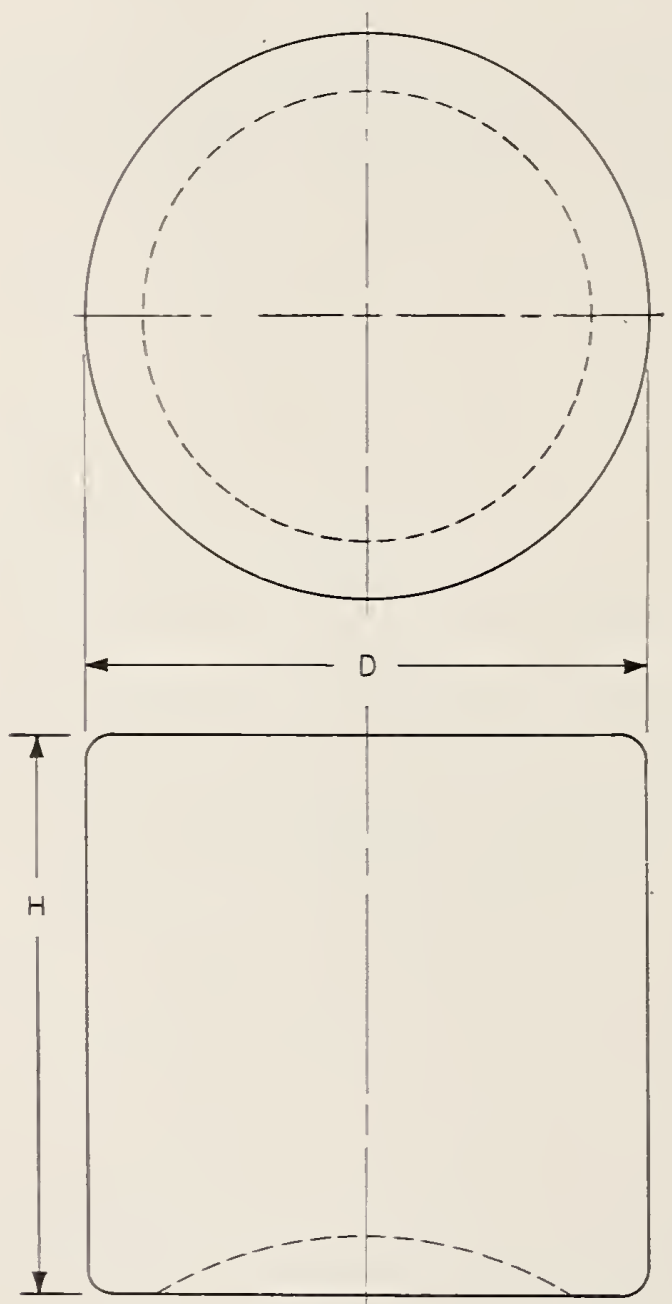

Figure 2. GROUP " $B$ " TIEIGHTS.

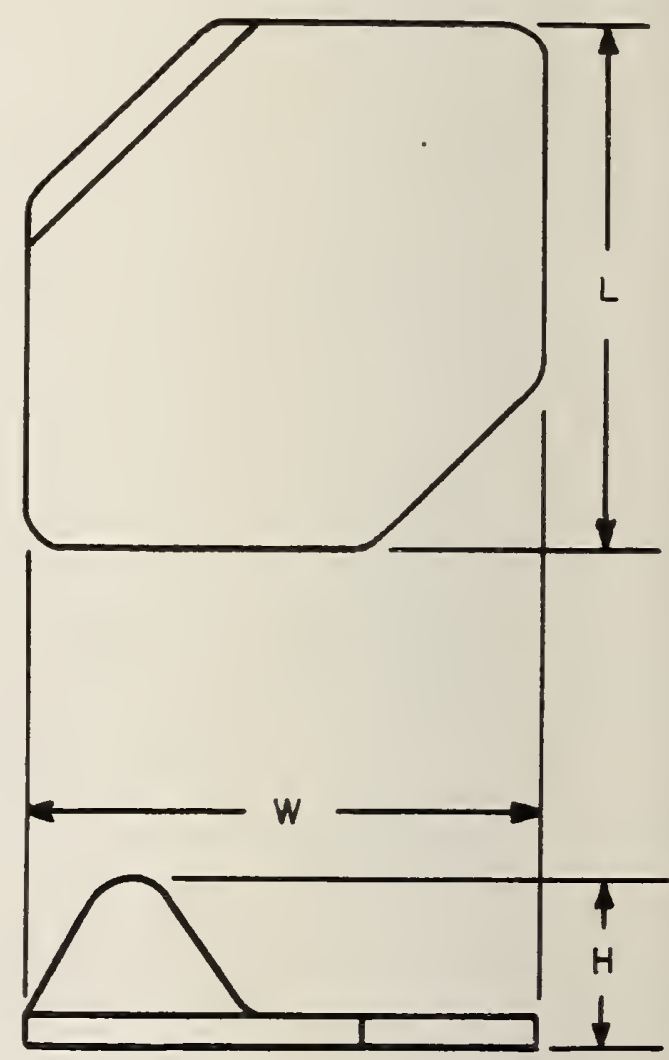

FIgURE 3. GROUP " $C$ " WVEIGHTS. 
vertical axis of the cylinder, for lifting the weight. The highest point of the hole (XH) shall be located at a distance 20 to 25 percent of the height of the weight below the plane of the top surface. The diameter of the hole (d) shall be not less than 10 percent or more than 25 percent of the height of the weight and shall be only sufficiently large to accommodate the lifter with appropriate clearance (specification paragraphs 3.6. and 3.6.1.) provided for lifting of the weight. The bottom of the weight shall be relieved (symmetrically hollowed out, see figure 1), leaving a flat ring as a base upon which the weight is to rest. The width of this ring shall be approximatel one-tenth the diameter of the weight.

3.2.1.2. Group B.-Group B weights shall be cylindrical in shape. The diameter (D) and the height (H) of each weight shall be essentially equal (the diameter shall not differ from the height by more than 10 percent of the height). The bottom of the weight shall be relieved (symmetrically hollowed out, see figure 2), leaving a flat ring as a base upon which the weight is to rest. The width of this ring shall be approxinately one-tenth the diameter of the weight.

3.2.1.3. Group C.-Group C weights shall be sheet metal weights with shape as shown in figure 3 . The weights shall be flat except that one corner shall be turned up at right angles and to a sufficient height to permit ready handling with forceps. The weights shall be free from cracks such as might be formed in bending and shall not be unnecessarily thin. but shall be of sufficient thickness that the surface tension of water will not distort them. The thickness shall in no case be less than 0.0005 inch. The surface area of one side of a weight shall not exceed 0.25 square inch. The surface areas of the weights shall be progressively smaller from the heaviest $(0.05$ pound $)$ to the lightest $(0.000001$ pound $)$.

3.3. Identification.-Each weight down to and including the 0.001-pound weight shall be plainly marked with its nominal mass value and with the abbreviated unit "lb". The abbreviated unit "lb" shall not be followed with a period. Each weight from 0.0005 to 0.000001 shall be marked only with its nominal mass value in millionths pound. (For example, 0.0005 pound will he nlarked 500 and 0.000001 pound will be marked 1.) The weights shall have no other markings. The identification shall be located on the upper surface of the weight. The markings shall be shallow, broad, and free from burs or: sharp angles. In no case shall the depth of the marking exceed 0.02 inch. The markings shall not perforate or crack the sheet metal weights.

3.4. Surface.-The entire surface of each weight, both interior and exterior, shall be smooth and highly polished and free from scratches, cracks, cavities, and depressions, except depressions necessary for identification. When inspected with the unaided eye, the surface shall appear to be free from pits and pores and show no evidence of porosity. The surfaces of each weight shall be free from deposits, residues, and other contaminants. All contours, edges, and corners of each weight shall be well rounded and finished smooth.

3.5. Tolerances.-The actual mass of a weight shall not differ from its nominal value by more than the tolerance shown in TABLE 1 -Tolerances.

3.6. Lifters.-Lifters or forceps shall be plovided of suitable design and strength for the expeditious liandling of the weights without damage. The lifters or forceps shall be smooth and free from sharp or raged edges. The lifters or forceps shall securely hold the weights for which they are designed. Excessive pressure on forceps for Group $C$ shall not cause the weights to slip from the jaws of the forceps. The construction of forceps shall be such that they will not warp in storage or use so much as to affect their performance.

3.6.1. Group A.-The lifters for the weights in Group A shall be as shown in figure 4 or of any other design that will provide proper handling of the weights and that is approved by the National Bureau of Standards prior to delivery. 'The parts of the lifters that come in contact with the weights shall be covered with some material that is softer than the surface of the weight, such as a plastic not affected by alcohol, velvet with a dense pile and a dense weave and with fibers that are not brittle, or chamois skin from which the grease has been removed.

3.6.2. Group $B$. - The forceps for the weights in Group $\mathrm{B}$ shall be as shown in figure 5 or of any other design that will provide proper handling of the weights and that is approved by the National Bureau of Standaris prior to delivery. The parts of the forceps that come in contact with the weights shall be of a material that is softer than the weights (ivory, close-grained 


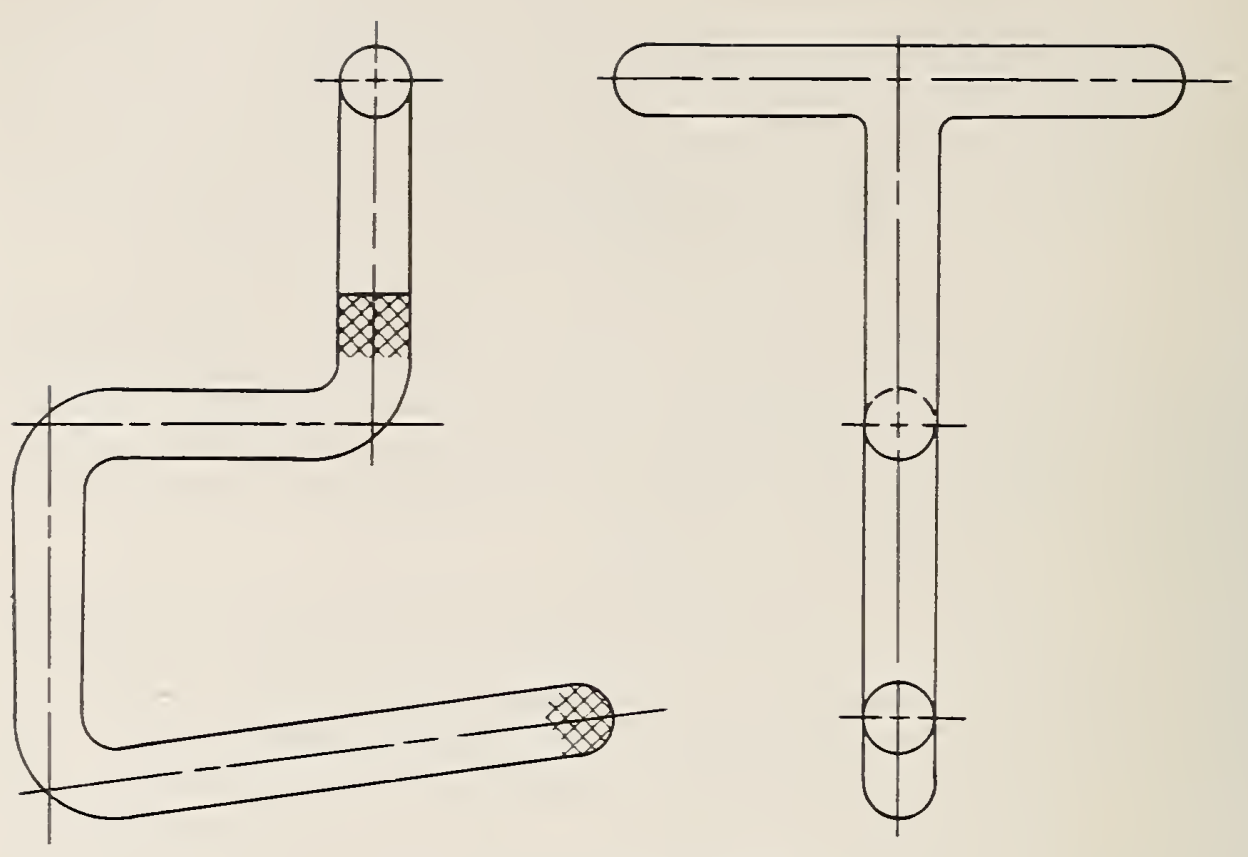

$30 \mathrm{lb}$ TO $2 \mathrm{lb}$ WEIGHTS

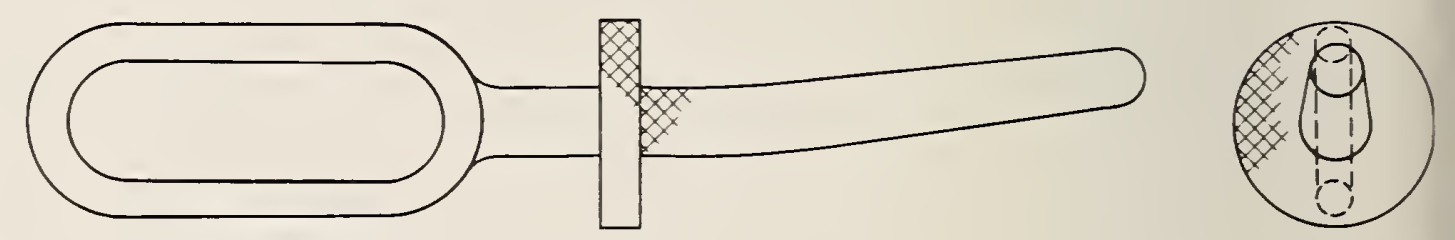

I Ib TO O.I Ib WEIGHTS

FIGURE 4. GROUP "A " LIFTERS.
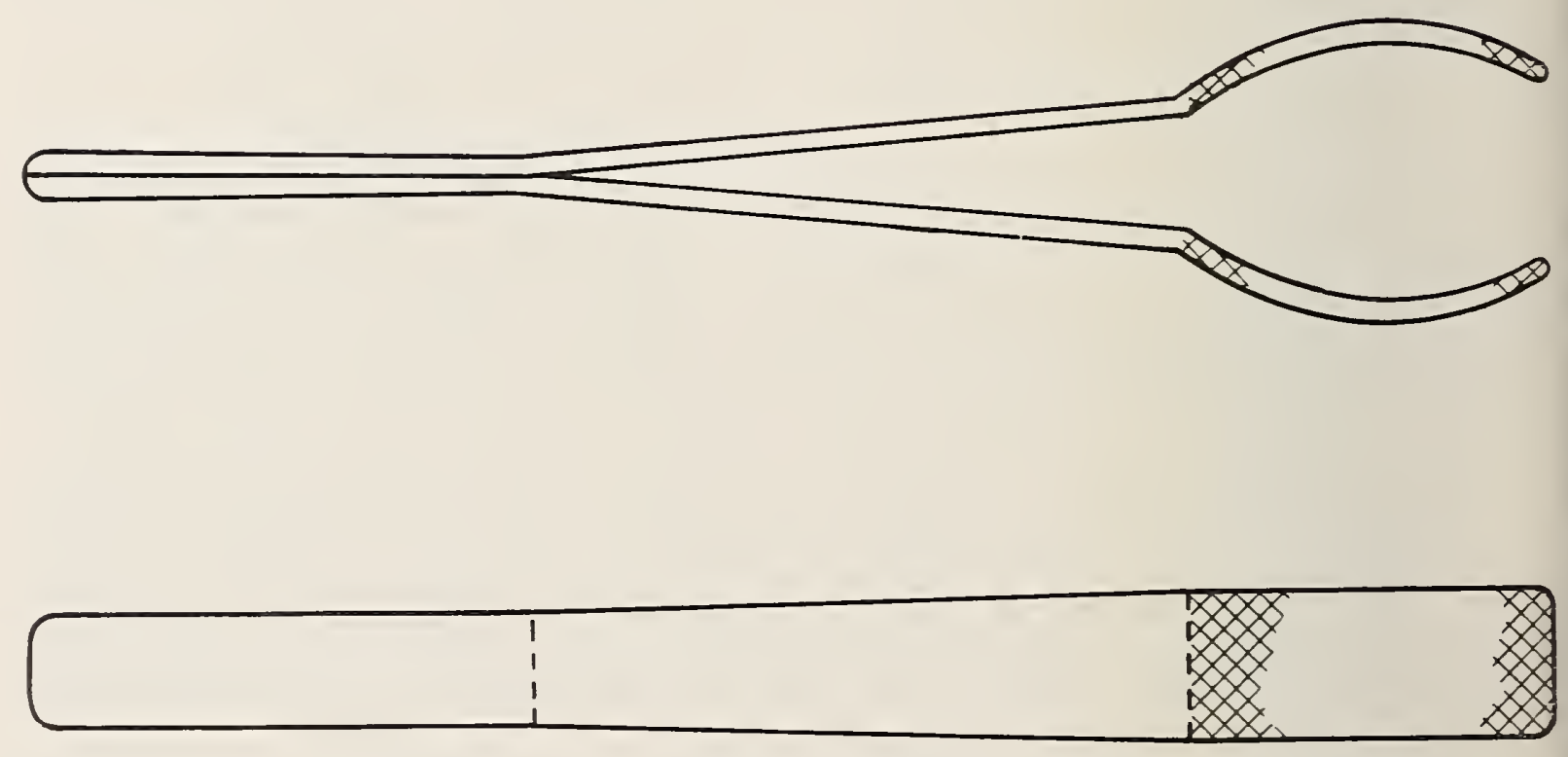

FIGURE 5. GROUP " $B$ " FORCEPS. 
wood, a plastic that is not affected by alcohol, or the like) or shall be covered with some material that is softer than the surface of the weight. such as plastic not affected by alcohol, velvet with a dense pile and a dense weave and with fiber's that are not brittle, or chamois skin from which the grease has been removed.

3.6.3. Group $C$.-The forceps for the weights in Group $\mathrm{C}$ shall be as shown in figure $6 \mathrm{or}^{\circ}$ of any other design that will provide proper handling of the weights and that is approved by the National Bureau of Standards prior to delivery. The parts of the forceps that come in contact with the weights shall be of a material that is softer than the weights (ivory, close-grained wood, a plastic that is not affected by alcohol, or the like) or shall be covered with some material that is softer than the surface of the weight, such as a plastic not affected by alcohol.

3.7. Case.

3.7.1. Groups $B$ and $C$ weights.-One or mole suitably lined dustproof cases shall be furnished with both Groul, B and Groul 6 weights. The design of the case shall be such that the weights cannot get out of their pockets when the lid is closed. The hinges and fasteners shall be adequate to keep' the lid closed during reasonable handling. The materials used in the cases and lining shall not cause discoloration of the weights when stored for long periods of time in warm or damp locations.

3.7.1.1. Pockets. - The case shall have a separate pocket for each weight and a special pocket or pockets for the lifters or forceps furnished for the handling of the weights in that case. Hach pocket for weights shall be large enough so that no appreciable frictional force will be encountered in removing or inserting the weights. Each pocket shall be lined with a soft material such as velvet.

3.7.1.2. Marking of case.-The range of denominations contained, followerl by the words "Pounds Avoilclupois", shall be marked permanently and conspicuously on the top of each case.

4. Preparation for delivery.

4.1. Packaging.

4.1.1. Group A.-Each weight shall be wrapped tightly in many thicknesses of tissue paper (the paper folded tightly around the ends so that any friction will be between the tissue paper and the outer wrapping, not between the weight and the tissue paper). The tissue paper shall be taped firmly in place. Several thicknesses of soft material, such as cloth or cotton wadding. shall be wrapped around the tissue paper and fastened in place with adhesive tape. Strong wrapping paper shall then be wrapped around the cloth or cotton wadding and marked on the outside thereof with the denomination of the weight ( $1 \mathrm{lb}$, etc.). The wrapped weights shall be packed in wooden boxes, with rough packing material (e.g., excelsior) packed around the weights to separate them from the box and from each other.

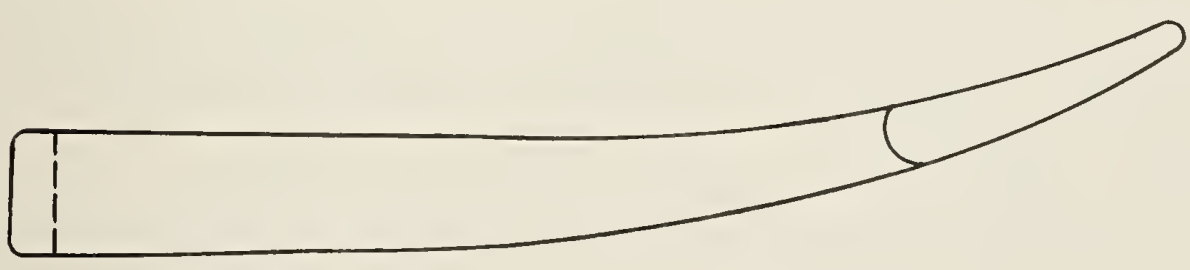

FIGURE 6. GROUP "C" FORCEPS. 
TABLE 1 - Tolerances

\begin{tabular}{|c|c|c|c|}
\hline Denomination & Tolerance & & Group tolerance \\
\hline $\begin{array}{l}30 \text { pounds } \\
20 \\
10\end{array}$ & $\begin{array}{l}136 \mathrm{mg} \\
91 \\
45\end{array}$ & \multirow{4}{*}{\multicolumn{2}{|c|}{$\begin{array}{l}\text { Not more than } 1 / 3 \text { of the weights } \\
\text { from } 30 \mathrm{lb} \text { to } 0.01 \mathrm{lb} \text {, inclusive, } \\
\text { are to be in error by more than } \\
1 / 2 \text { the tolerance. }\end{array}$}} \\
\hline $\begin{array}{l}5 \\
3 \\
2 \\
1\end{array}$ & $\begin{array}{r}23 \\
13.6 \\
9.1 \\
4.5\end{array}$ & & \\
\hline $\begin{array}{r}0.5 \\
.3 \\
.2 \\
.1\end{array}$ & $\begin{array}{l}2.3 \\
1.4 \\
0.91 \\
.45\end{array}$ & & \\
\hline $\begin{array}{l}.05 \\
.03 \\
.02 \\
.01\end{array}$ & $\begin{array}{l}.23 \\
.14 \\
.09 \\
.05\end{array}$ & & \\
\hline $\begin{array}{l}.005 \\
.003 \\
.002 \\
.001\end{array}$ & $\begin{array}{l}.050 \\
.050 \\
.050 \\
.050\end{array}$ & $0.075 \mathrm{mg}$ & \multirow{4}{*}{$\begin{array}{l}\text { For weights below } 0.01 \mathrm{lb} \text { neither } \\
\text { the sum of the positive correc- } \\
\text { tions nor the sum of the negative } \\
\text { corrections in a particular dec- } \\
\text { ade group shall be larger than the } \\
\text { amount specified under the group } \\
\text { tolerance. }\end{array}$} \\
\hline $\begin{array}{l}.0005 \\
.0003 \\
.0002 \\
.0001\end{array}$ & $\begin{array}{l}.028 \\
.028 \\
.028 \\
.028\end{array}$ & .042 & \\
\hline $\begin{array}{l}.00005 \\
.00003 \\
.00002 \\
.00001\end{array}$ & $\begin{array}{l}.028 \\
.028 \\
.028 \\
.028\end{array}$ & .042 & \\
\hline $\begin{array}{l}.000005 \\
.000003 \\
.000002 \\
.000001\end{array}$ & $\begin{array}{l}014 \\
.014 \\
.014 \\
.014\end{array}$ & 034 & \\
\hline
\end{tabular}

4.1.2. Groups $B$ and $C$.- The cases for Group B and Group C weights shall be used as shipping cases. Individual cylindrical and sheet-metal weights shall be wrappd with tissue paper of sufficient thickness so that each weight fits tightly in its pocket. The case shall be filled with soft material and then tightly wrapped with wrapping paper so that the case cannot open. These packages shall then be enclosed in a wooden box, with rough packing material (e.g., excelsior) packed around the packages to separate them from the box and from each other.

4.2. Packing.-The shipping containers shall be prepared for shipment to permit acceptance by carrier for transportation by railway express, Government Bill of Lading at destination, and to afford maximum protection from the hazards of such transportation.

4.3. Marking.-Shipping container's shall be marked with the denomination of weights contained therein as defined by the contract or order under which shipment is made, the name of the contractor, and the number of the contract or order, and addressed as follows: Mass and Scale Section, National Bureau of Standards, Connecticut Arenue at Van Ness Street, Washington 25, D.C.

5. Bids shall be submitted individually for the Group A weights, the Group B weights, and the Group $\mathrm{C}$ weights. A bidder need not submit bids on more than one group; but if he desires to bid on two or three groups, separate prices for each group must be submitted. 
APPENDIX 2. PROTOTYPE PRECISION BALANCES FOR USE IN STATE WEIGHTS AND MEASURES LABORATORIES

\title{
1. General
}

1.1. This specification covers three balances that will comprise one set of prototype precision balances for use in a State weights and measures laboratory for standard weight calibration.

1.2. Each bidder shall submit evidence (including the names and addresses of three customers) of having manufactured previously high precision balances (having a reproducibility of better than 1 part in 100,000 of the capacity load).

2. Designation.-The set shall consist of three balances, designated as follows:

\author{
Balance $X$-capacity 50 pounds \\ Balance $Y$-capacity 5 pounds \\ Balance $Z$-capacity 0.5 pounds.
}

3. Bid Requirements.

3.1. General.-A bid may be submitted for one or more of the designated balances, with a bid price being shown for each balance if more than one is bid on. Alternatively, a bid may be submitted for a complete set of balances with capacities different from those specified in paragraph 2.1., provided it is clearly demonstrated that, on all loads up to and including 50 pounds, identical or better precisions are obtainable than those specified in table 2. (If a bid is submitted under this alternative, a price must be shown for each balance in the set.)

The successful bidder shall furnish a prototype balance (or balances if the bid on more than one is accepted) and such engineering or shop drawings (with material specifications) as are produced in the manufacture of the balance (or balances). The balance (or balances), the engineering drawings, and the material specifications shall become the property of the United States Government.

3.2. Patent Rights.-This contract shall be subject to all patent clauses and conditions attached hereto. (The patent clauses and conditions are not reproduced here.)

3.3. Delivery.-Delivery is the responsibility of the vendor, and delivery shall include erection and adjustment in the Mass Laboratory of the National Bureau of Standards.

Delivery of the prototype balances is desired on or before August 1, 1960. By not later than August 1, 1960, a working model that substantially meets all requirements and needs only minor design alterations or other minor modifications shall be available for inspection in the laboratory of the supplier. Final delivery and installation at the National Bureau of Standards shall be accomplished by January 1, 1961.

Failure to meet any one part of the specifications shall be construed to be failure of delivery, except that any time spent in testing a balance or in studying a drawing by the National Bureau of Standards shall be compensated for by an equal time allowance after January 1, 1961.

3.4 Penalty.-Failure to delirer the balance (or balances) by January 1, 1961, shall entitle the National Bureau of Standards to collect from the supplier the amount of fifty dollars $(\$ 50.00)$ per day for each day between January 1 , 1961, and the date the balance (or balances) is actually delivered, up to a maximum total equal to the contract price, whether or not the contract is canceled due to failure of delivery. (In the event a supplier is the successful bidder for more than one balance, the penalty herein prescribed shall be imposed for the delayed delivery of each balance.)

4. Construction-All Balances. - The balances shall be of such rugged design and construction that they shall not only meet all sperifications herein set forth and all requirements as to precision, but they shall also maintain such precision under normal working conditions as are likely to be found in a State weights and measures laboratory. Failure to meet these conditions could under some circumstances be difficult to prove. The opinion of the staff of the Mass Laboratory and their advisers of the National Bureau of Standards shall be considered final.

5. Design-All Balances.

5.1. One Pan. - A balance shall be of one-pan design, having a counterpoise fixed to the beam, and shall weigh all loads at the nominal capacity of the balance. 


\begin{tabular}{|c|c|c|c|}
\hline 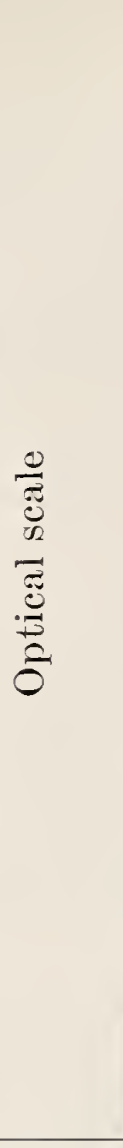 & 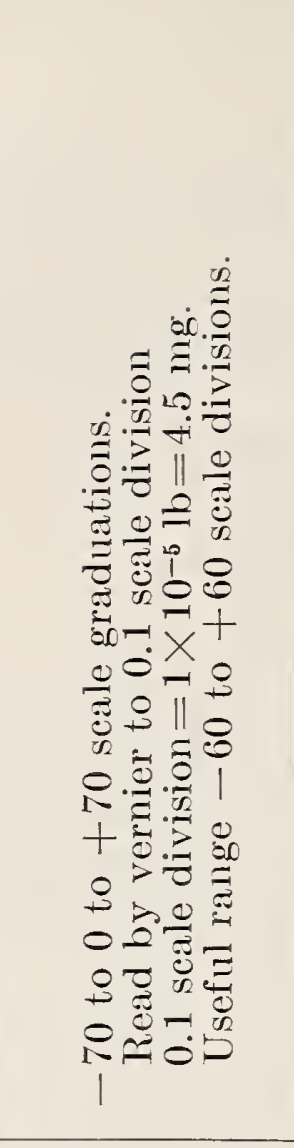 & 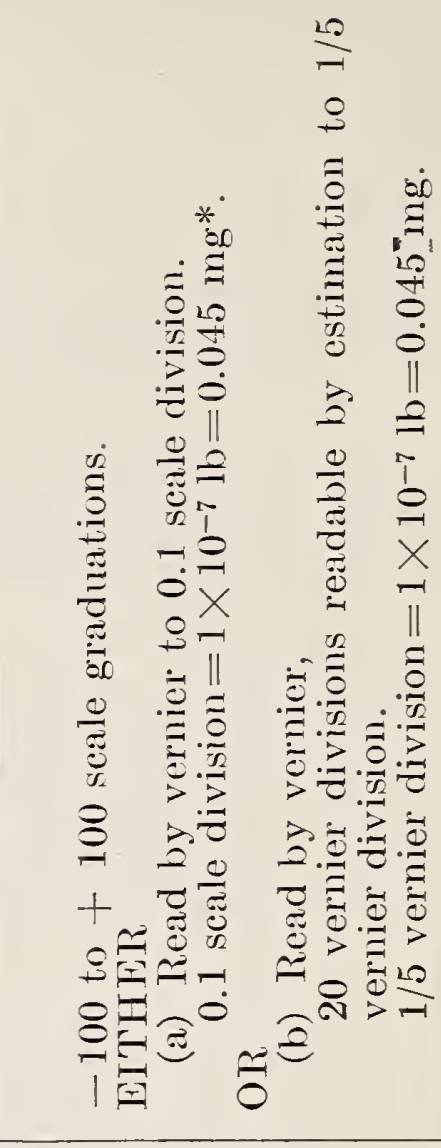 & 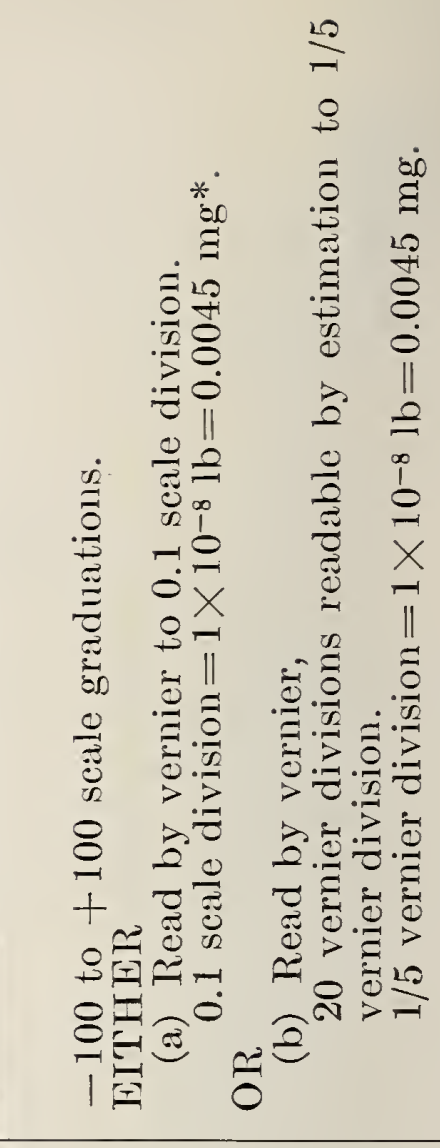 \\
\hline 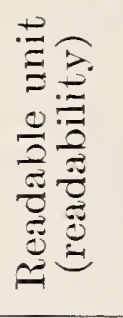 & 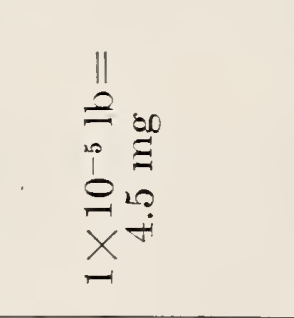 & 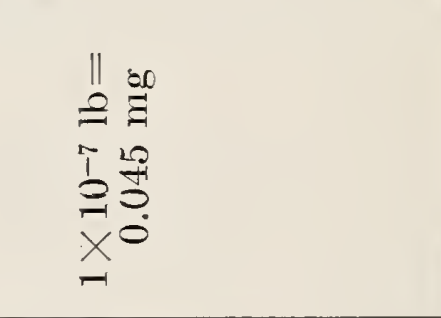 & 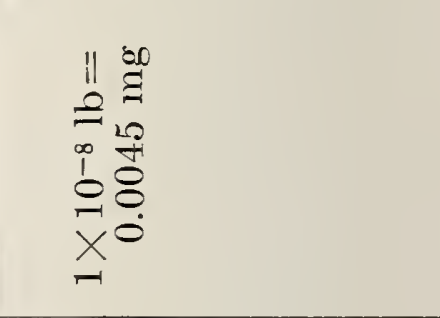 \\
\hline 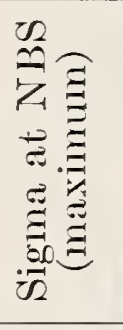 & 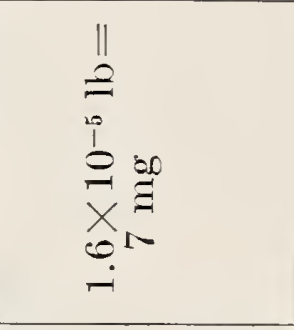 & 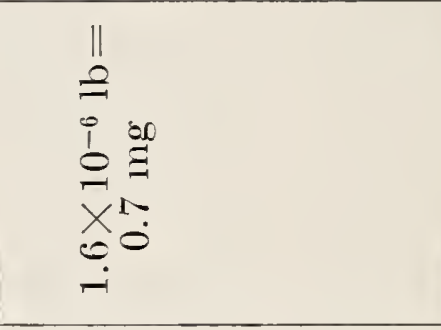 & 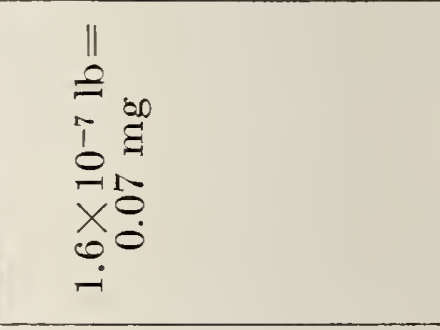 \\
\hline 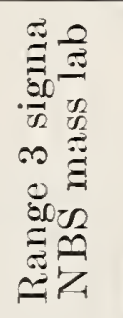 & 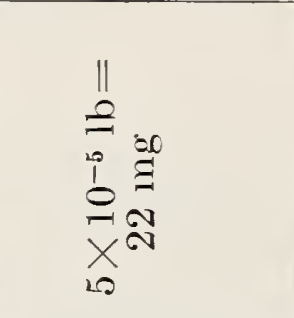 & 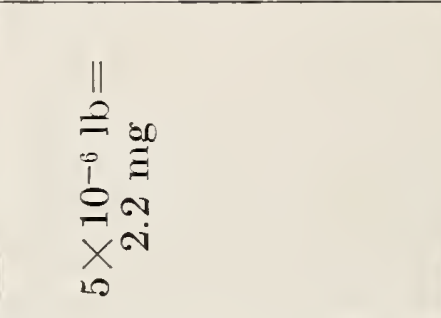 & 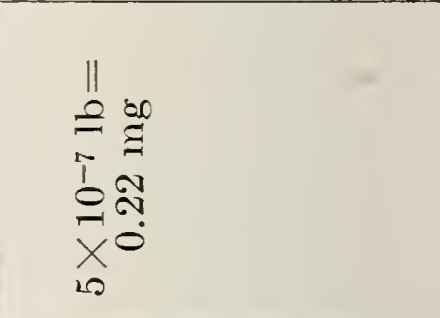 \\
\hline 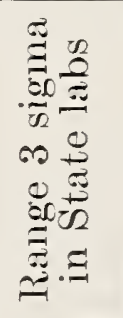 & 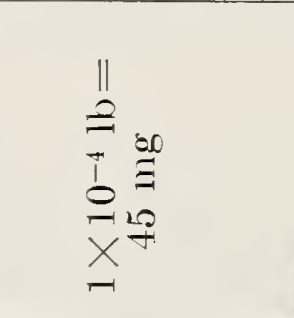 & 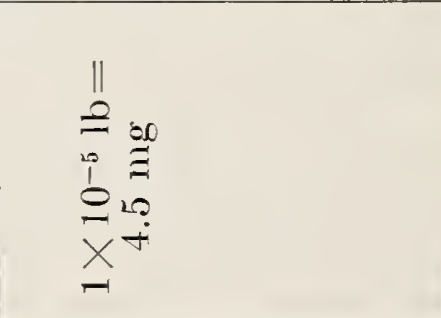 & 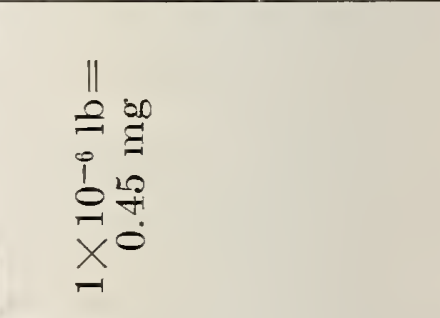 \\
\hline 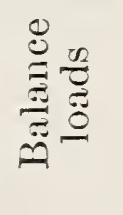 & 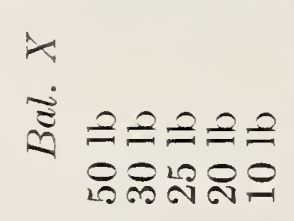 & $\overrightarrow{\tilde{\Xi}}=0 \Omega$ & 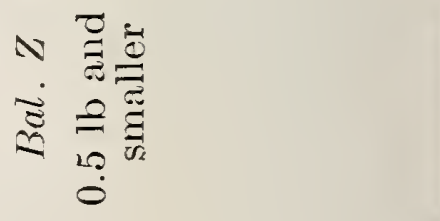 \\
\hline
\end{tabular}


5.2. Knife Edges.-The beam of a balance shall have two, and only two, knife edges, the parallelity of which shall be adjusted by suitable screws or other device to the highest precision, or the knife edges shall be located accurately parallel without hammering or swaging or bending of the beam.

5.3. Maintenance of Adjustment.- A balance beam shall be so designed and constructed that the bean can reasonably be assumed to be capable of maintaining adjustment under good working conditions for at least 10 years, except that the need for a small readjustment of sensitivity and level is recognized. 5.4. Built-in Weights.-A balance shall be brought into equilibrium through the use of built-in weights applied to that side of the balance on which unknown weights are placed on the pan. In use, such weights will approximately equal the difference between the nominal ralue of the load and the capacity of the balance, and the value of such weights shall be indicated on balance dials in pounds and decimal fractions of the pound.

The built-in weights shall meet the requirements of National Bureau of Standards Class S-1 weights, but failure to meet adjustment tolerances shall not warrant the rejection of the balance. Errors in built-in weights shall not be considered part of the imprecision of the balance.

A balance shall be so designed that, when a weight is supported from the pan suspension, the weight shall be prevented from swinging.

5.5. Indicating Element.-Decimal figures as required in addition to the built-in weights shall be provided by an optical read-out system which presumably will include a rernier or similar device.

The optical read-out of the indicated ralue in mass units shall not depart from scale linearity by more than one readable unit over the entire optical range of the scale. Tilt of the balance table shall not change the balance indication by more than one readable unit for one second of arc of tilt. If the number of scale divisions is such that one readable unit represents an angle smaller than one second of arc, then some means must be provided to reduce the effect of tilt of the balance table on the indication to that specified above.

5.6. Sensitivity and Equilibrium Adjustment.-Adjustment of sensitivity shall be made through the rertical movement of a small threaded weight that can be securely positioned. A similar threaded weight having horizontal morement parallel to the beam length shall provide adjustment of the equilibrium position.

5.7. Balance Pan.--The pan of a balance shall be so constructed as to present a minimum of surface to be acted upon by air currents and shall be so marked as to facilitate centering of the load.

5.8. Extraneous Effects.- Any extraneous magnetic effects, as well as any systematic change in indication with change in air density of 2 percent and variability in indication with humidity changes of up to 10 percent shall be considered part of the imprecision of the balance.

5.9. Balance Case.-A balance shall be enclosed in a case that will provide adequate isolation from drafts and thermal disturbances. The case shall, by means of windows or doors, permit good access to the pan. The case shall provide sufficient space to accommodate not only built-in weights, but also a standard weight in mass equal to the capacity of the balance. The case shall be of good appearance and of such material and design as may be reasonably expected to provide good protection for the balance over a period of at least 20 years.

5.10. Precision Design.-A balance shall be so constructed as to demonstrate the perfection expected of high precision balance manufacture. Ans detail features that are necessary to the rapid, convenient, and precision operation of the balance shall be provided by the manufacturer eren if mention of same is not made in the specifications.

6. Design-Balance $X$.

6.1. Operating Range.--The balance shall normally operate at only the following loads: 50-pound, 30-pound, 25-pound, 20-pound, and 10-pound. but provision shall be made for operating the balance at any load above 5 pounds and up to and including 50 pounds by adding. together with the weight or weights under test, other standard weights on the pan side of the balance. Such additional standard weights shall not be supplied with the balance.

6.2. Scale Adjustment.-There shall be a means of adjustment of the scale reading, the total range of which shall be not less than 0.0005 pound.

6.3. Damping.-The balance shall be so dampened and have such a period that a reading can be taken (with good ambient conditions) within 50 sec- 
onds of release. Any drift in reading after that time shall be considered as part of the inherent imprecision of the balance. (The time interval over which the zero variability will be tested is the time needed to perform a series of ten meighings of a test weight and a standard weight taken alternatively.) 6.4. Arestment.-The balance shall be equipped with an appropriate arrestment mechanism that shall be so designed as to prerent damage of the mechanism itself or any other component of the balance by loading the pan with loads up to 60 pounds.

6.5. Weight Transfer Mechanism.-A convenient weight transfer mechanism shall be provided by which the standard weight can be put into storage position inside the balance and by which a test weight can be transported from outside the balance onto the balance pan, and vice versa.

6.6. Weight Accommodation.-The balance pan shall accommodate weights up to 11 inches in height and 7 inches in diameter.

6.7. Built-In Weights.-The lowest portion of any built-in weight shall be not more than 12 inches above the pan.

6.8. Built-In Weights-Exemption.-Although dial-operated built-in weights are preferred for Balance $\mathrm{X}$, a bid for this balance may be acceptable without fully complying with specification paragraph 5.4. with respect to all weights being built in. In this case the reights, to bring all weighing at the capacity of the balance, would be added by hand without dial indication. The manufacturer shall supply such weights and shall provide, within the balance case, a location for such weights when ther are not in use, and shall also provide positions for such weights when they are in use on the pan side of the balance. However, such positions shall not be in the same pan area as is expected to receive the weight or weights under test.

7. Design-Balance $Y$.

7.1. Operating Range.-The balance shall be operable at all loads up to and including 5 pounds through the application of dial-operated built-in weights. 7.2. Scale Adjustment.-There shall be a means of adjustment of the scale reading, the total range of which shall be not less than 0.00005 pound. Any systematic effects due to the scale adjustment shall be considered part of the imprecision of the balance.

7.3. Dampinig.- The balance shall be air damped and with such a period that a reading can be taken (with good ambient conditions) within 40 seconds of release. Any drift in reading after that time shall be considered as part of the inherent imprecision of the balance. (The time interval over which the zero variability will be tested is the time needed to perform a series of ten weighings of a test weight and a standard weight taken alternatively.)

7.4. Arrestment.- The balance shall be equipped with an appropriate arrestment mechanism that shall be so designed as to prevent damage of the mechanism itself or any other component of the balance by loading the pan by as much as twice the nominal capacity.

7.5. Weight Accommodation.-The balance pan shall accommodate weights up to 8 inches in height and 5 inches in diameter.

7.6. Heat.-Any built-in sources of heat shall be so designed as to cause the minimum of disturbance to the balance.

8. Design-Batance $Z$.

8.1. Operating Range.-The balance shall be operable at its nominal capacits ( 0.5 pound) and at all smaller loads through the application of dial-operated built-in weights.

8.2. Scale Adjustment.-There shall be a means of adjustment of the scale reading, the total range of which shall be not less than 0.000005 pound. Any systematic effects due to the scale adjustment shall be considered part of the imprecision of the balance.

8.3. Damping.-The balance shali be air damped and with such a period that a reading can be taken (with good ambient conditions) within 30 seconds of release. Any drift in reading after that time shall be considered as part of the inherent imprecision of the balance. (The time interval over which the zero variability will be tested is the time needed to perform a series of ten weighings of a test weight and a standard weight taken alternatively.) 8.4. Arrestment.-The balance shall be equipped with an appropriate arrestment mechanism that shall be so designed as to prevent damage of the mechanism itself or any other component of the balance by loading the pan by as much as twice the nominal capacity.

8.5. Weight Accommodation.-The balance pan shall accommodate weights up to 4 inches in height and diameter. 
8.6. Heat.-Any built-in sources of heat shall be so desigued as to cause the minimum of disturbance to the balance.

9. Performance.-The precision, the readability, and the optical range for Balance $X$, Balance $Y$, and Balance $Z$ shall be as show in table 2 .

\section{WEIGHTS AND MEASURES STANDARDS USED BY THE AIR FORCE}

By Colonel Richard Stolle, Deputy Chief, Quality Control Office, Headquarters, Air Materiel C'ommand, Wright Patterson Ai, Force Base, Ohio

Gentlemen, it is an honor to have been invited here today to represent the United States Air Force at your National Conference on Weights and Measures. The Air Force is a relative newcomer in this business of measurement when compared to the weights and measurement programs of the great States of our nation which you gentlemen represent.

By joint resolution of Congress in 18:36, the Secretary of 'Treasury was directed to furnish each State a complete set of weights and measures adopted as standards for the customhouses. This was an extremely important erent because for the first time it standardized the weights and measures standards used throughout the country.

The average citizen probably does not realize how he is affected by standardized measurement. He takes it for granted that the gallon of gasoline, the yard of cloth, the pound of food, and the quart of milk that he buys will be the same wherever he buys it in the United States. This is possible only because of the activities of the States' weights and measures organizations, with their measurements emanating from the National Bureau of Standards.

I would like to acquaint you with some of the measurement problems we are facing in the Air Force today and with the steps we are taking to keep abreast of these problems. I will discuss this in two broad areas: the production of weapon systems by Air Force contractors and the maintenance of these reapon systems after delivery to Air Force operational mits such as the Strategic Air Command.

We require our weapon system contractor's to have a quality control system which is acceptable to the Air Force. As a part of this quality control system, the contractor must have an adequate precision measurement system to assure that his prorhct conforms to all contractual requirements. This includes standards, precision measurement equipment, tools, jigs, measurement procedures, and environmentally controlled standards laboratories.

All of the measurement used by Air Force contractors must be traceable back to one central source, the National Bureau of Standirds. Is I mentioned earlier, Congress recognized the importance of a single national source of measurement in 1836.

Why does the Air Force consider precision measurement so all important? The answer is quite obvious. The high quality and reliability so necessary in our modern weapon systems can be assured only by a system of accurate and repeatable measurement. This applies throughont design, development, production, and maintenance of a weapon system. Measurement is the only means we have to separate facts from opinions. 
As we enter the space age $\pi$ e are experiencing a measurement revolution. The drawing boards of reapons designers are pouring forth documents with tolerances which would have been considered fantastic a decade ago. But you must remember that only 10 years ago we considered the sound barrier an almost impenetrable barrier for aircraft. TVe have virtually catapulted into an era where both speed and range seem to be almost unlimited.

To produce reapon systems of this type, Air Force contractors have some of the finest precision measurement laboratories in the rorld. Many of these cover nearly all the rarious types of measurement known to man. This is understandable when you consider the complexity of a ballistic missile and the vast amount of ground support equipment required to back it up.

During World War II a relatively small amount of test equipment was required to support the various systems which made up an aircraft. Consequently, there was no formal program to calibrate test equipment. Since TVorld WTar II rapid increases in the complexity of reapon systems, especially in the area of electronics, have increased the requirement for test equipment enormously. This includes not only more items of test equipment, but also test equipment with accuracies which were not possible within the state-of-the-art a fer years ago.

As a result, the Air Force has established a formal calibration program to assure the accuracy of test equipment used to maintain reapon systems. At the present time, approximately 165 Air Force bases, worldwide, have precision measurement equipment laboratories. The measurement standards used by these bases are calibrated by the Air Materiel Command's Air Materiel Area precision measurement equipment laboratories. There are nine of these Air Materiel Command laboratories in the continental United States, tro in Europe, one in Japan, and one in Alaska. The measurement standards used by these Air Materiel Command laboratories are calibrated by the National Bureau of Standards.

To provide the skilled personnel to man its laboratories, the Air Force conducts a Precision Measurement Equipment Technicians Course at Lorry Air Force Base, Denver, Colorado. Only highly trained career airmen are eligible to attend this course.

Dayton Air Force Depot at Dayton, Ohio, is the prime technical agency for calibration in the Air Force. They are responsible for procuring all measurement standards, for writing all technical procedures, and maintaining the system for the transfer of measurement accuracies from the National Bureau of Standards down to the Air Force bases.

A question which is often asked is, "How can State and local reights and measurements organization assist in the Air Force precision measurement program?" I have given this question considerable thought and have discussed it with National Bureau of Standards officials, Air Force personnel, and industry representatives.

Our internal Air Force calibration program is capable of satisfying the present requirements of Air Force operational units. As I mentioned earlier, the requirements are quite varied with exacting accuracies in many specialized fields of measurement. It is tailor- 
made to support specific hardware items. These items may be weapon systems or supporting systems. With the large amount of electronic equipment, over 80 percent of our measurements are in the electrical-electronic area. In view of these special calibration requirements, I have been mable to find much commonality between the State and local weights and measures organizations and the Lir Force system. It appear's neither of us can do much to assist in the workload of the other:

Our Air Force contractors have a contractual obligation to obtain calibration service for their measurement standards. The policy of the Air Force is that the contractor is ordinarily free to get calibration service from a source of his choice. It is the contractor's responsibility to determine the adequacy of calibration source under the surveillance of Air Force Quality Control personnel.

Air Force contractor's get their calibration service from either the National Bureau of Standards, commercial calibration laboratories, other Air Force contractor's, or in special cases from Air Force laboratories. Most contractor's use one or a combination of these, depending on the accuracies required and the services available in their particular local area.

The Air Force has no objections to its contractors utilizing the State or local weights and measures calibration services. Of course, the contractor would be responsible for assuring that the accuracies available were adequate to meet his particular requirements. When a contractor utilizes this service, he would be prepared to pay just the same as if the service were rendered by a subcontractor".

The contractor most likely to request this type of service would be the small contractor or subcontractor who is producing supplies for a large contractor and who does not maintain a standards laboratory. There are also probably more requests for this service in the major industrial areas such as New York, Detroit, Chicago, and Los Angeles.

I would like to suggest that State and local weights and measures organizations utilize the services of the Air Force. I cannot do this, however, because of our limitations of facilities and manpower. The program I do propose is one in which cities, counties, or States and Air Force Bases or Air Materiel Areas intercompare their standards on a. voluntary basis. This is a very useful procedure when any doubt arises as to their accuracy between regular scheduled calibrations by the next higher echelon. For example, several of our Air Force precision measurement laboratories are located on Air Force Bases near State capitals. I know some of them have compared their standards with the adjacent State standards. In like manner, a State laboratory might compare their standard with a like standard at an Air Force Base and make a determination whether a special calibration by the National Bureau of Standards is necessary.

In closing, I would like to suggest that you encourage young people from your home States who are planning to enter engineering colleges to consider specializing in a curriculum which will lead to a career in precision measurement. 'The Nation desperately needs more people with training in this critical area. 


\section{By E. F. Menuax, Assistant Chief Engineer. Neptune Meter Company, Long Island City, New York}

The Secretary of the National Conference invited me, as a representative of the Neptune Meter Company, to address you on the topic of temperature compensation of LP-Gas liquid meters. Permit me first, if you will, to explain that this invitation was accepted in view of our company's decision to manufacture and market an LP-Gas compensator for our meters in areas where it is acceptable to the reights and measures authorities to sell a compensated $60^{\circ}$ gallon. It is in the area and spirit of cooperation with the users of our equipment and you, the reights and measures officials, that I am here to speak to you today.

When planning a talk of this type, it is dificult to know just where to begin. Perhaps it would be well to first explain why temperature compensation of LP-Gas is a timely topic, in order that those persons who have not been close to the subject of LP-Gas liquid metering can better understand the needs and problems of the people who are ritally concerned. I do not wish to infer that this need for greater understanding of the topic at hand lies solely with the weights and measures officials; all of us must first understand the subject and respect each other's position.

Propane, unlike other petroleum products measured and sold by liquid rolume, manifests several physical properties which make it a more challenging product to measure accurately. Tre know, for example, that it has low-lubricating qualities and low viscosity. Sereral years ago this Conference learned there were various problems encountered with the proving of meters simply because the very low boiling point of this petroleum product made it impossible to use conrentional volumetric testing procedures.

In spite of the development and use of practical metering and proving systems, there is still one remaining physical property of propane that complicates the problem of measurement. Simply stated, propane has an unusually large coefficient of rolumetric expansion. This somewhat technical term is used as an index of the change in rolume due to a change in temperature of a material.

Tre can chart the rolume of propane as it changes with temperature change. It is interesting to note that, while the average volume change is 1 percent for each $6^{\circ} \mathrm{F}$ change in temperature, a line connecting the volume, orer a range of temperatures, is not straight but slightly curved.

Because of the significant change in rolume, it becomes more apparent that a problem arises with the standard volumetric unit of measurement of this product (the gallon) because the product exhibits the high rate of volumetric expansion and contraction.

Many rear's ago and shortly after liquid metering of LP-Gas came into acceptable use, it was realized by the user that, even though metering provided a better means of achieving the desired inventory control, there was still a problem at hand. You might well ask why, as we ourselves first did. The problem will be more obvious to you too when you have given it further thought and study. 
I will try to cite the LP-Gas dealer's side of the problem-one who is desirous of using the compensated gallon.

Any businessman knows he must keep records of his financial investment, which in this case is the commodity. Let us assume a dealer has a known inventory of 10,000 gallons of propane at $60^{\circ}$ F. (Bulk inventories are recorded at a $60^{\circ} \mathrm{F}$ volume.) After metering product for retail sale purposes to his individual consumers, it becomes apparent that the dealer cannot relate the rolume sold to the volume remaining in stock. This is simply because the product sold was metered at varying unknown temperatures orer a wide range. Another way to visualize this is to take a look at the 10,000 gallons in inventory at $60^{\circ} \mathrm{F}$. If the product were metered out of stock at an average zero degree temperature, there would be less than 9,100 gallons available to deliver. Conversely, if a 100-gallon delivery were made to a customer at $90^{\circ} \mathrm{F}$, only 95 gallons would be withdraw from the $60^{\circ} \mathrm{F}$ inventory.

To cope with the problem, many ideas and suggestions have been proposed. Some of these included making a volume correction or price correction on the invoice based on product temperature during delivery. Other proposals included use of a sliding price scale or the calibrating of the meter in such a manner as to allow for some average seasonal temperature. None of the proposals were satisfactory to the LP-Gas dealer's.

I will now explain our position as the manufacturer of LP-Gas metering equipment. Aside from the principal function of manufacturing equipment, we must always pay heed to new markets and market demands, or give up these markets to other manufacturers, better known as competitors in our much preferred "free enterprise" system.

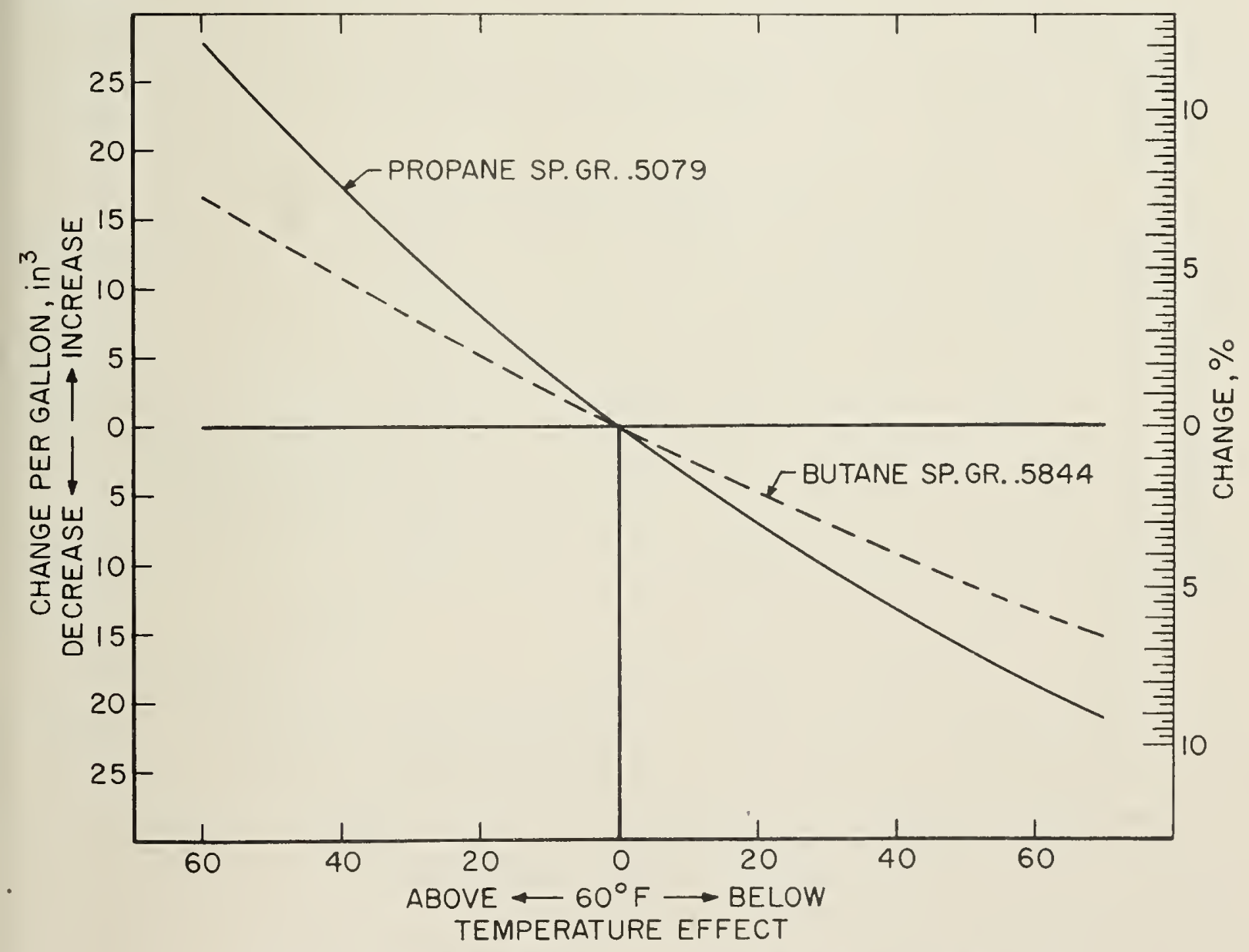

Figure 7. Temperature effect on product inlume. 
One prime purpose of liquid metering in industry is to proride good inventorr control. From what has been already stated, it must be realized that liquid metering of propane would proride a means of achiering the degree of inrentory control desired if the effect of temperature on the propane rolume were not as large as it is.

Naturally; reputable users of our equipment made their needs known to us. Mechanical automatic means to cope with the problem at hand was not a major obstacle, and I do not wish to orersimplify this aspect of the subject. Needless to sar, temperature compensation is not ner to the meter industry.

After studring the subject and dereloping our orn compensator unit. it was established as a matter of company policy to sell the derice only if a customer desiring an automatic temperature compensator were allowed to use the derice in the reights and measures jurisdiction where measurement and resale by the $60^{\circ} \mathrm{F}$ gallon is acceptable. To sum up, we as a manufacturer hare dereloped a mechanical temperature compensator for our propane meters to satisfy a market need and at customer request.

This brings us to the heart of the subject. Tre must now realize that we are dealing with a liquid product which for accurate volumetric measurement purposes has an undesirable but natural propertr of expanding and contracting to a far greater extent, due to temperature changes, than the comparative lower vapor pressure petroleum products in common use. Many purchasers and users of the LP-Gas liquid-metering equipment hare been and are desirous of having the means that automatic temperature compensation prorides

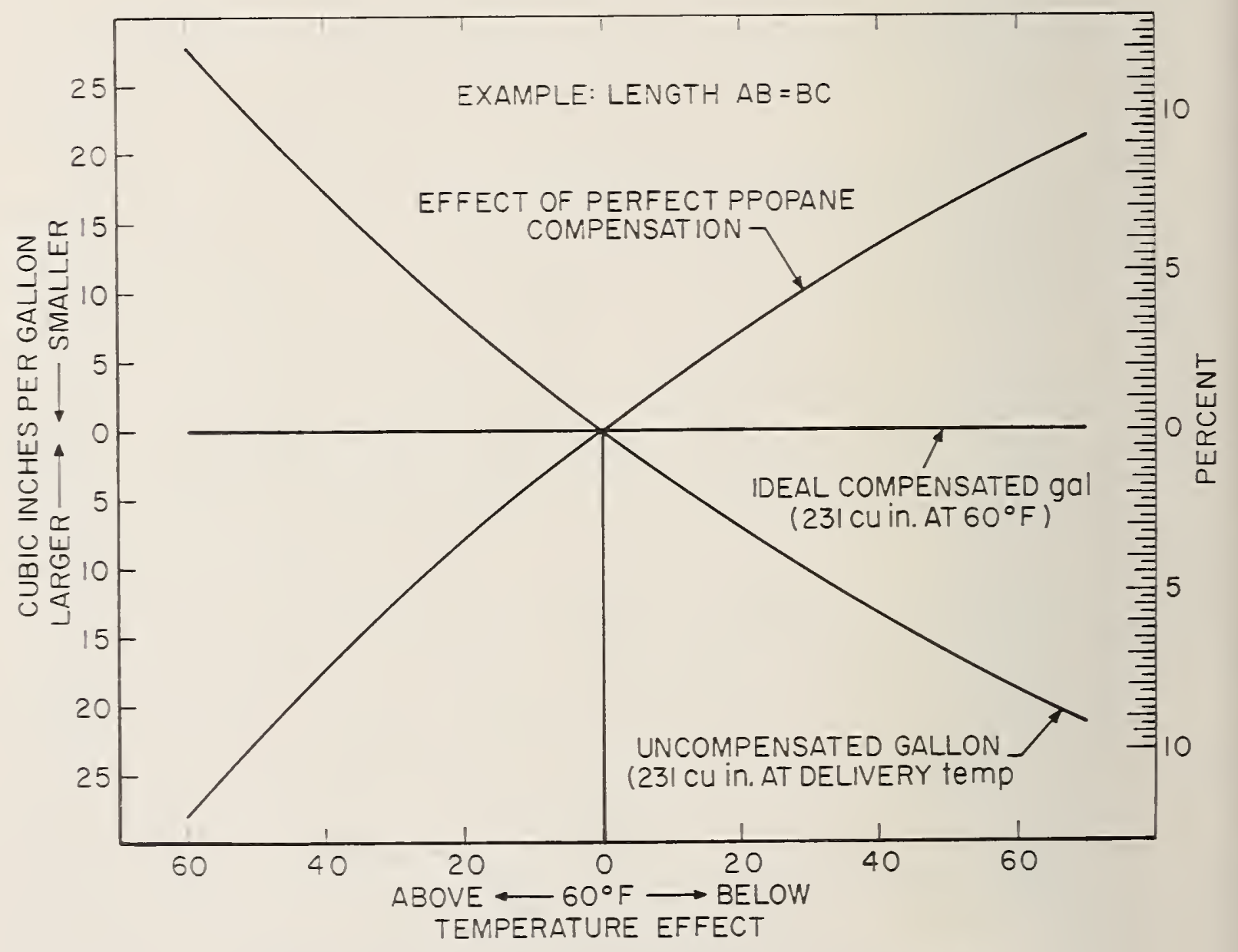

Firtue S. Propane temperature compensation. 
in order to achieve a more equitable base of rolumetric measurement for conducting their business.

Now let me explain LP-Gas compensation and the device referred to as a compensator. 'Temperature compensation in metering is merely an attempt to cancel out, to as great a degree as possible, the effect temperature change has on the volume of the product. Some years ago a $60^{\circ} \mathrm{F}$ base of reference temperature was established for various uses in the petroleum industry. Since the $60^{\circ} \mathrm{F}$ base temperature had been established, it was logical to also use this base for propane temperature compensation. 'The $60^{\circ} \mathrm{F}$ reference temperature does not represent an average product temperature in most areas where propane is sold.

If it were practical to do so, it might be considered desirable to automatically heat or cool the product to a uniform $60^{\circ} \mathrm{F}$ volume as it is metered and thereby cancel out the undesirable temperature effect on the volume. Since this approach cannot be accomplished practically and economically, what a temperature compensator does on a meter is to express the volume the propane rould have at $60^{\circ} \mathrm{F}$. This compensated volume is accomplished by using the coefficient of expansion even though the propane may be measured at another. temperature. This is what an LP-Gas compensator attempts to provide.

The compensator consists of two main elements :

1. A variable ratio drive unit placed between the meter measuring chamber and the meter register.

2. A liquid-filled thermostat immersed in the propane to directly control the ratio of the drive mechanism.

The variable drive unit is capable of an overall ratio change of approximately 22 percent-in other words, an approximate 11-percent reduction and an equivalent 11-percent increase from a 1 to 1 drive.

The desired drive ratio betreen meter and register is achieved by changing the center-to-center distance of a pawl and ratchet wheel and a rotating drive element. As the operating distance between the driving and driven-shaft centers is moved, the ratio of drive between meter and register is smoothly and continuously changed.

The temperature-sensitive liquid-filled bellows is immersed in the liquid product above the meter measuring chamber. 'This unit operates on the expansion and contraction of a fluid contained in the sealed metal enclosure of the thermostat. The thermostat, sensing a change in the propane temperature, moves a simple external lever which alters the ratio of drive between meter and its register.

The compensator mechanism is enclosed in a housing which is used as the upper half of the meter casing. 'This housing is equipped with a well for stem-type thermometers used in routine calibration of the meter, and is also used for the mounting and driving of the standard register. The entire unit and its adjustment can be sealed by a weights and measures inspector.

I would like to draw to your attention that our unit is designed for only one register. For the intended use of this compensator on LP-Gas meters in rehicle-tank truck service, there appeared to be no need to drive two registers from the relatively small sized meter. If a meter is equipped to indicate compensated readings, the only function an uncompensated register could serve would be for the checking of meter performance without compensation. It might be added, however, that, for compensated meters used where the sale of product is 
involved, the use of two registers might be distinctly disadrantageous.

To avoid the disadrantage of using two register's and still provide a means for testing the meter without compensation, a "lock-out" feature was incorporated on a lever operating between the thermostat and the variable ratio drive unit.

This lever is made up of two interlocking sections to permit disengaging the thermostat temporarily for field testing of the meter. Trith a transfer pin in one position, the register indicates compensated readings. With this same pin in a second position, the compensator is locked out and the register indicates uncompensated reading:s. From a weights and measures standpoint, we considered it essential to proride means to adjust the compensator separately, if necessary, after the meter has first been calibrated.

'The next phase of the subject that I would like to discuss is the procedure for testing a compensated meter. Five years age we offered, as our contribution to a symposium for this Conference, information accumulated from a project our company authorized to compared six methods of proving LP-Gas liquid meter's. Considering the "pros and cons" of the various testing procedures, we have been in basic agreement with the procedure subsequently published through the National Bureau of Standard's Office of Weights and Measures and referred to currently as the Handbook 45 supplement on Testing Liquefied Petroleum Gas Liquid-1Leasuring Devices. 'Those interested in this subject should obtain a copy from the Bureau's Office of Weights and Measures.

I have heard a few comments since the advent of the LP-Gas compensated meter suggesting that perhaps the best procedure now would be to use one of the gravimetric methods. I realize what is implied by these comments. A person would have to have a short memory, and mine is not that short, to suggest the gravimetric testing procedure. However, those who prefer the gravimetric method may still use this method for calibrating a compensated meter.

For the purpose of testing an LP-Gas meter with compensator, there is no basic change in the volumetric testing procedure. As stated earlier, to isolate meter calibration and performance from compensator adjustment, it is still recommended to first calibrate the meter with the compensator "locked out," using uncompensated register reading's for meter calibration.

After the standard procedure for testing the meter has been accomplished, it is only necessary to conduct one or two additional tests with the compensator engaged to obtain that data necessary to determine whether the separate adjustment on the compensator needs to be altered.

For example, the uncompensated meter registration is found to be 100 percent, but the compensated meter registration shows 105.5 gallons for 100.0 gallons delivered at $28^{\circ} \mathrm{F}$ when it should show 105.0 gallons; then the compensator" should be adjusted 0.5 percent "To Give More." Obviously, time on this program would not permit me to go into detail on the testing procedure. In those areas where we have thus far contacted the approprite weights and measures official regarding the LP-Gas compensator, we have furnished our suggestions on testing and adjusting the compensated meter.

In closing, there is one aspect of the mechanical compensator that should be covered for the sake of completeness. Compensators can 


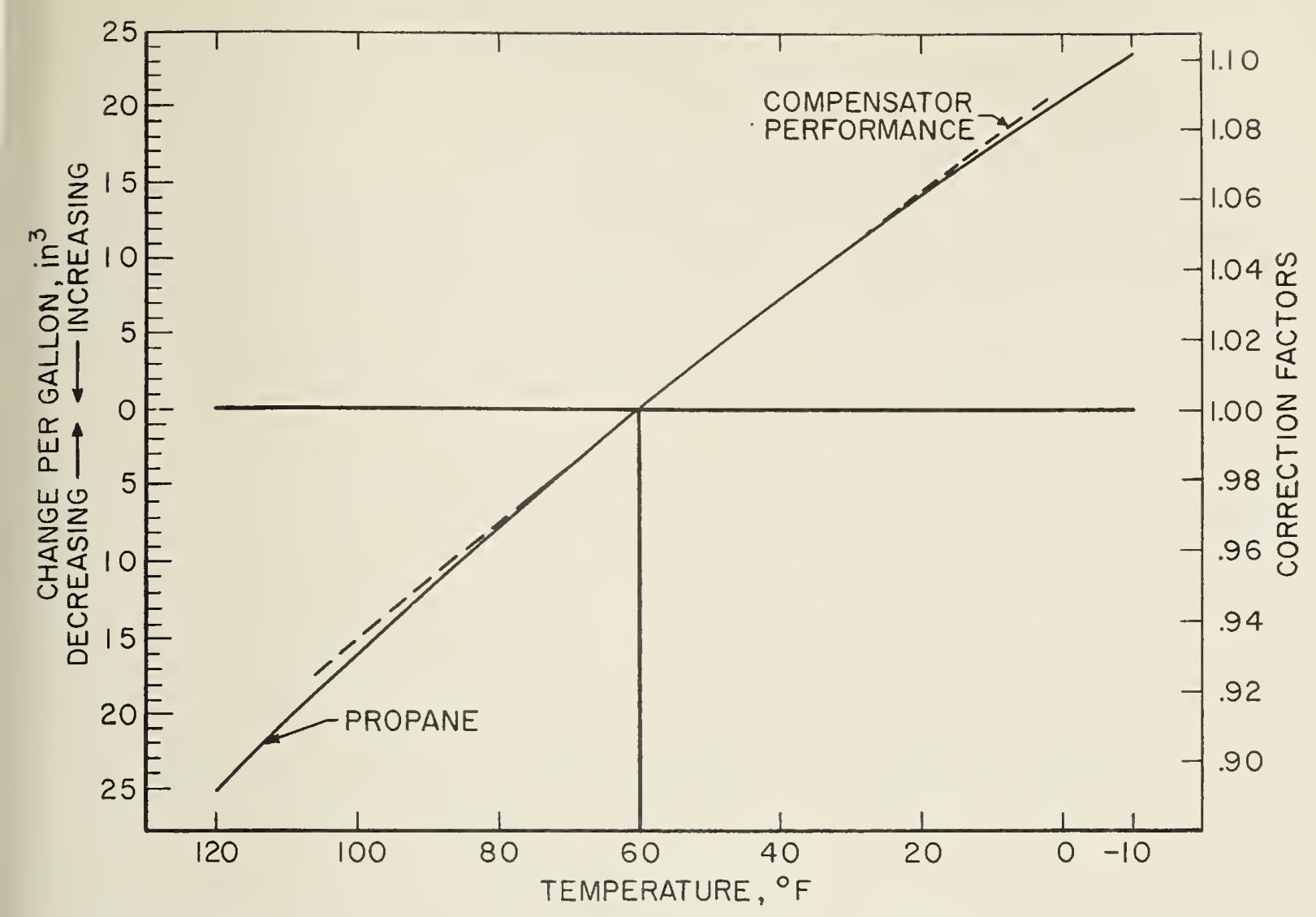

Figure 9. T.G.A.A. volume correction for propane-Sp. Gr. $0.50 \mathrm{rg}$.

be and are made with an adjustment for setting to the appropriate coefficient of expansion of the product. Obviously, this type of adjustment should be under the seal of the weights and measures office for control of the compensated registration. In this area we have chosen to design our unit to compensate for commercial propane. Our compensator is, therefore, designed to operate on meter's measuring propane, and it should be limited to that service. In other words, the compensator is not designed to be nised for compensating products such as butane or any other petroleum products. If a gravity selector were provided on a compensator, this would introduce a problem of proper setting of the coefficient adjustment, and the question of whether these changes were justified or proper. Interested parties have asked about compensation of butane. Te wish to draw your attention to an article which appeared in the January issue of the Butane-Propane News entitled "Is Butane Going off the Market?" From this article one may lightfully conclude that butane is being used more and more as a petrochemical rather than as a fuel.

\section{DISCUSSION ON FOREgOING PAPER}

Mr. IIowand: Are there prorisions for sealing the transfer pin so that the compensator cannot be placed in serrice at low temperatures and locked out at high temperatmies?

Mr. Wemans: Yes, the corer for the pin is so designed that it may be sealed down with a security seal.

Mr. Renurro: Are both the product being measured and the antomatic compensator affected by temperature in straight-line curves and are these curves parallel?

Mr. Wenunar: Within any anticipated range of temperatures, yes. 
Mr. R. E. Мекк: If temperature compensation is to be permitted in the retail sale of LP Gas, do you anticipate that this might be the beginning of a trend that later will cause pressure for compensated sale of other petroleum products?

Mr. Wehmane : I am not in a position to make a prediction in this connection. I do say, however, that propane gas in liquid form is an extremely elastic product. It might seem almost unreasonable to demand of a meter accuracy to a few tenths percent and then allow it to measure a product that might vary in volume up to 10 percent over a normal range of atmospheric temperatures.

\section{AFTERNOON OF WEDNESDAY, JUNE 8, 1960}

\section{-NO BUSINESS SESSION-}

A special ceremony for the presentation of standards of weight and measure to the new State of Hawaii was held at the U.S. Department of Commerce Auditorium.

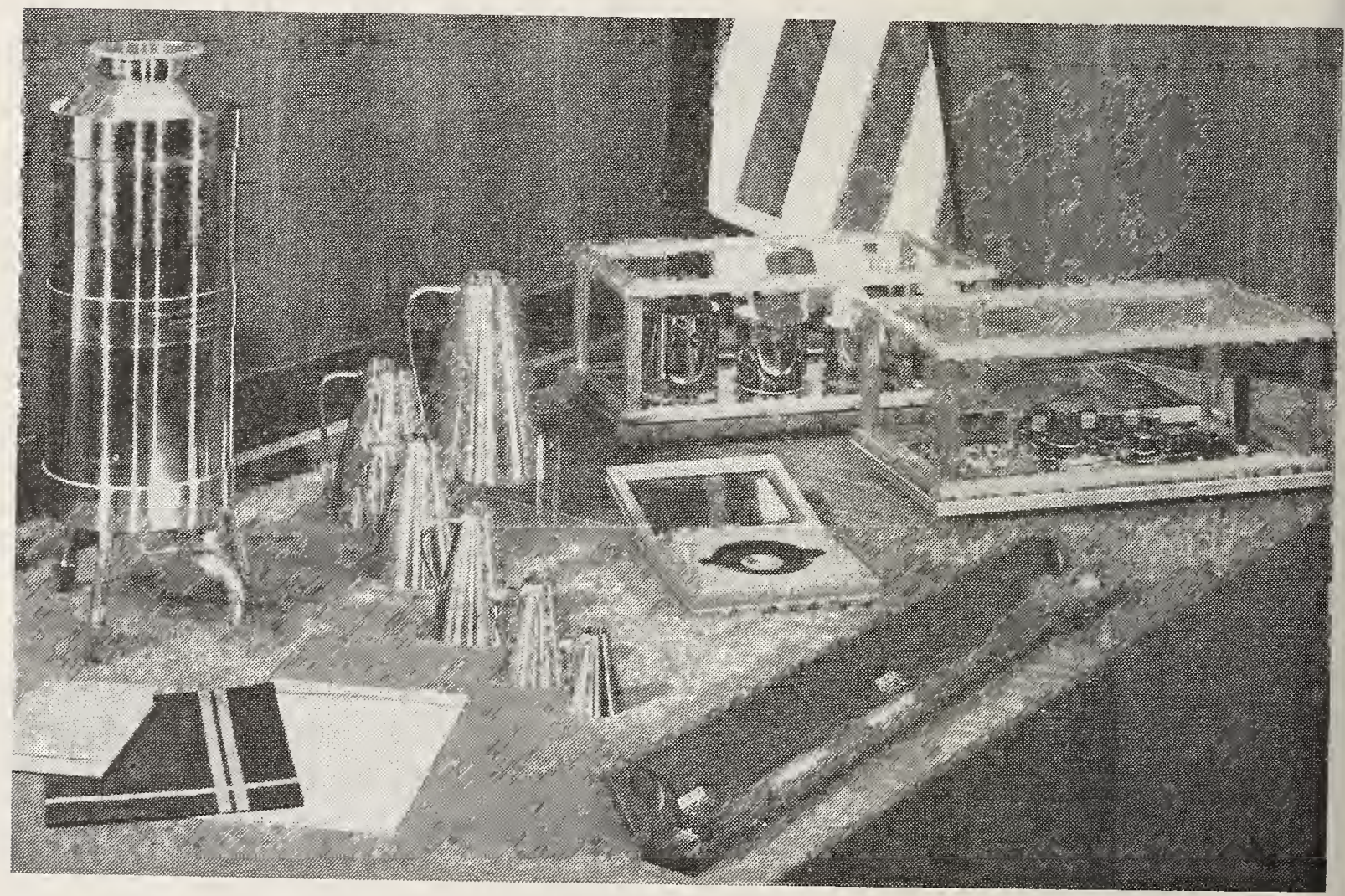

Figure 10. Standards of weight and measure presented to the State of Hawaii. 


\title{
FOURTH SESSION-MORNING OF THURSDAY,
}

\author{
JUNE 9, 1960
}

\section{(J. P. McBride Presiding)}

\section{CURRENT POSITION OF THE U.S. DEPARTMENT OF AGRICULTURE REGARDING THE LABELING OF POULTRY AND POULTRY PRODUCTS}

\section{By F. E. Blood, Deputy Director, Poultry Division, Agricultural Marketing Service, U.S. Department of Agriculture}

Prior to the time the Poultry Products Inspection Act of August 28,1957 , became effective, the Fecleral responsibility for the proper labeling of poultry and poultry products was vested in the Federal Food and Drug Administration. Since that time, the responsibility for appropriate labeling has been under the jurisdiction of the Department of Agriculture insofar as interstate shipment of poultry and poultry products is concerned. Section 18(a) of the Poultry Products Inspection Act rather clearly defines the jurisdiction of the law and treats with the relationship between the Poultry Products Inspection Act and the Federal Food, Drug, and Cosmetic Act. It reads :

For the purpose of preventing and eliminating burciens on commerce in poultry and poultry products, the jurisdiction of the Secretary within the scope of this Act shall be exclusive and poultry and poultry products shall be exempt from the provisions of the Federal Food, Drug, and Cosmetic Act, as amended, to the extent of the application or the extension thereto of the provisions of this Act.

To put the matter of jurisdiction briefly, it may be said that the Department of Agriculture is responsible for the wholesomeness of the product at the time of shipment from the official establishment. The Federal Food and Drug Administration is responsible for the wholesomeness of the product with respect to conditions arising beyond the official establishment so long as the product is in interstate commerce. The Department of Agriculture is responsible for the proper labeling of the product so long as it is involved in such commerce. One exception with respect to the labeling responsibility made by this Department deals with certain human food products which contain small quantities of poultry, but which have been exempted by the Department from the classification of poultry products under the Poultry Products Inspection Act. Such exception is also made for poultry sandwiches.

There are five or six different categories of such exempted products listed in Section 81.208 of the regulations gorerning the inspection of poultry and poultry products. Section 81.208 imposes certain labeling requirements on some of these products. With respect to these exempted products, the labeling other than as provided for in that section is the responsibility of the Federal Food and Drug Administration if such products are involved in interstate commerce.

The basic authority for supervision of labeling of poultry and poultry products is contained in Section 8 of the Poultry Products Inspection Act. This Act parallels many features of the Federal 
Meat Inspection Act and authorizes the Secretary of Agriculture to approve labeling for poultry products prior to its use in official establishments processing poultry under Federal inspection. Basic label requirements are specified to insure that labels are not false or misleading; that only approved "established trade name or names which are usual" to poultry products are used; and that certain specific mandatory information appears on the labels.

The Act and the regulations issued thereunder provide in general that each immediate container of a poultry product shall bear the following information :

1. The common or usual name of the product.

2. The net weight or other appropriate measure of content.

3. The name and address of the packer or distributor.

4. The official inspection mark.

5. The plant number of the establishment in which the product was inspected.

6. A statement of ingredients, listed in order of diminishing proportions, if the product is fabricated from two or more ingredients.

Shipping containers need be labeled only with the inspection mark and the plant number. 'They may, however, contain such additional labeling information as the packer desires, provided it is appropriate and not false or misleading.

The Act also authorizes the Secretary to permit reasonable variations and grant exemptions from these labeling requirements in a manner not in conflict with the purposes of the Act. One of the variations that has been permitted by the regulations includes certain modifications of the net weight requirements for poultry labeling. The omission of the net weight statement is permitted for immediate containers, provided certain requirements are met. First, the reailer or distributor supplying the retailer agrees in witing with the Administrator to mark the true net weight on the label prior to display and sale; second, the shipping container bears the statement, "Net weight to be marked on consumer" packages prior to display and sale"; and third, the total net weight of the contents of the shipping container shall be marked on such container. This provision is intended to permit flexibility in weighing and pricing systems of retail merchandising organizations within the limitations of applicable local reights and measures official requirements at destination.

Plant inspectors carry the responsibility of seeing that the signed agreement is on record prior to shipment of product without the net weight indicated on the immediate containers. This practice is followed for the most part with respect to frozen individually bagged consumer packaged turkeys. Most other poultry products bear the net-weight statement on the immediate container.

In present-day commercial poultry processing operations, large amounts of clean potable water are needed to accomplish good processing in a sanitary manner. Poultry carcasses must be thoroughly washed and chilled promptly. During the washing and chilling processes, poultry absorbs moisture and increases in weight in spite of all efforts to minimize this gain. Therefore, it is reasonable to permit the amount of moisture absorption and retention that is unaroidable under good sound operating practices. Our inspectors have been making weight tests continuously during the past year and a half to keep the moisture absorption problem under control. Result of weight test data indicate that the weight loss during the 
marketing of ice-packed poultry is difficult to estimate and control. The amount of weight loss depends largely on the temperature at which the poultry is held, the distance between the shipper and receiver, and the elapsed time between initial and subsequent weighings. Most processor's, as a result of experience based on weight tests they have made, know the amount of shrinkage that occurs in shipping their various types of packs to various markets. Consequently, they routinely allow sufficient tare to assure that the product delivered to receivers will be as marked on the shipping containers.

In regard to frozen poultry, the CSDA inspector's in the official establishments supervise the processing procedures and labeling of the containers. They must make sufficient inspections to assure themselves that the product is wholesome, prepared in compliance with the regulations, and is properly labeled. The washing and chilling procedures that are used in the preparation of whole-carcass poultry that is to be frozen must be approved. Only those procedures that result in a minimum of water absorption are permitted. By eliminating chilling procedures that result in excessive moisture pickup, and by continually making weight tests in processing plants, the problem of possible adulteration is controlled. Supervision by USDA inspectors of the weighing and marking of net weights on container's should help to eliminate problems in the weights and measures field.

Any weights and measures problems that are encountered after interstate commerce ceases would, of course, be within the jurisdiction of State and local weights and measures officials. The Poultry Inspection Service would welcome any information about weight problems encountered with respect to federally inspected poultry. This interchange of information would be most helpful to the Department in discharging its responsibility in this field and would be beneficial in achieving our common goal of accurate weights and proper labeling.

\section{Discussion ON FOREgOING PAPER}

Mr. Bord: I was particularly interested in Mr. Blood's statement relative to the jurisdiction of the State and local weights and measlires officials. My question specifically is: When in your opinion, Mr. Blood, does a commodity cease to be in interstate commerce and come within the jurisdiction of the local weights and measures officials?

Mr. BLoon: I would like to give you a very definite, flat answer on that, but we cannot even get that from our lawyer's. However, we consider the key to the answer to this question is when that product has ceased to more in commerce. This also seems to be where they have trouble defining such point, because there are a lot of products that come to rest at the first point in the State and are later transshipped out of that State into another State. Certainly, where products have reached the retail store level, there is no question. T'here the local chain store groups operate out of a centralized warehouse involving only intrastate movement, there could be no question about that. There is a grey area here and, as far as I know, I guess there may always be. But if there is any question on juristiction in any of the States, we certainly would be glad to entertain correspondence from any of you gentlemen raising specific points. We are sure this can be settled to our mutually complete satisfiaction.

After all, we are relying on you folks out there at the local level. This is particularly true in the morement of ice-packed poultry. As 
you all know, the vast majority of our broilers, by far the biggest part of poultry production, moves in ice-packed form.

This poultry usually mores in bulk pack, and the shipping container is in effect the immediate container. These birds are then received and further handled at the retail store, tray-packed or packed whole, and then individually marked as to weight. This we know is a problem. But in our work we hare, at the official plant, concentrated our attention on the poultry which is to be immediately frozen, because this is the poultry that does not lose its moisture. The modern operating and processing facilities in these plants, particularly the continuous chilling equipment, which in itself is a good progressive step, has emphasized the problem of increased moisture content in poultry. We have been checking this poultry as I mentioned in my talk. We have been running tests on such poultry for approximately a year and a half, all classes, at all seasons of the year, trying to arrive at a figure or a level which we would consider to be normal.

I believe we have finally arrived at these figures; roughly-this instruction has not as yet gone out to the plants, but we expect it to go out within the next 30 days - we have determined that the moisture retention in poultry of the light class, that is, fryer's, fryer-roaster turkeys, and ducks, appears to arerage around 8 percent. On the heavier product - that is, heavier turkeys, which is the biggest rolume, or any product which will weight orer 10 pounds, dressed weightthe average moisture retention figure is about 6 percent.

I might point out that this appear's to be a high percentage. When we started making our weight tests and looked back on the history of weight tests in the past, we found out that the workers came up with $5,6,7,8$, and as high as 10 percent moisture content - that is, moisture pickup and retention in poultry. The also found in almost every instance that the initial tests were made after the bird was washed, before it went into the cooling tanks, where they take the last of the body heat out of it and prepare it for packing.

TVe also found out that the rashing process on the line itself will add anywhere from 2- to 3.5-percent moisture. Now, when we talk about 6- and 8-percent levels, we are including that moisture absorption occurring during washing. In other words, we take the hot eviscerated weight of the bird and then we take the bird after it has been cooled, drained, and is ready for packing, and we weigh it. The absorption between those two times is the goal that we are seeking.

There is one other point that you folks will encounter a lot more than we will. We were asked, in our moisture control work on frozen poultry, why we did not use thawed, drained meight procedures, since this would be much simpler. We will grant you it would be a much simpler and much easier test to perform, but we do not get the answer.

I asked one of our inspectors to give me just four figures from our records to show this point a little more clearly. We find that moisture retention depends on the rate of freezing of the poultry. We have seen poultry that gained, according to our tests, 6.2-percent moisture. It was frozen, it was thawed, and it lost 10-percent moisture. Now, the last 4 percent of the loss was normal body tissue moisture. Another bird absorbed almost 11-percent moisture. On thawing and draining, we found it lost 6 percent. Another picked 
up 4 percent and lost 4.5 percent. Another gained 7.5 percent and lost 4.2 percent.

These results indicate why we could not go to a thawed drained weight procedure. In many instances when we compare the thawed drained-weight result and try to say that that was moisture absorp)tion and retention, we are incorrect, because we have these many instances where the poultry in the thawing process will lose more moisture than it picked up.

When you look at the growth of poultry consumption in this country and you look at the processing methods which utilize ice and water chilling, cooling, and washing, as against the old air-cooling methods in refrigerated rooms, we feel confident that a certain amount of moisture in the poultry is responsible for the increased flavor, tenderness, and succulence that has caused Mrs. American Housewife to buy the amount of poultry she is buying today. What we are trying to do is to prohibit this moisture content from becoming excessive.

I trust this will explain the reason why we are using the testing procedures we are, because we have been asked this question by several local authorities.

Mr. WrenN: At a farmers' market we have some farmers who produce a small amount of poultry and dress and bring them into the city market and sell directly to the consumer. I would like to know the extent of a farmer's privileges with respect to the poultry that he produces and dresses if he crosses a State line.

Mr. Blood: Section 81.200 of the regulations refers to a specific provision in the law. It merely has expanded somewhat the language in the law to make it clearer. This section states that "poultry producers are hereby exempted from the inspections and other requirements of sections," and then later, "and need not apply for exemptions with respect to poultry of their own raising on their own farms, which they sell either as dressed poultry or poultry products directly to household consumers or restaurants, hotels, boarding houses, for use in their own dining rooms or in the preparation of meals for sales direct to consumers only, provided that such poultry producers do not engage in buying or selling poultry products other than those produced from poultry raised on their own farms and provided, further, that such poultry is healthy and is slaughtered and processed under such sanitary standards, practices, and procedures as result in the preparation of sound, healthy, and healthful poultry products."

Now, what this means is that, if a producer raises poultry and handles no poultry from anyone else, he is free to market that poultry in live, dressed, or eviscerated form himself directly to consumers. 'This exemption is so provided directly in the Act and is expanded to the point as I read it, in the regulations.

I might mention that we have encountered a problem in Washington, because we have many producers coming in with poultry from Maryland and Virginia. However, they are the huckster-type producer who has also been picking up poultry from others. 'This exemption does not apply to these men. But the producer who is raising his own poultry, processing that poultry, and selling that poultry is exempt.

Mr. Leitmauser: How would that exemption affect the cooperative? Also, on cut-up poultry, do you define what is a leg; a breast, or, as some people term it, an economy cut?

$560160-60-6$ 
Mr. Blood: As to the first part, this exemption does not apply to a cooperative, but only to an individual poultry grower handling poultry raised on his own farm. In a cooperative, you have a group. The exemption would not apply.

On the second part, insofar as labeling of poultry in official plants is concerned, section 81.131, which is a section dealing with false or deceptire materials or derices and other labeling requirements, defines what can go on labels. In that section we define "(1) breast, (2) breast with ribs, (3) wishbones, (4) drumsticks, (5) thighs, (6) legs, (7) rings, (8) backs, (9) strip backs, and (10) necks."

Regardless of these requirements, parts of poultry may be cut in any manner the processor desires, so long as the labeling appropriately reflects the contents of the container.

Every one of our inspectors has these regulations and is familiar with the description of these parts, and all official plants must operate in accordance therewith. If a plant wishes to deviate from a standard cut or a standard package, as we describe it, it may do so. The only thing we say is that they must label their product properly.

Mr. RIce: During the month of May we checkweighted 8 different producers, fresh fryers packed in ice; and in all but one shipment of about 15 boxes, every box we weighed was underweight. Does this seem reasonable?

Mr. BLood: I assume, when you talk about producers, you are talking about official processors.

Mr. Rice: Yes.

Mr. Blood: I said thus far we had concentrated our attention on the poultry that was to be frozen at the plant. This was true because we found, on test after test, that ice-packed poultry, regardless of the way it was handled or cooled or chilled, was below the permitted tolerances. Here we are talking about fryers, so this would be below 8 percent.

Tre find that, in poultry that has been held 24 hours even just in the cooler at the plant, the moisture weepage has brought the poultry down to below the limits. We know such poultry continues to weep so long as it is in commerce. In fact, it will continue to weep right up to the time the housewife puts it in her refrigerator, but, of course, at a diminishing rate. For this reason we did not concern ourselves with moisture retention in ice-packed poultry. We have found that in almost all of these plants, no matter how much moisture is in each of their different types of poultry, the moisture loss is going to differ among different classes of poultry and different weights of poultry, and they have a pretty good idea of how much moisture their poultry will lose on shipping to certain customers, certain distances, depending on the pack. The plant should make allowances for anticipated losses.

This has been a problem. I know it has been a problem because we have had quite a few firms around the country who have retained our grading-service people to check on condition and weight of poultry being receired at their central warehouses for distribution to their stores.

It used to be that our people ran into underweight or overweight marks on the box, time after time. We were checking those records just the other day in four local warehouses, and I think out of the last two months' operation there were only three shipments received that were not within the weights marked on the box. 
By H. E. Petersox, President. Peterson Filling and P'arliaging Company, Danville, Illinois (representing Chemicul Specialties Mamfacturers Association)

I welcome this opportunity to talk with you today on a topic that is of tremendous interest to our industry-the net contents of pressurized or so-called aerosol packages.

In order for you to appreciate our answers to the questions some of you have posed to us in the arrosol industry, we would like to tell you something of the history of the industry and how it operates.

Work was instigated in 1945 by the can companies to try and develop a light gage disposable container. In order to utilize these containers, effective low-pressure formulations were developed, and these containers came on the market in 1947. The initial product to enter' the commercial market was low-pressure insecticides. Low pressure in 1947 generally meant pressures under 40 pounds per square inch gage at $70^{\circ} \mathrm{F}$.

After the successful introduction of insecticides, various other products followed rapidly:

(a) Fine sprays such as insecticides and room deodorants.

(b) Coarse sprays such as hair lacquers, paints, residual insecticides.

(c) Foams, such as whipped cream, shaving cream, charcoal lighter, etc.

(d) Products utilizing hydrocarbon gas such as window cleaners, furniture polishes, etc. Pour products utilizing a propellant such as nitrogen-e.g., vitamin syrup, various fla vored toppings.

Recently it has been stated that the industry now has 75 different types and shapes of contriner's to choose from, and it is predicted that there will be about 150 variations by 1965 . 'Ten years ago there were only two stock cans from which to choose.

This greater selection of container's has been an important factor in the growth of aerosols and in part is due to the efforts of the glass, plastic, and aluminum industries to secure a share of the market originally held only by the timplate and blackplate producer's.

\section{COMPOSITION OF AEROSOLS}

The composition of aerosol products can for simplicity be classified into three categories - namely, active material, solvents, and the propellant. At this point we would like to stress that usually the absence of any one of these would prohibit the proper formulation of an aerosol.

Active Material.-That which characterizes the specific aerosol product. In an insecticide it is the knockdown and killing agents; in a room deodorant, the deodorizing and fragrance ingredients; in hair lacquers, the hair treating components. The percentages of active ingredients in an aerosol package can vary widely from as low as ? percent in some silicone aerosols to a high of about 99 percent in some food aerosols.

Solvents.-Solvents are a necessary adjunct to practically every aerosol formulation. They may function as an active material by ability to control particle size or augment the operation of other ingredients-e.g., petroleum distillates in insecticides.

Solvents may also function as part of the propellant. 'This is said 
to happen if it can be replaced with propellant with no compromise of utility and desirability-example, methylene chloride.

However, the most universal reason for the addition of solvents is to insure compatibility, when desired, between the active ingredients and the propellant.

Propellants.-The workhorse of the aerosol package is the propellant. Without the propellant there would be no aerosol industry. Propellants, whether liquefied or noncondensible gases, create the pressure which makes an aerosol operative. In addition, they may affect the particle size, act as solvents, be an inherent part of all foams, and allow the active material to be dispensed in a highly effective and efficient fashion. In some cases they may act as a flammability inhibitor or reducer.

The use of propellants in aerosol container's permits the use of highly concentrated active materials and, as a result, very little product need be dispensed in order to be effective.

The propellant is an integral part of the product in the sense of a solvent-in the same manner that alcohol is part of a cologne, water a part of soup.

A question has been raised why different propellants are used. We believe the best method of answering this is to mention the various types of propellants that are now being used commercially.

(a) Fluorocarbon propellants ( such as Freon, Genetron, Isotron, and Ucon).These were first utilized in 1933 in the refrigeration field and have been widely used since the inception of the aerosol industry. These compounds are chlorinated, fluorinated hydrocarbons, characterized by nonflammability, inert behavior, high density, and very low toxicity. These propellants are commonly used in room deodorants, hair lacquers, insecticides, paints, and other similar type spray products.

(b) Hydrocarbon propellants (such as propane, butane, isobutane, etc.).This type of propellant is used mainly with water-based products, namely, window cleaners, shaving cream, and charcoal starters. It is beginning to be used in combination with fluorocarbons for many other products. The main reason for the use of this type of propellant is its low cost.

(c) Noncondensable propellants.-These are limited at the present time to nitrogen, carbon dioxide, and nitrous oxide. There are several others such as argon and krypton. These are very useful in formulations where limited or little solubility of the propellant in the active ingredients is desired. These include whipping creams, dental creams, food toppings, and others. This type of propellant is also useful for products which need fair pressures at low temperature. An example would be diesel starting fluids. Certain pharmaceuticals also use this type of propellant.

Consequently, it is apparent that the choice of propellant is predicated on the end use of the product.

\section{PROCESSES INVOLVED IN FILLING AEROSOLS}

There are two methods commonly used in the filling of aerosol container's. These are simply referred to as refrigeration and pressure filling.

(a) Refrigeration filling.-Refrigeration filling may be conducted by the single stage operation where all of the ingredients and the propellant are mixed together in a large pressure tank, pass through cooling coils, and are then filled as an ordinary liquid. The second method of refrigeration filling is the so-called double stage operation, whereby all of the active ingredients and solvents are blended together and these are then filled into the can at cold temperature. Either immediately prior to this operation or immediately fol- 
lowing, the remaining propellant is filled into the container at low temperature, in some cases as low as a minus 30 to 40 degrees $\mathrm{F}$.

This method of filling is used when products can withstand very low tenperatures without separation $0 r^{\circ}$ excessive thickening, or when the products are not highly flammable or toxic. Also, until recently this has been the only method of filling that allowed extremely high speeds of production. Fairly elaborate refrigeration equipment is needed in refrigeration filling.

(b) Pressure filling.-This method of filling aerosol containers consists of blending the various ingredients at essentially room temperature, filling them into the container, crimping on the aerosol valve, and then forcing the propellant gas into the can through the valve by means of high pressure. This method is useful for the addition of flammable propellants-necessary for introduction of numerous condensable propellants, required where products will not withstand chilling. It has been limited to low or medium speed production until recently. It will become more prominent in the future.

After the containers are filled, the valve crimped into place, and the propellant added by either of the two methods described above, the containers are then passed through a hot water bath so that the temperature reaches a point designated by the Interstate Commerce Commission regulations. Containers showing signs of any defect, leakage, or deformation are rejected and cannot be shipped in Interstate Commerce. Very rigid statistical quality control procedures are constantly in use, and it has often been said that they are the most stringent in the entire packaging field. After this step, the aerosol containers are handled essentially the same as any other container. The appropriate protective caps are placed over the aerosol valves and the cans are then packed in cartons.

Why is the CSMA qualified to answer questions about the weights and measures in the aerosol industry?

Through its parent trade association, the Chemical Specialties Manufacturers Association, the infant aerosol industry became well informed on how to fit logically, carefully, and commercially into the activities and interests of such organizations as the Federal Trade Commission, the Bureau of Explosives, the Interstate Commerce Commission, the Compressed Gas Association, and the U.S. Department of Agriculture. The industry recognized that this new pressure packaging concept required regulation and assistance from all of these groups if it were to grow soundly. As problems were solved and methods were developed, the character and makeup of special committees following these problems changed. Today the CSMA aerosol division has 21 scientific committees investigating and keeping the industry and its members up to date. Some of the committee names show the extent of our investigation.

Commercial Standards Subcommittee

Safe Fill Subcommittee

Glass and Plastic Container Subcommittee

Insecticide Standard Methods Subcommittee

Pressure Determination Subcommittee

Personal Products Standard Methods Subcommittee

Protective Coating Standard Methods Subcommittee

Each of these active committees is considering:

(a) Ways to assure the consumer that he is getting a quality product free of misrepresentation and safety hazard.

(b) Ways to establish quality control in the materials and operations used in aerosol manufacture. 
(c) Wars to assist in the clarification and establishment of Gorernment, State, and local regulations beneficial to the consumer and to the growth of the industrs.

Through the activities of these subcommittees, CSMLA is the technical hub of the industry and continues as central watchdog for good, legal, ethical, and safe practices.

CSMA feels qualified to discuss the questions that have been asked, and here they are:

Is the weight of the propellant included in the labeled net reight? If so, why--since the propellant is not a usable part of the product dispensed?

We would answer the question-Yes, the propellant reight is included in the designation of net contents because it performs a useful function as follows:

The propellant (a) supplies pressure to dispense material from the container-a basic justification for the convenience of aerosols; (b) disperses the active ingredient in usable form-thus supplying the peculiar effectiveness of many aerosols; (c) allows the package to be sealed, free from spillage, air contamination, or premature evaporation.

Cases in point.-Congress has charged the Department of Agriculture with the responsibility to regulate the sale of economic poisons. This responsibility includes aerosol insecticides. One of the requirements for space insecticides is that all particles dispelled from the aerosol package must be less than 50 microns in size and 80 percent of the particles must be less than 30 microns. Tre are talking of particles, not pinhead sizes but pinpoint size. Particle size is, of course, influenced by the valve design; but for any given valve, particle size of dispensed insecticide is a function of pressure of the propellant and its ratio to nonvolatile liquids in the container. In the final analysis, the amount and composition of propellant determines whether a space insecticide passes the Department of Agriculture regulations or not.

Thether you like the product or not-and about 30 percent of U.S. men do-another example of propellant effectiveness is shaving creams. Here, rolatilization of the propellant after discharge from the container produces the billowy foam-the inherent reason for aerosol shave cream in the first place.

An extreme example of why the propellant weight should be included in the marking of the contents is the room deorlorant. In most room deodorants, the active ingredients may be less than 1 percent. A one-second burst of room deodorant, eren at this low concentration of perfume or other active ingredient, discharges billions of molecules in a room. A 12 -ounce can of room deodorant comprising a tenth of an ounce of active ingredient would look strange, I am sure, to the houserife if it were marked only "active ingredient one-tenth of an ounce" while, when she picked up the can, it weighed nearly a pound.

In hair spray the particle size and rate of solvent evaporation controls the coating effectiveness of resin on the strands of $\mathbf{M}_{\mathrm{r}}$ Lady's hair. Again, particle size and rate of evaporation are a controlled contribution the propellant makes to the product. In fact, the amount of propellant and its composition from arailable alternatives supply the heart of aerosol technology and determine to a large extent whether the product is, therefore, effective and useful. Each product 
and active ingredient must be carefully formulated and tested with various amounts and kinds of propellant to arrive at an effective total aerosol package. The propellant, therefore, is a part of the package. It puts the "pressure" in the growing T50-million-dollar" pressure package industry.

Why are commodities that have been traditionally labeled by liquid rolume being measured by weight in aerosol containers?

The Department of Agriculture insists on active ingredients being marked on insecticide products in terms of percent by weight. The composition of the other ingredients besides the toxicants in an aerosol insecticide can vary substantially. This is so because the nontoxicant portion of the package is a mixture of propellants having densities between 1.3 and $1.45 \mathrm{grams} / \mathrm{ml}$ and organic solvents having densitjes of 0.75 to $1.0 \mathrm{grams} / \mathrm{ml}$. An insecticide marked "Contains 2-percent DD'T" may appear the same to the consumer in brand $\mathrm{X}$ insecticide containing 6 fluid ounces of total formula as compared to brand $\mathrm{I}$ having 6 fluid ounces of total formula. However, if brand $\mathrm{X}$ contains 8 weight ounces of formula and brand $Y$ contains only 7 weight ounces of formula, the two products would not contain the same bug killing power. It is the industry's belief after reviewing the requirements of the Federal Trade Commission that designating insecticides by total weight is, therefore, a truer representation of bug killing power and is consistent with the Department of Agriculture regulations on weight percentable of insecticide toxicants.

The practice adopted for: insecticides has been applied to other aerosol products and for some other reasons as well as consistency.

(a) Since the contents of most aerosol containers cannot be seen and the container cannot be opened, weight of the container and how it feels when shaken are the main indications for comparison of one product with another.

(b) People are more understanding of a "weight ounce" than they are of a "fluid onnce." Most people think of fluids in telms of quarts and gallons.

(c) Many aerosols contain ingredients whose specific volume changes significantly with temperatures. Aerosol products such as hair sprays, insecticides, room deodorants, and paints will experience a liquid rolmme increase of more than 1 percent for each $10^{\circ} \mathrm{F}$ rise in temperature. This is a liquid expansion rate approximately ten times that of watel-based products. Using weight designations avoids the necessity of specifying on the aelosol package a temperature of volume measurement.

Is the industry working toward standard containers for similar commodities?

The answer to this question is "No."

Of the questions which we want to answer for you today, on this one we have to be less definite. There is continual interest by marketers and package designers in changing the appearance of the aerosol package to make it distinctive. In the early days of the industry in the late 1940 's, there was just one tin and steelplate can of standird design and capacity. Shortly, another design of tinplate can was introduced by another can manufacturer, followed by each of these manufacturers introducing other sizes. A third can manufacturer then appeared, and later on several aluminum container's were offered. Glass bottles, coated with plastic and uncoated, were introduced, followed by various plastic container's. The trend today is definitely toward more and different container sizes, shapes, and materials. 'The statement, "The package sells the product," is not less true in the aerosol industry than for any other line of nseful products.

We have attempted to answer all of the questions that were asked 
of us, and the entire aerosol industry assures all of you of its complete willingness to fully cooperate with you on any matters applicable to our history.

(EDITOR:S NOTE: LITERATURE SUPPLIED BI CHEMICAL SPECIALTIES MANUFACTURERS ASSOCIATION, INC., IN SUPPORT OF MR. PETERSON'S PAPER.)

\section{AEROSOL DIVISION}

CHEMICAL SPECIALTIES MANUFACTURERS ASSOCIATION, INC.

50 East 4lst Street, New York 17, N.Y.

C.S.M.A. AEROSOL GUIDE

\section{PREMARKETING PRODUCT CHECK}

Preliminary Studies Before Production. (Prepared by the Product Check List, a Subcommittee of the Aerosol Division Scientific Committee. Published in the Proceedings of the 38th Midyear Meeting of the C.S.M.A.-Page 53.)

\section{Pre-Marketing Check List}

The design of the check list assumes that various marketing questions have been answered and that the management of the company has decided to go ahead with the development and marketing of the product. This master check list, of necessity, refers to the broad base of all Aerosol and Aerated products and is meant to be applicable to all those currently produced and new products under derelopment.

I. Formulation Checks

1. Low-temperature characteristics (stability, viscosity) of non-volatile concentrate
a. $100^{\circ} \mathrm{F}$
c. $0^{\circ} \mathrm{F}$
b. $70^{\circ} \mathrm{F}$
d. $-20^{\circ} \mathrm{F}$

2. Compatibility of non-volatile concentrate with propellent

a. critical solubility range

b. effect of ratio of propellent to concentrate on stability

c. effect of temperature on stability of combination of propellent and nonvolatile concentrate
1. $100^{\circ} \mathrm{F}$
3. $0^{\circ} \mathrm{F}$
2. $70^{\circ} \mathrm{E}$
4. $-20^{\circ} \mathrm{F}$

3. Specific heat of non-volatile concentrate

4. Vapor pressure characteristics (curve below boiling point through $\left.170^{\circ} \mathrm{F}\right)$

5. Specific heat of propellent

6. Co-efficient of expansion of completed formulation of non-volatile concentrate and propellent (giving head space requirements)

7. Determination of flammability of product

8. $p \mathrm{H}$ of product

9. Density of product

10. Determination of toxicity

a. Review of literature on various ingredients

b. Confirmation of literature reports by :

1. Mist chamber tests

2. Shock or massive-dose type topical application

3. Chronic topical application

4. Diet tests

5. Skin sensitivity tests 
11. Effectiveness of product for purpose intended determined by commercially accepted techniques:
a. Association test methods
b. Federal specifications
c. ASTM standards
d. Bureau of Standards techniques

II. Container and Valve Components vs. Formulation.

Accelerated Aging at Laboratory Level in Actual Container with Valve as Well as Individual Components Under Pressurized Glass

1. Does product affect container?

a. Effect on internal coating, lacquer or plate

b. Effect on seam component

2. Does product affect ralve mechanism?
a. Metal components
b. Elastomeric seals
c. Plastic components

3. Performance of valve with formulated product

Product Check (1)

a. Spray characteristics

b. Spray rate

c. Valve action

III. Valve and Container Selection

1. Suitability of container to formula (See II. 2b)

2. Bursting strength of container

3. Effecting of formulation on outside finish of container

4. Suspectibility of ralve to clogging

5. Delivery rate of valve

6. Spray characteristics of valve

7. Valve attachment to dispenser

8. Syphon tube selection

9. Valve testing prior to use

10. Commercial history of containers and valres

11. Sales appeal of container and valve

12. Adaptability of valve and dispenser to other products

13. Tamper-proof seal

14. Packaging of empty dispensers (receiring cartons)

15. Packaging of filled dispensers (shipping cartons)

IV. Completed Products Use Test

1. Effectiveness of product (See Item I, II)

2. Development of instructions and label (directions and cautions)

3. Determination of odor

4. Ease of operation

5. Possible adver:se effects on materials in home

6. Flammability hazards

7. Test pack for obtaining storage data at various temperatures and various positions of container during storage

a. Effect on component parts of container and ralre

b. Changes in wressure characteristics of product

c. Changes in odor

d. Changes in color

e. Changes in $\mathrm{pH}$

f. Effect on valve of intermittent spraying

g. Effect of tendency to leak

h. Effect on delivery rate

i. Possible crystallization in expansion chamber

8. Determination of products not exclusive of manufacturing cost

V. Manufacturing

1. Bill of material

2. Filling processing procedure

3. Quality control procedure

a. Raw materials

b. Processing

c. Finished product

4. Manufacturing cost

VI. Regulatory Considerations

1. United States Department of Agriculture-Insecticide, Fungicide and Rodenticide Act. (Also State Acts) 
2. Bureau of Explosives, Association of American Railroads and Interstate Commerce Commission

3. Food and Drug Administration-Federal Food, Diug and Cosmetic Act. (Also State Acts)

4. State and Municipal regulations

Reported by the Check List Sub Committee, June, 1952

Adopted by the Scientific Committee, June, 1952.

\title{
AEROSOL DIVISION
}

\section{CHEMICAL SPECIALTIES MANUFACTURERS ASSOCIATION, ING,}

\author{
50 East 41st Street, New York 17, N.Y.
}

\section{C.S.M.A. AEROSOL GUIDE}

\section{MINIMUM FILLS}

Minimum Commercial filling of Self Pressurized Packages offers many problems. Special committees of C.S.M.A. are constantly studying these problems. There will be occasional additions to this list. The following were recommended by the Commercial Practices Committee and adopted by the Aerosol Division.

(Originally published in the Proceedings of the 3sth Midyear Meeting of the C.S.M.A., Page 53, with revisions passed May 18, 1953, May 21, 1956 and May 22, 1957)

RESOLVED, That the following size packages are recommended for use of aerosols or pressurized products: namely, insecticides, room deodorants, and artificial snow, having no greater than $20 \%$ non-volatile materials in the formulation to contain a label contents, not under 6 ounces (aroirdupois).

1. American Can size $211\left(2-11 / 16^{\prime \prime}\right)$ diameter by $413\left(4-13 / 16^{\prime \prime}\right)$ body height.

2. Continental Can Company dome style can, size $211\left(2-11 / 16^{\prime \prime}\right)$ diameter by $413\left(4-13 / 16^{\prime \prime}\right)$ body height.

3. Crown Can size $211\left(2-11 / 16^{\prime \prime}\right)$ diameter by $413\left(4-13 / 16^{\prime \prime}\right)$ body height.

4. Continental Can concave style, size $211\left(2-11 / 16^{\prime \prime}\right)$ diameter by 413 $\left(4-13 / 16^{\prime \prime}\right)$ body height.

5. Crown Can size 214 (27/8") diameter by 411 (4-11/16") body height.

RESOLVED, That the following size packages are recommended for use of aerosols or pressurized products : namely, insecticides, room deodorants, and artificial snow having no greater than $20 \%$ non-volatile materials in the formulation, to contain a label contents, not under 6 ounces (avoirdupois).

1. American Can dome or flat top style, size 202 (21/8") diameter by $314\left(3 \% 8^{\prime \prime}\right)$ body height.

2. American Can size $202\left(2-2 / 16^{\prime \prime}\right)$ diameter by $406\left(4-6 / 16^{\prime \prime}\right)$ body height.

3. Crown Can tall style, size 202 (21/8"') diameter by $411\left(4-11 / 16^{\prime \prime}\right)$ body height.

4. Continental Can dome style, size 202 (21/8") diameter by $314\left(37 / 8^{\prime \prime}\right)$ body height.

5. Continental Can concave style, size 202 (21/8") diameter by 314 (37/8") body height.

6. Continental Can size $202\left(2-2 / 16^{\prime \prime}\right)$ diameter by $406\left(4-6 / 16^{\prime \prime}\right)$ body height. The following cans to contain a label contents, not under specified weight:

1. American Can size $202\left(2-2 / 16^{\prime \prime}\right)$ diameter by $214\left(2-14 / 16^{\prime \prime}\right)$ body height. Not under 3 ounces (avoirdupois).

2. Continental Can size $202\left(2-2 / 16^{\prime \prime}\right)$ diameter by $214\left(2-11 / 16^{\prime \prime}\right)$ body height. Not under 3 ounces (aroirdupois).

3. Continental Can $211\left(2-11 / 16^{\prime \prime}\right)$ diameter by $510\left(5-10 / 16^{\prime \prime}\right)$ body height. Not under 14 ounces (aroirdupois).

4. American Can $211\left(2-11 / 16^{\prime \prime}\right)$ diameter by $604\left(6-4 / 16^{\prime \prime}\right)$ body height. Not under 16 ounces (aroirdupois).

5. Continental Can $211\left(2-11 / 16^{\prime \prime}\right)$ diameter by $604\left(6-4 / 16^{\prime \prime}\right)$ body height. Not under 16 ounces (avoirdupois). 
The above is as reviewed and approved September 2.5, 1956 by the Administrative Committee, Aerosol Division, at a meeting held in Osterville, Mass.

Amendments voted Mar 20, 1957 by the Administrative Committee, Aerosol Division, at a meeting held in Chicago, ill.

Copyright 1957 .

Chemical Specialties Manufacturers Association, Inc.

Minimum Fills

C.S.M.A., June 1957

\section{AEROSOL DIVISION}

GHEMICAL SPECIALTIES MANUFACTURERS ASSOCIATION, INC.

50 East 4lst Street, New York 17, N.Y.

\section{C.S.M.A. AEROSOL GUIDE}

\section{GLOSSARY OF TERMS USED IN THE AEROSOL INDUSTRY}

\section{(Tentative)}

Active Ingredient-component of an aerosol formulation that produces the specific effect for which the formulation is designed.

Aerosol-a suspension of fine solid or liquid particles in air or gas, as smoke, fog, or mist. As defined by the Department of Agriculture, 100 percent of the particles in an insecticiclal aerosol spray must have a diameter less than 50 microns and $80 \%$ of the particles must have a diameter less than 30 microns. Aerosol Insecticides Storage Test-tentative official method (sponsored by CSIIA) for determining storage characteristics of aerosol insecticides.

"Aerosol" Product-self contained sprayable product in which the propellent force is supplied by a liquefied gas. Includes space, residual, surface coating, foam and various other types of products but does not include gas-pressurized products such as whipping cream. The term aerosol as used here is not confined to the scientific definition.

Aerosol Test Method for Flying Insects-official bio-assay method (sponsored by CSMA) using houseflies and O'TA.

Auxiliary Solvent-liquid material used in addition to the primary solvent. Generally used to replace part of the primary solvent to produce some specific effect or as a matter of economics.

Chemical Attack-chemical reaction or solvent effect, causing failure or deterioration of plastic and rubber parts, or'ganic coatings, metals, or lithography involved in the complete package.

Compatibility-broad term meaning that the rarious components of an aerosol formulation can be used together without undesirable physical or chemical results.

Concentrate-a basic ingredient or mixture of ingredients to which other ingredients, active or inactire, are added.

Container-netal, glass or plastic shell in which an aerosol formulation is packaged.

Corrosion-chemical alteration of the metal parts of container or valve. May lead to package failure and/or product deterioration.

Cosolvent-solvent used to improve the mutual solubility of other ingredients.

crimp-one operation by which the valve may be permanently seated in some aerosol containers.

Density-weight of a given volume of material at a specified temperature.

Delivery Rate-weight of mixture discharged from dispenser per unit of time at a specified temperature. Usually expressed as grams/second at $80^{\circ} \mathrm{F}$.

Dispenser-metal, glass, or plastic shell with valve from which an aerosol or pressurized formulation is dispensed.

Eductor Tube-tubing connecting the lower portion of container or dispenser with valve. Sometimes miscalled "syphon tube" or "dip tube".

Foam Product - aerosol formulation containing a solution or emulsion which is dispensed in a highly expanded fluffy form by a liquefied gas propellent.

Head Space-volume in upper portion of dispenser not filled with liquid contents. Usually expressed as percent of total volume of dispenser at a specified temperature.

High Volatile Ingredients - see Volatile Ingredients. 
Inert (or Inactive) Ingredient-component of an aerosol formulation that does not contribute to the specific effect of the formulation. In some cases, may be quite arbitrarily defined. For example, with insecticides, only the propellents are considered as iner't ingredients.

Low Volatile Ingredients-see Nonvolatile Ingredients.

Metering Tatre-ralve that deliver's a definite, limited amount of aerosol formulation each time the ralve mechanism is operated.

Tonvolatile Ingredients-components of an aerosol formulation with a rapor. pressure less than atmospheric pressure $(>14.7 \mathrm{lbs} / \mathrm{sq}$. in. absolute) at a temperature of $105^{\circ} \mathrm{F}$. Sometimes called low volatile components.

Official Test Aerosol, or OTA-a standard insecticide dispenser and formulation prepared by CSMA for use in Official Aerosol Test Method for Flying Insects.

Particle Size-diametel of solid or liquid particles expressed in microns (thousandths of a millimeter).

Pressure-internal force per unit area exerted by any material. Since the pressure is directly dependent on the temperature, the latter must be specified. The pressure may be reported in either of two ways :

(A) Absolute pressure - the total pressure with zero as a reference point. Usually expressed as pounds per square inch absolute (psia).

(B) Gage pressure-the pressure in excess of atmospheric pressure. Under standard conditions at sea lerel, the numerical value of the absolute pressure is 14.7 higher than that of the gage pressure. The gage pressure is usually expressed as pounds per square inch gage (psig).

Product Deterioration-chemical reaction or physical change within or betreen components considered compatible in original formulation. Mas be due to time or temperature of storage or other factors.

Product Formulation-specific formulation of completed product, including propellent(s). Usually expressed as weight/weight $(\pi / w)$ percent.

Propellent-liquefied gas with a rapor pressure greater than atmospheric pressure $\left(>14.7\right.$ lbs. pel sq. in. absolute) at a temperature of $105^{\circ} \mathrm{F}$.

Solubility - the extent to which one material will dissolre in another. Generally expressed as percent by weight. May also be expressed as percent by volume or parts per 100 parts of solvent by weight or rolume. The temperature should be specified.

Solvent-liquid part of an aerosol formulation used to dissolve solid or other liquid parts.

Spray-the dispersed discharge from an aerosol-type dispenser in the form of small droplets or particles. Does not include foam-type discharge.

Spray Coating-aerosol spray product for surface application, which leares a residual clear or pigmented finish for protective ol' decorative purposes.

stabitity-abilits of a product to maintain its original characteristics over extended storage periods, under normal variations in temperature conditions.

Synergist-an auxiliary material that has the property of increasing the effect of the actire ingledient eren though it may have little specific actirity itself.

NOTE: In the case of insecticides, synergists are considered as active ingredients.

Talve-mechanism for discharging products from aerosol-type dispensers.

Tiscosity-internal resistance to flow of a solid (powder), liquid or gas at a specified temperature. A definite measurement for the consistency of a material.

Tolatile Ingredients-components of an aerosol formulation with a vapor pressure greater than atmospheric pressure ( $>14.7$ lbs. per sq. in. absolute) at a temperature of $105^{\circ} \mathrm{F}$. Sometimes called high volatile components.

Reported by the Sub-Committee on Definitions and Terms, April 25, 1956.

Adopted by the Scientific Committee, May 20, 1956.

Adopted by the Administrative Committee of the Aerosol Division, May 20, 1956.

Copyright 1957.

Chemical Specialties Manufacturers Association, Inc.

Glossary and Terms (2) C.S.M.A., June 1957 
Mr. Howard: There is one area that, I believe, should receive the attention of the aerosol industry - that is in the declaration of quantity on the individual containers. We find many different marking methods used, some quite confusing.

Mr. Hallorv: Should a consumer expect to be delivered by an aerosol container product in the amount labeled on the container?

Mr. Peterson: If you are referring to the efficiency of the aerosol, the answer would be yes. Most manufacturers overpack.

Mr. Howard : Is temperature a factor?

Mr. Peterson: Yes, but there should be no difficulty at normal room temperatures.

\section{PHILOSOPHY OF LAW ENFORCEMENT}

\section{By Major P. W. Crews, Executive Officer, Department of State Potice, State of Virginia}

Law enforcement in the United States is based on the English system. Yet, until the middle of the 18th century, England was the only European country without an organized police force. This is difficult to understand, but a glance at existing conditions can help to explain it.

The British, even then, were fierce champions of individual liberties and felt that a police department would seriously interfere with these. Continental nations were possessed with large standing armies, which were not necessary to England because of the protection of the English Chanmel and the nation's large fleet. Large parts of these standing armies were converted into police organizations and the soldier-policeman, with his highhanded methods, left much to be desired.

As late as the middle of the 16th century, Oliver Cromwell formed a type of police department, but it was so unpopular that it soon died. Arrest was first made through "hue and cry" methods whereby an entire community came out under arms to apprehend a thief. Later a very harmful system of thief taker's was established whereby private citizens were given rewards by the Crown for apprehending criminals. Some of the most vicious criminals, wise in the ways of the criminal, turned to this form of work although they had no official standing. Rewards were giren on a sliding scale according to the seriousness of the crimes, so lesser criminals were largely ignored. So were the prominent criminals because the thief takers were a fraid of them.

The first British police, as we know police today, were the Bow Street Runners, established in 1749 and given official sanction 15 years later. This organization did a remarkable public relations job in selling itself to the public and this job has been successful and continuous, as witness the respect the British today hold for law and order.

The main tenets of the faith, which hold good today, were that an officer's personal conduct must be above reproach, that he must be an 
impartial protector of the people, and that his main reason for being was the prevention of crime rather than the harassing of citizens.

Yet these concepts were not so very far remored in time from ordeal by combat in which the accused and accuser fought it out, ordeal by fire in which a person was burned and declared guilty if his burns did not heal within a stated time, and ordeal by water in which an accused was bound, flung into water, and declared guilty if he sank.

In short, we might say that the philosophy of law enforcement is the conforming of the behavior of groups and individuals to those restrictions imposed by the society in which they live and of which they are a part. At the same time, the rights of the indiridual must be sacredly observed.

During the memory of many of us, there have been two events which have seriously affected police work. One dealt a hard blow to the profession and the other created a difficult problem.

The first was national prohibition. Ulysses S. Grant, as a President, had little to say, but he did say that he knew of no method so effective in achiering the repeal of unpopular laws as their stringent enforcement.

Whatever our feeling might be on the use of beverage alcohol, no one can deny that prohibition was unpopular. 'The police, charged with enforcing this unpopular law, were the butt of public scorn, derision, and even hatred. Good officers left the profession rather than be subject to this widespread disapproval, and those who filled the ranks too often succumbed to temptation in the form of bribes and political pressure.

This heritage has been, and is still to some extent, an "Old Man of the Sea" to the police. Once wholesale disrespect for the law is bred, it takes generations to eradicate the harm.

The difficult problem came with the automobile, which struck us with an unprecedented impact. As late as 1900, only 60 years ago,

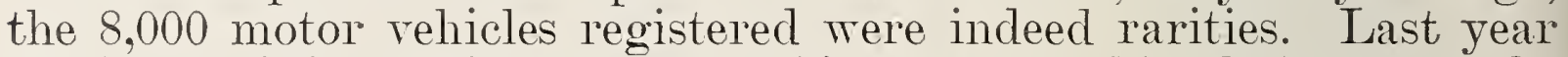
the $701 / 2$ million registered automobiles not only killed 37,800 people, but caused $11 / 2$ million disabling injuries and an economic loss approaching $\$ 6$ billion. 'This staggering tragedy is an almost direct result of wholesale public indifference; and thereby lies the police problem.

'The police must encounter daily hordes of people who are violating laws designed to prevent this, yet who feel they are not actually performing a criminal act. 'This attitude by people with no arrest experience and who hold respected places in society makes the enforcement of traffic laws difficult and has somewhat revised the philosophy of law enforcement.

The feeling that traffic laws are relatively unimportant is demonstrated in the utterly unreasonable sympathy for violators which is reflected in juror and witness action. Thus, the overall attitude poses a public relations problem for police, brings them often in public disfavor, and heightens the difficulties of proper enforcement.

Some 90 percent of a police officer's public contacts are with people who are law abiding or who are involved in a traffic violation which, though it might be dangerous, cannot be classified as deliberately vicious. Yet we must remember that the police do not, as a rule, deal with people who are at the time emotionally normal. They are re- 
senting arrest or what they might term undue interference, they are worried, they are in pain, in trouble, in sorrow, or otherwise disturbed.

A good officer must recognize this and regulate his conduct accordingly. There is no point in arousing any more unpleasantness than is absolutely necessary. The laws governing the eviction of a trespasser, for example, give the property owner only the right to use such force as is necessary, and no more, after other methods have failed. 'The officer' should strive to keep unpleasantness to the barest minimum consistent with bringing the immediate situation to a conclusion.

In expert on police relations (Dan Hollingsworth) states that about 75 percent of the complaints directed a gainst police officers arise not from the officers' lack of technical knowledge as to their work, but from simple lack of ability to get along with people to one degree or another. It is an old saying, but "the iron hand in the relvet glove" theory still holds true.

The warning of violators, since the adrent of the automobile, now plays an important part in lan enforcement. In the old days, a "beat" officer administered a warning in the nature of telling someone to move on, to watch his step, or not to do that again. With the traffic violator, it is a different matter.

To be strictly technical, an officer viewing an offense should make an arrest. However, some 150 years before the birth of Christ, the Roman dramatist Terence said, "Rigorous law is often rigorous injustice." We feel the same holds true for too rigorous law enforcement.

There can be no set rules laid down for demarcation between the issuing of a warning and the writing of a summons. Each case must be decided on according to the circumstances. If the violation is not excessive and the conditions of traffic, the road, the rehicle, and the driver do not worsen it, a strong point should be scored for a warning. The attitude of the driver should also come in for consideration.

We camnot deny that we are governed by more rules and regulations in connection with our automobiles than in almost anything else in our lives tolay. While it cannot be condoned, it is not a difficult matter for a driver to inadvertently miss a sign, allow his speedometer to creep a bit beyond the limit, or forget to signal. 'The driver' who is out to get away with what he can is a different breed.

In weighing the difference between a warning and a ticket, some thought might be given as to whether a court is going to convict. It is certain to happen from time to time, but bringing a person into court only to see him dismissed is not good police public relations. We must remember that judges are often going to take account of human failings in such matters where deliberate intent, damage, or harm, and great danger are not present.

Many police officers underestimate the importance of proper attitude and proper presentation of evidence in court. On arrest, the oflicer should firmly fix the circumstances in his mind, resorting to notes if necessary. He should bring the matter to the attention of the prosecuting attomey and confer with him if the case is serious enough for the attention of this official.

'The attitude of a police officer who is testifying should be correct and strictly impartial. He should be neatly dressed, refrain from any conduct which might dram molue attention while he is waiting 
to testify, and should express no disagreement with the court. It is most important that he remember that he is there only to testify as to the facts as he sees them and not to gire opinions or act as an assistant prosecutor. A thorough grounding in the laws of evidence is most desirable.

If an officer or any other witness adheres absolutely to the truth as he interprets it and does not try to answer questions when he does not know the whole truth, he camnot be shaken by the best defense lawyers.

An enforcement problem that is heard of more than it actually occurs is that of false arrest. I feel, personally, that an officer has :mple safeguards against such a charge, which is often brought unjustly and through resentment on the part of the arrestee.

Without a protective warrant, ail officer must view a misdemeanor or have reasonable grounds to believe that a felony has been or might be committed to make an arrest. Note that word "reasonable", for it is the background of nearly all civil litigation. "Reasonable" here simply means what an average person might do under certain circumstances. Of course, jury interpretations will vary, but this must be the rule of thumb.

So arrest, in connection with false arrest, boils down to plain common sense and proper observation. The law gives an officer rather broad leerray, since it is realized that an officer camnot always conduct an investigation before he makes an arrest. He must often make his decision in a matter of seconds, and thus, in the absence of sheer spite or malice or blatant stupidity, an action for false arrest normally will not lie.

In any police organization, it is most desirable to achieve uniformity of enforcement methods. This can be brought about through the firm establishment of policies at the top in keeping with the laws of the State or community, through administrative conferences and peliodic retraining courses which reach all levels.

In passing, I might add that a great breeder of public dissatisfaction with a police department can spring from lack of uniformity in law enforcement procedures. Previously we discussed policies that might govern the difference betreen warnings and arrest. In striving for uniformity, the issuance of warnings must be kept strictly to those cases in which the officer is satisfied the violation was inadvertent, that little, if any, immediate danger was present, or that there were drastic extenuating circumstances.

Since Virginia is a "bridge" State on the Eastern Seaboard and since the State attracts a large number of tourists, we are constantly exposed to what might be termed the "tourist traffic philosophy". The risitor appears to feel that, because he is a risitor, he should be given special treatment and violations should be condoned.

Others, usually those from Statas having "reasonable and proper" speed laws, ignore the fact that Virginia's limits are absolute and feel they can set their own limits when they feel conditions justify them.

A third type convinces himself, upon arrest, that he is a victim of "speed traps" through which residents may pass with immunity but which are revenue gainers as far as nonresidents are concerned.

Let me explain briefly our policy here. Our limits are plainly posted along the highway, and these include warning signs for motorists approaching any zones of speed deceleration. Other conspic- 
uous and frequent signs adrise that our highways are checked with radar. Our troopers are trained to give tourists all aid, courtesy, and advice consistent with impartial and realistic law enforcement. Radar devices are not placed in open view by the roadway, since they present a marked psychological influence when a motorist has no way of knowing where he might encounter one.

"Speed trap" accusations are common throughout the Southern States and, of course, arise also in other States. I bona fide speed trap might be compared to the legal defense of entrapment. Entrapment consists of influencing or othervise causing someone to commit an offense he did not originally contemplate. The manipulation of signs, the absence of signs, and the swiftly changing speed limits all can constitute speed traps, but such is not the case in our State.

Great strides have been made today in orercoming the adrerse public philosophy toward law enforcement through the recruiting of high type personnel for police work and the thorough and continuous training of them.

We seek public respect and feel strongly that a violator who is arrested but who can be made to understand the error of his ways is a potential friend of law enforcement gained without any type of favoritism. On the other hand, the violator who is curtly handed a ticket along with a sarcastic remark is going to resent law enforcement, no matter how richly he deserves the ticket.

In this connection, we point with considerable pride to our file of complaints from those who have been arrested. Those of a commendatory nature far outnumber the uncomplimentary ones.

In summing up, the present public philosophy concerning law enforcement, which I feel is consistently and steadily undergoing a change for the better, is an understanding that laws and restrictions imposed by society for its betterment and protection are necessary. However, this attitude can undergo a marked change when the individual runs afoul of the law. He appears to ignore the fact that laws are enacted by his elected representatives and that it is the police officers' job to enforce them impartially. This attitude is well summed up by the British poet, A. E. Housman, who said:

The laws of God, the laws of man,

He may keep that will and can;

Nor I : let God and man decree

Laws for themselves and not for me.

And to quote another British poet, Sir TV. S. Gilbert, "A policeman's lot is not a happy one."

In closing, I will qualify this remark by saying that a policeman's lot is not always a happy one. It can be, and has for me often been, a source of deep satisfaction and pride.

\section{REPORT OF THE COMMITTEE ON NOMINATIONS AND ELECTION OF OFFICERS}

\section{Presented by RoBer'T Wilumars, Chaiman, County Sealer of Weights and Measures, Vassau County, New York}

Under the rules of general procedure of the Conference, the Director of the National Bureau of Standards, Dr. A. V. Astin, is the 
President of the Conference, and the Chief of the Office of Weights and Measures, Mr. William S. Bussey, is the Secretary of the Conference, both ex officio.

In selecting the men for offices, as presented in this report, consideration was given by the committee to sereral factors, such as attendance records, geographical distribution, Conference participation, and interest in promoting weights and measures.

The Nominating Committee submits the following report, nominating for office for the 46th National Conference on Weights and Measures, and to serve during the ensuing year or until such time as their successors may be elected:

For Chairman: Rollin E. Meek, of Indiana.

For Vice Chairmen: J. IV. D. Harver, of Georgia; H. D. Robinson, of Maine; A. D. Rose, of Kern County, California; J. D. Whaton, of Dallas, Texas.

For Treasurer: C. C. MoRgax, of Gary, Indiana.

For Chaplain: R. WV. Searles, of Medina County, Ohio.

For members of the Executive Committee: All officer's, and, in addition, E. W. Bucklin (Montgomery County, Maryland); H. H. Houstox (Colorado); Nathas Kalechman (Hartford, Connecticut); H. R. Kexnelu (West Virginia); J. H. Lewis (Washington); J. F. McCartiy (Boston, Massachusetts); William Milier (Passaic County, New Jersey); J. J. Powers (Philadelphia County, Pennsylvania); Johx Seres (Lackawamna, New York); Delbert T'alrath (Montana).

RoBer' WiLlians, Chairman

Nallis Berritan

F. M. Greene

S. H. Christie, JR.

C. H. STENDER

II. M. TURRELL

L. E. WITT

(The report of the Committee on Nominations was adopted by the Conference and the officers were elected by (1) a motion by Mr. Cichowicz, adopted unanimously by voice rote, to close the nominations, and (2) the unanimous adoption by roice vote of a motion by $\mathrm{Mr}_{\mathrm{r}}$. Jackson to the effect that the Conference Secretary be instructed to cast a single ballot for the nominees selected by the committee.)

\section{REPORT OF COMMITTEE ON SPECIFICATIONS AND TOLERANCES}

\section{Presented by C. L. JAcksor, Chaiman, Chief, Division of Economic Practices, Department of Agriculture, State of Wisconsin}

In order to afford the opportunity for oral presentations to the committee and in order that the committee might discuss in detail the matters on its agenda, an interim meeting of the committee was held in Madison, Wisconsin, on January 11 and 12, 1960. During the open session of this meeting, representatives of business and industry and reights and measures officials presented themselves before the committee and made known their recommendations. In addition to this meeting, consultation among committee members and between the committee and weights and measures officials, industry representatives, and others has been carried on by correspondence. 
A tentative report was prepared by the committee and this was distributed widely. At an open hearing held on the afternoon of Monday, June 6, at the headquarters hotel, the tentative report was offered for' discussion, item by item. 'The hearing was well attended and numerous comments were made and suggestions were offered relative to the tentative proposals of the committee. 'These matters were further considered at an executive session of the committee following the open hearing.

Presented below are the final recommendations of the committee, together with appropriate comments, grouped under the code hearlings as found in Handbook 44 - 2 Edition, as amended through the 4 th National Conference.

\section{CODE FOR SCALES}

1. Tolerance at Zero.--The committee, at the suggestion of the Scale Manufacturers Association, recommends the formal adoption, for addition to Appendix II of Handbook 44, of the following interpretation:

TOLERANCES AT ZERO LOAD.-The impracticability of requiring perfection on zero return of a scale is recognized by experienced officials. Notwithstanding this, no specific tolerances are prescribed in the scale Code on the performance of a scale with respect to its repeatabilits of zero-load indication. This omission is deliberate because the inclusion of a numerical criterion for this element of scale performance is considered inadrisable; a numerical tolerance at zero load might be construed as providing legal justification for scales in commercial service not being maintained in balance.

The gorerning principle, which might be accepted as an enforcenent guide, shall be that a scale that will not return to a correct zero indication within reasonably narrow limits cannot be considered satisfactory for commercial serrice. Any such failure of acceptable repeatability indicates faulty design or construction, or the need for repairs.

(This matter is discussed in detail in National Bureau of Standards Handbook 37. Testing of Weighing Equimment.)

(Item 1 of the committee report, on motion of the chairman and seconded from the floor, was adopted by the Conference by voice rote.)

2. Maximum Tatue of Minimum Graduated Interials on Certain Classes of Large-Capacity Scales.-This matter has been given much attention by the committee and by the Scale Manufacturers Association since 1955. It has been generally agreed that the requirements presently contained in the code are inequitable and, accordingly, unsatisfactory. The committee acknowledges, with gratitude, the service rendered by the Scale Mamufacturers Issociation and the willingness of representatives of that organization to contribute their efforts toward the solution of this problem. The committee now tentatively recommends the following amendments to the Scale Code of NBS Handbook 44:
Amend performance paragraph P.1.2.1. to read as follows:

P.1.2.1. GENERAL.-The maximum maintenance SR, except as prescribed in P.1.2.2., P.1.2.3., P.1.2.4., X.1.2.5., and P.1.2.6., sball be the value of two of the minimum graduated intervals on the weighbean, or 0.1 percent of the nominal capacity of the scale, or' $f 0$ pounds, whicherer is least. 'The maximm acceptance $\mathbf{S R}$ shall be one-half the maximun maintenance sR.

Amend regulation paragraph R.4.6. to read as follows: 
R.4.6. ON CRANE SCALES.-The value of the minimum graduated interval on the weighbeam elements and on the reading-face elements of a crane scale shall be not greater than 0.2 percent of the nominal capacity of the scale.

Delete regulation paragraphs R.4.6.1. and R.4.6.2.

Amend regulation paragraph R.4.7. to read as follows:

R.4.7. ON LARGE-CAPACITY SCALES OTHER THAN LIVESTOCK, ANIMAL, VEHICLE, WHEEL-LOAD, AXLE-LOAD, HAND-OPERATED GRAIN HOPPER, CRANE, AND RAILWAY TRACK SCALES.-The value of the minimum graduated interval on the main weighbeam elements, on the tare weighbeam elements, and on the reading-face elements of large-capacity scales other than livestock, animals, vehicle, wheel-load, axle-load, handoperated grain hopper, crane, and railway track scales shall be not greater than 0.1 percent of the nominal capacity of the scale, or 1/4 pound, whichever is greater, and in any case not greater than 50 pounds.

Delete regulation paragraph R.4.7.1. and R.4.7.2.

\section{DISCUSSION OF FOREGOING ITEM}

Mr. JACKson: This has been a very involved study extending, according to my information, over the past 5 or 6 years. The present committee has not had the full benefit of this entire discussion. So that we all may understand the matter thoroughly, I am going to ask that Mr. Bussey give us some background information .

Mr. Bussey: As Mr. Jackson said, this matter has been under consideration and under study for several years. The principal point at issue at this time is that, previous to the adoption of the present code language, there was quite a large range of large-capacity scales for which no minimum value graduations were specified. In an attempt to cover such scales, the present paragraphs were inserted, and, in the insertion of these paragraphs, we have developed a situation whereby a different minimum graduation value is required for scales in the same category, the only difference being that one is equipped with a weighbeam and one is equipped with an automaticindicating mechanism. After much additional study and consideration, the committee has come up with the recommendations offered today. These will require the same minimum graduation interval on a scale in a certain category, whether it is equipped with a dial, a weighbeam, or any other indicating element.

This is an attempt to get a consistent, defensible, and enforceable set of regulations in this field. One question that was raised was that the minimum values that are now prevalent on certain beam scales could be increased under this regulation and that it might thus encourage a lower quality scale. To prevent that, the SR requirements are modified.

Mr. SANDers: The Scale Manufacturers Association has withdrawn practically all objection to these amendments. We do, however, feel that wheel-load and axle-load scales should be removed from the paragraph that requires 20 -pound intervals. If this were done, new paragraph R.4.7. would apply and minimum graduated intervals of 0.1 percent of the nominal capacity would be required. Our reasons are that smaller intervals bring about both higher initial costs and slower weighings. As we see it, since these scales cannot be used commercially, 20-pound intervals should not be required.

(Item 2 was adopted by unanimous consent.) 
3. Committee Interpretation of Scale Specification S. 10.-In response to a request made during the 44th National Conference, the committee prepared and distributed an interpretation of specification S.10. VALUE GRADUATIONS IND GRADUA'TED INTERVAIS with respect to its application to prepackaging scales of the selector type (G-D.19.) designed to record, by digital means, weight values to the nearest 0.01 pound and corresponding money values. In order to clarify the intended meaning of the cocle and to eliminate the necessity for this interpretation, the committee recommends that specification paragraph S.10. be amended to read as follows:

S.10. VALUE GRADUATIONS, GRADUATED INTERVALS, RECORDED TALUE REPRESENTATIONS, AND IIGITAL TALCE INDICATIONS.

S.10.1. TALUE GRADUATIONS AND GRADUATED INTERVALS.-The value of the graduated intervals representing money values on a computing scale having value graduations shall be (a) not more than 1 cent at all unit prices of 30 cents per pound and less and (b) not more than 2 cents at all higher unit prices. However, special graduations defining 5 -cent intervals may be employed, but not in the spaces between regular graduations. Talue figures and graduations shall not be duplicated in any column or row on a graduated chart.

S.10.2. RECORDED TALUE REPRESENTATIONS AND DIGITAL VALUE INDICATIONS.-Any recorded money-value representation or digital moneyvalue indication on a computing scale shall be in combination with a weight representation or indication, and the associated money-ralue and weight representation or indication, as the case may be, shall be in accurate mathematical agreement to the nearest 1 cent of money ralue.

(Item 3 ras adopted by unanimous consent.)

4. Prepackaging Scales.-There apparently has been some confusion about the application of the specification paragraphs directed to prepackaging scales, and the code has not been explicitly clear about the recorded representations representing quantities on labels for packages. It should be kept in mind that, when a prepackaging scale prints weight values and money values directly on a package label, such printing must be so as to meet all legal requirements for package marking. To improre this situation, the committee recommends that the two requirements now included under specification paragraph S.13. be set forth as sepalate paragraphs and that a new nonretroactive requirement covering the recorded representations of prepackaging scales be added, by amending specification paraglatph S.13. to read as follows:

\section{S.13. PREPACKAGING SCALE.}

S.13.1. MARKING.-A prepackaging scale shall be conspicuously marked on the operator's side and on the opposite side with the words "For Prepackaging Use Only" or with a similar and suitable statement. A prepackaging scale so marked shall be exempt from the requirements of S.11. and, if "customer's" weight indications" are not provided, from the requirements of S.12. that relate to customer's' weight indications.

S.13.2. BALANCING DEVICE.-A prepackaging scale may be equipped with an auxiliary, manually-operable balancing device if this is so designed that it will operate only in a backward direction (that is, in the direction of underregistration) with respect to the balance condition established by the primary, mechanically-operable balancing device of the scale.

S.13.3. LABEL RECORDER.-Effective July 1, 1961, a prepacliaging scale that, as a part of the scale itsclf or of any auxiliary device attached thereto or used in connection therewith, produces a recorded representation of either the weight value or money value, or both the veight value and money value, on the label of or for a package shall be so designed that any veight value and 
any money value recorded shall be recorded digitally and shall be of such size, style of type, and color as to be clear and conspicuous on the label.

(Item $t$ mas adopted by unanimous consent.)

5. Prepactaging Scales-Tare Graduations Back of Zero.-The matter of tare graduations back of zero on prepackaging scales was retained on the committee agenda, as requested by representatives of scale manufacturers, at the $t$ th Tational Conference. Oral comments with respect to this point also were made by representatives of the scale industry during the Madison meeting.

There is no doubt that, if graduated intervals forward of zero and those in back of zero have different values, confusion could result and this could cause incorrect quantity statements on packages. It is claimed that an arbitrarily numbered series of graduations back of zero offers convenience to the scale user in identifying a tare setting for a particular type of package. 'This fact is acknowledged by the committee, but the point is clear that resulting errors from nonuniformity of containers and rrapping material and from unnecessary confusion in the ralues of the graduated intervals are too great a sacrifice for any admitted convenience.

The committee is convinced that the principle of graduations back of zero being uniform with those forward of zero on prepackaging scales is sound and that the adrantages with respect to this principle far outreigh any disadrantages.

In order to provide complete clarification of this matter, it is recommended that a new nonretroactive paragraph S. 13.4. be added to the Scale Code, as follows:

S.13.4. GRADUATED INTERVALS.-Effective July 1, 1961, the weight values represented by individual graduated intertals on a prepackaging scale shall be uniform throughout the entire reading face, and these ueight walues shath be not greater than the values of any increments or graduated intertals of any recorded representation of such scale.

\section{DISCUSSION OF FOREGOING ITEM}

Mr. KExdall: I would like to ask as to the acceptability under this amendment of a prepackaging scale that prints digitally the weight on the plus side of zero, but that has risible analog weight representations with greater minimum ralues, on both the plus and minus sides of zero.

Mr. Jackson: Tould either Mr. Bussey or Mr. Jensen anstrer Mr. Kendall?

Mr. Jexsex: I believe that a scale such as you describe would not conform to this proposed paragraph.

Mr. SAxders: This is a new proposition. The scale industry has not had an opportunity to study it. Tre have urged that we be permitted to provide a different series of graduations in back of zero from those on the plus side of zero. Tre ask that this matter be delayed for further study.

Mr. J. T. KEN more that consideration of this matter be postponed for one year.

(Mr. Kennedy's motion for postponement was seconded from the floor.)

Mr. JACKsoN: This is not a new matter. The committee has maintained throughout the years that the minimum graduated intervals 
on all elements of a prepackaging scale should be uniform. This principle now is being set forth formally as a code amendment at the recommendation of sereral scale manufacturers.

(The Chairman called for a roice vote on Mr. Kennedy's motion and ruled that the motion was calried. This was followed by a motion for reconsideration, which was duly seconded and adopted by standing vote. On reconsideration, Mr. Kennedy's motion for postponement was defeated by standing vote33 ayes, 63 nays. The amendment then was adopted by standing rote-69 to 31.$)$

6. Livestock and Animal Scales-The apparent inequity of the current legal requirements with respect to the use of livestock and animal scales is brought frequently to the committee's attention. Under current practice, all livestock may be weighed commercially on scales having minimum graduations of or pounds. Although the scale Code of Handbook 44 provides for animal scales (D. 20., R. 4.3., et al.) with a graduated interval of 1 pound, relatively few yards operate such scales. As a result. loads of livestock ranging from over 20,000 pounds down to 200 pounds, and eren less, are weighed on scales with 5 -pound graduated intervals. The committee feels very strongly that steps should be taken to correct this situation. It recognizes, however, that any amendment in the code would, in itself. have little if any influence because of the strong role played by the U.S. Department of Agriculture in the field of livestock reighing.

The committee will keep this subject on its agenda for further study, and requests the cooperation of the Tnited States Department of Agriculture and the National Association of State Departments of Agriculture in a joint effort to reach a practical and constructive conclusion.

(Item 6 was adopted by unanimous consent.)

7. Installation and Other Recommendations.-I State weights and measures official has sugerested that the committee consider the advisability of code requirements to corer installation of pit-type scales and other considerations that affect weighing accuracy. 'The committee is not disposed to recommend code amendments at this time, but it would like to hare other weights and measures officials and scale manufacturers, repairmen, and user's gire the matter careful study. If it is deemed that the handbook should include language with respect to such matters, it could be handled in any of three ways:

(1) Specific language (with legal status) could be incorporated in the code.

(2) Present language in the code could be strengthened.

(3) A new section of the code could be added under "Recommendations" that would, as the name indicates, be recommendatory only.

The committee recommends that it be retained on the committee:s agenda, and that the committee be assisted by the S'cale Manufacturers Association, weights and measures officials, and others, to the end that uniformity in the requirements of the States may be promoted.

(Item 7 was adopted by unanimous consent.)

CODE FOR LIQUID-MEISCRING DEVICES

8. Retail Devices, Minimum Detivery Indication.-. Ilthough there is required for both wholesale liquid-measuring derices and rehicletank meters a minimum delivery indication, none has been required 
for retail liquid-measuring derices. To help correct this, the committee recommends that specification paragraph S.11.1. be amended by adding a nonretroactive sentence reading, "The value of the smallest unit of indicated delivery on a retail liquid-fuel device shall not exceed 1 pint." This addition would make paragraph S.11.1. read as follows:

S.11.1. INDICATION OF DELITERY.-A retail liquid-fuel device shall be constructed to show automatically its initial zero condition and the amounts delirered up to the nominal capacity of the derice. If the nominal capacity is less than 50 gallons. this shall be conspicuousls shown on each face of the derice. The value of the smallest unit of indicated delivery on a retail liquid-fuel device shall not exceed 1 pint.

(Item 8 was adopted by unanimous consent.)

\section{CODE FOR FARII MILK TANKS}

9. Tolerances.-The committee has received a recommendation from a State reights and measures official that the tolerances on some farm milk tanks, at least the smaller sizes, be reduced. The committee recommends that this matter be retained on its agenda, and that the National Association of Dairy Equipment Manufacturers continue its study of the problem. The committee further recommends that the National Association of Dairy Equipment Manufacturers take, without delay, such steps as may be needed to bring about a reduction of the effectire cross-sectional areas of farm milk tanks to the practicable minimum, and a positioning of the gage rods as nearly as practicable in a central position with respect to the walls of the tanks.

(Item 9 was adopted by unanimous consent.)

\section{CODE FOR TEHICLE TANKS}

10. Relocation of Certain Specification Paragraphs.-It has been brought to the attention of the committee by the National Truck Tank and Trailer Tank Institute and National Tank Truck Carriers, Inc., that specification paragraphs S.1., S.2., and S.3. are presented in the code as being "applicable both to rehicle tanks used as measures and to rehicle tanks equipped with meters" when actually these paragraphs should apply only to rehicle tanks used as measures. The committee concurs and accordingly recommends the following amendments to the Tehicle Tank Code:

Amend specification paragraph S.1. to read:

S.1. STREYGTH.-A rehicle tank shall be so constructed that under conditions of normal use there will be a reasonable expectancy that excessive distortion of parts will not occur and that the unit will continue to operate as designed.

Delete specification paragraphs S.2. and S.3.

Insert, following S.10. DESIGN., new specifications paragraphs S.10.1., S.10.2., and S.10.3., as follows:

S.10.1. COMPARTAIENT DISTORTION.-The shell and bulkheads of a rehicle tank shall be so constructed that under any condition of liquid lading the will not become distorted sufficiently to cause a change in the capacity of any compartment (as determined by rolumetric test) equal to more than $1 / 2$ pint 
per 200 gallons, or fraction thereof, of the nominal compartment capacity, or to more than 1 pint, whichever is greater. ('This specitication prescribes a limit on permissible distortion only, and is not to be construed as setting up a secondary tolerance on compartment capacities to be added to the values given in paragraph T.1.)

S. 10.2. TENTING.-Effective renting means shall be provided to prevent the formation of air pockets in a compartment br permitting the escape of air from all parts of the compartment designed to be filled with liquid, and to permit the influx of air to a compartuent during discharge therefrom.

S.10.3. DOME FLANGE AND BAFFLE PLA'TES. Any dome flange extending into a compartment shall be provided with sufficient perforations or openings flush with the compartment shell to prevent any trapping of air. All baffle plates in a compartment shall be so cut away at top and bottom, and elsewhere as necessary, as to facilitate loading and mloading.

Appropriately renumber specification paragraphs S.10.1. to S.10.7.; inclusive, to become S.10.4., S.10.5., S.10.6., S.10.6.1., S.10.6.1.1., S.10.6.1.2., S.10.6.2., S.10.6.3., S.10.6.4., S.10.6.5., S.10.7., S.10.8., S.10.9., and S.10.10.

\section{DISCUSSION OF FOREGOING ITEM}

Mr. Jackson: I would like for a representative of the Office of Weights and Measures to give us an explanation of these amendmenrs. Mr. Busser: 'These paragraphs, dealing entirely with the distortion, venting, and the like of vehicle-tank compartments, have been so located in the code as to be applicable both to rehicle tanks equipped with meter's and rehicle tanks used as measures, whereas their appropriateness is only with the latter.' This recommendation simply mores the paragraphs to their proper location.

The requirements themselves were given lengthy study at the time they were placed in the corle-not cnly by this committee, but also by representatives of the American Petroleum Institute, of tank manufacturers, and of the North American Gasoline Tax Conference. The Tax Conference is ritally interested in rehicle tanks used as measures, because large portions of gasoline taxes are collected on the basis of tank-compartment measurement.

(Item 10 was adopted by manimous consent.)

OTHER CONSIDERATION;

11. Electrical, Electronic, or Magnetic Impulse-per-L nit of Indication.-The Southern Weights and Measures Association has recommended that "the committee study and make recommendation dealing. with the matter of electrical, electronic, or magnetic impulse-per-unit of indication for those reighing and measuring devices that produce a change in value indicated or recorded as a result of impulses generated by the measuring mechanism." The committee recognizes that this matter bears particular significance with respect to a new design of retail gasoline dispenser, and perhaps to other weighing and measuring devices. Such developments will continue to receive the attention of the committee and will, at an appropriate time, be brought to the attention of the Conference.

12. Suitability of Equipment.-The committee emphasized the importance of selecting commercial reighing and measuring equipment that is suitable for the service in which it is to be used, in its report 
to the 44th National Conference. Also, an amendment to regulation paragraph G-R. 3. of the General Code, designed to strengthen and expand the paragraph, was presented to and adopted by the Conference. The committee wishes again to invite special attention to this paragraph and to point out that all commercial devices should meet this criterion regardless of all other code requirements.

(Items 11 and 12 were adopted by unanimous consent.)

13. Harmonizing Handbook 44 Requirements with Change in Model Law.- With the adoption by the Conference of the amendment to section 11 of the Model Law recommended by the Committee on Laws and Regulations, the Model Law no longer includes in the category of commercial devices requiring testing for correctness those devices that are used for determining weight or measurement when the charge for the weighing or measuring service is the only relation to commercial transactions. This committee therefore recommends that the Secretary be authorized by the Conference to make such changes in the code as will bring them into conformance with this Model Law amendment.

The Model Law as adopted by this Conference thus excludes from official inspection such devices as person weighers and axle-load scales over which weighings are made for a charge.

\title{
DISCUSSION OF FOREGOING ITEM
}

Mr. R. E. Meek: How would such amendments to the handbook affect axle-load scales used by law enforcement officers for highway weight control?

Mr. Jackson: Such scales would not be affected.

Mr. Jensen: Perhaps an explanation of the change in the Model Law would clarify this situation.

In the Model Law, before it was amended by this Conference, there was included in that category described as commercial equipment and accordingly subject to the jurisdiction of the weights and measures officials the following: "all weights and measures commercially used in determining weight or measurement when a charge is made for such determination". With the adoption by the Conference of the recommendation of the Committee on Laws and Regulations, that clause was dropped from the Model Law.

It is recognized by both committees that this action by the Conference will not affect present State statutes. In the States where such devices are commercial by statutory definition, they will remain commercial until the statutes are amended.

[There was considerable more discussion on this point. Major participants in the discussion were Mr. Campbell, Mr. R. E. Meek, Mr. Wrenn, Mr. Jensen, Mr. Sanders, and the committee chairman.]

(On motion of Mr. Kerlin, seconded by Mr. Meek, this subject was returned to the committee for inclusion in its tentative report to the 46 th Conference by a standing vote of 29 ayes to 8 nays. )

\author{
C. L. JACKson, Chairman \\ A. H. DitTrich \\ R. IV. Searles \\ D. M. Turnbulat \\ IV. S. Bussey, Secretary
}


(At this point, on motion of the chairman, seconded from the floor, the report of the Conference Committee on Specifications and Tolerances, as amender by the Conference, was adopted by voice vote.)

\section{FIFTH SESSION-AFTERNOON OF THURSDAY, JUNE 9, 1960}

(Robert Williajs Presiding)

\section{REPORT FROM THE FOOD AND DRUG ADMINISTRATION}

By C. T. HubBle, Director of Division of Administrative Review, Bureau of Enforcement, Food and Diug Administration, U.S. Department of Health, Education, and Welfare

I am glad to have the opportunity to participate in the 45 th National Conference on Weights and Measures and to bring your a report from the Food and Drug Idministration. I have been told that this is one of the most enthmsiastic, energetic, and cooperative gromps with which we are associated in our day-to-day efforts to protect the pocketbook of the more than 170 million Anerican consumers. It the Trashington level, we in the Food and Drug Administration keep abreast of your activities largely by the routine flow of correspondence and news clippings. It would be fitting if we could get together for personal contacts more often than once a rear. Iou may be sure, however, that your very able representative, Mr. Bill Bussey, constantly keeps us aware of any old and any new problems in your area of interest.

He tells me that you will be rery much interested in the results of our survey of the net weight of packaged foods in 1959. At your meeting last year, Depnty Commissioner Harvey was able to report the findings of only one of our 17 field districts, as the others at that time had not submitted their reports. Our Division of Program Planning and Appraisal has now tabulated and analyzed all of the results, and copies of this analysis are available for distribution to any of you who are interested in reviewing them. Some of the highlights were as follows:

The survey involved 3.5 different food groups from beverages to vegetable shortening. A total of 106,695 packages were weighed. Without taking into consideration the amount or significance of the shortages, it was observed that 15.2 percent of all lots sampled were below the stated net contents. For the purpose of regulatory action, howerer. factor's other thin the shortage require consideration. For example, a 2 percent shortage in a relutively expensive item such as butter or coffee is more significant than in a cheaper product such as corn meal. Again, a shortage in a hermetically sealed can such as coffee is easier to evaluate than a shortage in the case of food packed in a cloth bas. The percentage of short weight lots in a given food groul examined in the surrey valied from 1 in 88 for baby foods to $3: 3$ of 84 in the case of corn meal. Only 0.5 percent of the lots were short by jorcent or more.

By way of followup on the findings of the investigational program and in connection with theil investigations of possible violations of the law in the varions project aneas, oul field districts in the past year have reported to us for appropriate regulatory action al number. of short weight and/or short volume riolations. "These included of candy samples up to 12 percent short weight: fo frozen fruit samples up to 4.2-percent short weight; various samples of spices. edible oils. tomato sauce, frozen fish, peanuts, ice cream topping, popeorn, soup 
mixes, pickles, liquid malt, and canned vegetables; and, of all things, a shortage of over 11 percent in some packaged antioxidant used for keeping peeled potatoes white. 'The largest percentage shortage in any seizure case was 13 percent in 11/2-ounce-size spice containers. 'Three firms, all manufacturers of alimentary paste products with unsatisfactory regulatory histories were criminally prosecuted based on shortages ranging up to 17 percent in some spaghetti packages, with the average shortage for all products of over 5 percent. The fines were $\$ 600, \$ 600$, and $\$ 1,000$. In the case of the larger fine, there were also included charges that the firm had shipped contaminated products prepared under insanitary conditions.

Mr. Bussey has told me of your increasing interest in assisting us, as well as enforcing your own special requirements applicable to the conspicuousness of the quantity of contents declarations on food packages. We can all readily agree that such declarations are not very helpful to the prospective purchaser if they are not readily seen and understood. We are constantly alert to criticize proposed labels that reach us for comment and doubtlessly bring about many voluntary changes, but sometimes encounter stout resistance. We have consistently advised our inquirers that, in order to be certain of compliance with the conspicuousness requirements of the Federal Act, the mandatory label information should appear prominently and conspicuously on the principal display panel or panels. Once there is a departure from this general rule, it then of course becomes a question of fact in each individual case. Recently, representatives of the manufacturers of packaged breakfast cereals advised us that they did not believe the law required this information to appear on the main panel as we suggest, but that other locations could be used to meet the requirements of section 403 (f). They did agree that, for the sake of uniformity and to avoid confusion, their industry would be willing to select one specific location, such as the top portion of one of the two side panels of the carton, and use it consistently. We replied that, although this seemed a desirable step and was in the right direction, we could not join them in their conclusion that this would constitute full compliance with the law.

It seems not unlikely that our inability to give full attention to economic violations in the past has encouraged some of the current labeling trends which are sometimes disturbing. Those in the art departments of some firms and/or their label manufacturers say they do not like "busy labels" but prefer a "clean look" and often try to keep to a minimum printed material on the main display panel. In the process, the quantity of contents statement and other required information is often relegated to some remote place on the label, camouflaged by using very small type or noncontrasting colors or by submerging it in lengthy statements of nonrequired wording. WVe have seen one label designer's outline of 10 points to consider in making an attractive label which listed as the last considerationpoint 10-"comply with Food and Drug laws if possible."

Another subject that is of considerable interest to many, although not within the area of responsibility of all of you, is deceptive packaging. The Federal Food, Drug, and Cosmetic Act and some State laws class a food as misbranded if its container is so made, formed, 
or filled as to be misleading. Soon after the law was enacted, we took action against such things as indented paneled bottles with long necks and thick glass in oversize cartons, packages with false bottoms, two-layer candy boxes with the bottom layer only partially filled, and other cases where we considered the abuses to be flagrant. Most such actions were uncontested, but in all three instances where there was a court contest the judgment was in faror of the claimant and against the Government.

These adverse decisions, coupled with our inability a few years ago to adequately deal with so-called economic violations, caused us to be somewhat cautions in resuming activity in the area of foods alleged to be misbranded for the sole reason that they were deceptively packaged. Starting, however, with a background of complaint based on unfair trade competition, we selected for seizure action a consignment of chocolate covered thin mints packed by Delson Candy Company of New York. The pieces of candy were discshaped. The package was approximately $111 / 2$ inches long by $13 / 4$ inches high and 2 inches wide. The bottom part of the box or "boat" had two hollow ends and two hollow divider's. The candy occupied approximately 34 percent of the cubic capacity of a carton having these overall dimensions. Although there was no shortage below the 10 ounces net weight declared, the cart on could have held 11 more units than the 30 actually packaged in it if the divider's and ends had been made of single thickness paper.

In resisting the seizure action, the claimant contended that the package was designed solely for the purpose of affording a more efficient and protective package and that it constituted a recognized advance in the art of candy box design. The Government presented the testimony of other candy manufacturers who said that a carton of this design was not required to prevent breakage of the product and that they packed more candy in boxes of the same outer dimensions. We presented a packaging engineer to show that single thickness paper dividers in the package have essentially the same protective effect as hollow dividers, and another to show that the hollow ends do not add strength to the package. We presented a marketing expert to show what consumers expect from packages having the appearance of those involved in the case, and conducted an actual survey of 50 purchasers of this product in a store to show that some were surprised they did not get as much candy as they expected. Nevertheless, the Court held that there was insufficient evidence that the containers (properly labeled as to net weight) were so made, formed, or filled as to be misleading within the meaning of section $403(\mathrm{~d})$ of the Act. The question of possible appeal has not been completely resolved but is now being considered.

Although this experience indicates that there are some areas of enforcement where our ability to bring about changes may be somewhat limited, you may be assured that we will continue to welcome any reports from you on any enforcement matters which you feel warrant our attention, and it will be our purpose to deal with them to every extent possible consistent with our facilities and the provisions of the laws we enforce. 


\section{SUMMARY OF FDA'S SURVEY OF NET CONTENTS IN RETAIL PACKAGED FOODS, 1959}

During 1959 the Food and Drug Administration made a special study of net contents of retail packages of 35 different food products. Each FDA District sampled and examined approximately $;$ wholesale lots of each of the :3.) foods. Altogether, 83 to 110 different wholesale lots of each of the 35 foods were sampled. The total number for all foods was 3,451 lots. Twentyfive to 50 retail packages from each wholesale lot were individually weighed. The total number of packages weighed was 106,695 .

The weighings indicated that 15.2 percent of all the lots sampled were below declared net contents. The proportion of short contents lots varied from 1 of 88 lots of baby foods (fruits or vegetables) to 33 of 84 lots (39.3 percent) of corn meal. Other foods with a low proportion of short contents lots were candy bars, 2.7 percent; fruit juice concentrates, 4.2 percent; and potato or corn chips, 5 percent. Other foods with a high proportion of short contents lots included butter, 33.6 percent; oleomargarine, 29 percent; salad dressing, 27.1 percent; coffee, 26.4 percent ; and sugar 24.1 percent.

Of all lots sampled, 8.9 percent were short by 0.01 percent to 0.99 percent; 3.2 percent of the lots were 1 percent to 1.99 percent short; 1.5 percent were 2 percent to 2.99 percent short; 1.1 percent were 3 percent to 4.99 percent short; and 0.5 percent were short by 5 percent or more.

Of the samples of all wholesale lots which showed an average content equal to or over the declared contents. 14.8 percent of the individual packages were below declared net contents. Sugar with 25.4 percent of individual packages below declared weight, and coffee with 21.2 percent, showed the highest proportion of short-weight individual packages in lots which nevertheless averaged declared contents or over. Frozen fruit juice concentrates with $\mathbf{5 . 6}$ percent and baby foods with 6.2 percent showed the least proportion of short contents units in the lots which averaged declared contents or over.

For the short content lots within the shortage range 0.01 percent to 0.99 percent, 63.5 percent of the individual packages were below declared contents. Other shortage ranges and proportions of packages below declared contents are: 1 percent to 1.99 percent shortage, 78.2 percent of packages; 2 percent to 2.99 percent, 91.9 percent; 3 percent to 4.99 percent, 86.7 percent and 5 percent or over, 98.9 percent.

The range in contents in individual packages, the difference between the lightest and heariest package in one sample, was determined for each lot examined within each food group. For each District and each food product the smallest difference (or range between maximum and minimum net contents of packages in one lot) was set down and likewise the finding on the lot with the largest difference. Finally the average of the ranges for all lots in the food group was calculated. These data were kept separately for those lots averaging declared contents or over and for those averaging below declared contents.

In the up-to-declared contents group, the arerage of the minimum ranges was $0.32 \mathrm{oz}$. for the 35 foods. This represents firms which appear to exercise the best net contents control. The average minimum range varied from $0.08 \mathrm{oz}$. for dessert or pudding powder's to $0.98 \mathrm{oz}$. for corn meal. The average of the maximum ranges, representing firms apparently exercising less control over net contents, was $1.40 \mathrm{oz}$. for the 35 foods. Corn meal, with a range of 3.23 oz., again provided the largest range found. The average of all ranges within the up-to-weight lots was $0.74 \mathrm{oz}$.

In the short contents lots, the average of the minimum ranges was $0.72 \mathrm{oz}$. These minimum ranges varied from $0.22 \mathrm{oz}$. in oleomargarine to $1.54 \mathrm{oz}$. in one lot of dried milk. The arerage of the maximum ranges was $0.99 \mathrm{oz}$. The a verage of all ranges for all short weight lots was $0.85 \mathrm{oz}$.

Generally, the smallest range in the up-to-contents lots was less than half of the smallest range in the short contents lots. However, on the whole, the average range in up-to-contents lots was iittle different from the average for short weight lots. It might be construed from these data that firms achieving the smallest range in contents of packages are less prone than the others to produce short contents lots. However; it appears, on the whole, that poor 
control of individual package contents is not consistently related to production of short contents lots.

The findings on each of the 35 food prodncts are summarized in the following chart and tables.

\section{FDA'S NET CONTENTS SURVEY - 1960 \\ $\%$ OF LOTS FOUND BELOW DECLARED CONTENTS \\ BY FOOD PRODUCTS}

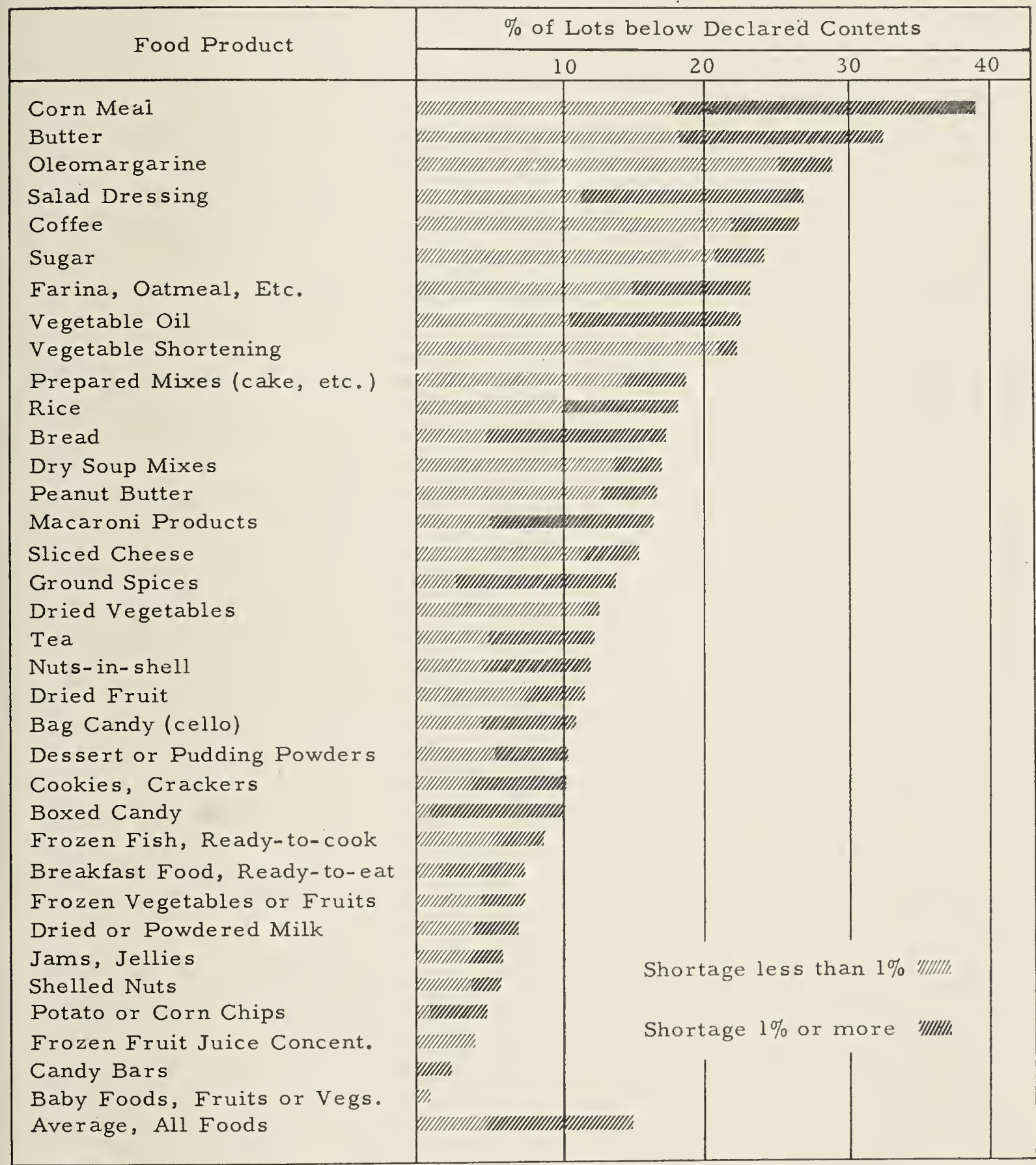




\begin{tabular}{|c|c|c|c|c|c|c|c|}
\hline \multirow{2}{*}{ Commodity } & \multirow{2}{*}{$\begin{array}{l}\text { Number } \\
\text { of lots } \\
\text { exam- } \\
\text { ined }\end{array}$} & \multirow{2}{*}{$\begin{array}{l}\text { Percent } \\
\text { of lots } \\
\text { short } \\
\text { contents }\end{array}$} & \multicolumn{5}{|c|}{ Percent of lots short contents by: } \\
\hline & & & $\begin{array}{c}0.1- \\
0.9\end{array}$ & $\begin{array}{l}1.0- \\
1.9\end{array}$ & $\begin{array}{l}2.0- \\
2.9\end{array}$ & $\begin{array}{l}3.0- \\
4.9\end{array}$ & $\begin{array}{l}5 \text { and } \\
\text { over }\end{array}$ \\
\hline 1 Coffee. & 110 & 26.4 & 21.8 & 3.6 & & & 0.9 \\
\hline 2 Tea. & 103 & 12. 6 & 4. 9 & 5.8 & 1. 9 & & \\
\hline 3 Bread & 103 & 17.5 & 4. 9 & 5.8 & 2. 9 & 1.9 & 1. 9 \\
\hline 4 Cookies, crackers & 108 & 10. 2 & 3. 7 & .9 & & 2. 8 & 2. 8 \\
\hline 5 Macaroni products. & 103 & 16.5 & 4. 9 & 8. 7 & 1.9 & 1.0 & \\
\hline 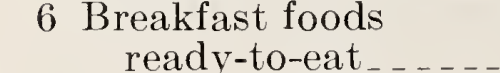 & & & & & & & \\
\hline 7 Farina, oatmeal & $\begin{array}{l}102 \\
103\end{array}$ & $\begin{array}{r}73.8 \\
23.2\end{array}$ & $\begin{array}{r}1.9 \\
14.5\end{array}$ & $\begin{array}{l}1.9 \\
6.8\end{array}$ & $\begin{array}{l}1.9 \\
1.9\end{array}$ & 1.9 & \\
\hline 8 Corn meal & 84 & 39. 3 & 17. 9 & 10. 7 & 7. 1 & 3. 6 & \\
\hline 9 Rice $\ldots \ldots$ & 92 & 18. 5 & 9.8 & 3. & 1. 1 & 4. 3 & \\
\hline 10 Prepared mixes & & & & & & & \\
\hline (cake) & 102 & 18. 6 & 14. 7 & 2.9 & 1. 0 & & \\
\hline 11 Bag candy (cello) & 107 & 11. 2 & 4. 7 & 3.7 & 2. 8 & & \\
\hline 12 Box candy & 101 & 10. 0 & 1. 0 & $4 .($ & 5. 0 & & \\
\hline 13 Candy bars & 109 & 2. 7 & & & & 1.8 & y \\
\hline 14 Sugar & 83 & 24.1 & 20.5 & 1. 2 & 1. 2 & 1. 2 & \\
\hline 15 Sliced cheese & 97 & 15.5 & 11. 3 & 1. & 2. & 1. 0 & \\
\hline $\begin{array}{l}16 \text { Dried or powdered } \\
\text { milk }\end{array}$ & 99 & 70 & & 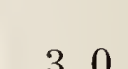 & & & \\
\hline 17 Frozen fish, ready- & 80 & & & & & & \\
\hline to-ec & 89 & 9. 0 & 5. 6 & 2.3 & & 1. 1 & \\
\hline 18 Salad dressing & 96 & 27.1 & 11.5 & 5. 2 & 2. 1 & 5. 2 & 3. 1 \\
\hline 19 Ground spices_-_ & 106 & 14. 1 & 2. 8 & 1.9 & 1.9 & 4. 7 & 2. 8 \\
\hline 20 Frozen fruit juice & & & & & & & \\
\hline & 95 & 4. 2 & 4. & & & & \\
\hline 21 Dried fruit & 99 & 12.0 & 8. 0 & 2. 0 & 2.0 & & \\
\hline 22 Jams & 98 & 6. 0 & 4. 0 & 1. 0 & 1. 0 & & \\
\hline 23 Nuts-in-shell & 90 & 12. 2 & 4. 4 & 4. 4 & & 1. 1 & 2. 2 \\
\hline 24 Shelled & 99 & 6. 0 & 4. 0 & 2. 0 & & & \\
\hline 25 Pean & 98 & 17. 0 & 13.0 & 2. 0 & 2. 0 & & \\
\hline 26 Vegeta & 97 & 22.7 & 10.3 & 8. 2 & 2. 1 & 1. 0 & 1. 0 \\
\hline 27 Vegetable shortening. & 90 & 22. 2 & 21. 1 & & & & 1. 1 \\
\hline 28 Dried vegetables_... & 100 & 13.0 & 12.0 & & 1.0 & & \\
\hline $\begin{array}{l}29 \text { Frozen fruits or } \\
\text { vegetables }\end{array}$ & 110 & 7. 3 & 4. & 9 & & 1. 8 & \\
\hline 30 Potato or corn chips & 99 & 5. 0 & 1. 0 & 1. 0 & 2.0 & & 1. 0 \\
\hline 31 Des & 97 & & & & & & \\
\hline 32 Drys & 87 & $\begin{array}{l}\text { 10. } 3 \\
17.2\end{array}$ & $\begin{array}{r}\text { 5. } 2 \\
13.8\end{array}$ & 4. & $\begin{array}{l}\text { 1. } 0 \\
1.1\end{array}$ & 2.3 & \\
\hline 33 Baby f & 88 & 1. 1 & 1. 1 & & & & \\
\hline 34 Butter & 107 & 33.6 & 18. 7 & 11. 2 & 2. 8 & .9 & \\
\hline 35 Oleomargarine & 100 & 29. 0 & 25. 0 & 3.0 & 1. 0 & & \\
\hline Total or average & 3,451 & 15. 2 & 8. 9 & 3. 2 & 1.5 & 1. 1 & .5 \\
\hline
\end{tabular}


FDA'S NET CONTENTS SURVEY, FOODS-1959 SUMMARY FOR 35 FOOD PRODUCTS

\begin{tabular}{|c|c|c|c|c|c|c|c|c|}
\hline \multirow{3}{*}{ Commodity } & \multicolumn{2}{|c|}{$\begin{array}{l}\text { No. pkgs. } \\
\text { examined }\end{array}$} & \multicolumn{6}{|c|}{$\begin{array}{c}\text { Percent packages under declared } \\
\text { net contents }\end{array}$} \\
\hline & \multirow{2}{*}{$\begin{array}{l}\text { OK } \\
\text { lots }\end{array}$} & \multirow{2}{*}{$\begin{array}{c}\text { Short } \\
\text { con- } \\
\text { tents } \\
\text { lots }\end{array}$} & \multirow{2}{*}{$\begin{array}{l}\text { For } \\
\text { OK } \\
\text { lots }\end{array}$} & \multicolumn{5}{|c|}{ For short contents lots } \\
\hline & & & & $\begin{array}{c}0.1- \\
0.9\end{array}$ & $\begin{array}{l}1.0- \\
1.9\end{array}$ & $\begin{array}{l}2.0- \\
2.9\end{array}$ & $\begin{array}{c}3.0- \\
4.9\end{array}$ & $\begin{array}{l}5 \text { and } \\
\text { over }\end{array}$ \\
\hline Coffe & 2,255 & 1,322 & 21. 2 & 68. 6 & 89.5 & & & 100.0 \\
\hline $\mathrm{Te}$ & 2,501 & 549 & 16. 4 & 68.1 & 74.7 & 55.0 & & \\
\hline Brea & 2,2 & 811 & 12.9 & 51.6 & 77.1 & 83. 2 & 72.8 & 100.0 \\
\hline Cookie: & 2,615 & 484 & 14. 8 & 55.5 & 82.0 & & 82.9 & 98.7 \\
\hline Macaroni pr & 2,275 & 762 & 17.7 & 66. 8 & 77.6 & 98. 0 & 100.0 & \\
\hline $\begin{array}{l}\text { Breakfast foods, ready- } \\
\text { to-eat }\end{array}$ & 2 & & 12 & & & & & \\
\hline $\begin{array}{l}\text { to-eat } \\
\text { Farina, oatmeal }\end{array}$ & $\begin{array}{l}2,402 \\
2,027\end{array}$ & $\begin{array}{r}1,33 \\
1,133\end{array}$ & $\begin{array}{l}\text { 12. } 8 \\
15.0\end{array}$ & $\begin{array}{l}53.0 \\
68.3\end{array}$ & $\left|\begin{array}{l}60.0 \\
91.4\end{array}\right|$ & $\begin{array}{l}92.9 \\
97.0\end{array}$ & & \\
\hline Corn me: & 1,396 & 1,550 & 19. 0 & 73. 7 & 92.3 & 100.0 & 95.3 & \\
\hline Rice & & 800 & 14. 9 & & $86.5 \mid$ & 100.0 & $|95.5|$ & \\
\hline$($ cake $)$ & 2, & 768 & 17.7 & 65.8 & 80.0 & 86.0 & & \\
\hline Bag & 2, & 560 & 15. 7 & 70.0 & 67 & 97.3 & & \\
\hline Box & 2,4 & 399 & 12.5 & 40. 0 & 74.3 & 87.8 & & \\
\hline $\mathrm{Ca}$ & 2,6 & 150 & 8. 7 & & & & 79.0 & 100. \\
\hline $\mathrm{Su}$ & 1, & 932 & 25. 4 & 63.7 & 60.0 & 100.0 & 96.0 & \\
\hline Sli & 2,0 & 656 & 17.8 & 59. 2 & 74.0 & 81.5 & 84.0 & \\
\hline Dried or powdered milk & 2,423 & 350 & 15. 2 & 59.5 & 91.3 & & & \\
\hline $\begin{array}{l}\text { Frozen fish, ready-to- } \\
\text { cook }\end{array}$ & 2, & 3 & 17 & 7 & 7 & & 82. 0 & \\
\hline Salad dress & 2,7 & 1,218 & 10. 2 & 65.0 & 89.0 & 100.0 & $\mid 99.0$ & 100 \\
\hline$S_{-} \ldots \ldots$ & 2,438 & 674 & 17.1 & 58.0 & 74.0 & 94.0 & $|78.7|$ & 93. \\
\hline $\begin{array}{l}\text { Frozen fruit juice con- } \\
\text { centrate }\end{array}$ & & & & & & & & \\
\hline Dried $\mathrm{f}$ & 2,300 & 600 & 14. 6 & 58. 7 & 82.0 & 82.0 & & \\
\hline $\mathrm{Ja}$ & & 300 & 12. 3 & 74.5 & 82. 0 & 94.0 & & \\
\hline $\mathrm{Ni}$ & 2, & 400 & 16. 7 & 68.0 & 79.4 & & 100.0 & 99.0 \\
\hline & & 275 & 19. 0 & & 61.0 & & & $\ldots$ \\
\hline $\mathrm{Pe}$ & & 774 & 13. 3 & & 99.0 & 100.0 & & \\
\hline Ve & 2 & 1,094 & 10. 4 & 70.9 & 86.9 & 94.0 & 100.0 & 100. \\
\hline $\mathrm{Ve}$ & 2,0 & 900 & 15.5 & 80. 2 & $\ldots$ & & $\ldots$ & 100.0 \\
\hline Dried veg & 2,348 & 550 & 14. 3 & 66.1 & & 100.0 & & \\
\hline $\begin{array}{l}\text { Frozen fruits or vege- } \\
\text { tables }\end{array}$ & & 348 & & & & & 71.4 & \\
\hline chips & 2,423 & 224 & 8. 8 & 52. 0 & 14. 0 & 86.7 & $\mid$ & 98.0 \\
\hline Dessert, pudding pow- & & & & & & & & \\
\hline & 2,400 & 509 & 9. 0 & 56. 7 & 73.8 & 91. 7 & & \\
\hline $\begin{array}{l}\text { Dr } \\
\mathrm{Ba}\end{array}$ & $\begin{array}{l}1, \\
2,\end{array}$ & $\begin{array}{r}00 \\
24\end{array}$ & $\begin{array}{r}\text { 14. } 0 \\
6.2\end{array}$ & $\begin{array}{l}60.0 \\
50.0\end{array}$ & & 90.0 & 77.0 & \\
\hline Butt & 2,022 & 1,548 & 18. 9 & 77.7 & 96.6 & 94.0 & 60.0 & - \\
\hline Oleomargarine -_- & 2,185 & 1,271 & 21. 1 & 64.7 & 100.0 & 100.0 & $\ldots$ & $\ldots$ \\
\hline Total or average & 83,139 & 23,556 & 14. 8 & 63.5 & 78. 2 & 91.9 & 86.7 & 98.9 \\
\hline
\end{tabular}




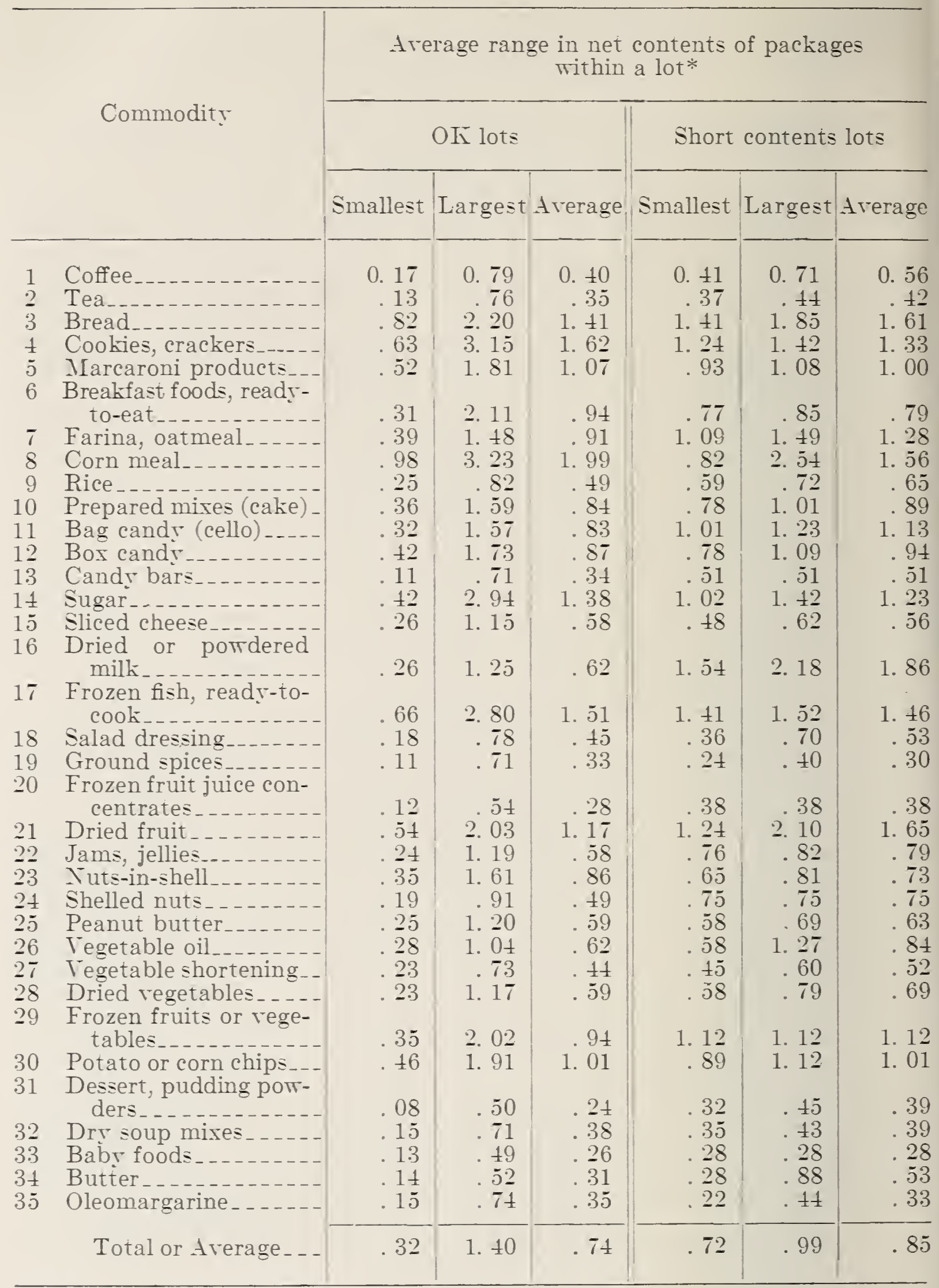

*Aroirdupois ounces except fluid ounces for commodities 18,20 , and 26. 
Mr. Daniflu: We have observed that many drug packages have quantity declarations in ounces and that the ounces are unqualified as to fluid or avoirdupois. Does your agency approve such labeling?

Mr. Hubble: No, the Federal statute requires that, when the quantity statement includes a term with two or more meanings, the declaration mustidentify the meaning of the term.

\section{TWENTIETH CENTURY PROBLEMS IN EQUITY IN QUANTITY}

\section{By Mrs. Mndmed E. Brunr, Editorial Director, Consumers Union, Mount Vernon, Lew York}

Consumer behavior has become one of the most popular fields of inquiry since World Wrar II. Some of our most elaborate methods of analysis are applied to what makes John Doe buy brand X, switch to brand $Y$, and then fall tor the premium offer made by brand $Z$. So much attention has been centered of late on these consumer reactions to meaningless product differentiations that more profound changes in consumer behavior have gone unobserved, hidden under the smog of promotional rivalry that now pollutes the marketplace. For example, we at Consumers Cnion have puzzled in recent years over why there seems to be an apathy on the part of the general public about the enforcement of weights and measures-the function for which you here are responsible.

Why does a nation that holds the card cheat in a Western rightfully doomed appear to tolerate short weight? How has it happened that a population aware of the odds against drawing to an inside straight, accustomed to handicaps in sports, familiar with Dow Jones averages on the stock market, seem unable to remember how many pints there are to the gallon or how many ounces there are to the pound? IVhy are there almost no reasonably priced, precisely accurate, reliable kitchen scales on the market? Two year's ago, when Consumers Union scheduled a kitchen scale testing project, our marketing and purchasing department found that locating eren unreliable, poor quality types of kitchen scales was no easy job. What percentage of the households in the country would you guess are equipped with a scale adequate to check one of the most common types of short weights today-the ounce, or partial ounce, of packaging weight included in the net weight of prepackaged meats, poultry, and fish, those small sharings on the weight that are so reminiscent in our day of the coin clipping in ages past?

Since there are no highly accurate, temperature-proofed scales designed for home use, would you guess that as many as 10 percent of today's ultimate consumer's own a scale useful for determining weight clipping? Do you imagine that even 5 percent do? Would you bet that, in as many as 1 percent of the homes, in 600,000 of them, a good scale stands in the kitchen between the $\$ 50$ electric mixer and the $\$ 2.5$ electric can opener?

Now this is a remarkable situation, this lack of a household scale of high quality on a market that groans with a surplus of high-priced kitchen gadgetry. Certainly, in terms of the history of the last 3,000 years, this seeming disinterestedness in weight is a new phenomenon. 
A just weight so concerned men of ancient times that Jehovah, Himself, commanded Ezekiel during the Babylonian captivity that the princes of Israel must refrain from their exactions on His people. "Ye shall have just balances," the Lord commanded, "a just ephah, and a just bath." From the Greeks on up through the Romans to the Middle Ages, the cheat of the seller through short weight was condemned in folk sayings and made the subject of kingly edicts. "Let the buyer be present when the wine is drawn," began an English royal pronouncement on fair measure issued in the fourteenth century. Late in the eighteenth century, the best scientific minds of the age were joined in the monumental effort of the French to establish with the metric system an internationally acceptable scale of weights and measures. And during most of the nineteenth century, here in this nation, the establishment of procedures to carry out the national objective of "equity in quantity" was a major public concern. So how does it happen that here and now in the midtwentieth century people seem to have forgotten? Has the consumer grown foolish and careless, so dulled and benumbed with plenty that he submits to robbery without resentment-robbery organized not by some gallant Robin Hood to distribute from the strong to the weak, but robbery that takes from the many to enrich the few?

During the days of the depression when young writers had time for contemplation, a couple of newspapermen I knew used to while away many an evening in inexpensive entertainment concocting fanciful schemes all designed toward one simple and obvious end. They put it to me this way. "If we could just figure out", they said, "a way to collect a penny a year from every individual in the country, we would have an annual income of over a million dollars, and nobody would be noticeably any the worse off for it." Since my friends and I were journalists whose eyes were fixed by newspaper policy on local murders, national party politics, gangsters, and prohibition, we were not equipped to know then that the baker, the butcher, the candlestick maker, the milk distributor, the soap advertiser, and the bread brander had already found the best possible scheme. And since those days of the 1930's - simple days they now seem, before supermarket merchandising, before packaging became a sales device, and before the battle for shelf space launched a nationwide contest in trickery-as you here know so well, since those depression days the number and variety of successful schemers who are, each, after just a penny or a part of a penny more per person have grown geometrically.

Would a household scale help us protect our penny losses, our multiplying penny losses?

To be sure, that ounce of packaging that we pay for at chicken prices when we buy prepacked chickens would, in a year, total more than we would pay for an extra chicken. If, instead of paying at the rate of an ounce at a time for a chicken that we do not get, we were forced to give the seller a free chicken every New Year's Day as a kind of merchant's tax, then we would know and probably we would revolt. But even if we do know today that a seller who shaves a thin ounce off a million daily transactions collects a million free ounces, there is not much that we, as individuals, can do. As our economy and our technology grow more complex and more and more highly centralized in control, the number of problems removed from the realm where individual action can be corrective multiplies. 
As fewer and fewer sellers sell to greater and greater masses of customers, the opportunities to make big total robberies by myriad tiny dishonesties which are thus opened up can only be closed by regulatory controls, by institutional means, by legal tolerances enforced by established weights and measures agencies. And the kitchen scale cannot contribute much, if anything at all, to the disciplines required to handle this problem.

In other words, a part of what appears to be public apathy about weights is not so much apathy as a kind of acceptance of good sense in effort-a good sense that is not resolved into theory; nor eren, perhaps, into conscionsness of what lies behind the action taken or foregone after a multitude of small experiences. Furthermore, this acceptance of multiple tiny cheatings without complaint is more an apparent, than a real, evidence of apathy, because in other areas where another kind of cheating in quantity is taking place, and where consumers could exercise corrective action if the means were provided them, there is growing rebellion. I refer to deceptive packaging.

Each year Consumers Union sends out a lengthy questionnaire to subscribers about buying plans, buying experiences, and about what kinds of problems reader's would like to have more fully discussed in Consumer Reports. In last year's questionnaire, 20 general classes of produce and problem categories were listed and reader's were asked to report their desires by checking one of three reactions to indicate whether they would like more emphasis, the same as now, or less emphasis on these topics in future issues of Consumer Reports. Deceptive packaging was one of those included in the list which offered readers the chance to vote for more or less editorial attention to automobiles, home appliances, health and medicine articles, TV sets, and so on. The vote for more about deceptive packaging was the highest on the list. Better than half of the 150,000 answering the questionnaire wanted more about deceptive packaging in the Reports.

This remarkably high response was a surprise to us at Consumer's Union, although it should not have been. Our mail on the subject has been heavy. I would like to reat to you here some excerpts of the kind of complaints we are receiving in growing volume. 'These letters, it seems to me, indicate clearly not only that consumers are not dulled and complacent about deceptions in quantity, but also that a greater part of the effort and attention of weights and measures officials should perhaps be tumed to this area.

[Mrs. Brady read from a number of letters received by Consumers Inion. The following are typical.]

This letter is from Largo, Florich :

Dear CU:

I find myself constantly aggratrated lately by the American manufacturer's trying to "gyp" me in one way or" another. Just recently there were two more incidents. I traveled it miles to the "S \& II Green stamp store"-three trips-to order, pick up, and return a "Corning Ware" saucepan. According to the carton a $13 \%$ qt. size but inside a $1 \mathrm{qt}$. size. All other's were the sameconsequently I did not accept ans.

The second incident concerned a plastic clothesline. I purchased what surposedly were two 50-foot lengths. IIy husband proceeded to hang the lineit would not reach, we measured it $-1 \frac{1}{2} \mathrm{ft}$. short. We returned it to the store and received a refund. We drove into town, stopping at rilrious stores on the 
way, trying to buy line from a reel. It seems no one sells it that way. Most of the stores had this same company's line (Drop Lite Electric Mfg. Corp., New Iork City) that we had returned. My husband informed all salesmen of the "short measurement deal" and asked if they would guarantee him correct length in each package. Naturaly they would. Would they reimburse him for gas used to return it should it be short? Certainly not! WVould they measure it? Only one did-it was eight inches short. Prices ranged from 77 cents (a special) to $\$ 1.39$ (all the same type). A 30 -mile round trip in vain. A few days and a few stores later, my husband returned in desperation to the store with the special and purchased the clothesline. You guessed it-short eight inches! How many people are getting bilked this way, if they have no cause to measure they are none the wiser. I, for one, am getting tired of being made the goat and am turning into a very suspicious person; afraid to believe anything I read.

\section{This one is from Cambridge, Massachusetts:}

\section{Dear CU:}

While incurring the risk of self-flattery, my wife and I claim to be members extraordinary of the "shopulation." (This is a new advertising term to describe consumers who are wise, careful shoppers.) Not only do we fill the specifications you printed, but in addition we shop with a slide rule.

The quality of many products varies little from one brand to the next; this tends to be true for detergents, toothpastes, canned and bottled fruit juices, oleomargarines, and a host of other products. On the other hand, many tricks are used to make each brand appear a better bargain than the others. We decided that the only sensible way to shop for these items is based strictly on price. A slide rule permits us to choose $53 / 4$ ounces of toothpaste for 83 cents over $4 \%$ ounces for 69 cents. It also shows that the highly advertised canned apple juice on "sale" and prominently displayed is actually significantly more expensive than the regular bottle hidden on a shelf in the back of the store.

'Two or three dollars invested in a cheap slide rule pays for itself in a few weeks, and also gives a gratifying smug sense of satisfaction in the knowledge that you are defeating the amassed forces of evil from Madison Avenue.

\section{Here is one from Cincinnati, Ohio:}

\section{Dear CU:}

I recently came across an advertisement in a trade publication which carries on its face a blatant advocacy of deceptive packaging. Perhaps you will want to call this ad to the attention of the FTC or mention it to your readers.

The ad in question appeared in Chemical Week magazine, issue of December 26, 1959, occupying page 54. This magazine you may know is directed primarily to management in the chemical process industries. The ad by Hooker Chemical Corp., Phosphorus Division, Dept. CW-12, 60 E. 42d St., New York 17, N.Y., carried the banner line:

How spray-dried phosphates give your detergents 30 percent more bulk at the same cost $* * *$ and the same weight.

The text said that Mooker's spray-dried sodium phosphate, a detergent ingredient, has air bubbles entrapped in each particle. 'The entrapped air makes it 70-pelcent bulkier than conventional phosphates and will increase the bulk of packaged detergents by 20 percent to 30 percent without increasing their cost or weight. This was the main sales point of the ad.

Speaking of detergents, you would have thought some years ago that they had gone "jest about as fur as they can go"; but you would have been wrong. The brand and package-size explosion in detergents continues. The dishwashing detergent Joy, for example, which made its bow in a perfectly adequate bottle or can choice (12 ounces net weight) some years ago, now commands triple shelf space in three sizes, 12 ounces, 22 ounces, and 1 quart. Each size is packaged in gleaming white plastic; gaudily labeled in red, green, and blue; priced 
at 37 cents, 65 cents, and 93 cents, with net weight contents in small type at the bottom of the label on the back of the elaborate containers. The cost-per-ounce difference from size to size, by the way, is less than 0.2 of a cent.

In the old fashioned heavy-duty detergents there are also multiple sizes-regular, large, giant, super giant, and king. 'The giant sizes of seven of the same type of all-purpose detergents that CU picked up recently were exactly alike in package contour-the same height, the same width, and the same breadth. The prices for these samesized packages varied, however, from 85 cents a box to 5:3 cents, and the net weight contents of the seren, printed in type so small and so located on the box as to almost completely baftle the seeker, were as iollows :

$\begin{array}{ll}\text { Surf } & 2 \mathrm{lbs} .131 / 2 \mathrm{oz} . \\ \text { Cheer } & 3 \mathrm{lbs} .5 \mathrm{Oz} . \\ \text { Rinso } & 3 \mathrm{lbs} .6 \mathrm{oz} . \\ \text { Super Suds } & 2 \mathrm{lbs} .15 \mathrm{oz} . \\ \text { Tide } & 3 \mathrm{lbs} .11 / 4 \mathrm{oz} . \\ \text { Sail } & 2 \mathrm{lbs} .15 \mathrm{oz} . \\ \text { Oxydol } & 3 \mathrm{lbs} 11 / 4 \mathrm{oz} .\end{array}$

The 2-pound 131/2-ounce size was 85 cents, with a per-ounce cost of 1.86 cents. The cheapest came not with the heaviest net weight, howerer, but with the private-brand package containing 2 pounds 15 ounces. Its 1.13 cents-per-ounce cost was about 40 percent below the cost of the most expensive.

I could go on for the rest of the afternoon reading you such samples from our mail and not touch another kind of growing complaint we hear about packages - those where the pictures on the outside are false and misleading-fillets or steaks of fish on the package, irregular frozen chunks inside; thick slices of ham in the picture outside, paperthin cuts inside. And the bacon that is packaged so that the only lean cuts are centered under the glassine opening with practically plain fat lying underneath the top-lean layer that shows. Or those packaged pork chops where the top three are loin but the bottom two or three are rib chops.

Let me read a final example, however, of another kind of packaging chicanery that is also arousing consumer ire-the change in can sizes. This letter is from Belvedere, California:

\section{Dear CU:}

This type of thing gets me down. Can't we discourage it? I recently returned home with what I thought was two No. 303 cans of peas, only to find that the net weight is $14 \frac{1}{2}$ oz. or 411 grams-a new size I have never met with before.

I am writing this in protest to the technique of changing can sizes. The not-too-long-ago abandonment of the No. 2 can in favor of the No. 303 is still in my mind and I do not like it one bit. Newspaper publicity said the public was "tested" to see whether they preferred the No. 303 over the No. 2. 'That is not so-the two cans never appeared side by side to my knowledge. But by selling the No. 303 on a "2 for " or a "3 for —" basis, the No. 303 was promoted so rapidly that the No. 2 at regular prices did not have a chance.

Now, I know that this problem of deceptive packaging is one that does not rest entirely on the shoulders of State weights and measures agencies. I know that the Food and Drug Arministration, the Federal Trade Commission, and the U.S. Department of Agriculture are also charged with controlling some of these economic cheats. And I 
know, too, that the courts have not made enforcement easy for these Federal agencies. It takes a while, sometimes a very long while, to educate the judges of the land to an appreciation of the significance of trade practices. Law schools simply do not turn out lawyers who are well educated in the facts of life in this area of commercial behavior. Furthermore, those lawyers who become highly skilled in the legal ins and outs of trade practices usually do so servicing the packager who is deceiving rather than the regulatory agency charged with controlling the deceit.

Furthermore, we at Consumers Union are a ware that the resources of the Federal agencies, limited though they be, are generally superior to those available at State and local levels. And finally, it is usually, but not always, true that State enforcement standards lag behind those of Federal agencies. But here in weights and measures is one field where, it seems to me, the State agencies could take the lead and lead with a heavy right to the chin. Weights and measures laws already provide that any package that is deceptive in appearance with regard to its contents is illegal. If just one of the larger States in the Nation should take up deceptive packaging as a local campaign, that State and that State alone could stem this flowing tide of disorder and inequity in quantity. Judging on the basis of our mail, any State agency taking up these cudgels would have ardent consumer support. It would also gather commercial support. The retailers are getting fed up. Have you noticed how most supermarket operators no longer try to stand breakfast food cereal packages upright on their shelves, but fill the coveted shelf space with these weightless giants lying on their faces? Only the small, narrow rectangles on the bottom of these outsized packages now show along the shelf facethus, incidentally, defeating the efforts of cereal manufacturers who spend millions designing multiple sizes of come-on packages to lure the shopper wheeling along between crowded shelves-shelves, gentlemen, crowded with packages, many of them deceptive packages. And the misleading, bad package bids fair to drive out any remaining good packages.

Branding and packaging has, over the past quarter of a century, progressively swallowed up all but a small fraction of those goods we buy often-goods where repeat purchases multiply endlessly the cost of cheating and deception-goods such as soap, paper products, cleaning materials, raw food, pickled food, dried food, canned food, frozen food, and aerosol food. (And, by the way, what is the net weight contents of an aerosol food-that which is put in the can or that which you can get out of it?) Neither the scale in the kitchen nor the scale in the store has much of a role to play in this kind of quantity inequity. Thus, the discipline of consumer sovereignty is lost in the twentieth century packaging chaos. The better mousetrap is hidden in the merchandising smog. The just balance that Jehovah required of Ezekiel is gummed and falsely weighted by the deliberate intent of the advertising agency and packaging designer.

We know the answer-we at Consumers Union and you here. In fact, we at CU learned it from you, from the resolutions you pass from time to time calling for standardized package sizes. Standardized package sizes, together with the requirement that the net weight contents be placed in large type on package faces, would make it possible for consumers to leave their slide rules at home and to put 
their mathematics to use in trying to figure out the true cost of consumer credit, for example, where, I can assure you, the arithmetic requirements are matched only by those now laid on careful shopper's trying to choose between $51 / 4$ ounces at 63 cents and $21 / 2$ ounces at 36 cents.

\section{DISCUSSION ON FOREGOING PAPER}

Mr. R. S. Miller: It has come to my attention that in one State there has been established a committee of housewives which works under the office of the attorney general. The committee operates in the area of advertising and brings to this problem the viewpoint of the consumer. Practices that are considered by this group to be fraudulent are brought to the attention of the attorney general for appropriate action. It is my understanding that this system has been working out very well. Would you not consider such a plan advisable for every State?

Mrs. BraDY: I certainly think it would be helpful. I would hope that retailers would be eager to cooperate and that the judges would endeavor to show greater interest in consumer problems than has heretofore been evident.

Dr. Gordon: Is Consumers Union planning on including in their monthly publication anything in the weights and measures area?

Mrs. Brady: What do you think we ought to do?

Dr. Gordon: I believe that Consumer's Union is nearing its 2.5th anniversary and that throughout the years very little attention has been given to the quantity aspects of consumer merchandise. I should like to see a regular feature in Consumer Reports along this line.

Mrs. Brady: Our problem is in finding precisely how to approach a weights and measures feature. As you know, we have in the past tested merchandise and reported in terms of quality-price ratio. Tre have thus furnished the consumer with what we call self-help material. In the field of reights and measures, the problem goes beyond self help. There must be developed a closer working relationship between consumers who are aware of the problem and their weights and measures officials.

We have attempted, as explained in the paper, to look into the matter of an appropriate kitchen scale.

I can say that it is our intention to enter the measurement field just as soon as we can establish the proper formula.

Mr. Harris: I would like to suggest that Consumer's Union might, for the benefit of consumers generally, enter into communication with the legislative and administrative officials of the several States in support of adequate weights and measures administration.

Mr. Levy: The city of Chicago has had a consumer education program for about 10 years. This program has met with great response from consumer groups and various other organizations. It is my opinion that it is not difficult to develop public interest in consumer protection.

Mr. J. T. Kennedr: I believe that the one step that would eliminate consumer confusion in packaged commodities is standardization of package sizes. This Conference has eridenced interest and support for standardization, but as of now there have been very few results. 


\section{THE FEDERAL TRADE COMMISSION AND CONSUMERS}

\section{By J. R. Hens, Director, Bureau of Consultation, Federal Trade Commission}

In my comments this aftermoon I shall be expressing my personal riews and shall not be speaking or expressing the official views of the Federal Trade Commission.

A businessman recently asked a Bureau of Consultation attorney, "Thatever happened to caveat emptor?" The evolution in the relation between the Federal Trade Commission and the consumer is a partial answer to this question.

It was well into the Sixteenth Century when "caveat emptor" first appeared in print. Appropriately, it arose in connection with a dispute between buyer and seller over a horse trade. Wrote Fitzherbert in his Boke of Husbandrie, "If he be tame and have been rydden upon, then caveat emptor." "Though conceived in England and found in a few English decisions prior to the Revolutionary WVar, the principle became more popular in America. It possessed a certain ruggedness that our then-frontier economy found congenial.

In one case, a man who bought two paintings by an obscure artist, believing them to be works of a master, was thrown out of court. It was held that the name of the painter set down in the catalog represented no more than the opinion of the dealer. Jendwine v. Slade, 2 Esp. 572 (1797).

Another man bought a steamboat to be used on a particular route, relying on the representation that, when fully loaded, it drew only 3 feet of water, as no boat drawing more than this amount could reach some of the docks. Then placed on the route, it grounded in 5 feet of water. In denying relief to the buyer, the United States Supreme Court said, "Where the means of knowledge are at hand and equally available to both parties, and the subject of purchase is alike open to their inspection, if the purchaser does not avail himself of those means and opportunities, he will not be heard to say that he has been deceived by the vendor's misrepresentations." Slaughter v. Gerson, 13) T.S. 379, 20 I. ed. 627 (1872).

The consumer's plight in this state of the law was not a happy one. Although the common law as it developed permitted the buyer to sue the seller for deceit or breach of warranty, and later for negligence or breach of an implied warrranty, there was no government regulation. In addition, cost of litigation and difficulties in proof of liability or damages often made the private remedies lllusory.

Beginning in 1911 the first States enacted false advertising laws. At the same time the Associated Advertising Clubs advocated Federal legislation to cover advertising in interstate commerce. Representatives of the clubs and other business groups supported proposals to create a Federal Trade Commission whose powers would include the prevention of false advertising.

However, the Federal Trade Commission Act, enacted in 1914, made no mention of advertising or deception and proscribed unfair methods of competition only. George Rublee, who represented President Trilson in conferences with Congress in drafting the bill and who was a member of the first Commission, later wrote that there had been no intention to include advertising. 
Nevertheless, from the very outset, the Commission found deceptive advertising to be an unfair method of competition where competitors were injured. The first two cases reported in the Federal Trade Commission Decisions-Federal Trude Commission r. Yagle, et al., trading as Circle Cill Co., 1 F.T.C. 13 (1916), and Federal Trade Commission v. Abbott de Co., 1 F.T.C. 16 (1916)-prohibited manufacturers from using the word "silk" in reference to any of their products other than silk in connection with any of their trademarks, trade names, labels or advert ising matter.

The charges against respondents in those two cases are interesting. The first sold a cotton thread labeled with the trade name "Circle Cilk". At no place did it divulge the cotton content or the absence of silk.

The second described its product in labeling and advertising as "Kapock Sun Fast Silks" and then included in minute inconspicuous letter's "Is not a Torm Silk".

The Commission continued to proceed against false and misleading advertising, always on the basis that it was an unfair method of competition. One important question remained unresolved until 1931whether the Commission could prohibit adrertising that misled the public even though there was no proof of competitire injury.

This question was resolved in 1931 by the Supreme Court in Federal Trade Commission v. Ratadam Co., 283 U.S. 643 (1931). The Court held that the Commission lacked jurisdiction to proceed against false advertising where no substantial competition, present or potential, was shown to have been injured or clearly threatened with substantial injury by the alleged deceptive adrertising.

This decision was soon followed by agitation for an amendment to the Federal Trade Commission Act to permit the Commission to act to protect the consumer as well as inonest competitor's. 'These efforts resulted in the passage of the T'heeler-Lea Amendments in 1938. To enable the Commission to protect the consuming public, "unfair or deceptive acts or practices in commerce" were declared unlawful. However, this amendment went beyond this in relation to foods, drugs, cosmetics, and derices, both in expanding the definition of interstate commerce and in the provision for remedies. Specifically, by an added Section 13 to the Act, it gave the Commission for the first time the right to apply in Tnited States District Courts for an injunction to prohibit immediately the dissemination of false advertising concerning these articles pending the Commission proceeding. In addition, the amendment added a Section $1 \pm$ prescribing criminal penalties for false advertising of such products if the commodity may be injurious to health if used as contemplated or if the adrertising was published with the intent to defraud or mislead. 'These represent substantial additions to the remedies available to the Commission in limited areas. Parenthetically, it is interesting to note that legislartion proposed or under discussion today includes a proposal that the Federal Trade Commission be granted authority to petition the District Court for a temporary injunction in any case involving a violation of laws administered by it, including an ordinary case of false advertising.

Other laws enacted since the Trheeler-Lea Amendment and enlarging the Commission's authority have also been consumer legislation. The first of these, the Wool Products Labeling Act of 1939, was en- 
acted against a background of long, continuing consumer deception in the sale of woolens. Many garments then sold as wool were composed of used or reprocessed wool. It is noteworthy this law was enacted despite strong objection from some members of the industry. Consumers insisted on its need.

The purpose of the law is concisely stated: "To protect * * * consumers from the unrevealed presence of substitutes and mixtures *** in wool products.'

Two important features of consumer legislation are stated in that purpose. First, that consumers are to be protected. Second, there should be an affirmative disclosure of material facts when failure to disclose may deceive the consumer. The second feature is a distinguishing characteristic of this Federal consumer legislation.

Chronologically, the next statute was the Fur Products Labeling Act, which was enacted in 195 .

Prior to the Act, the fur industry had gotten itself into almost desperate shape. Orerglamorized fur names and false and fictitious animal names had caused consumer's to lose confidence. Our Division of Textiles and Furs has prepared a list of these names. There are 96 names under which dyed rabbit was sold, including Artic Seal, Australian Coney, Baltic Leopard, Belgian Beaver, and Meskin Ermine. Dyed dog was marketed as Belgium Lynx, Black Pioret Fox, Chinese Wolf, Isabella Fox, and Manchurian Fox.

After receiving this type of treatment for years from the industry, consumers became disenchanted with fur's. They had so completely lost confidence that sales rere decreasing drastically. Particularly hard hit were the producers of genuine quality furs and scrupulous merchants.

In this situation the National Board of Fur Farm Organizationsthe growers of mink and fox-sought the help of the Commission and sponsored the Fur Products Labeling bill.

After the Fur Act came the Flammable Fabrics Act in 1953, brought about by the torch sweater tragedies, and the Textile Fiber Products Identification Act (1958) to remedy consumer confusion arising from the introduction of many new man-made fibers.

The powers granted the Federal 'Trade Commission under the Acts are not trifling. All of the acts contain injunctive provisions. They provide for condemmation of the goods misrepresented or sold in violation of the statute. Criminal penalties in each law are at least $\$ 5,000$ fine or 6 months in jail, or both. In one law, on a second offense, $\$ 10,000$ fine or 1 year in jail, or both, may be levied.

There can be no clearer expression of public policy than criminal sanctions to eliminate practices which flourished under careat emptor.

These statutes did more than extend the authority of the Commission in relation to specific products. They also, through changes in the definition of "interstate commerce" extended the Commission's jurisdiction to what had previously been local matters.

The Federal Trade Commission was created in 1914 by the Congress in its exercise of its power to regulate interstate commerce. It has long been recognized that, in exercising this porer, the Congress may leave a large part of regulation to the States and the local communities, or it may enact laws to the full extent of its power.

In the original Federal Trade Commission Act the Commission was empowered to prevent unfair methods of competition in commerce. 
From the very beginning the Commission regarded this as authority to prevent false or deceptive advertising in connection with sales in commerce. Under this theory, the Commission has jurisdiction of the advertising of only those retailers whose products are sold in interstate commerce, and, in performing its duty, may place the interstate merchants in a disadvantageous competitive position.

Since the establishment of the Commission in 1914, the Congress has enacted legislation expanding the responsibilities of the Commission relating to false advertising and other deceptive practices. Trhen it has found that a need for such amendment was demonstrated, the Commission has recommended or sponsored such legislation. In any consideration of the possibility of further expansion of Commission jurisdiction over local advertising, a review of this legislation is of particular interest.

In 1938 Congress passed the Wheeler-Lea Amendments to the Federal Trade Commission Act, with two apparent purposes: (1) to enable the Commission to proceed against unfair and deceptive acts and practices without regard to competition, and (2) to provide the Commission with more effective control in the exercise of its jurisdiction over false advertisements of food, drugs, devices, and cosmetics. In this amendment it was stater that:

It shall be unlawful for any person, partnelship, or corporation to disseminate, or cause to be disseminated, any false advelisement (1) by the United States mails, or in commerce by any means, for the purpose of inducing, or which is likely to induce, directly or indirectly, the purchase of food, drugs, devices, or cosmetics ***

This amendment specifically recognized that the use of the mails or the dissemination of the advertisement in interstate commerce is sufficient to give the Commission jurisdiction to prohibit the false advertising.

This statute has been interpreted recently in the case of Krenneth W. Shafe v. Federal Trade Commission, 256 F. 2d 661 (6th Cir. 1958). In that case a medicine company sold O-Jib-Ta Bitters as a cure for arthritis, rheumatism, and rarious other ailments. Although it was specifically found that the bitters were not sold outside the State of Michigan, the court sustained an order of the Commission against the dissemination by respondent of false advertising. Adrertising was done only in 35 or 40 newspapers throughout Michigan, which were circulated outside the State of Michigan in some instances.

By analogy, this case means that any adrertisement of a product falling in one of these four categories-food, drugs, devices, and cosmetics-by a local retailer in a local newspaper which in almost every instance would be circulated to some extent outside the State or' through the United States mails would be subject to the jurisdiction of the Federal Trade Commission.

The four laws relating to specific products or groups of productsnamely, the Wool Products Labeling Act, the Fur Products Labeling Act, the Flammable Fabrics Act, and the Textile Fiber Products Identification Act-passed by Congress since 1938 also have a far greater local application than the original Federal Trade Commission Act.

For example, in defining the jurisdiction of the Commission in the Fur Act, it is stated that the introduction or manufacture for intro- 
duction into interstate commerce, the sale, advertising, or offering for sale in interstate commerce, or the transportation in commerce, of any fur product which is misbranded or falsely adrertised or invoiced shall be an unfair method of competition in interstate commerce. It states further that the manufacture, sale, adrertising, etc., of any fur product made in whole or in part of fur that has been shipped and receired in commerce is in interstate commerce.

The remarks of the U.S. Court of Appeals for the Ninth Circuit, in De Gorter r. Federal Trade Commission (244 F. 2d 270 (9th Cir. $1957)$ ), concerning the question whether the respondent, a retail Iurrier located in Los Angeles, was engaged in interstate commerce, are of interest here. The Court said:

The sales to persons residing outside California, the adrertising in newspapers of interstate circulation, and the out-of-state origin of approximately one-fourth of the products sold, taken together, establish the fact that the petitioners were engaged in interstate commerce as that term is defined in the special Act under consideration and in the Federal Trade Commission Act. Both from a legal and social standpoint, an interpretation that would eliminate false adrertising as to ralue and price at a local lerel from the evils which the special Act sought to eradicate, would render it ineffective. Such exclusion would open the door to the type of adrertising which is most harmful-a type of adrertising which, as will appear further on in the discussion, was characteristic of that carried on by the petitioners. In these dars when, through the rarious media of communication, adrertising has so important a part in promoting a wider sale and distribution of products on which the productiritr and the well-being of the American economy depend. misrepresentations as to the ralue and price are more likely to hare a harmful effect on interstate commerce than misbranding or false in roicing.

All these reasons conrerge in calling us to reject the narrow interpretation which the petitioners would have us place upon the statute in question in order to aroid the consequences of a trpe of adrertising of prices which the Commission characterized in its findings as "fictitious." * * *

There can be no question that the Congress can constitutionally enlarge the Commission's power orer local advertising. The trail has been blazed, widened, and in fact pared by other Federal regulatory acts. For example, window washers employed by a local office building hare been held to come within the Fair Labor Standards Act when tenants of the building were engaged in the production of goods for interstate commerce (Kirschbaum Co. T. WTalling, 316 U.S. 517 (1942)). Under the Federal Food, Drug, and Cosmetic Act, a retail druggist was found guilty of misbranding. How did he come under the jurisdiction of this Federal statute? He purchased properly labeled tablets from a wholesaler and 6 months thereafter removed them to another container not so labeled. The Court upheld this application of the statute (United States r. Sullivan, 332 U.S. 689 $(1948))$.

In its Guides Igainst Deceptive Pricing, the Commission listed seven principles which it applies in interpreting and evaluating adrertising. These principles are illustrative of the manner in which adrertising is read to further protection of the consumer.

1. Advertisements must be considered in their entirety and as they would be read by those to whom they appeal.

2. Adrertisements as a whole mar be completely misleading although erery sentence separately considered is literally true. This may be because things are omitted that should be said, or because adrertisements are composed or purposely printed in such a way as to mislead.

3. Adrertisements are not intended to be carefully dissected with a dictionary at hand, but rather to produce an impression upon prospective purchasers. 
4. Whether or not the advertisel knows the representations to be false, the deception of purchasers and the diversion of trade from competitors is the same.

5. A deliberate effort to receive is not necessary to make out a case of using unfair methods of competition ol unfair ol deceptive acts ol practices within the prohibition of the statute.

6. Laws are made to protert the trusting as well as the suspicious.

7. Pricing representations, howerel made, which ale ambiguous will be reat favorably to the accomplishment of the purvose of the Federal Irade Commission Act, as amended, which is to prevent the making of claims which have the tendency and capacity to mislead.

I have attempted to develop the picture of our responsibilities relating to advertising and other merchandising activities directly affecting the consumer. While there can be no doubt that the Commission's antitrust enforcement is equally important to the consumer, its effect is much more indirect and I vill not attempt to deal with it.

Despite our direct connection with consumer interests, it is prob: ably very doubtful that the average consumer knows of the Commission and its responsibilities. To a large extent this may be attributable to our origin as an agency charged with preventing unfair methods of competition and to the fact that our direct responsibility for protection of the consumer has evolved gradually over the years. Thus, our first meeting with a consumer group occurred just last December.

There can be no doubt that the majority of complaints currently reaching the Commission come from competitors of alleged law violators and that the number of such complaints emallating from consumers is relatively small. The Commission is conscions of the fact that this lack of consumer knowledge impedes the adequate performance of its duty. It has made an effort, during the last few years particularly, to tell its story through the daily press and other media of general circulation to the extent that it can. Partially as a result of this and partially as a result of the recent TV scandals and the attendant publicity concerning the Commission, we find that the consumer is coming to recognize that there is a Federal Trade Commission and that it has responsibilities relating to false advertising and other deceptive merchandising practices. Ifowever, we are sure that this knowledge is fragmentary and is limited to a small group. TVe realize that there is no general public knowledge of the scope of the Commission's authority and certainly no knowledge of the nuances of that authority.

We are hopeful that, to a limited degree at least, the Guides which we have recently issued will be a solution to this problem. Although these Guides have been directed generally to the staff of the Commission to assist them in their law enforcement duties, they have been purposely written in the layman's language. 'They can serre as valuable guidance, in the limited areas that they cover, to a consumer in appraising advertising. 'Thus far, guides against deceptive pricing, bait advertising, and concerning the advertising of cigarettes and tires have been issued by the Commission. In most instances, they do not proscribe particular forms of advertising, but rather serve to highlight areas in which misrepresentations may occur. For example, Guides Against Deceptive Pricing do not say that all advertising of bargains is illegal. Is a matter of fact, we feel that the consumer is genuinely interested in buying bargains and we feel most strongly that a businessman is entitled to tell a consumer when he has a bargain. Likewise, similar logic applies to other practices referred to in the Guides. They will, howerer, be valuable to the consumer in 
appraising advertising and will point out to him possible areas of deception.

As a staff member I cannot speak for the Commission, but it is my impression that, as time passes, additional guides will be issued where it appears that they will be helpful to the consumer and to business. I think also that I can safely say that the consumer and his problems are firmly entrenched in the picture of Federal Trade Commission law enforcement.

\section{LABOR'S STAKE IN CONSUMER PROTECTION}

By S. H. Rutrenbera, Director of Research, American Federation of Labor and Congress of Industrial Organizations, Washington, D.C.

'The AFL-CIO, with its 131/2 million union members and their families, represents probably the largest number of consumers in the country who are part of an organization. Consumers, as individuals, are notoriously uninformed about their rights as buyers in the marketplace and they are apathetic to the government agencies which act in their behalf. Too often they fail to give these agencies the support they need to do their job and fail to understand the problems facing these agencies. We in the AFL-CIO, both as individuals and as a group, have tried and shall continue to try to keep our members informed.

Anyone who begins to think seriously about the need for consumer protection is struck almost immediately with the vast unmet needs facing every program-the need for more effective legislation, the need for additional budgets, and the need for greater public understanding and support.

The deficiencies in our system of consumer protection have been spectacularly called to public attention in the past year. No consumer protection agency has escaped its share of headline attention. Scandals in TV quiz shows, the exposes of "payola" in the broadcasting industry, the investigation of high drug prices, the highlighting of advertising excesses, the investigations of the installment credit field by the Douglas Committee, the derelictions of high officials in Federal regulatory commissions, and, of course, the unearthing of large-scale short weight frauds in the Brooklyn meat markets-these several seemingly scattered events have served to demonstrate dramatically (1) the multiplicity of fields in which the consumer interest lies and (2) even more forcefully the neglect into which public apathy has permitted this interest to fall.

Labor unions cannot afford to neglect these events. The wage increases negotiated at the bargaining table must not be lost at the store counter-in the form of unfair prices, misrepresented goods, or short weights and measures. Practically every cent of labor's take-home pay goes into the purchase of products at retail. We have, therefore, a special stake in programs that protect the value of the consumer dollar.

In common with most other consumer protection programs, administration of weights and measures legislation suffers from vast ignorance on the part of the public, including the membership of labor mions. Union members directly involved in the processing or selling of products for retail trade may be somewhat better off in this respect, 
but nonetheless I would renture a guess that very few have even the slightest notion of what weights and measures laws are about, much less whether the laws are good ones or whether they are adequately enforced, or even who administers them-that is, whether it is done by the Federal Government or by State governments or both. As buyer's at retail, people are apt to expect and simply take for granted that their 3 pounds of hamburger is a genuine 3 pounds, that the meter on the gasoline pump states the true amount of gasoline going into the automobile tank, and that a bolt of cloth measures exactly the number of inches it purports to measure. That milk comes in standard containers and bread in standard weights are facts of everyday existence. It is all too easy to assume, in fact, that the weights and measures system is automatic or self-operating, without an active agency of government in the picture at all.

The absence of a critical consciousness regarding weights and measures is heightened by the fact that it is extraordinarily difficult for the average buyer at retail to detect the presence of something wrong. Deficiencies, either accidental or deliberate, may involve only a few of the many buying transactions any one individual concludes. He cammot himself check the honesty of scales used to weigh his purchases. The seepage of his dollar is likely to be in the form of minute quantities-a quarter ounce here, an eighth of an ounch there. Grosser shortages, which he might be likely to notice, are concealed in the mysterious mechanics of metering devices too esoteric for him to catch up with. With packaged commodities, the individual, even were he to take the trouble to do so, cannot check the stated net weight at the time of purchase, but would have to wait until he got home to strip the container and try out a sample checkweighing:

Advancing technologies in processing and packaging make quantity measurements even more elusire for the average citizen, and indeed for the experts themselves. I noted with some interest, for example, that your committee on aerosal bomb-type containers has not yet reached a recommendation as to how quantities in such containers should be labeled. I confess that it is now with some uneasiness that I shall be wondering how much of the contents of such containers is product and how much is fizz.

In short, the very difficulties of consumer self protection at the store counter, the trusting acceptance of the merchant's say-so, plus the special technical problems involver, require that the buyer's convenience and self protection be developed primarily in the form of active citizen interest and support in the public management of these problems. 'That such interest and support is needed is perfectly apparent from some of the truly startling statistics on the losses to the consumer from short weighing and short measuring. Dr. Leland Gordon has cited estimates of $\$ 2$ to $\$ 3$ billion a year. He has stated that the short weighing and short measuring "tax" per family may amount to as much as $\$ 1.60$ a week, the equivalent, roughly, of an 8 -percent sales tax on food purchases.

The principal concern of this annual National Conference on Weights and Measures is one that should also be of important concern to the average citizen-that is, the promotion of uniform State weights and measures laws of high quality through continual improvements in the Model Law agreed upon by Conference participants. As a labor organization, our own experience with State laws in 
other fields is that this is a very slow and difficult process, and that it frequently takes the leverage of a Federal law to bring about significant adrances, sometimes in the form of direct Federal legislation, sometimes in the form of special inducements to bring about desired changes in State laws. With memployment insurance, for example, we know from hard experience that legislation on a State-by-State basis has kept the system in a condition of constant disrepair. Labor has, therefore, pressed for the enactment of minimum Federal standards for State provisions on such items as benefit amounts and length of time for benefits to be payable to jobless workers. The Federal statute on unemployment insurance contains a tax credit derice which can be used to encourage compliance with such Federal standards as Congress can be persuaded to enact. In another field, minimum wage legislation, nearly half a century of effort since the first statute was passed in Massachusetts in the year 1912, has left 21 States today still without any effective minimum wage law. It took a Federal law to bring protection to any very laroe number of workers, and it is mainly through further Federal legislation that future improvements can be expected. In other areas, such as public assistance, State programs have been encouraged through Federal grants-in-aid. In the field of consumer credit, which has traditionally been within the jurisdiction of the States, abuses have grown up in the use of retail installment credit, and States have begun only recently to enact remedial legislation in this field. Currently a bill is pending in Congress to require lenders to make certain disclosures about finance charges in connection with extensions of consumer credit. The bill would provide exemptions where a State law contains the same requirements as the Federal law, thus encouraging new State legislation.

With these experiences in mind, my initial question as a layman in the field of weights and measures is whether more leverage cannot be put into the accomplishment of uniform standards through enactment of some kind of Federal law.

On the surface, the coverage of State reights and measures laws looks fairly complete, with nearly all States having at least some kind of law in this field. But a glance at the map in the back of the report of the last National Conference shows that in 14 States National Conference specifications, tolerances, and regulations for commercial weighing and measuring derices were completely lacking and had been promulgated only partially in 3 others. And Dr. Leland Gordon, whose careful evaluation of State weights and measures laws was published in 1957, gave a "passing mark" to only 5 States in measuring their laws against the provisions of the 1951 version of the Model Law in effect at the time of his study. On a different evaluation basis, he came out ranking only 13 States as excellent or very good, and he found that 7 had laws ranging from "very poor" to "nothing." In the great majority of States, budgets were believed to be inadequate. These observations are not to decry the rery substantial progress I know has been made, but to suggest the presence of a situation in which consumers should interest themselves. Pending Federal standards through legislation, it would seem a clear duty for us, as a labor organization, to support the adoption in the States of the Model Law set out by this Conference, and to support adequate appropriations for its enforcement.

'The present crescendo of public interest in consumer protection 
programs generally will, I am certain, have beneficial results for all such programs, including weights and measures work. I think these results will be long-run, rather than only short-run correction of immediate difficulties. The consumer is becoming a much more selfconscious citizen, and the area of his interest is approaching a clearer definition. There is a buildup of consumer consciousness about a great many problems-everything from food and drugs to used car financing-and an effort to think about them in some kind of orderly and related manner. Consumer programs-and weights and measures work is a very good example of this-have suffered from the fact that they often appear to perform a highly specialized, technical function unrelated to other consumer concerns, and they can sometimes get lost in the shuffle. Unfortunately, every individual has a great many such concerns, and some of them are of immediate and pressing personal urgency - such as heary debt, for example, or a very large medical bill, or the purchase of a house.

There is a move toward unification of the consumer interest, and with it should surely come more effectiveness on a number of fronts. One of the signs of the times is the effort to set up in rarious States a specific office or department for the consumer, such as was pioneered by Dr. Persia Campbell in the State of New York and also by Mrs. Helen E. Nelson of California. A department of consumers has been proposed at the Federal level, as well as a special Senate Select Committee on Consumers. The AFL_CIO has wholeheartedly endorsed these developments.

Within our own organization, the AFL-CIO, I think we are experiencing something of a parallel development. The AFI_CIO has always concerned itself with various aspects of consumer protection such as housing, public health, food and drug programs, and pitfalls in the use of installment credit, for example. But it is only recently that a number of subjects have been consciously put together as part of a definite consumer interest effort as such.

Thus, as many of you probably know, the AFL-CIO, through its Community Services Committee in New York, has started an active consumer counseling program under which consumer information classes are conducted for union members and their families in cities in different parts of the country. 'This program got under way in .Tanuary 1959 . The classes are given under the sponsor'ship of city central labor bodies, and include 10 two-hour sessions on a very considerable variety of consumer subjects. The classes are aimed principally at consumer self protection, not at legislative issues. One of the sessions is specifically deroted to consumer protection laws, including those on weights and measures. Perhaps some of you have already been involved in these sessions as guruest speaker's.

A second development, even more recent, has been the establishnent of a Consumer Legislative Committee in the headquarters of the national AFL_CIO, in order to give special attention to consumer programs and legislative problems at the Federal level. This committee, which is composed primarily of Wrashington legislative representatives of international unions, keeps track of legislative developments on the consumer front and coordinates union efforts in supporting legislation of interest to the consumer. In this session of Congress, the various AFI,-CIO unions have given specific support on the following: 
The color additives bill to require pretesting of color additives used in foods, drugs, and cosmetics.

The hazardous substances bill to require warning labels on toxic household chemicals not covered by the Caustic Poison Act.

The preservation of the lamb-grading program which had been threatened with discontinuance.

The interest-labeling bill to require lenders to disclose the full amount of finance charges on consumer loans and the statement of these charges in terms of the true annual interest rate. We testified on that the day before yesterday.

Appropriations bills for consumer protection programs of the Federal Trade Commission, the Food and Drug Administration, and the Department of Agriculture.

There ar's other measures supported by the AFL-CIO, such as the proposal for a department of consumers, which have not yet come to a hearing. Tre expect to testify next week a gainst a bill that would weaken the new Poultry Products Inspection Act through continuing indefinitely the temporary authority to exempt poultry processing plants from continuous inspection.

In addition to these efforts, the Research Department of the AFLCIO prepares occasional publications to furnish background information on consumer programs, particularly those in which a legislative issue is involved. The department also helps in developing supporting material for direct testimony on particular bills.

TTeights and measures laws, however, like many other consumer programs, are entirely within the jurisdiction of States and localities. 'This makes it harder for a national organization such as I represent to furnish orerall leadership on specific issues in a particular program that may be changing in $\breve{0}$ different places at once and may involve very different problems in different jurisdictions. Yet in the national office we would like to be in a position to furnish whatever helpful perspectives and technical assistance we can to our State organizations with respect to this and other programs. I know that a number of the State AFI-CIO organizations have taken a keen interest in consumer issues, and I think you will find them receptive to your cause.

In conclusion, let me reiterate to you that the AFL-CIO recognizes the stake that all union members and their families have in obtaining the best possible programs for the protection of the consumer. We count the reights and measures programs in the States as one of the important segments in a well-rounded program for the relfare of consumers, and we hope we will be able to give effective support for the very worthwhile objectives you are setting for yourselres in this Conference.

\section{WEIGHTS AND MEASURES IN CALIFORNIA-A CONSUMER VIEW}

\section{By Helex E. Nelsox, Consumer Counsel, Govemor's Office, State of California}

Shortly after the plane took off on my flight here from Sacramento, the sterardess came down the aisle with an armful of magazines and when she reached me offered me the latest issue of a women's fashion magazine. I declined with the explanation that I needed to write a speech.

The stewardess asked what I was speaking about and where. When I told her, "On weights and measures at the National Confer- 
ence on Weights and Measures," her response was, "Weights and measures, what is that about?"

Her response was no different from what I have gotten from dozens and dozens of Californians in the last 8 months-from responsible, public-spirited, well-educated consumers, consumer groups, government officials, and industry leaders. "Weights and measures-what's that? What do you mean?"

Perhaps I should qualify myself a bit before going any further and describe for a moment the position I hold in California. I am often identified out there as a campaign promise that was kept. When Governor Brown was campaigning for the gorernorship, he proposed the establishment of the position of consumer counsel, whose duties would be to speak for and represent the people as consumer's. In his Inaugural Message to the Legislature, Governor Brown said, "We are all consumers. Tet we have never been able to speak in a single voice because we are disorganized and our needs are so diverse. Without a forceful spokesman in government, we have little defense against highly organized special interests. I therefore recommend the appointment of a Consumer's' Adrocate ***"

As was Dr. Persia Campbell's position in New York, the Office of Consumer Counsel in California is in the Governor"s Office. The consumer counsel is appointed by the governor and serres at the pleasure of the governor.

The legislation creating the office spelled out its functions as follows:

1. Advise the governor as to all matters affecting the interests of the people as consumer:s;

2. Recommend to the governor and to the legislature legislation deemed necessary to protect and promote the interests of the people as consumers:

3. Make studies deemed necessary and render reports thereon to the people; and

4. Appear before governmental commissions, departments, and agencies to represent and be heard on behalf of consumer's' interests.

When I was sworn in as Californial's first consumer counsel on October 2, 1959, Governor Brown gave me this one directive:

I want you to study problems affecting the consumer and make your own independent judgments; then I want you to fight for what rou think is right.

The Office of Consumer Counsel has neither law enforcement powers nor administrative responsibilities. It is entirely adrisory. Yet, it has been provided that we may call upon the resources of the State government. In creating this office, the legislature spelled out that

Each agency, officel, and employee of the State shall cooperate with the consumer counsel in carrying out his functions under this article.

Moreover, we can in effect call upon the resources of the citizenry of California, for the statute creating the office enables the gorernor to appoint adrisory committees to assist the consumer counsel in carrying out the functions of the office. These advisory committees work under the direction of the consumer counsel.

The day I was sworn in I accepted my first invitation; to join 3 days later in the annual meeting of the State Association of Weights and Measures Officials.

I learned a lot there. I have learned a good deal since. I have learned enough now to know that I have most of my learning still to do. That is why I am here. 
I am an economist by training, a housewife by sex and instinct. When appointed consumer counsel, I had never had any training that dealt with weights and measures, and as a housewife my ignorance and my unawareness that I personally needed to act to protect my own rights in transactions conducted by weight and measure were almost complete. Complaisancy is the rord that probably best describes the attitude I held and the attitude I have encountered among friends, women's organizations, and organized consumer groups. I have encountered a natural, hearty, healthy, I believe typically American attitude that "All is well, the merchants I deal with are reputable. I have confidence in them. They could not stay in business if they were not."

Events of the last 8 months are shaking that confidence and complaisancy and confirming Gorernor Brown's concern for consumer's rights.

Beginning with the annual meeting of the California weights and measures officials last year, I and many other consumers have learned some of the tricks of deceptive packaging that are being played upon consumers.

TVe have been made aware of the technical nature and the wide scope of the task of weights and neasures enforcement today-with blending pumps serving gasoline to our octane order drawn from tro unseen underground tanks; with unseen computing scales weighing, calculating, and stamping to the hundredth of a pound the meat and cheese we are offered in supermarkets: with more and more familiar products appearing in aerosol dispensers; with private suppliers of heating fuels serving more and more beach and mountain homes and trailer parks. Too, we have become aware of the increasing size of the job of weights and measures administration as we have stopped to realize that the majority of all families own their own homes and are stretching their budgets to buy such maintenance items as paint, lumber, nails, and drapery yardage and carpeting-all sold by weight or measure.

As we have been realizing these facts, confidence has been considerably shaken in our hitherto-held assumption that we need only compare prices in shopping for an item and assume some unseen public servants and the suppliers of our needs have made sure the quantities are as quoted.

Most but not all of the responsibility for weights and measures enforcement in California lies with the $\check{5} 8$ counties. In a majority of the 58 there is a county sealer of weights and measures responsible to the board of supervisors or the county manager. In 26 of the 58 the function of the sealer of weights and measures has been merged with the Office of County Agricultural Commissioner. In these counties the agricultural commissioner is also the sealer of weights and measures. On the State level, the Bureau of Weights and Measures is in the State Department of Agriculture. The State agency certifies the competence of county sealers, has authority to fill a county sealer office if it is left vacant, and maintains general supervision over the respective county sealers and deputy State sealers employed in the various counties of the State.

The State Bureau maintains four branch offices in the State. These branch offices are concerned with enforcement of the petroleum prorisions of the weights and measures law. The State Bureau also 
determines tare weight of containers used by processors, shippers, or other handler's for the delivery to their places of business of edible agricultural products. ${ }^{1}$

The State Bureau of Weights and Measures has maintained general supervision over the respective county sealer's and deputy State sealer's employed in the various counties largely by force of the personality and integrity of the recently retired State Sealer, James Brenton, and the loyalty and conscientiousness of the county sealers and agricultural commissioners.

In 1957 the Department of Agriculture sponsored a bill in the State legislature specifically establishing the authority of the State director of agriculture to make rules and regulations governing the procedures to be followed by county sealers in performance of their functions.

As passed and enacted into law, this bill carried an additional provision specifically authorizing the director of agriculture to make rules and regulations prescribing tolerances, including minimum deficiency tolerances.

Last November the director of agriculture announced a hearing on several petitions put before him requesting that he use this authority. As consumers we had to learn again, as Patrick Henry tried to teach us, that eternal vigilance is the price of freedom. All complaisancy was gone by December 17, the day of the hearing.

The petitions which, as consumers, shocked us most were requests for minimum deficiency tolerances in numerical amounts of as much as $1 / 2$ ounce on an 8 -ounce package of frozen vegetables or fruit. One packaged meat item was included among the items petitioned-cellopacked frankfurters. Named in the petitions were 32 different frozen vegetables and fruits, 100-pound bags of asphalt, chitterlings, and cello-packed frankfurters.

We read minimum deficiency tolerance as legalized short weight. We could see the hidden price increase in our grocer bill. We could also see the precedent that would be created if numerical tolerances on this miscellany of items were granted. There could be no holding back the rush of petitions from other packagers requesting the privilege of short weighing.

We protested. We protested vigorously. We were joined by the California AFL-CIO, by the State Grange, and by some of the consumer cooperatives. We released our brief to the press simultaneously with its delivery, and it was reported throughout the State. The petitions were not granted, and, though twice since then another date has been set to continue the hearing, no further hearing has been held on these petitions.

This near breakthrough has served to alert and, yes, alarm consumers. It has served also to show that the sealer's of weights and measures in California, State and county, were on the same side with consumers. The State Association of Weights and Measures Officials, I am proud to say, spoke at the hearing in opposition to the granting of these petitions.

It has served to show consumers in California that their sealer's are public servants desirous of protecting the consumer interest. Perhaps most important, the near breakthrough has taught consumers, as only a closely averted disaster can, that it is time to bestir themselves. They have learned that they must support the sealers in an

1 California Department of Agriculture Special Publication \#27:. What We Do, p. 36. 
organized and forward-moving program if their sealers are to give them the protection they want in this modern, technical, supermarket, electronics world they shop in today. I beliere I can honestly report enough consumers are ready to do just that in California now.

Governor Brown has urged me to use the full capacities of my office as Consumer Counsel to work with his recently appointed Director of Agriculture, William Warne, and with the counties in rehabilitating and updating our weights and measures laws and their administration.

The structure of our law bears signs of deep erosion. It no longer stands upright, but leans away from the prevailing winds because we have failed to support it with reinforcing and stabilizing rules and regulations. It shows signs of neglect on all sides.

The have our work to do. We do not know the answers, but I for one look forward to the assignment.

In the Office of Consumer Counsel we now have requests from over 30 organizations in the State-momen's groups, public affairs groups, consumer groups-who have asked us to keep them informed and call on them for help with the job. And by far the greatest resource of all is the caliber of our sealer's themselves.

I have never met a group of professional people more derlicated, more determined, more desirous to a man of serving the public interest than the weights and measures sealers in California. I beliere they will be reporting real progress at your next Conference.

(EDITOR'S NOTE: THE BRIEF REFERRED TO IN IIRS. NELSON'S PAPER IS PRESENTED BELOW.)

\author{
BRIEF \\ PRESENTED BEFORE \\ STATE OF CALIFORNIA \\ AT
}

HEARING TO CONSIDER PROPOSED CHANGES

IN THE REGULATIONS OF THE DEPARTIENT OF AGRICULTURE

PRESCRIBING TOLERANCES FOR CERTAIN

PROCESSED COMMODITIES IN PACKAGE FORM

\author{
$\mathrm{BY}$ \\ HELEN EWING NELSON \\ CONSUMER COUNSEL \\ SACRAMENTO, CALIFORNIA
}

December 16,1959

IIy name is Helen Nelson. I appear at this hearing as Consumer Counsel to represent the consumer's' interest. I appear under authority of Article 5, Chapter 1, Part 2, Division 3, Title 2 of the Gorernment Code, enacted by the 1959 session of the California Legislature.

Speaking in behalf of the consumer's' interests, I oppose the granting of legal sanction to process and sell packages of food which are short-weight.

To allow "tolerance and variations from the quantity marked on the container" as is proposed is to legalize short-weighting.

For 32 different frozen foods in package form it is proposed that the maximum "tolerance in deficiency" shall "not be greater than 1 ounce for each 2 pounds or fraction thereof of the marked weight."

Each of the 32 frozen foods listed in the proposal are conventionally packed for consumers, not in two-pound packages, but "in fractions thereof."

Iost are in packages of 8,9 , or 10 ounces.

To allow a "maximum tolerance in deficiencr" - or short-reight-of 1 ounce 
on a package marked 8 ounces is to allow a short-weight of $121 / 2$ percent. On a 10-ounce package, a 1 ounce "tolerance in deficiency" would be a legalized shortweight of 10 percent.

As Consumer Counsel, I am equally opposed to legitimizing short-weights at the meat counter.

Under the heading of "MEAT PRODUCTS" the proposal readied for adoption reads: "The maximum tolerance in deficiency for any of the following commodities in package form shall not be greater than $1 / 2$-ounce for each 2 pounds or fraction thereof of the marked weight."

Frankfurters (cello-packed) are the only produce listed in the present proposal under the heading of "MEAT I'RODUCIS." let the whole form of the proposal is in the plural and appears ominously foresighted and ready for future additions.

The proposed allowable "deficiency" of $1 / 2$ ounce in the weight of cello-packed frankfurters would be a short-weight of 3 percent on a 1-pound package, or 4 percent on a 12-ounce package.

For many years, in California, it has been one of our rights as consumers to go to the grocery store knowing that every packaged product is marked with its net weight. This statement of weight is net weight to the purchaser-a statement of fact we have come to trust.

As taxpayers, we employ weights and measures officials to patrol the marketplace and make sure that a package marked net weight 10 ounces weighs at least 10 ounces. Since 1921 the responsibility for adopting administrative regulations on weights and measures in California has rested with the Department of Agriculture. Under regulations your Department has made and our local weights and measures officials enforce, we as consumers have come to trust the marked net weight of a food package.

As consumers, we see no cause that can justify your removing that right to trust from us now.

The packing and sale of frozen food is not new. Frankfurters have been cello-packed for years. What can now justify granting legal sanction to sell any one of us a package marked "net weight 9 ounces" when its net weight is only 8? In behalf of the consumer's of California, I say that nothing can justify it. I urge you not to adopt this proposal. I urge you to support and defend, as you have in the past, the right of each of us as a consumer to receire the full-stated weight we are paying for.

To sanction short weight is to sanction a concealed price increase to every person who is sold a short-weighted package.

For example, a short weight of 1 ounce on a 9-ounce package of frozen asparagus spears costing 49 cents would be a price increase of 13 percent to the consumer.

Similarly, a short weight of 1 ounce on a 10-ounce package of chopped spinach would be the same as a 10 percent price increase to the purchaser of that package.

Price increases on the 32 frozen food items nnder consideration would range all the way from 5 percent to 15 percent if a 1-ounce short weight tolerance were allowed.

I do not believe the Departunent of Agriculture or any other State agency should be party to such back-(loor pricing practices.

As consumers we are not consoled by the provision that only some, not all, packages would be short-weight-that all the packages in a lot would be expected to a verage ont to the marked weight (after excepting from the calculation of the average any "unreasonably large" error").

As a consumer, each of us buys not an "average" package of peas, but a specific package one which, if this proposal is adopted, can legally be short in weight as much as an ounce.

A mother who buys a 9-ounce package of regetables and gets only 8 ounces is not going to be cheered while she is serving her fimily's plates at dinner by the knowledge that some other family somewhere got an onnce more than they paid for.

As consumers, we have watched our rights in the grocery store being steadily whittled away.

As a result of deceptive packaging and disuse of grade labeling, we already find ourselves in a game of blind man's bluff when we seek to distinguish quality. Now we are asked to play rowlette at the frozen food bin and the meat counter.

We oppose this ultimate affront of being told to take our chances hereafter 
between short weight or long weight but that we can't have net weight any longer.

We oppose this ultimate affront of being asked to believe that 8 ounces are 9 . May I quote from the law creating the standards of weights and measures in 1850: "There shall be but one standard of measure of length and surface, one of weights and one of measure of capacity throughout this state."

California consumers have long had the assurance that the marked weight on a package of food is net weight to the purchaser. As Consumer Counsel, speaking on behalf of the people as consumers, I remind you it is your responsibility to continue that assurance.

\section{BREAKFAST MEETING OF THE INCOMING EXECUTIVE COM- MITTEE OF THE CONFERENCE, FRIDAY, JUNE 10, 1960}

On Friday morning, June 10, the newly elected Executive Committee, the chairmen of the standing committees, and the weights and measures members of the Advisory Committee were invited to meet to study and reach decisions regarding the 46 th Conference. The meeting was presided over by the newly elected Conference Chairman, Mr. R. E. Meek of Indiana. The following decisions were reached regarding the 46th National Conference on Weights and Measures, 1961:

1. Place: Sheraton-Park Hotel, Washington, D.C.

2. Date: June 11-16, 1961.

3. Duration: Open committee meetings on IIonday and Tuesday if deemed necessary by the Secretary; opening session Tuesday afternoon or Wednesday morning, depending on duration of committee meetings; Wednesday afternoon free of any scheduled business session; business sessions Thursday and Friday according to program plans.

4. Registration Fee: $\$ 10.00$.

5. Entertainment: Similar to entertainment this year ; left to the discretion of the Secretary.

6. The committee heard an invitation extended by Mr. J. H. Lewis in behalf of the State of Washington Department of Agriculture for the 47th National Conference to be held in Seattle, Washington, in conjunction with the "Exposition Century Twenty-one". On motion, the Chairman was directed to designate a special committee to study the feasibility of the Conference being held in locations other than the District of Columbia. (The Chairman has appointed to this committee the Chairman and the Vice Chairmen elected by the 45th National Conference to serve during the 46th National Conference.)

\section{SIXTH SESSION-MORNING OF FRIDAY, JUNE 10, 1960}

(H. E. Crawford, Chairman, Presiding)

\section{REPORT OF THE COMMITTEE ON RESOLUTIONS}

Presented by H. R. Kexnex, Chairman, Commissioner, Department of Labor, State of West Virginia

HAWAII

Whereas, since the adjournment of the 44th National Conference in 1959, Hawaii has become the 50th State of the United States; and

Whereas, this event has been signalized during the 45 th National Conference by the presentation to the State of Hawaii, by the Secretary of Commerce, of new State standards of weight and measure, 
together with a proposed State weights and measures statute prepared by the National Bureau of Standards: Therefore be it

Resolved, That this 45th National Conference on Weights and Measures welcome Hawaii to the community of States and express the sincere hope that the State will be represented regularly at the meetings of the National Conference, and that its representatives will participate actively in all of the deliberations of the Conference.

CONGRATULATIONS TO THE NEW JERSEY WEIGHTS AND MEASURES ASSOCIATION

Whereas, the New Jersey Weights and Measures Association will celebrate its Golden Jubilee Conference at Atlantic City on September $6-9,1960$; and

Whereas, this date marks the fiftieth amniversary of the founding of this organization, comprising all New Jersey weights and measures officials; and

Whereas, the New Jersey delegation extends an invitation to all present at this National Conference to attend its Golden Jubilee Conference: Therefore, be it

Resolved, That the 45th National Conference on Weights and Measures wishes to congratulate the New Jersey Weights and Measures Association on its achievements during these past 50 years and on the occasion of its Golden Jubilee.

Resolutions of appreciation were adopted as follows:

1. To Honorable Frederick H. Mueller for his constructive contribution to the program of the 45th National Conference on Weights and Measures.

2. To the Swiss Colony, the Wisconsin Gift Cheese Shippers Association, the National Association of Dairy Equipment Manufacturers, and the Wisconsin State Department of Agriculture for a most enjoyable cheese buffet on Wednesday evening.

3. To governing agencies for their cooperation in facilitating attendance at the Conference.

4. To business and industry for cooperating with the Conference, for attending and participating in its activities, and for hospitality extended.

5. To program speakers.

6. To the Director and staff of the National Bureau of Standards for the assistance in planning and administering the program and other details of the meeting.

\author{
H. R. Kennelu, Chairman \\ W. C. BoYD \\ IV. H. Cramer \\ P. I. Morris, JR. \\ J. F. McCarthy \\ Raymond Rebuffo
}

A. D. Rose

(On motion of the chairman, seconded from the floor, the report of the Committee on Resolutions was adopted by roice rote.)

\title{
OPEN FORUM-WEIGHTS AND MEASURES ADMINISTRATION NEW DEVELOPMENTS IN TESTING EQUIPMENT
}

By Office of Weights and Measures, National Bureau of Standards

[W. S. Bussey, Chief, introduced members of the staff of the Office of Weights and Measures, M. W. Jensen, H. F. Wollin, and R. L. Steiger, who informally described developments under way at the Na- 
tional Bureau of Standards toward advanced testing equipment for weights and measures officials. Mr. Jensen spoke of a special prover for liquid meters in liquid fertilizer service; Mr. Wollin described the developments of a weighing scale and volumetric standards to be used in package checking; and $\mathrm{Mr}$. Steiger demonstrated an electrically powered two-wheel dolly for moving 1,000-pound test weights.]

\section{UNIFORM REPORTING AND RECORDS}

\section{By L. J. Gondon, Director, Weights and Measures Research Center, Denison University, Granville, Ohio}

Yesterday afternoon I was in a meeting of the National Advisory Committee and Mr. Moss made a statement which seemed to all of us very apt, that biblical allusion to hiding one's light under a bushel seems to be applicable to the work of weights and measures officials. Those of us, you particularly, and I now take pleasure in including myself with you, who are close to the administration and enforcement of the weights and measures laws, are familiar with the program. But I know that you are a ware, as I am, of the discouraging lack of knowledge of what you are doing on the part of the public at large.

I find the same thing in my profession. Is far as I am aware, I am the only economist who has ever undertaken any serious study of the significance of weights and measures to our economy. Every time we make a purchase, there is involved a quantity, a degree of quality, and a price, and we are in the peculiar position that the fact that a quantity is involved seems of little concern to anyone.

Oftentimes friends of mine in the rarious economic associations ask me with such a quizzical expression, "What is this you are doing in weights and measures?"

IThen I begin to tell them about it, there is apparent first an understanding, then interest, and then enthusiasm. After having worked in this field now for some years, I decided to try to develop further interest among my fellow economists, and I have in mind publishing an article for a journal under the title "Quantity Competition." You gentlemen will recognize at once what I have in mind, because many of you have given me illustrations of the man who sells an apparent bargain which, when you begin to check the quantity compared with the quantity of a competitor, turns out not to be a bargain.

Last August I accepted an invitation to give a lecture at a southern Illinois university which was attended by all of the members of the Department of Economics plus many of the students. I thought this would be a good time to try out a discussion along the line of the proposed article.

As I began working on it, I was conscious of the difficulty of getting good, solid, measurable, comparable statistical material. Finally I just had to give up and I began my presentation by saying, "There simply is not yet available in this field the kind of material with which one can make a statistical comparison, so I shall have to give you illustrative material." After the presentation of an array of illustrative material drawn from your various reports mostly, my audience proceeded with a fairly technical analysis in economic terms showing the effect of quantity competition.

By diagrammatic illustrations, the degree with which one seller 
can increase his profits by short weighing or short measuring was shown, and then, by contrast, the degree to which his profits may be diminished as a result of overweighing or overmeasuring.

The response to that by the group of about this size was very enthusiastic, and there were many questions. I then decided to put the lecture in form to submit to one of the journals. At this stage, my colleagues, a professor of statistics in my institution and another professor in economics, and I decided we wanted to get some statistical material we could use.

We consulted with Mr. Bussey, and at the time of the Conference on Consumer Protection we met in this city. John Mahoney of Maryland sat in with us, and we drafted a questionnaire, and then we selected 12 States. One of my colleagues, who was doing consulting work for the United States Department of Agriculture, wanted some material on fertilizer also, so we chose States where that would be important and we sent this questionnaire to 12 of you, all of whom I know personally, with an explanatory letter. The results we got were very disappointing.

Everyone wanted to help us, of course, but some said, "TVe operate on a project basis. At the beginning of the year we set up our program and this is too late," or" "We do the same thing. This is too early. We have not made up our program for next year." Others said, "We do not keep our records this way, so we just do not have this information, and cannot get it for you."

I went ahead and prepared the article anyway and sent it to the Journal of Marketing, which is the logical one for publishing this kind of an article. I was not surprised when it came back with a note of appreciation for sending it to them, but saying that it just was not a good, solid, analytical paper based upon good, solid, statistical material.

My next choice was to send it to the Harvard Business Review, thinking I would bring it to the attention that way of business executives for whom that journal is published. An even more sympathetic friendly response came from them, but nonetheless it was a rejection.

It is now in the hands of the editors of the Southern Economic Journal. I will not at this moment indicate just why I chose that journal next, but I had a good reason for doing so. Maybe they will publish it as it is. If they do not, I am going to send it to the Journal of Business, published by the Cniversity of Chicago.

But I am fully aware of the difficulties from the standpoint of the editors. "Sure, this is very interesting, but we have to have something more scholarly than this if we are going to publish it." So you can see, if we are going to bring this important problem of quantity competition to the attention of the economists through one of their journals, we need your help.

Everything I have said so far leads up now to this plea: that the appropriate committee of this Conference take under consideration a study with a view to drafting uniform methods of testing, record keeping, and reporting.

In Handbook 67 you have the begimnings of uniform testing. What I would like you to do next is to get uniform record keeping, and then uniform reporting.

Perhaps I can illustrate what I have in mind by saying that years ago when the Interstate Commerce Commission began serious regula- 
tion of railroads they found they could not really do anything effective because of the different ways in which the railroads kept their sets of accounts. So one of the first things they did was to require all Class I railroads to keep a uniform set of accounts and then a uniform reporting system.

In weights and measures, this has to be on a voluntary basis, and I would hope that as a beginning perhaps a dozen of you gentlemen representing State or major municipal jurisdictions might rolunteer to participate in the establishment of this kind of a plan.

Something of what I have in mind is now being done in the Southern Weights and Measures Association. Most of you, I am sure, maybe all of you, know about the method by which several States in the Southern Association are now reporting jointly through a clearing house which currently is George Johnson's office in Frankfort, Kentucky. I am on the mailing list and receive those reports, and I find them very interesting.

I think that, when we have maybe a 5 -year base, we will have some rery interesting material, and that then an economist will be able to use the statistical information and draw some conclusions which would be supported by this information.

Last year you heard Claire Jackson give his report of the study he had made. He was very generous and sent me samples of his material. But my statistical colleague said, "This is just a beginning. After we have 5 years of this kind of record, where we can begin to see trends, so we can see whether this is typical or whether it is sporadic, then we can make some use of this."

I hope very much, Mr. Jackson, that you will continue the kind of study that you made last year and that other jurisdictions will do likewise.

If you were to press me with questions now about "How are you going to do this ?" and so on, I would sidestep them because I do not have experience that you gentlemen have. You are the ones, if the spirit moves you, who can make a great stride forward in this aspect of your work.

I know you may be thinking already, "WVe have more work now than we can do." I have talked with enough of you to know that that is true. But if somehow we could, through one of your committees, find time to do the basic groundwork in setting up a form which you could use for keeping the records and then a form for reporting them, say through this Conference or through the Office of Weights and Neasures or through your annual reports, then I believe it would be simpler for you in the end.

I now receive from many of you monthly reports, quarterly reports, and annual reports, but, when I sit down and spread those on my desk and try to make comparisons, I cannot do anything because they are presented in a rariety of ways.

So, Mr. Chairman, I conclude this very informal statement with an expression of hope that this suggestion might be submitted to one of the standing committees of the Conference for study and recommendation.

\section{DISCUSSION ON FOREgOING PAPER}

Mr. Harris: I would like to compliment Dr. Gordon as being the first professional economist who has developed a real meaning for the third phase of buyer consideration. Buyers long have been aware of 
the first two phases-price and quality-but, only through the efforts of Dr. Gordon, has the third phase-quantity-become important. In some 36 States the weights and measures agency resides in the State department of agriculture. I believe it behooves the officials of those States particularly to pursue the quality-quantity-price concept.

Mr. Sanders: Dr. Gordon's point in regard to planned reporting for planned results is excellent. I believe that the counsel of both economists and statisticians should be sought in the derelopment of uniform reporting systems.

Mr. Jackson: It seems to me that weights and measures officials have not taken full advantage of the availability of professional assistance in the area of economics. Dr. Gordon has broken ground through his interest and certainly has been a tremendous influence. It is up to us to pursue this matter.

Dr. Gordon: Surely the weights and measures officials have lines of communication with the educational institutions of their States. Intelligent young economists should be sought for research in this vital area of economics.

\section{ESTABLISHING A BUREAU OF STANDARDS IN OKLAHOMA}

\section{By V. C. Kennedr, JR., Executive Director, University of Oklahoma Research Institute. Norman, Oklahoma}

Oklahoma became a State in 1907. It was approximately 1910 that the first laws relative to weights and measures were enacted. In 1915, legislation was passed establishing a State Bureau of Standards, which was to be located at the State University of Oklahoma, now the University of Oklahoma. It was further provided that the president of the university should appoint a director for this Bureau of Standards from the faculty of the university, and two additional members of the faculty to serve as assistant directors. The director and assistants were designated as the Board of Control of the Bureau of Standards. It was specifically provided that this Board of Control should receive no salary.

The Board of Control was assigned the responsibilities of the custody of the various standards of weight and measure and the testing devices in the Bureau of Standards. It was provided that the Bureau of Standards should be available to all State departments, municipalities, private corporations, and citizens of the State. The Bureau was designated the highest official authority in regard to standards of weights, measures, and tests, and methods of weighing, measuring, and testing. It was stated that the findings of the Bureau of Standards in any case of question shall be considered prima facie evidence of the correctness thereof. It also provided that all enforcing officers of weights and measures in the State of Oklahoma should submit their weighing, measuring, and testing derices to the State Bureau of Standards for certification and seal at such periods as set by the Board of Control.

At some time between 1915 and 1920 a large number of standards were acquired by the university. Among the important pieces of equipment that are currently available in the Bureau of Standards are a 50-pound, wide ar'm balance, numerous smaller balances, a length comparator, a set of gold-plated reference standards, several 
sets of working standards, volumetric standards (both liquid and dry), length standards, precision tapes, a wide rariety of electrical standards, and considerable additional laboratory apparatus.

The weights and measures situation in Oklahoma is complex in that there are at least eight different State agencies that have some enforcement responsibilities relative to weights and measures. Among them are the Bureau of Weights and Measures, the State Board of Agriculture, the Oklahoma Corporation Commission, the State Mining Board, the State Board of Health, the State Board of Pharmacy, the Oklahoma Tax Commission, and the Department of Public Safety.

One of the more interesting aspects of weights and measures enforcement in Oklahoma is that in 1910 legislation was passed providing that it was the duty of the sheriff of each county in person, or by his regular deputies, to inspect all scales used by the public weigher or any deputy weigher, that such scales should be tested with United States standard weights, and that each sheriff should place his seal upon such tested scales at conspicuous places. It was further provided that any failure on the part of the sheriff to comply with the provisions of the law would be a misdemeanor and, upon conviction, the offending official would be liable to a fine of not less than $\$ 10$ or more than $\$ 100$ for each scale omitted from inspection.

In the past years the rarious standards of weights and measures were carefully preserved by the university. However, extremely limited use was made of them. In fact, many of them were still preserved in their original sealed packages as received from the National Bureau of Standards.

In 1959 the university decided to reactivate the Bureau of Standards. This was made possible when the University of Oklahoma Research Institute occupied new quarters on the north campus of the university which was formerly a naval air station. The Research Institute is a nonprofit corporation which was established in 1941 by the University of Oklahoma to handle contract research. It is through this organization that various governmental agencies, industry, and citizens of this area are able to make use of the facilities through the technical assistance of the members of the faculty of the university. The activities of the Bureau of Standards will be conducted under the administrative support of the Research Institute.

A room of approximately 970 square feet was set aside for the Bureau of Standards and the standards and equipment, much of it for the first time cleaned and put into first-class condition. In view of the fact that none of the standards had been tested since 1919, it was necessary to return the weights to the National Bureau of Standards for recertification. Tolumetric measures followed sometime later.

The general situation is becoming particularly important in Oklahoma in that at the present time the State is going through considerable industrialization. Industry as well as the scale dealers and the various enforcement agencies are becoming more conscious of the necessity of properly certified weights. It is planned that, as soon as the certified weights and measures have been returned from the National Bureau of Standards, a major effort will be put forth to calibrate the working standards that are in the hands of the various enforcement officers. 
Presently the Bureau of Standards is quartered in a temporary building and its scope is quite limited. It is hoped that, in the not too distant future, more adequate permanent quarters will be established for the Bureau and that the scope of the Bureau will be enlarged. Among the first activities to be undertaken will be provision for calibration of electrical instrumentation as well as the physical measurements. It is also proposed that a Russell balance be ordered to supplement the existing equipment in the laboratory. This will allow testing of weights of large capacity that are used by the State enforcement officials. It is also planned that in the near future calibrated tanks of large capacity be acquired by the State for use by the Bureau of Standards.

One major problem that lies ahead of the State of Oklahoma is attempting to improve the weights and measures law and generally bringing it into conformity with the Model Law. A preliminary study has been made by the Bureau of Government Research at the university. It appear's that this will be a relatively complex action, since statutes in 48 different titles of the Oklahoma statutes are involved as well as the large number of agencies that are directly charged with some aspect of weights and measures enforcement. It is anticipated that several years will be required before any major change can be satisfactorily presented before the legislature.

\section{DISCUSSION ON FOREgOING PAPER}

Mr. Peiser: Mr. Bussey of the Office of Weights and Measures has told us of the new dynamic outlook in Oklahoma, and we at the National Bureau of Standards are very much interested in your activities. You raised the point as to the constancy of mass standards if they are not used. There is a reasonable amount of data on such standards and I am glad that some of the Oklahoma standards recently submitted will give us some further information.

An example of data available relates to the West Virginia standards, down to 0.001 gram, that were calibrated by the Bureau in 1915. In a recent recalibration, it was determined that the values of these standards today agree with the 1915 values within two-millionths of a gram. What this really amounts to is that it confirms that (1) our claims for accuracy in 1915 were sound, (2) our claims for accuracy today are sound, and (3) properly designed and constructed mass standards will remain reasonably constant.

We hope that the new type of mass standard that we now are developing, if left packaged, would remain in tolerance for more than 100 year's.

\section{NATIONAL TYPE APPROVAL}

\section{By C. H. STender, Assistant to Commissioner of Agriculture, State of South Carotina}

In presenting a statement to you entitled "National Type $\Lambda$ pproval", it is only fair that I preface my remarks with some history leading up to the possible reason this subject was placed on the $\mathrm{Na}$ tional Conference 1960 program.

Type approval is not a new subject. It has been discussed, formally and informally, during many of these Conferences. National type 
approval, however, is relatively a new subject and apparently a subject that interests many jurisdictions.

Realizing its importance, T. C. Harris of Virginia, President of the Southern Association in 1959, made the subject one of the 1959 program assignments at the Richmond Conference last October. Ralph Magoffin, our National Chaplain and one of my coworkers in South Carolina, presented the paper at the Southern Conference. The statement was well prepared; it provoked sound conference discussions, and the Southern Conference unanimously endorsed the reference of Mr. Magoffin's paper to the National Conference.

In the meantime, the statement has been reproduced in a number of news media and in all probability has reached the attention of many of you.

Ralph Magoffin is in attendance at this National Conference, but his plans prevented him from accepting the opportunity of bringing this subject to your consideration.

To show customary courtesy to any request of the Southern Association, the Secretary of the National Conference has asked that I present a discussion on this subject. I consider it a privilege to have this opportunity.

I am not advocating national type approval over local type approval. I am asking the question that concerms many weights and measures jurisclictions-shall it be national type approval or, for some, no type approval at all? I am sure many jurisdictions have not required type approval because they were unable to procure appropriations for either personnel or test equipment. It has been a perennial. struggle to obtain funds to "keep our shops open."

National type approval to me seems the answer for a need that grows every day and a need which many of us will never be able to meet in our local jurisdictions. I say many of us will not be able to have a sound type approval program, but frankly I am seriously prompted to say none of us will be able to provide a sound and comprehensive program.

I do not have to tell you that modern equipment is a "far cry" from the even-arm balance scale, the hanging spring scale, the hand gasoline pump with visual glass bowl, the tin liquid or the wooden dry measures. Testing these antiquated pieces of equipment with a kit of weights or a group of metal measures may have constituted type approval in the years passed. All I can call this is regular scale and pump testing with a high sounding name-type approval.

Many of our weights and measures laws would have been equally as outmoded if most jurisdictions had not decided to progress with the times.

I do not hesitate to say the National Conference on Weights and Measures-which is the congress of weights and measures officialshas been the prime medium for the progress that has been made to keep our profession in the front ranks of public service.

The National Bureau of Standards has been our clearing house for national distribution of the deliberations of weights and measures officials.

Together, the Conference and the Bureau have been a democratic body working together to meet the challenge of changing times. It has been my considered opinion that our relationship has been mutually beneficial to both organizations. I know in my State we 
take pride in saying our equipment meets Bureau standards. I can tell you this statement quiets many skeptical minds. When over 3,000 weights and measures officials tell this story over and over again, it appears to me the Bureau has a nationwide delegation of good will ambassadors.

Through the years many jurisdictions, with their sights on progress, have legislated requirements for type approval. How these jurisdictions administered their laws or to what extent they were able to perform actual type approval certainly must have depended on qualified personnel. Having a law does not mean sound and effective enforcement. It takes experienced practical minds to effectively promote the ideals of the theorist.

South Carolina does not have a type approval law-not because of any concerted action against such a law-but because the powers that be, in our formative days of reights and measures, believed the best way to eliminate faulty equipment was to confiscate and destroy. Our law has that provision. But what about today?

Several weeks ago I had the privilege of visiting the plant of one of our well known scale manufacturers. What I saw convinced me that type approval is more than two words put together to make a highsounding title with which to impress nobody but yourself. I am sure I could not impress anyone because I would be, first, unable to impress myself. That to me is the crux of the question-but what about today? If you are fortunate enough to have equipment and trained personnel, then type approval is just part of the day's work. For those less fortunate, there is an answer-national type approval.

I quote in part from Ralph Magoftin's statement when he says:

First, what is type approval? It is more than the inspection of a derice in the field to see that it meets certain requirements over and above its ability to work accurately. Accuracy is one thing. Correctness is another. Type approral is, briefly, a preinspection for correctness and the approval or disapproval of a device to meet a certain set of ground rules. You have your ground rules spelled out either in Handbook $44^{\circ}$ or by your own standards set forth by your own law. These standards came about over many years in order to promote uniform requirements which could be met by the manufacturer of the derice.

Why, then, you might ask, is there a need for type approval? If the mannfacturer makes a derice which meets Handbook 44, is there any need to look at it? I say that there is. And I say that type approval has its place in the complete weights and measures program, but again I set a specific limitation.

My first reason for saying that type approval is necessary is that not all manufacturers follow Handbook 44 to the letter, and only in those jurisdictions where type approval is in effect are these devices "headed off at the pass." Even in the modern adult western, the sheriff still finds it easy to take the short cut and catch the bad guys in the rocks before they can "fan ont." We found that our lack of ground rules was permitting the installation of several devices which had been rejected by a neighboring jurisdiction.

Type approval surely aids the field inspector in any jurisdiction. The knowledge that a device is "cleared" for use leaves him free to test and inspect for any local changes which might have been made long after the device left the hands of the manufacturer.

Type approval surely aids the buyer in any jurisdiction. The knowledge that a device has met the approval of a qualified judge gives the buyer confidence that he can be free of the possibility of having an instrument that he bought in good faith condemned for failure to meet a requirement in a code that he knows nothing about and which he is not likely to stop and read.

Type approval surely aids the manufacturer. The knowledge that his device is able to meet the standards established by the enforcement agency is certainly a matter of pride in craftmanship, engineering, design. and sales.

Type approval may be effective only when competent administration is avaitable. Modern devices are complex. Many are delicate instruments which 
are not entrusted to the judgment of untrained personnel. I class myself in this group. Were I an engineer trained in the theory of design or were I able to pay for such a man. I would not hesitate to start type inspection tomorrow. Many of those jurisdictions haring type approral hare such men, and the jurisdictions are the more blessed for it. Some who perhaps would contemplate type approval do not and would not have such a man. A good man in scale work mas not be the man to pass judgment on a new meter. A hrdraulic engineer would have a tough time with an eiectronic load cell.

What, then, is the jurisdiction to do? How can the derices failing to meet one jurisdiction's standards be headed off before thes are already in such ridespread uses that eradication is impossible?

B 5 having 50 separate trpe approrals, one for each jurisdiction? No manufacturer can afford the time nor can he afford the space for putting 50 separate approval plates on his derice.

By an industry committee? Hardly possible, unless industry is in the habit of inviting the competition over for tea and cookies and a discussion of the latest design with the admonition that thes go back to the plant and speak only of the excellence of the cooking and hospitality.

By an independent testing agency? Supported by whom and staffed by whom?

By an exchange of agreement between the jurisdictions haring approval and those who do not?

No, the erentual answer lies where qualified judges mas be found; where a full knowledge of the ground rules mas be found: where adequate inspection means, both phrsicalls and from plans, mas be found: where there is no reason to lean one way or another: where sectionalism does not apply. since the whole country is involved. The erentual answer lies in NATIONAL TYPE APPROTAL and in the front door of the National Bureau of Standards.

It can work, gentlemen. It alreadr works in the field of science. The scientific glassware eren the primary chemical standards-are manufactured to close design and requirements of the National Bureau of Standards.

You mas alreadr work with trpe-approred standards. Your weights are not just made into random shapes and of random materials. Try sending a 5-pound rock to the Bureau for certification as a primars standard. It mas weigh exactly 5 pounds, but sou will not get a certification of approral.

That ends the quote from Ralph Magoffin. The type of this argument has my approval. I am sure a summation is all that is nom necessary to complete my statement.

Let us be honest in our conrictions. If you have a type approval setup in your jurisdiction and conscientiously believe you have competent engineers and adequate equipment to perform the service, then you do not need added assistance. But think of those who want real type approval and see absolutely no chance of realizing that service in their jurisdictions. Certainly you would not interfere with these less fortunate jurisdictions obtaining the service at the national lerel, especially when this service would hare the stamp of approval from the highest authority in the Nation.

There is a group of us who would welcome type approval at the national lerel and specifically at the National Bureau of Standards. Many in industry have also roiced their preference for this service. I believe we can have this service if we start the "ball rolling," and certainly the best place to give the ball the initial "push" is right here at the National Conference.

In bringing this to a close, I have reread this statement to find out if I have used one word anywhere in the context-that word is compulsory. This will be the first time it has been used, and I hope you will fully appreciate why it is now mentioned.

I join with those who adrocate national type approval-not compulsory type approval. Each jurisdiction will have, as it has always 
had, the right to adopt or reject that which its officials believe is for the best interest of the people they serve.

Toward obtaining a sound and recognizable program of type approval, I urge you who are satisfied with your program to support a move toward national type approval for those who either do not have a program or know that the service they now perform is inadequate.

You who are fortunate enough to have an adequate program have nothing to lose. Those who "hare not" can then more forward toward the ideals of intelligent, orderly, efficient, uniform, and sound weights and measures to all segments of our national economy and welfare.

\section{DISCUSSION ON FOREgOING PAPER}

Mr. Greene: An effective national type approval plan could be worked out through consultation with the States that presently are administering in their State a type approval program. I am sure all of us would be willing and even anxious to cooperate.

Mr. Rice: Although we have realized the weakness of a city type approval program, we have felt it necessary for the protection of our people. It has been necessary for us to issue certificates for devices on the basis of the representation of the manufacturer that the device conforms to the requirements of Handbook 44.

\section{REPORT OF AUDITING COMMITTEE}

Presented by J. H. Lewrs, Chairman, Chief, Weights and Measures Section, State Department of Agriculture, State of W ashington.

It is my pleasure to report that it is apparent that the books are in order.

I would like at this time to commend Mr. Morgan for the method and the manner in which he keeps the books and the records. I also feel it would be well if the group would be cognizant of the fact that he is handling our funds in a very efficient manner, especially the reserve funds. He has, as you will no doubt hear from his report, placed these funds in a savings account and we have realized some increase in funds through the interest factor.

I think he is to be commended. I know that we all should extend our appreciation to the fine job he is doing.

$$
\begin{aligned}
& \text { J. H. Lewis, Chairman } \\
& \text { N. P. Tillewan } \\
& \text { J. D. Walton }
\end{aligned}
$$

(On motion of the chairman, seconded from the floor, the report of the Auditing Committee was adopted by the Conference.) 


\section{REPORT OF THE TREASURER}

\section{Presented by C. C. Morgan, Treasurer, City Sealer of Weights and Measures, Gary, Indiana}

Balance on hand June 1, 1959

RECEIPTS :

Registration fees-1959 Conference, 330 at $\$ 10--\$ 3,300.00$
Bank interest accrued $\$ 7.04$
Miscellaneous
Subtotal $\$ 3,393.84$

Total $3,393.84$

$\$ 5,492.70$

Disbursements :

Expenses of 44th National Conference:

Conference party:

Sheraton Hall, reception and dance, sand-

$\$ 2,098.86$ miches, sodas, punch and waiters

Music, Jack Morton Productions_._-_-_-_--

Ladies' entertainment:

Old Club Restaurant

AB\&W Transit Co

Bus transportation of delegates to Beltsville Laboratories

$\$ 685.67$

175.00

168. 75

220.00

87.60

12.95

401. 20

Miscellaneous hotel and Conference expenses.-

Expenses of Conference subsequent to June 12, 1959:

National Weights and Measures Week:

Stamps

J. E. Bowen

American Electrotype Co. for 2,000 mats.--

G. W. Allen Co. for letterheads

Travel expense of Special Flour Committee members

Travel expense of Committee on Specifications and Tolerances for interim meeting ........

Stamps for secretary

G. W. Allen Co. for certificates

Flowers

Bank charges

Subtotal

$\$ 2,861.35$

$2,861.35$

$\$ 2,631.35$

8.00

$\$ 2,639.35$

Total balance on hand June 1, 1960

28.85

61. 20

42. 23

141. 24

720.30

30.00

54. 06

8. 00

4. 30

Check No. 28 outstanding

DEPOSITORY :

Gary Trust and Savings Bank, Garr, Indiana.

First Federal Savings and Loan Association, Gary Indiana.

(Signed) C. C. MORGAN, Treasurer

(On motion of the chairman, seconded from the floor, the report of the Treasurer was adopted by the Conference.) 


\section{INTRODUCTION OF AND STATEMENT BY CONGRESSMAN BYRON L. JOHNSON OF COLORADO}

Dr. Gondon : I should like to introduce to the Conference my friend and fellow economist Congressman Byron L. Johnson of Colorado. Congressman Johnson has a broad background and great interest in a wide range of topics, including weights and measures. We are honored by his presence with us this afternoon.

Congressman Johnson: I am pleased to see the cooperation between an agency of the Federal Government and agencies of the State Governments. This is an excellent example of good Federal-State relationships and is, I am convinced, proving fruitful toward effective law enforcement.

Yours is an unglamorous field, not frequently in the public eye. Nonetheless you have a vital job to do-vital to producers, retailers, and consumers alike. If there is anything that I can do to help you get a more sympathetic support for your program, I shall be happy to advise you.

\section{STATEMENT OF NEWLY ELECTED CONFERENCE CHAIRMAN R. E. MEEK}

The Executive Committee of the 46th National Conference on Weights and Measures, during its session this morning, discussed the absence from the Statement of the Organization and Procedure of the Conference of any provision for executive sessions. 'The committee felt that under certain circumstances an executive session, attended only by active and advisory members, would be desirable. The committee therefore proposes, in accordance with section 10 of the Organization and Procedure of the National Conference on Weights and Measures, two amendments to said Organization and Procedure, to be voted on during the 46th Conference in 1961, as follows:

Amend the final paragraph of section 3, Constituent Membership, which now reads, "Members of all classes hare the privilege of the floor at meetings of the Conference" to read:

Members of all classes have the privilege of the floor at all meetings of the Conference except executive sessions. Attendance at an executive session is limited to the active and advisory membership, members of both classes having the privilege of the floor.

Amend the second paragraph of section 6, Duties of Officers, by adding at the end of the present paragraph a sentence reading:

The Conference Chairman is authorized to order an executive session of the Conference at any time such a session is deemed by him to be in the best interests of the Conference.

(The benediction was delivered by the newly elected Conference Chairman, Mr. R. E. Meek. Thereupon at 11:40 a.m. the 45th National conference on Weights and Measures adjourned sine die.) 


\section{PERSONS ATTENDING THE CONFERENCE}

\section{Delegates-State, City, and County Officials}

\section{ARIZONA}

State

Nerio Bertocchi, Deputs Inspector, State Department of Weights and Measures, 139 Capitol Bldg., Phoenix.

\section{CALIFORNIA}

State

B. G. Wood, Acting Chief, Bureau of Weights and Measures, Department of Agriculture, 1220 "N" St., Sacramento.

H. E. Nelsox, Consumer Counsel, Office of Consumer Counsel, Gorernor's Office, Sacramento.

County :

Alameda_..... W. A. Kerlix, Counts Sealer of Weights and Measures, 333 Fifth St., Oakland.

Kern

A. D. Rose, County Sealer of Weights and Measures, 1116 East California Are., Bakersfield.

Los Angeles:

F. M. RAYmuxd. County Sealer of Weights and Measures, 3200 North Main St., Los Angeles.

San Diego

H. J. McDade, County Sealer of Weights and Measures, 1480 "F" St., San Diego.

Santa Clara_-_-- D. R. PrAtr, County Sealer of Weights and Measures, 142 N. Market St., San Jose.

Ventura

E. H. Black, County Sealer of Teights and Measures, P.O. Box 1610, Ventura.

\section{COLORADO}

State

B. L. Johxsox, Congressman, District No. 2.

H. X. Duff, State Superrisor, Teights and Measures Section, Department of Agriculture, State Serrices Bldg., 1525 Sherman St., Denrer.

H. H. Houstox, Director, Oil Inspection Department, 1024 Speer Blrd., Denrer.

\section{CONNECTICUT}

State

F. M. Greene, Chief, Division of Weights and Measures, Department of Consumer Protection, Room 514 State Office Bldg., Hartford.

Counts :

Hartford

A. E. Paganetri, County Sealer of Weights and Measures, 95 Washington St., Hartford.

P. J. MCCARThr, Deputy County Sealel.

V. H. ZAJACK, Assistant Sealer.

New London_--- A. S. KArgul, County Sealer of Teights and Measures, 103 Slater Are., Jewett Cits.

Tolland

R. P. Fraxcinr, County Sealer of Weights and Measures, 125 Main St., Stafford Springs.

Windham

Thomas Supixa, Jr., Countr Sealer of Teights and Measures, Route 3, Stafford Springs.

Hartford.

Nathax Kalechmax, City Sealer of Weights and Measures, 550 Main St.

Middletown _-_.- Peter Grassi, City Sealer of Teights and Measures, P.O. Box 223.

New Britain _._. A. J. Albanese, City Sealer of Teights and Measures, City Hall. 
Weights, Measures, and Markets Branch, Department of Licenses and Inspection, Room 227 Esso Bldg., 261 Constitution Ave. NW., Washington, D.C.

District J. T. Kennedy, Chief.

J. M. Bouciner, Supervisor.

J. T. BENNICK, Inspector and Investigator.

R. E. BradLEY, Inspector and Investigator.

W. R. Cornelius, Inspector and Investigator. KENNETH HAYden, Inspector and Investigator. II. P. Hutcinsson, Inspector and Investigator. W. H. Jennings, Inspector and Investigator. G. P. Kosuros, Inspector and Investigator. I. L. WAGNER, Inspector and Investigator. W. W. WELLS, Inspector and Investigator.

\section{FLORIDA}

State

City :

Jacksonville

Miami

City :

Chicago

Rockford

State

County :

Gibson

Grant

St. Joseph

Vigo City :

Gary

Indianapolis

New Albany

South Bend

Terre Haute

Nalls Berryman, Director, Weights and Measures Division, Department of Agriculture, Room 107 Nathan Mayo Bldg., Tallahassee.

H. E. Crawford, Inspector, Department of Weights and Measures, Room 203, City Hall.

H. E. IIoward, Supervisor, Division of Trade Standards, Coconut Grove Station, P.O. Box 708.

\section{GEORGIA}

P. I. Morris, Jr., Director, Weights and Measures Division, Department of Agriculture, 19 Hunter Street SW., Atlanta.

J. W. D. Harver, State Oil Chemist, State Oil Laboratory, Department of Rerenue, 264 Capitol Pl., Atlanta.

\section{IILINOIS}

I. M. Levr, City Sealer of Weights and Measures, Room 302 Central Office Bldg., 320 North Clark St.

R. J. Fary, Chief Deputy Inspector.

R. J. Nicosia, City Sealer of Weights and Measures, 425 East State St.

\section{INDIANA}

R. E. МеEк, Director, Division of Weights and Measures, State Board of Health, 1330 West Michigan St., Indianapolis.

W. C. Boyd, State Inspector.

W. R. Sevifr, County Inspector of Weights and Measures, Somerville.

R. C. PArks, County Inspector of Weights and Measures, Court House, Marion.

S. C. Grzeskowiak, County Inspector of Weights and Measures, 513 Indiana Ave., South Bend.

R. J. Sincock, County Inspector of Weights and Measures, Room 5 Court House, Terre Hante.

C. C. Morgan, City Sealer of Weights and Measures, Room 204 City Hall.

W. R. Copeland, Supervising Inspector, Department of Weights and Measures, $202 \mathrm{~N}$. Alabama, Room 2.

M. A. Steinert, City Inspector of Weights and Measures, 37 West Fifth St.

B. S. Cichowicz, City Inspector of Weights and Measures, City Hall.

J. T. HARper, City Inspector of Weights and Measures, City Hall. 
State

J. F. Trte, State Sealer, Dirision of Weights and Measures, State Board of Agriculture, State Office Bldg., Topeka.

\section{KENTLChY}

State

G. L. Johrsor, Director, Dirision of Teights and Measures, Department of Agriculture, Capitol Annex. Frankfort.

\section{LOLISIAYA}

State

F. F. Thompsor, Chief Chemist, Petroleum Products Tax Dirision. State Department of Rerenue, Unirersitr Station, P.O. Box \$3it, Baton Rouge.

\section{MAINE}

State

City: Portland

H. D. Robirsox. Deputy state Sealer of Weights and Measures, Department of Agriculture, State House, Augusta.

C. J. WrLls, Jr.. Citr Sealer of Weights and Measures, Room 16, 389 Congress St.

\section{MARILAID}

State-

Countr :

Montgomers_-_. E. W. BLckis. Director. Department of Inspections and Licenses, Countr Building, Rockrille.

L. B. Mortox, Countr Inspector of Weights and Measures.

J. P. Soltrsiak, County Inspector of Teights and Measures.

Prince George s.. R. J. Cond, Chief Inspector of Weights and Measures, Court House, Upper Marlboro.

City: Baltimore

G. H. Leithatser. Chief Inspector, Dirision of Weights and Measures, Room 1106 Municipal Building.

\section{MASSACHUSETTS}

State-

Cits :

Boston_..-_-_. J. F. McCarthy. Cits Sealer of Weights and Measures, Room 105 Citr Hall Annex.

J. T. Bradrex, Deputr Sealer.

Cambridge_.... A. T. Axpersox, Cit sealer of Teights and Measures, Citr Hall.

Ererett_-_-_-_-_ L. L. ElliotT. Ciț Sealer of Teights and Measures, Cits Hall.

Nerton_-_-_-_- J. E. Bowex, Citr Sealer of Weights and Measures, City Hall. Nenton Centre.

Quincr-........ H. H. Hcghes, Citr Sealer of Teights and Measures, Cits Hall Annex, 63 Sarille Ror.

Salem_-_._-_- B. A. KotTI.AK, Cits Sealer of Teights and Measures, 1it Bridge st.

Somerrille Works Bldg. 
State

City :

Dearborn

Detroit

Livonia

Muskegon

Pontiac

City :

Minneapolis

State

State

tate.

(Minneapolis

B. F. Nelson, Alderman, 307 City Hall.

J. G. Gustafson, Chief Inspector, Department of Licenses, Weights, and Measures, Room 101-A City Hall.

\section{MISSISSIPPI}

W. G. SEllers, State Inspector of Weights and Measures, Department of Agriculture and Commerce, Route 1, Laurel.

\section{MISSOURI}

State

V. M. Gray, Assistant Commissioner, Department of Agriculture, Jefferson City.

G. W. BAY, Chief, Weights and Measures Division.

City : St. Louis

J. A. Bernard, Commissioner of Weights and Measures, Room 12 City Hall.

\section{MONTANA}

State

Delbert Walrath, Chief Sealer, Division of Weights and Measures, Department of Agriculture, Capitol Bldg., Helena.

\section{NEVADA}

State

Raymond Rebuffo, Assistant Director, Division of Plant Industry, State Department of Agriculture, Capitol Hill at Wells, P.O. Box 1209, Reno.

\section{NEW HAMPSHIRE}

State

City : Manchester
A. H. Ditrrich, Chief Inspector, Bureau of Weights and Measures, Division of Markets and Standards, Department of Agriculture, State Office Bldg., Concord. Franklin St.
F. A. Genest, City Sealer of Weights and Measures, 180 
R. S. Milleer, Deputy Attorney General, Department of Law and Public Safety, 23 Hardwick Dr., Trenton.

W. H. Crayier, State Superintendent, Division of Weights and Measures, 187 West Hanover St., Trenton.

S. H. Christie, Jr., Deputy State Superintendent.

R. K. Bonenweiser, Supervisor of Enforcement.

A. T. Sмrth, Supervisor of Technical Services.

J. R. BIRD, Senior Technician.

E. N. Colgax, Regional Supervisor.

II. N. Edmonstor, Chief, Bureau of Fruit and Vegetable Service, Division of Markets, Department of Agriculture, 1 West State St., Trenton.

County :

Atlantic

Bergen

Burlington

J. E. Myers, County Superintendent of Weights and Measures, 350 South Egg Harbor Rd., Hammonton.

M. J. Saxtmiauro, County Superintendent of Weights and Measures, 66 Zabriskie St., Hackensack.

E. E. Dawsox, Assistant County Superintendent.

P. F. NUNN, County Superintendent of Weights and Measures, County Office Bldg., 49 Water St., MIt. Holly.

Camden

D. F. Humnel, Assistant County Superintendent.

Cumberland......

A. C. BECkER, County Superintendent of Weights and Measures, City Hall, Camden.

Essex

G. S. Franks, Acting County Superintendent of Weights and Measures, 1142 East Landus Ave., Vineland.

W. H. Schneidewixd, County Superintendent of Weights and Measures, 278 New St., Newark.

Mercer

R. M. Bodenweiser, County Superintendent of Weights and Measures, Court House, Trenton.

Monmouth_._._ W. I. THompsor, County Superintendent of Weights and Measures, P.O. Box 74, Allenhurst.

J. A. J. Bovie, Assistant County Superintendent, 82 West Wall St., Neptune City.

W. G. Dox, Assistant County Superintendent, 12 Campview Pl., Keansburg.

J. J. Elkker. Inspector, P.O. Box 74, Allenhurst.

Passaic

William Miller, County Superintendent of Weights and Measures, 317 Pennsylvania Ave., Paterson.

Union

JAMes Dietz, County Superintendent of Weights and Measures, Court House, Elizabeth.

Warren_....... G. E. Con rolly, County Superintendent of Weights and Measures, R. D., Belvidere.

City :

Bayonne

J. G. YAYDA, Municipal Superintendent of Weights and Measures, 450 Avenue $\mathrm{E}$.

Camden

Alfred DiPiero, Municipal Superintendent of Weights and Measures, City Hall.

Englewood

Leorard DeRienzo, Municipal Superintendent of Weights and Measures, City Hall.

Garfield_..._.... Charles Benanti, Municipal Superintendent of Weights and Measures, City Hall Annex, Commerce St.

Jersey City__.-- H. J. MYrers, Municipal Superintendent of Weights and Measures, City Hall.

Kearny

JAMES Pollock, Municipal Superintendent of Weights and Measures, Town Hall.

Linden

L. T. Reagax, Municipal Superintendent of Weights and Measures, Room 206, City Hall.

Passaic_._._... PAul DeVries. Iunicipal Superintendent of Weights and Measures, City Hall.

Joseph SHAw, Assistant Municipal Superintendent.

Paterson _-_.-_. J. P. Leonard, Municipal Superintendent of Weights and Measures, 115 Van Houten St.

W. J. Kenoe, Jr., Assistant Municipal Superintendent.

Union City

A. O. Ostund, Municipal Superintendent of Weights and Measures, City Hall, 3715 Palisade Are. 
State

County :

Genesee

Monroe

Wayne

City :

Ithaca

Lackawanna

Rochester

White Plains

Yonkers
J. F. MAdDen, Director, Bureau of Weights and Measures, Department of Agriculture and Markets, State Office Bldg., Albany.

J. D. McGarty, State Inspector, North Granville.

G. A. Puldmax, County Sealer of Weights and Measures, 19 Buffalo St., Bergen.

E. D. Hubble, County Sealer of Weights and Measures, 1400 South Are.. Rochester.

Richard Vexess. Deputy Sealer.

Robert Williàs. County Sealer of Weights and Measures, 58 Third A re., Mineola, Long Island.

A. W. Weidner, Jr., Assistant County Sealer.

H. H. Wright, County Sealer of Weights and Measures, 30 Catheline St., Lrons.

Richard DeNagel, County Inspector, County Court House, Lyons.

E. P. Nedrow. City Sealer of Weights and Measures, City Hall.

J. J. Seres. City Sealer of Weights and Measures, 84 Rosary Are.

A. C. Samenfixin, City Sealer of Weights and Measures, Rochester Public Market.

T. E. Latmone, City Sealer of Weights and Measures, Department of Public Safety, 279 Hamilton Are.

Johr Drmase, City Sealer of Weights and Measures, City Hall.

\section{YORTH CAROLIYA}

State

M. L. Kinlaw, State Inspector, P.O. Box 507, Hope Mills.

\section{OHIO}

State

C. W. Yax SchoIK, Chief, Division of Weights and Measures, Department of Agriculture, Agriculture Laboratories, Reynoldsburg.

V. D. CAMPBELL, State Inspector (Ohio Sealers Association).

County :

Ashland

J. H. NigH, Deputy County Sealer of Weights and Measures, c/o County Auditor, Ashland.

Auglaize

Ferd Wellarax, County Sealer of Weights and Measures, New Knoxville.

Defiance

Medina

A. D. Elliott, County Auditor. Court House, Defiance.

R. W. Searles. Deputy County Sealer of Weights and Measures. County Board of Education Bldg, Medina.

City :

Cincinnati

W. E. G. RheIs, Superintendent, Dirision of Markets, Weights and Measures, 316 George St.

Springfield

Walter Hall, City Sealer of Weights and Measures, 812 Snowhill Blyd.

Youngstown

F. B. Jones, City Sealer of Weights and Measures, City Bldg.

\section{OKLAHOMA}

State

H. K. SharP, Assistant Director, Marketing Division, Board of Agriculture, Capitol Bldg.. Oklahoma City.

I. C. Keñeny. JR., Executive Director University of Oklahoma Research Institute. Faculty Exchange. Norman.

City : Tulsa

\section{Room 200 IL unicipal Bldg.}


State

Counț :

Philadelphia_.--

City : Altoona

H. M. Turrel., Director, Bureau of Standard Weights and Measures, Department of Internal Affairs, Capitol Bldg., Harrisburg.

E. A. Vadelund, Assistant Director.

J. IT. Houser, Field Supervisor.

J. J. Powers, Chief Supervisor, Bureau of Weights and Measures, 306 City Hall, Philadelphia.

R. I. Cummings, City Inspector of Weights and Measures, Ciț Hall.

\section{SOUTH CAROLINA}

State

C. H. Stexider, Assistant to Commissioner, Department of Agriculture, P.O. Box 1080, Columbia.

E. TI. Ballentine, Supervisor, Weights and Measures.

R. M. Magoffir, Chief Chemist.

\section{SOUTH DAKOTA}

State

D. C. Haxxa, Senior Scale Inspector, Public Utilities Commission, spencer.

JAMEs Etzkons, Scale Inspector, Public Utilities Commission, Pierre.

C. H. McKEe, Scale Inspector.

\section{TENNESSEE}

State

City: Nashrilie
Matт Jexnixgs, Director, Dirision of Marketing, Department of Agriculture, 406 State Office Blig., Nashrille. Tox WebB, City Sealer of Weights and Measures, 300 Demonbreun St.

F. J. Forto, Deputy Sealer.

TEXAS

City : Dallas

J. D. Walton, Supervisor. Weights, Measures and Marliets, City Hall.

\section{UTAH}

State

F. D. Morgar, Supervisor, Weights and Measures, Department of Agriculture, 412 State Capitol, Salt Lake City.

\section{VIRGINIA}

State

T. C. HARris, Jr., Supervisor, Weights and Measures Section. Division of Markets, Department of Agriculture and Immigration, 1200 East Main St., Richmond.

E. W. Hudson, State Inspector, Route No. 1, Big Island.

J. F. WELls, State Inspector, 4314 Williamson Rd., Roanoke.

P. W. Crews, Executire Officer, Department of State Police, Richmond.

City :

Danrille

C. H. Wrexx, City Sealer of Weights and Measures, Curb Market Bldg., Spring Street.

Norfolk_

W. F. Bradlex, City Sealer of Weights and Measures, City Hall.

Richmond

II. L. RICE, Senior Inspector, Bureau of Weights and Measures, Room 112 The Mosque Building, Laurel and Main Sts.

I. C. BAUGHAX, Inspector.

E. C. Rager, Inspector. 
State

City : Seattle

J. H. Lew Is, Chief, Weights and Measures Section, State Department of Agriculture, P.O. Box 120, Olympia. D. M. 'Turn bull, Director, Licenses and Standards, Office of the Comptroller, 100 County-City Bldg.

\section{WEST VIRGINIA}

State

H. R. Kennell, Commissioner, Department of Labor, 643 State Office Bldg., 1800 East IV ashington St., Charleston.

\section{WISCONSIN}

State

D. N. McDowel, Director, Department of Agriculture, State Capitol, Madison.

C. L. Jackson, Chief Dirision of Economic Practices.

N. E. Kinschbaum, Supervisor, Weights and Measures Section.

S. J. Hallor, State Inspector, 850 Marquette Are, Green Bay.

E. G. Wrnell, State Inspector, 110 North Third St., Onalaska.

City :

Beloit

L. IV. Raymond, City Sealer of Weights and Measures, Municipal Center.

Green Bay_._.. N. P. Tilnemax, City Sealer of Weights and Measures, City Hall.

Milwa ukee

L. F. WrtT, City Seaier of Weights and Measures, 1331 Nolth Fifth St.

Sheboygan

J. A. Perkert, City Sealel of Weights and Measures, City Hall.

West Allis

J. J. Persak, Deputy Sealer of Weights and Measures, City Hall.

\section{Advisory Members}

U.S. Department of Commerce:

F. H. Mueller, Secretary of Commerce.

National Bureau of Standards:

Director's Office :

A. V. Astin, Dilectol.

A. T. McPherson, Associate Director for Engineering:

Henry Birnbaum, Assistant to the Director.

W. A. Wild Ack, Special Assistant to the Director.

Office of Weights and Measures:

W. S. Bussey, Chief.

M. W. Jenser, Assistant Chief.

L. V. Judson, Physicist.

R. W. Smitr, Consultant (Honorary Life Member).

H. F. Wollin, Engineer.

R. L. STEIGER, Engimeer.

G. H. Borders, Library Assistant.

Mrs F. C. Belr, Administrative Assistant.

Mrs. E. L. Brueckner, Secretary.

Mrs. M. M. Broduerkel, Secletary.

Office of Technical Information:

W. R. Trlley, Chief.

Miss Jane Cunningham, Administrative Assistant.

P. E. W' ILSH, Chief, Information Section.

P. L. REın, Publications Editor.

J. F. REILly, Publications Editor.

Miss A. L. Wright, Information Clerk.

Electricity Division:

F. R. Kотter, Physicist, Resistance and Reactance Section.

Mechanics Division:

B. I. Wilson, Chief.

M. E. Young, Administrative Officel. 
Metrology Division :

H. S. Peiser, Chief, Mass and Scale Section.

L. B. Macurdr, Chief, Mass Unit, Mass and Scale Section.

C. L. Carroll, Jr., Mechanical Engineer, Mass Unit, and Mass and Scale Section.

M. E. Boyd, Physicist, Mass Unit, Mass and Scale Section.

Miss Eleator Axdersox, Physicist, Mass Unit, Mass and Scale Section.

P. S. Shoexfeld, Phrsicist, Mass Unit, Mass and Scale Section.

Mrs. E. M. McMahox, Secretary, Mass Unit, Mass and Scale Section.

G. T. Backes, Physical Science Technician, Mass Unit, Mass and Scale Section.

Mrs. M. W. Joxes, Phrsical Science Aid, Mass Unit, Mass and Scale Section.

H. H. Russell, Chief, Scale Unit, Mass and Scale Section.

H. L. BADger, Phrsicist, Scale Unit. Mass and Scale Section.

C. W. ATWELL, Laboratory Mechanic, Scale Unit, Mass and Scale Section.

J. F. Saunders, Student Trainee. Scale Unit, Mass and Scale Section.

R. W. Crouch, Jr., Technologist, Photometry and Colorimetry Section.

J. C. Hughes, Supervisory Phrsicist, Volumetry and Densimetry Section.

B. C. Keysar, Physical Science Technician, Volumetry and Densimetry Section.

S. H. Eurara, Guest Worker, Egrpt.

U.S. Department of Agriculture:

R. D. Thompsox, Supervisor of Scales and Weighing. Packers and Stockrards Branch, Lirestock Division, Agricultural Marketing Serrice, Washington, D.C.

C. H. OAKLer, Scales and Weighing Specialist, 403 Lirestock Exchange Building, Denrer, Colo.

M. W. STEPHexs, Scales and Weighing Specialist, 3507 Department of Agriculture Building, Washington, D.C.

U.S. Department of Defense:

Richard Stolle, Deputy Chief, Quality Control, Air Materiel Command, U.S. Air Force, Wright-Patterson Air Force Base, Ohio.

Federal Trade Commission:

J. R. Herm, Director, Bureau of Consultation. Washington, D.C.

C. R. Moone. Legal Adrisor on Deceptive Practices, Bureau of Inrestigations, Washington, D.C.

C. J. Coxioluy, Project Attorney.

R. W. Slodx, Project Attorner.

U.S. Department of Health, Education, and Welfare:

C. T. Hubble, Director, Dirision of Administratire Reriew, Bureau of Enforcement, Food and Drug Administration, Washington, D.C.

L. M. Beachair, Deputy Director, Dirision of Food. Bureau of Biological and Phrsical Sciences, Food and Drug Administration, Washington, D.C.

U.S. Department of the Treasury :

E. W. Teagardex, Engineering Specialist, Dirision of Technical Serrices, Bureau of Customs, Washington, D.C.

\section{Associate Members-Manufacturers of Weighing and Measuring Devices}

American Meter Co.: W. V. Sтосктох, JR.. Product Manager, 13500 Philmont Are., Philadelphia, Pa.

Badger Meter Manufacturing Co.: Mr. E. HARTz. Director of Research and Engineering. 4545 West Brown Deer Rd., Milwaukee. Wis.

Bowser, Inc. : E. J. ReIxHarT, Serrice Manager, Fort Warne, Ind.

Brewer, C. A., Co.: C. A. BREwEr, Vice President, 308 Buell Rd., Rochester, N.Y. Brodie, Ralph N.. Co. :

E. D. Brodie, Vice President, San Leandro, Calif.

C. J. McCaffrey, Vice President, 550 South Columbus Are., Mount Vernon, N.Y.

D. W. Kixgstey, Eastern Manager.

H. E. Sifbold, Sales Engineer, Room 528 Chrrsler Bldg., New York, N.Y.

Chatillon. John, \& Sons: G. C. ReIler, Vice President, Sales, 85-93 Cliff St., New York, X.Y. 
Creamery Package Manufacturing Co.: L. T. Gustafsox, General Sales Engineer, 1243 West Washington Blvd., Chicago, Ill.

Dairy Equipment Co.: K. S. HART, Vice President, 1444 East Washington Are., Madison, Wis.

Detecto Scales, Inc: MAck RAPp, Vice President, 540 Park Are., Brooklyn, N.Y.

Dixie Cup Division of American Can Co. :

C. G. McBride, Assistant to the Vice President and General Manager, Easton, $\mathrm{Pa}$.

J. G. Rogers, Consultant, Weights and Measures, 4730 Sterens Dr., Sarasota, Fla.

Exact Weight Scale Co. :

W. A. Scheurer, President, 538 East Town St., Columbus, Ohio.

WV. J. Schieser, Vice President.

J. F. Sullivar, Manager, Research and Derelopment.

O. H. Watson, Manager, Midwest Division, 608 South Dearborn St., Chicago, Ill.

Factory Equipment Co.: J. F. FEInd, President, 190 State St., Bloomfield, N.J.

Fairbanks, Morse \& Co.:

C. G. Gehringer, General Sales Manager, Scale Division, 600 South Michigan Ave., Chicago, Ill.

Jerome Kenney, Field Engineer, 659 East Twenty-fifth St., Baltimore, Md.

W. J. RUzEK, Field Engineer.

Gilbert \& Barker Manufacturing Co.: William Kear, Manager, Sales Service, West Springfield, Mass.

Granberg Corp.: W. M. MIlligan, Easteinn Division Sales Manager, 489 Fifth Ave., New York, N.Y.

Gurley, IV. \& L. E. :

R. G. Betts, President, 514 Fulton St., Troy, N.I.

F. G. Wrluams, Washington Representative. 5.514 Nerada dre. NW., Washington, D.C.

Hobart Manufacturing Co. :

K. C. Allen, Vice President, Scale Operations, 448 Huffman dre., Daston, Ohio.

E. A. Reussenzehn, Chief Scale Engineer, Dayton Scale Division.

M. E. Bone, IVeights and Measures Representative.

H. W. Heady, Regional Manager, Penn Ave., Troy, Ohio.

Hot Spot Detector, Inc. : Bruce Fulexw Moines. Iowa.

Howe Scale Co.

R. F. Straw, Vice President, 68. Stewart dre. SIV., Atlanta, Ga.

G. D. Wilkinson, National Service Manager, 2941 Scale Are.. Rutland, Vt.

Kaspar Scale Co.: F. J. Kaspar, Owner, 6700 Storer Ave., Cleveland, Ohio.

Kimble Glass Co.: J. J. Moras, Technical Director, Scientific Sales Division, P.O. Box 230, Vineland, N.J.

McIntyre, John J., Sons : F. I. McIntrke, Owner, 514-16 Knorr St., Philadelphia, $\mathrm{Pa.}$

Measuregraph Co.: F. L. WALL, Representative, 6603 Arlington Blvd., Falls Church, Va.

Mettler, E. : Hans Merer, Zurich, Switzerland.

Mettler Instrument Corp. : F. C. 'Tobler, President, Hightstown, N.J.

Miller, Byron, \& Associates: B. D. Mrlete, Owner, 7712 Geolgia Are. NW., Washington, D.C.

Neptune Meter Co. :

E. F. WEHMANN, Assistant Chief Engineer, 47-25 Thirty-fourth St., Long Island City, N.Y.

F. Kutch, Sales Manager, Petroleum and Industriai Meters.

IVILliaM MEDFord.

Nicol Scales, Inc.: W. F. Nrcol, President, 1315 S. Akard, Dallas, Tex.

Owens-Illinois Glass Co.: F. B. Busch, Specifications Engineer, P.O. Box 1035, Toledo, Ohio.

Pottermeter Co.: M. BAYER, Sales Manager, Industrial Meter Division, P.O. Box 1426, Union, N.J.

Reyere Corp. of America : H. L. ZupP, Sales Engineer, Wallingford, Comn. ; C. WV. Silver, Sales Manager.

Rockwell Manufacturing Co.: A. J. Koмrch, Product Manager, Liquid Meters, Statesboro, Ga.

Sanitary Scale Co. :

E. C. KarP, Vice President, 910 East Lincoln Are., Belvidere, Ill.

R. D. KlaAs, Assistant Plant Manager. 
Sauter, August, of New York, Inc.: H. G. Shmp, Manager, 866 Willis Ave., Albertson, N.Y.

Scientific Glass Apparatus Co., Inc.: C. R. Heatr, District Representative, 9419 Georgia Ave., Silver Spring, Md.

Seraphin Test Measure Co.: T. A. Seraphin, Manager, 1314 North Seventh St., Philadelphia, Pa.

Smith, A. O., Corp. :

H. D. LeIsenring, Director of Marketing, 250 Park Ave., New York, N.Y.

L. G. Blumenberg, Manager, Field Service, Smith-Erie Division, 1602 Wagner Ave., Erie, Pa.

Spinks Scale Co.: D. F. LAIrd, Manager, 836 Stewart Ave. SW., Atlanta, Ga.

Stimpson Computing Scale Co. : J. J. WAAge, President, 829 Logan St, Louisville, Ky.

Streeter-Amet Co. :

R. T. Is Ham, Executive Vice President, Executive Offices-Main Plant, Grayslake, Ill.

C. L. Richard, Consultant.

Symington Wayne Corp. :

IV J. Dubsky, Manager of Engineering, Salisbury, MId.

F. IV. Love.

Thatcher Glass Manufacturing Co., Inc. :

A. C. Thomas, Quality Control Department, Elmira, N.Y.

J. A. Harper, Customel Service.

Tokheim Corp.: William Loutrin, Manager, Field Service, 1600 Wabash Ave., Fort Wayne, Ind.

Toledo Scale Co.:

D. B. Kendall, Manager, Product Engineering Department, 5225 Telegraph Rd., Toledo, Ohio.

R. V. Miller, National Manager of Weights and Measures, and Sanitary Standards.

J. G. Lewis, Manager, Government Division, 3329 Eighth St. N.E., Washington, D.C.

Torsion Balance Co.: J. P. Slane, Eastern Sales Representative, 35 Monhegan St., Clifton, N.J.

Triner Scale \& Manufacturing Co. : T. T. JANsey, Executive Vice President, 2714 West Trenty-first St., Chicago, Ill.

Troemner, Henry, Inc.: C. F. Rosica, Sales Manager, Twenty-second and Master Sts., Philadelphia, Pa.

Turner, E. H., Professional Engineer, Balances and Weights, 79 Kenneth Pl., New Hyde Park, N.Y.

Veeder-Root, Inc. :

A. E. McKeEver, Sales Manager, Master Meter Duplicator Division, 70 Sargeant St., Hartford, Conn.

H. W. Barnes, Assistant Sales Manager, Special Products Division.

R. J. Kenny, Service Manager, Altoona, Pa.

Voland \& Sons, Inc.: Bernard Wasko, Chief Engineer, 27 Centre Ave., New Rochelle, N.Y.

Washington Scale \& Equipment Co., Inc.: AAron Yochelson, President, 1107 New Jersey Ave. NW., Washington, D.C.

Wood, John, Co. :

L. G. Close, Manager, Mid-Atlantic States, Bennett Pump Division, 2127 North Charles St., Baltimore, MId.

W. M. Hoxie, Service Manager, Bennett Pump Division, Broadway and Wood Sts., Muskegon, Mich.

\section{Associate Members-Associations, Business and Industry, and Railroads}

Allied Oil Co., Division of Ashland Oil \& Refining Co. : E. F. Marquard, Department Manager, Heating \& Burner Department, Standard Bldg., Cleveland, Ohio.

American Federation of Labor and Congress of Industrial Organizations: A. G. Draper, Research Assistant, 815 Sixteenth St., Washington, D.C.

American Meat Institute: Chester Adaxs, General Attorney, 59 East Van Buren St., Chicago, Ill.

American Petroleum Institute:

J. E. Moss, Director, Division of Transportation, 1625 K St. NIV., Washington, D.C.

D. L. Grant, 1271 Avenue of the Americas, New York, N.Y.

P. IV. ENGELs, Consultant. 
American Standards Association: A. C. Huttox, c/ National Bureau of Standards, Washington, D.C.

Association of American Soap and Glycerine Producers, Inc.: C. R. Matmis, Counsel, Davies, Richberg, Tydings, Landa, and Duff, 1000 Vermont Ave. NIV., Washington, D.C.

Chemical Specialties Manufacturers Association, Inc. :

R. L. Ackerly, Counsel, Cummings, Sellers, Reeves, and Comner, $1625 \mathrm{~K}$ St. NW., IVashington, D.C.

H. E. Peterson, President, Peterson Filling \& Packaging Co., Hegeler Lane, Danville, Ill.

C. E. BEacir, 50 East Forty-first St., New York, N.Y.

A. H. Lawrence, Jr., Sales Manager, Aerosol Propellents, 8447 Nemours Bldg., Wilmington, Del.

A. A. Mulliken, 50 East Forty-first St., New York, N.Y.

J. J. ToMLINSON.

Consumers Union: Mrs. M. E. Brady, Editorial Director, Mount Vernon, N.Y.

Cooperative League of the U.S.A.: J. T. JEnnings, Associate Director, 1025 Vermont Ave. NT., Washington, D.C.

Dairy Industries Supply Association: D. H. WILlians, Technical Director, 1145 Nineteenth St. NW., Washington, D.C.

Dairy Industry Newsletter: A. O. Nicold, Director, 203 Munsey Bldg., Washington, D.C.

Esso Standard: L. L. Kennedy, Manager. Construction and Maintenance, 500 North Broad St., Elizabeth. N.J.

Fruit Dispatch Co.: R. B. Tewksburr, Assistant Traffic Manager, c\% United Fruit Terminal, Weehawken, N.J.

Gasoline Pump Manufacturer's Association: G. 'T. Wright, Managing Director, 551 Fifth Ave., New York, N.Y.

General Foods Corp.:

J. J. Halsex, Quality Services Manager, 250 North St., White Plains, N.Y. E. P. LeE, Manufacturing and Engineering Manager.

General Mills, Inc.: O. A. Oudal, Director, Products Control, 9200 Wayzata Blvd., Minneapolis, Minn.

Glass Container Manufacturers Institute, Inc.: C. E. W.ager, Development Engineer, 99 Park Ave., New York, N.Y.

Grand Union Co. :

T. J. Streithonst, Executive Vice President and General Manager, 2060 West Virginia Ave NE., Washington, D.C.

EARL REDNER, Superintendent of Store Operations.

Liquefied Petroleum Gas Association, Inc.: A. C. Krfutzer, Yice President and Counsel, 11 South La Salle St.. Chicago. Ill.

Mayer, Oscar, \& Co.: J. C. BARD, General Product Controller, 910 Mayer Ave, Madison, Wis.

Mobil Oil Co.: L. H. REed, Manager of Motor Vehicles, 150 East Forty-second St., New York, N.Y.

National Association of Dairy Equipment Manufacturers: Joirs Marsinal, Executive Vice President, 1012 Fourteenth St. NT., Washington, D.C.

National Association of Food Chains: W. N. Furst, Vice President, 1025 Connecticut Ȧ ve. NW., Washington, D.C.

National Tank Truck Carriers, Inc. : LouIs Reznek, Director of Engineering and Safety, 1424 Sixteenth St. NW., Washington, D.C.

National Truck Tank and Trailer Tank Institute: A. R. Sxitr, Executive Secretary, 120 South LaSalle St., Chicago, Ill.

Paper Can Association: A. W. Howe, JR., Assistant to Executive Secretary, Philadelphia National Bank Bldg., Philadelphia, Pal.

Paper Cup and Container Institute, Inc.: R. W. Foster, Assistant to Executive Director, 250 Park A ve., New York, N.I.

Pennsylvania Railroad: G. F. YEAGEr, Assistant Foreman. Scales, Altoona. Pa. Phillips Petroleum Co. : A. F. Dyer, Technical Representative, Bartlesville, Okla.

Pillsbury Co.: C. E. Joyce, General Claim Manager, Pillsbuṛ Bldg., 608 second Ave., S., Minneapolis, Minn.

Republic Steel Corp.: D. R. Sмгтн, Corporation Weighing Supervisor, 410 Oberlin Rd. SW., Massillon, Ohio.

Saybolt, J. W., Business Counselor on Weights and Measures Laws, 9209 Carlyle Ave., Surfside, Miami Beach. Fla.

Scale Journal : M. Wr. Pickell, Editor, 176 West Adams St., Chicago, Ill. 
Scale Manufacturers Association. Inc. :

Arthlr SAxpers. Executire Secretar C. P. ITgRAM.

Shell Oil Co.: Fred Larsox, Project Engineer, 50 West Fiftieth St., New Iork. I.T.

Sinclair Refining Co.: T. F. Fisher. 600 Fifth Are., New Fork, N.I.

Skelly Oil Co.: R. R. Wellixgtox, Assistant Engineer, 605 West Fortr-serenth St.. Kansas City. Mo.

Suburban Propane Gas Corp.: W. S. BIgelow. Manager; Insurance and Safetr, P.O. Box 206, Whippant, X.J.

Sun Oil Co.:

A. H. MARsh, Manager, Equipment and Station Maintenance, 1600 Talnut St., Philadelphia, Pa.

IT. A. PIERSox.

Texaco. Inc. :

J. A. Wrxger, Manager, Operations, 135 East Fortř-second St., Nerr Iork, N.I.

R. H. Tolsox, Assistant Manager. Construction \& Equipment Division.

Thread Institute. Inc. :

TI. F. Operer, Executive Director. 15 East Fortieth St., New York, N.Y.

DAIID Sxrder, Consultant.

IT. D. Semler, Member, Legislation Committee. Coats \& Clark. Inc., 430 Park Are. New Tork. N.X.

Tissue Association, Inc.: R. A. Fife, Consultant, 122 East Forty-second St., Nerr Iork. N.I.

Tisking Co.. Dirision of Union Carbide Corporation: ElıIot B.Alestrer, Assistant to President. 210 Main St.. Hackensack. X.J.

Testern Weighing and Inspection Bureau: C. G. Johxsox. Supervisor, Weight Agreements and Weighing. Room 460 Union Station, 517 West Adams St.. Chicago. Ill.

\section{Guests}

Blicklex, J. F.. 4538 North Carlisle St., Philadelphia, Pa.

Catlfield, M. J., Almonesson, X.J.

Gordox, L. J., Director. Weights and Measures Research Center, Denison Unirersity, Granrille, Ohio.

LIRIo, Alfred, P.O. Box 369. Tineland, X.J.

MCBride, J. P., 3 Livermore Rd., Belmont, Mass.

MeEk, J. H.. Mine Rum, Ta.

MIller, D. R., 3521 Thirty-sixth St., NT., Washington. D.C. 


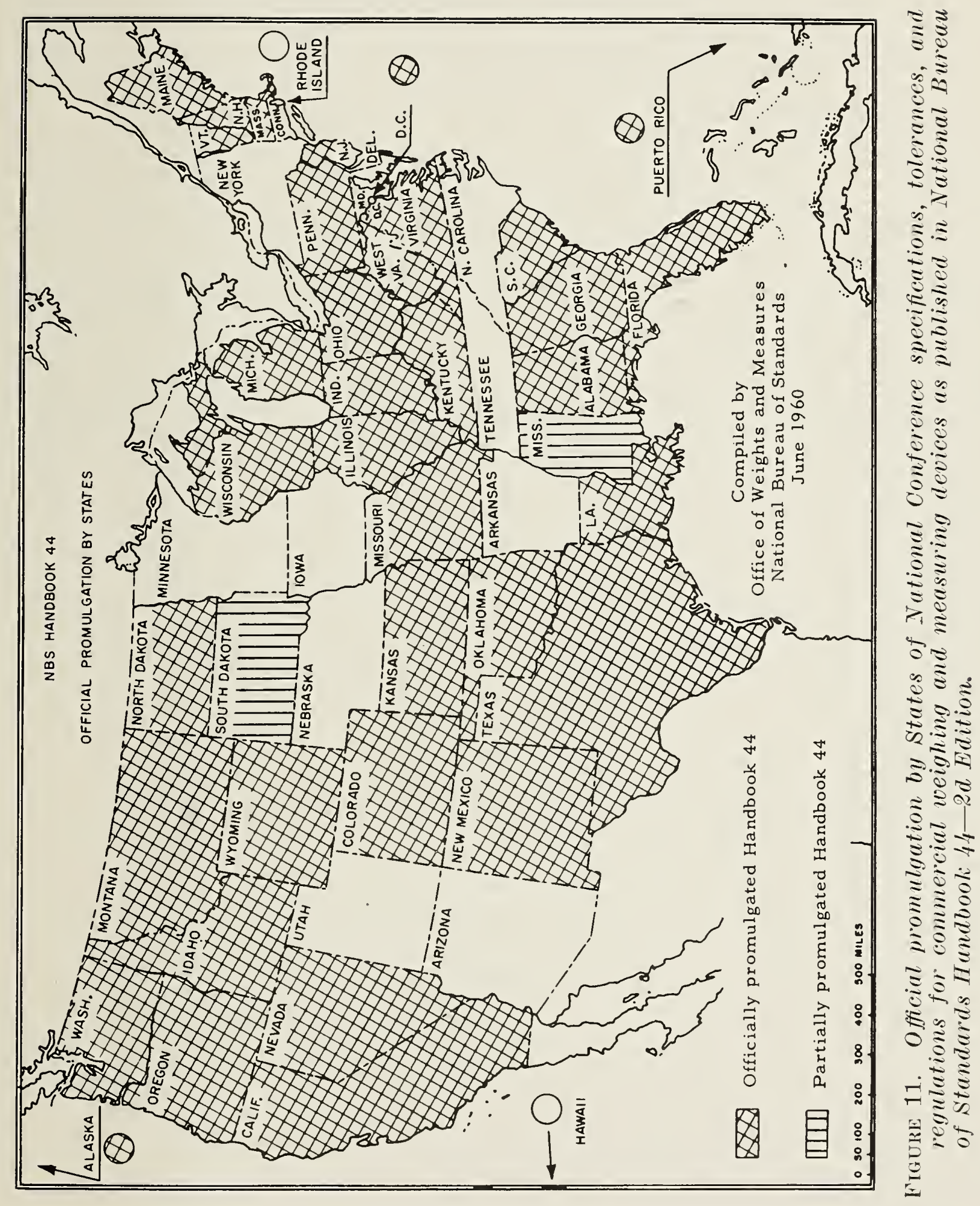





\section{Continued from page 4 of Cover}

\section{Office of Weights and Measures}

\section{BOULDER, COLORADO}

Cryogenic Engineering. Cryogenic Equipment. Cryogenic Processes. Properties of Materials. Gas Liquefaction.

Radio Propagation Physics. Low Frequency and Very Low Frequency Research. Ionosphere Research. Prediction Services. Sun-Earth Relationships. Field Engineering. Radio Warning Services.

Radio Propagation Engineering. Data Reduction Instrumentation. Radio Noise. Tropospheric Measurements. Tropospheric Analysis. Propagation-Terrain Effects. Radio-Meteorology. Lower Atmospheric Physics.

Radio Standards. High-Frequency Electrical Standards. Radio Broadcast Service. Radio and Microwave Materials. Electronic Calibration Center. Millimeter-Wave Research. Microwave Circuit Standards.

Radio Communication and Systems. High frequency and Very High Frequency Research. Modulation Research. Antenna Research. Navigation Systems. Space Telecommunications.

Upper Atmosphere and Space Physics. Opper Atmosphere and Plasma Physics. Ionosphere and Exosphere Scatter. Airglow and Aurora. Ionspheric Radio Astronomy. 


\section{THE NATIONAL BUREAU OF STANDARDS}

The scope of activities of the National Bureau of Standards at its major laboratories in Washington, D.C., and Boulder, Colo., is suggested in the following listing of the divisions and sections engaged in technical work. In general, each section carries out specialized research, development, and engineering in the field indicated by its title. A brief description of the activities, and of the resultant publications, appears on the inside of the front cover.

\section{WASHINGTON, D.C.}

Electricity. Resistance and Reactance. Electrochemistry. Electrical Instruments. Magnetic Measurements. Dielectrics.

Metrology. Photometry and Colorimetry. Refractometry. Photographic Research. Length. Engineering Metrology. Mass and Scale. Volumetry and Densimetry.

Heat. Temperature Physics. Heat Measurement. Cryogenic Physics. Rheology. Molecular Kinetics. Free Radicals Research. Equation of State. Statistical Physics. Molecular Spectroscopy.

Radiation Physics. X-ray. Radioactivity. High Energy Radiation. Radiological Equipment. Nucleonic Instrumentation. Neutron Physics. Radiation Theory.

Chemistry. Surface Chemistry. Organic Chemistry. Analytical Chemistry. Inorganic Chemistry. Electrodeposition. Molecular Structure and Properties of Gases. Physical Chemistry. Thermochemistry. Spectrochemistry. Pure Substances.

Mechanics. Sound. Pressure and Vacuum. Fluid Mechanics. Engineering Mechanics. Combustion Controls.

Organic and Fibrous Materials. Rubber. Textiles. Paper. Leather. Testing and Specifications. Polymer Structure. Plastics. Eelital Research.

Metallurgy. Thermal Metallurgy. Chemical Metallurgy. Mechanical Metallurgy. Corrosion. Metal Physics.

Mineral Products. Engineering Ceramics. Glass. Refractories. Enameled Metals. Constitution and Microstructure.

Building Technology. Structural Engineering. Fire Protection. Air Conditioning, Heating, and Refrigeration. Floor, Roof, and Wall Coverings. Codes and Safety Standards. Heat Transfer. Concreting Materials.

Applied Mathematics. Numerical Analysis Computation. Statistical Engineering. Mathematical Physics.

Data Processing Systems. SEAC Engineering Group. Components and Techniques. Digital Circuitry. Digital Systems. Analog Systems. Applications Engineering.

Atomic Physics. Spectroscopy. Radiometry. Mass Spectrometry. Solid State Physics. Electron Physics. Atomic Physics.

Instrumentation. Engineering Electronics. Electron Devices. Electronic Instrumentation. Mechanical Instruments. Basic Instrumentation.

(Continued on page 3 of cover) 





